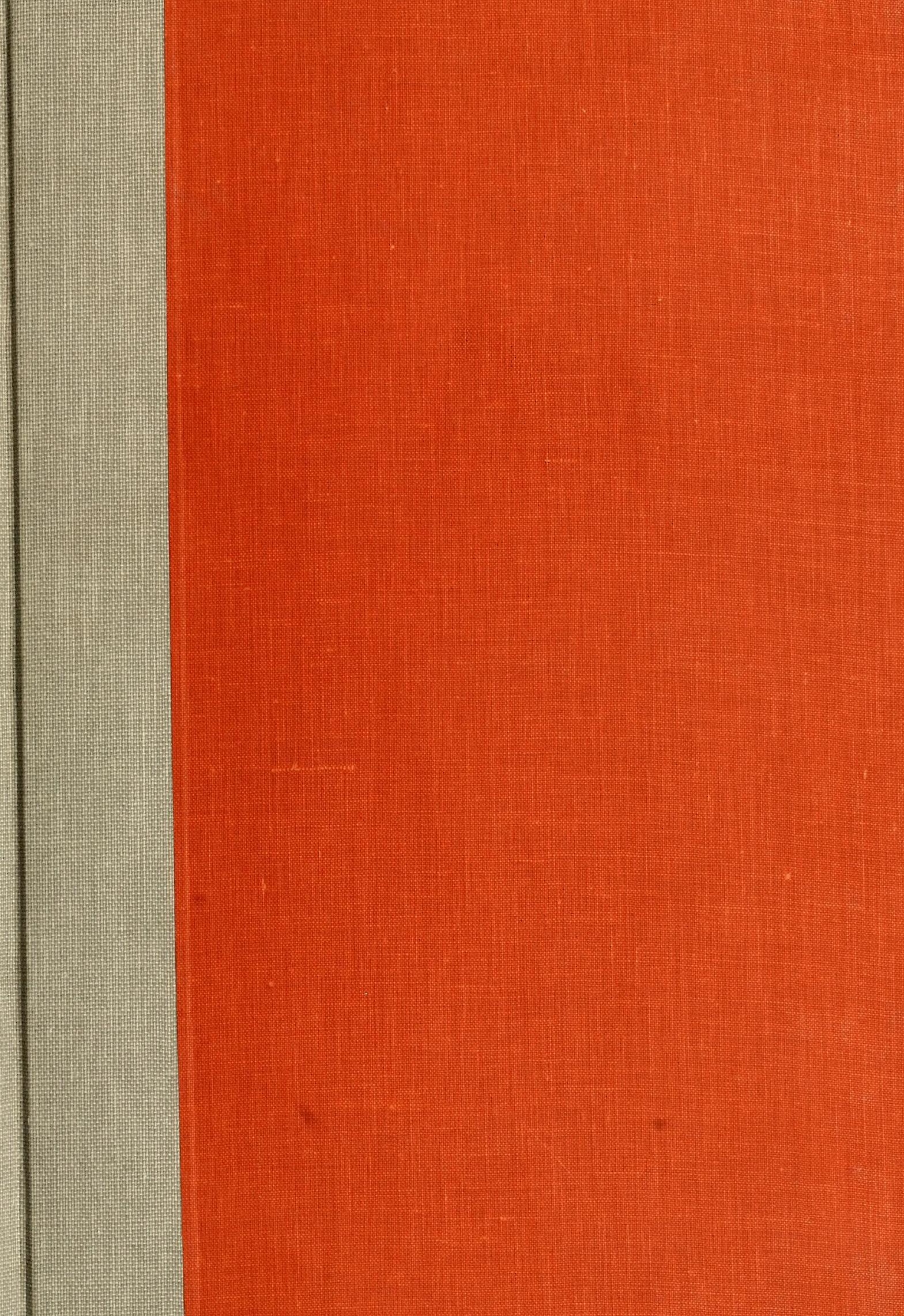




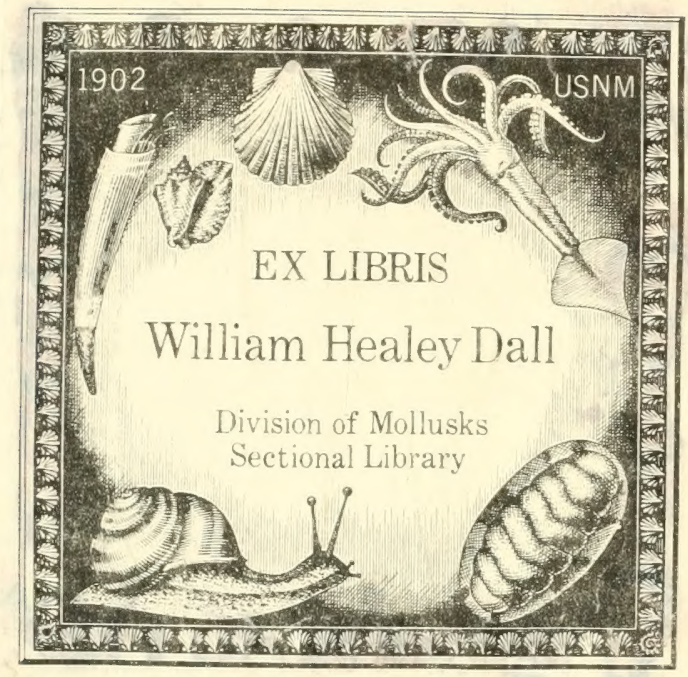







Livr. XXIX.

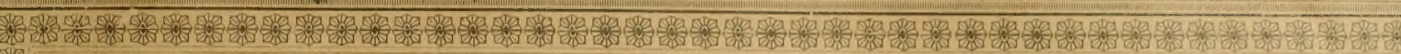
siva

RÉSULTATS DES EXPLORATIONS

ZOOLOGIQQUES, BOTANIQQUES, OCÉANOGRAPHIQUUS ET GÉOLOGIQUES ENTREPRTSKS AUX

INDES NÉRRTANDAISES ORIENTALES EU 1899-1900,

à bord du SIBOGA

SOUS LE COMMAANDEMENT DE

G. F. TYDEMAN

pUbut́s par

M A X W E B F F

Chef de l'expédition.

* I. Iutroduction et description de l'expédition, Max We ber. *II. Le bateau et son équipement seientifique, G. F. T y de ma n

*III. Résultats hydrographiques, G. F. Tydeman.

IV. Foraminifern, F. W. Winter.

IVbis. Xenophyophora, T. E. Schulze.

V. Radiolaria, M. Hartmann.

* VI. Porifera, F. E. Schulze, G. C. J. Vosmaer et

VII. Hydropolypi, Ch. Julin. [J. H. Vernhout')

* VIII. Stylasterina, S. J. Hickson et Mllo H. M. England.

IX. Siphonophora, Mlles Lens et $v$ an Riemsdijk.

*X. Hydromedusae, O. Ma as.

*XI. Scyphomedusae, O. Ma as

* XII. Ctenophora, Mile F. Moser.

* XIII Gorgonidse Alcyonidse, J. Verslnys et S. J. Hickson ')

XIV. Pennatulidae, S. J. H ickson.

XV. Actiniaria, P. Me Murrich.

*XVI. Madreporaria, A. Alcock ${ }^{2}$ ) et L. Döderlein.

XVII. Antipatharia, P. N. van Kampen.

XVIII. Turbellnria, $L$, von Graff et. R. R. von Stummer.

XIX, Cestodes, J. W. Spengel.

XX. Nematodes, H. F, Nierstrasz.

*XXI. Chaetognatha, G. H. Fowler.

XXII. Nemertini, A. A. W. Hubrecht.

XXIII. Myzostomidae, R. R, von Stummer.

XXIV1. Polychacta errantia, R. Horst.

XXIV2, Polyehaeta sedentaria, M. Caullery et F. Mesuil.

* XXV. Gephyrea, C. Ph. Sluiter.

XXVI. Enteropueusta, J. W. Spengel.

* XXVIbis. Pterobranchia, S. F. Harmer.

XXVII. Brachiopoda, J. F, vau Bemmelen.

XXVilI. Polyzoa, S. F. Harmer.

XXIX. Copepoda, A. Scott.

XXX. Ostracoda, G, W. M üller.

XXXI. Cirrhipedia, P. P. C. Hoek.

XXXII. Isopoda, H. J. Ha n sen.

XXXIII. Amphipoda, Ch. Pérez.

* XXXIV. Caprellidae, P. M a yer.

XXXV. Stornatopoda, H. J, Ha nsen.

* XXXVI. Cumacea, W. T. Calman.

XXXVII. Schizopoda, H. J. Hansen.

XXXVIII, Sergestidae, H. J. Hansen.

XXXIX. Necapoda, J. G. de Mau.

XL. Pantopoda, J. C. C. Loman.

XLI. Halobatidae, J. Th. Oudemans.

XLII. Crinoidea, I, Döderlein et C. Vancy.

* XLIII. Echinoidea, J. C. H. de Me ejjere.

* XLIV. Holothurioidea, C. Ph. Slu i ter.

*XLV. Ophiuroídes, R. Köhler.

XLVI. Asteroidea, L. Döderlein.

* XLVII. Solenogastres, H. F. Nierstrasz.

* XLVIII. Chitonidae, H. F, Nierstras

XLIX1, Prosobranchia, M. M. Sehepman.

XLIX2. Prosobranchia parasitica, H. F. Nierstrasz.

* L. Opisthobranchia, R. Bergh.

* LI. Heteropoda, J. J. Tesch.

* LII. Pteropoda, J. J. Tesch.

LIII. Lamellibranchiata. P. Pelseneer et Ph. Dautzenberg.

LIV. Scaphopoda, Mile M. Boissevain.

LV. Cephalopoda, L. Joubin.

*LVI. Tunicata, C. Ph. Sluiter ').

LVII. Pisces, Max Weber.

LVIII. Cetacen, Max Weber.

LIX. Liste des algues, Mno A. W eber.

* LX. Halimeda, Mille E. S. Barton. (Mwe E. S. Gepp).

* LXI. Corallinaceae, Mrme A. Weber et M. Foslie.

LXII, Codiaceae, $\Lambda$. et Mme F. S. Gepp.

LXIII. Dinoflagellata. Coecosphaeridae, J. P. I.utsy.

LXIV. Diatomaceae, J. P. Lotsy.

LXV. Deposita marina, O. B. Bögg ild

LXVI. Résultats géologiques, A. Wi chmann.

\section{Siboga-Expeditie}

DIE

HEPEROPODEN DER SIBOGA.BXPEDTTION

VON

J. J. TESCH

Mit 14 Tafeln

Division of $\mathrm{Mo}$

Soctional Libra

Monographie LI aus:

UITKOMSTEN OP ZOOLOGISCH,

BOTANISCH, OCEANOGRAPHISCH EN GEOLOGISGH GEBIED

verzameld in Nederlandsch Oost-Indië $1899-1900$

aan boord H. M. Siboga onder commando van

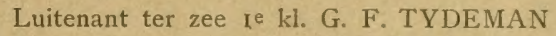

UITGEGEVEN DOOR

Dr. MAX WEBER

Prof, in Amsterdam, Leider der Expeditie

(met medewerking van de Maatschappij ter bevordering van het Natuurkundig onderzoek der Nederlandsche Koloniën)

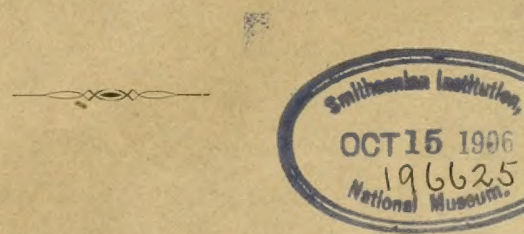

BOEKHANDEL EN DRUKKERIJ

E. J. BRILI

LEIDEN 


\section{Voor de uitgave van de resultaten der Siboga-Expeditie hebben bijdragen beschikbaar gesteld:}

De Maatschappij ter bevordering van het Natuurkundig Onderzoek der Nederlandsche Koloniën.

Het Ministerie van Koloniën.

Het Ministerie van Binnenlandsche Zaken.

Het Koninklijk Zoologisch Genootschap "Natura Artis Magistra" te Amsterdam.

De ,Oostersche Handel en Reederij" te Amsterdam.

De Heer B. H DE WAAL Oud-Consul-Generaal der Nederlanden te Kaapstad.

M. B. te Amsterdam. 


\section{SIBOGA-EXPEDITIE.}




\section{Siboga-Expeditie}

\section{UTTKOMSTEN}

OP

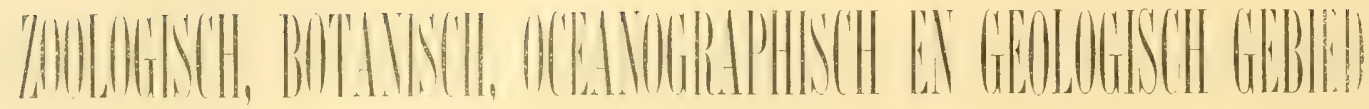

VERZAMELD IN

NEDERLANDSCH OOST-INDIË I899-ı900

AAN BOORD H.M. SIBOGA ONDER COMMANDO VAN Luitenant ter zee $1^{\text {e }}$ kl. G. F. 'T'YDEMAN

LITGEGEVEN DOOR

Dr. MAX WEBER

Prof. in Amsterdam, Leider der Expeditie

BOEKHANDEL EN DRUKKERI]

F. J. BRILL

LEIDEN 
Siboga-Expeditie

LI

DIE

\title{
HETEROPODEN DER SIBOGA-EXPEDITION
}

$\mathrm{V}() \mathrm{N}$

\author{
D. J. J. TISSCH
}

Mit 14 Tafeln

BUCIHANDLUNG TYI) DRLCKEREI

E. J. BRILL

T.EIDEN - 1906 

INHALT.

Vinw14t.

linchntt I.

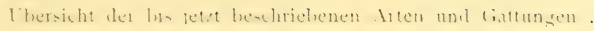

. Wrechnitt II.

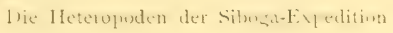

Ah-uhnilt III.

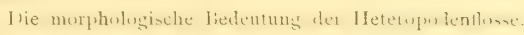

l.itceratuli-te

$95-106$

$107-110$ 



\title{
DIE HETEROPODEN DER SIBOGA-EXPEDITION
}

\author{
VON
}

\section{J. J. TESCH,} Utrecht.

Mit I4 Tafeln.

\section{VORWORT.}

Bei der Bearbeitung der Heteropoden der Siboga-Expeclition musste natürlich die Systematik im Vordergrund der Interessen stehen. Hier stellten sich mir aber die grössten Schwierigkeiten entgegen; denn die grosse Mehrzahl der Beschreibungen und Abbildungen stammt aus der älteren Litteratur und wurde offenbar ohne die nöthige Berücksichtigung der spezifischen Unterschiede veröffentlicht.

So gestaltete sich meine Aufgabe zu einer durchaus undankbaren; meistens erhielt ich bei meinen wiederholten Versuchen nur negative Resultate. Und doch hat die gründliche Bearbeitung der älteren Litteratur mich zu einer ausfïhrlichen systematischen Darstellung aller bekannten Arten angeregt, welche zweifellos ihren Nutzen haben kann.

Es zerfällt diese Arbeit in drei Abschnitte.

Der erste Abschnitt ist eine Zusammenstellung aller bis jetzt bekannten Arten, wozu die urspriinglichen Abbildungen wiedergegeben wurden. Als ich, dank sei dem freundlichen Entgegenkommen seitens des Herrn Prof. Max Weber, im October des vorigen Jahres das „British Museum” in London besuchte, war ich in der glücklichen Lage, viele Originalexemplare, namentlich Souleyet's, untersuchen zu können, wodurch meine Bearbeitung der Atlantiden sehr wesentlich gefördert wurde. Damals kam ich auf den Gedanken alle bis jetzt bekannten Arten zusammenzufassen und dadurch eine systematische Monographie der Heteropoden zu liefern. Meinen verbindlichsten Dank sei hier den Herren Prof. Jeffrey Bell und Edg. A. Smiti gebracht, welche mir in freundlichster Weise die Untersuchung des Materiales gestatteten. 
Der zweite Abschnitt behandelt das Material der Siboga-Expedition. Zunächst sei hervorgehoben, dass die Conservirung im Allgemeinen sehr gut war. Die Aufbewahrung in Formol (nach Fixirung in schwacher Chromsäure und gründlicher Auswaschung) ist für die sehr wasserreichen Tiere entschieden die günstigste Conservirung. Nur muss die Behandlung sehr sorgfältig geschehen, sonst ist die Schrumpfung, durch schnelle Wasserentziehung, zu stark.

Mit Ausnahme der Gattung Pterosoma waren sämtliche Genera vertreten. Bezüglich der Anzahl Arten gebe ich die folgende Liste:

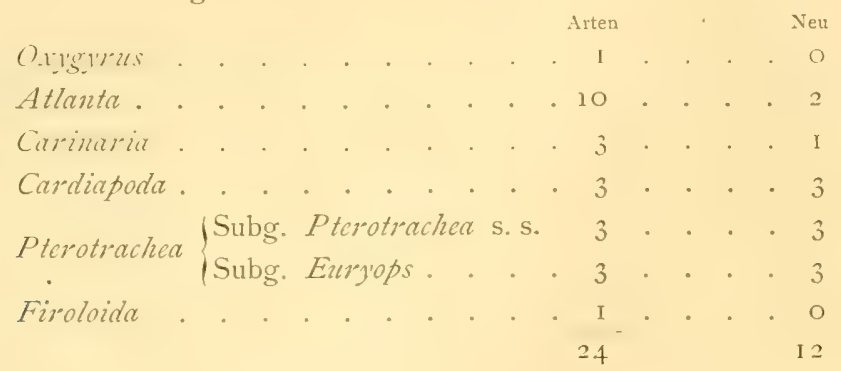

Von den 24 Arten, welche gefunden wurden, musste die Hälfte mit neuen Namen belegt werden. Ein grosses Gewicht ist aber diesem Umstande nicht beizulegen, weil die Systematik, namentlich die der Gattung Pterotrachea, höchst unsicher ist.

Bei meinen Diagnosen habe ich oft auch anatomische Tatsachen beriicksichtigen müssen, weil auch die Anatomie nicht selten wertvolle Artunterschiede beibringen kann.

Der dritte Abschnitt behandelt die morphologische Bedeutung der Heteropodenflosse und die Umbildung des Fusses. Wenn ich mich in dieser Hinsicht der Ansicht Grobbex's am meisten nähere, so weiche ich doch in einigen Punkten von ihm ab; und so habe ich im letzten Abschnitt dieser vorwiegend systematischen Arbeit meine eigene Meinung über die Morphologie von Flosse, Saugnapf, Schwanz und Deckelträger bei den Heteropoden näher zu begründen versucht.

Utrecht, März I 906. 


\section{ABSCHNITT I.}

\section{ÜBERSICHT DER BIS JETZT BESCHRIEBENEN ARTEN UND GATTUNGEN.}

Es hat sich im Laufe der Zeit, seit Fonski zum ersten Male die Pterotrachea beschrieben hat, eine ziemlich beträchtliche Litteratur angehäuft, die in mehr oder weniger vollkommenen Weise die verschiedenen, bis jetzt bekannten Arten der Heteropoden zu characterisiren versuchte. Allein in der Mehrzahl der Fälle sind leider die betreffenden Beschreibungen und Abbildungen so ungenügend, dass der spätere Forscher, auch beim besten Willen, es einfach aufgeben muss, jemals die beschriebene Form aus den Angaben des Autoren zu erkennen. Die systematische Litteratur der Heteropoden ist ein enormer Chaos geworden, aus dem Keiner sich herausarbeiten kann. Die ursprünglichen Beschreibungen sind entweder ganz kurz, oder verlieren sich in Allgemeinheiten, die nur für die Gattung, nicht für die Art, kennzeichnend sind. Bis vor wenigen Jahren waren, trotz der bewunderungswürdigen Arbeit Souleyex's, eigentlich nur drei oder vier Formen der Mittelmeeres hinreichend bekannt; in neuester Zeit ist freilich die Wissenschaft, dank dem Bestreben VAyssière's, um die Kenntniss einiger neuen Arten bereichert worden, aber dieser Autor hat sich, wie es scheint, oft gescheut, das iiberaus gefährliche Gebiet der früheren Forschung zu betreten.

Mir scheint es aber die unumgängliche Pflicht eines jeden Forschers zu sein, die Leistungen seiner Vorgänger, soviel wie möglich, richtig zu würdigen, und aus ihren Angaben alles das herauszufinden, was vielleicht zum Wiederauffinden der betreffenden Form behuilflich sein kann.

Zweck der vorliegenden Arbeit wird es nun sein, sämtliche Arten, die je beschrieben und meist auch abgebildet wurden übersichtlich, in einer Monographie darzustellen und Copieen der Figuren beizugeben. Zwar geschieht dies meistens nur zur Beruhigung des (wissenschaftlichen) Gewissens, aber doch hege ich einige Hoffnung, dass es auf diese IVeise gelingen dürfte, vielleicht einige Formen später wiederzuerkennen, indem derjenige, der späterhin irgendwelches Material von Heteropoden zu bearbeiten wünscht, hier alles zusammen findet, was in systematischer Hinsicht iiber diese Molluskengruppe bekannt ist. Meine Bemühungen auf diesem Gebiete werden dann, wie ich hoffe, von einigem Werte sein.

Einige Bemerkungen möchte ich noch vorausschicken. 
I" Die Abbildungen geben oft nur die Umrisse der Art wieder; die Einzelheiten in den urspringlichen Figuren sind meistens nicht angegeben worden; da aber, wo solche zur Characterisirung der Art nützlich schienen, habe ich sie eingezeichnet.

2" Wenn eine Art öfter, wenn auch bisweilen unter verschiedenen Namen, beschrieben wurde, kam es mir überflüssig vor, sie jedesmal wiederzugeben; dies gilt z.B. von Atlanta peroni, Carinaria lamarcki u. e. a.

$3^{n}$ Eine gewisse Zahl der Arten werden noch im zweiten Abschnitt dieses Werkes ausführlich besprochen, weil die Siboga-Expedition einige Formen erbeutete, die ich glücklicherweise mit früher Beschriebenen identifizieren konnte. Ich war in der Gelegenheit, die Originalexemplare der Sammlung Souleyet's, welche sich in London befinden, studieren zu können, und hatte bisweilen die Genugthuung, die Identität einiger durch letztgenannten Autor bekannt gewordenen Arten festzustellen. Freilich war das Material nach der fast siebzigjährigen Aufbewahrung oft recht unkenntlich geworden.

4" Ich verzichte vollständig auf eine Synonymie der verschiedenen Arten, da eine solche schon in trefflicher Weise von EDG. A. Smitu in seiner Challenger-Publication geliefert wurde, und sich seitdem die systematische Litteratur über Heteropoden nur wenig gemehrt hat. Allerdings werde ich bisweilen Gelegenheit haben, eine, wie mir scheint, irrtümliche Auffassung Sirth's zu rectifizieren.

Familie I. Atlantidae.

Die ursprünglichste Familie der Kielfüsser bildet eine scharf umschriebene Gruppe, welche sämtliche Arten enthält mit Spiralschale, in welche das Tier sich ganz zurückziehen kann, in welchem Falle die Öfnung durch das am Schwanze befindliche Operculum geschlossen wird. Eine nähere Beschreibung wird erst im zweiten Abschnitt gegeben werden.

Die Gruppe zerfällt in die beiden Gattungen Oxygyrus und Atlanta, die leicht an der Beschaffenheit der Schale unterschieden werden können.

\section{Oxygyrus Benson 1835 .}

Die Schale ist merkwürdig durch ihre hornige Consistenz; nur an den ersten Windungen ist Kalk eingelagert. Der hohe Kiel, der auch an der Mundöffnung der Schale noch steil aufragt, ist ebenfalls hornig. Die Schale selbst ist nautiloid, d.h. der letzte Umgang hat sich um die vorhergehenden gelagert; die Spira ragt nicht hervor, da die Umgänge alle in einer Ebene aufgerollt sind, eine Nabel ist also an beiden Seiten der flachen Schale sichtbar.

Das Operculum ist dreieckig, ohne spiraligen Teil, nur mit parallelen Linien versehen.

Die Gattung zählt drei Arten:

$$
\begin{aligned}
& \text { I. O. keraudreni (Rang non Lesueur). } \\
& \text { 2. O. rangi (Souleyet). } \\
& \text { 3. O. inflatus Benson. }
\end{aligned}
$$

Eine vierte Art wurde von Macdonald beschrieben, aber ohne besonderen Namen. 
I. Orygyrus keraudreni (Rang). (Taf. 1, I.ị. 1, 2).

Diese Form ist leicht kenntlich an der grossen, grösstenteils hornigen Schale, ohne besondere Sculptur, nur mit Zuwachsstreifen versehen. Der hohe, hornige Kiel setzt sich auf die erste Hälfte der letzten Windung noch fort.

Im Jugendzustande kommt eine Bellerophina-Form vor, clie eine mit spiraligen Linien versehene Schale besitzt. Ein Kiel ist noch nicht vorhanden. Genaue Abbildung̈en dieser Bellerophina sowie der erwachsenen Schale finden sich bei OBERWMMER.

Der Mittelzahn der Radula trägt drei Fortsätze, von denen der Mitteldorn viel grösser ist als die beiden anderen.

Die Reibplatte wird ausführlicher im zweiten Abschnitt besprochen werden.

Obwohl diese Art schon sehr oft beschrieben wurde, sind nur sehr wenige Abbildungen wirklich gewissenhaft angefertigt worden. Auch VAYsstère iirt sich, wenn er einen Einschnitt am Mundrande, nahe der Innenlippe, einzeichnet; der Verfasser muss sich durch den durchschimmernden Mantelrand geirrt haben, der gerade an dieser Stelle eine Einbuchtung zeigt.

Die hier gegebene Abbildung ist nach Oberwimater.

Durchm. bis zu Io mm.

Verbreitung: Westliches Mittelmeer: Lo Bianco, Cantratne, Gegendaur, Leuckart, Pirajno, Philippi, Verany. Östliches Mittelmeer und Adria: Oberwimer. Azoren und Canarische Inseln: VAyssière. Atlantischer und Indischer Ozean: Souleyet.

2. Oxygym rangi (Souleyet). (Taf. I, Fig. 3, 4).

Kleiner als O. keraudreni; der Kiel setzt sich auf die erste Hälfte der letzten Windung nicht fort (Souleyet).

Nähere Beschreibung im zweiten Abschnitt.

Copie nach Souleyet.

Verbreitung: Pazif. und Atl. Oz.: Souleyet.

2a. Oxygyrus n. sp. Macdonald (Taf. I, Fig. 5).

Ganz mit spiraligen Wellenlinien versehen, Radula mit drei gleich langen Fortsätzen (MACDONALD).

Diese Art ist mit $O$. rangi identisch, wie ich durch eigene Untersuchung feststellen konnte.

Nähere Beschreibung im zweiten Abschnitt.

Copie nach Macdonald.

Verbreitung: ?: MACDONALD.

\section{Oxygyrus inflatus Benson.}

"Testa tumida, anfractibus transverse confertim striolatis; suturis profunde excavatis" (Bexson). Weiter ist von dieser Art nichts bekannt. Eine Abbildung besteht nicht.

Verbreitung: Süd-Atl. Oz,; Süd-Indischer Oz. bis zu $17^{\circ}$ N. : Benson. 
Anhang: "Hclicophlegma candei" d'Orbigny ist eine Embryonalschale von Echinospira. Beschreibung im zweiten Abschnitt.

\section{Atlanta Lesueur IS17.}

Die Schale ist flach, kalkig, sehr dünn und leicht zerbrechlich, nur lose aufgerollt, $\mathrm{d}$. h. die Windungen schliessen oft nicht fest aneinander, eine Spira ist vorhanden, ganz flach oder vorragend; der Nabel also nur von der einen Seite sichtbar. Der Kiel ist kalkig, nicht hornig. Das Operculum besitzt einen spiraligen Teil.

Seit dem Jahre I797, als Lamanon eine Atlanta unter den Namen „corne d'Ammon" abbildete, ist die Zahl der Arten beträchtlich zugenommen, namentlich durch die Beschreibungen Souleyet's. Es ist die stattliche Zahl von 25 Arten zu verzeichnen, aber es muss gleich erwähnt werden, dass diese Zahl wegen ungenügender Unterscheidung noch zu vermehren wäre.

Die Liste wiirde also lauten:

1. Atlanta peroni Lesueur.

2. Atlanta lamanoni (Eschscholtz).

3. Atlanta. helicialis Sowerby:

4. Atlanta sp. Gray.

5. Atlanta sp. Gray,

6. Atlanta planorboides (Forbes).

7. Atlanta turriculata d'Orbigny.

8. Atlanta lesuenri Souleyet non d'Orbigny.

9. Atlanta involuta Souleyet.

10. Atlanta inflata Souleyet non d'Orbigny.

II. Atlanta gibbosa Souleyet.

12. Atlanta helicinoides Souleyet.

I3. Atlanta inclinata Souleyet non Vayssière.

14. Atlanta inclinata Vayssière non Souleyet.
I5. Atlanta gaudichaudi Souleyet.

I6. Atlanta fusca Souleyet.

I 7. Atlanta depressa Souleyet.

is. Atlanta rosea Souleyet.

19. Atlanta quoyana Souleyet non Vayssière.

20. Atlanta quoyana Vayssière non Souleyet.

21. Atlanta mediterranea Costa.

22. Atlanta violacea Gould.

23. Atlanta tessellata Gould.

24. Atlanta primitia Gould.

25. Atlanta cunicula Gould.

26. Atlanta sonleyeti Smith.

27. Atlanta steindachneri Oberwimmer.

Zwei neue Arten werden noch im zweiten Abschnitt besprochen werden.

Wenn man die verschiedenen Abbildungen vergleicht, wird man ersehen, dass die Arten sich zu bestimmten Gruppen zusammenbringen lassen.

A. Arten, bei welchen die Schale sehr flach ist und die Spira gar nicht hervorragt, oder doch, von der Seite betrachtet, kaum sichtbar ist. Hierher gehören: A. peroni, steindachneri, lesueuri, und uiberhaupt, wie es scheint, die grosse Mehrzahl der hier aufgezählten Arten.

$B$. Arten, bei welchen die Schale etwas höher scheint, weil die Windungen fest aneinander schliessen, und im Querschnitt mehr rundlich sind; die Spira ragt mehr oder weniger hervor. Hierher gehören einige leicht kenntliche Arten, wie A. turriculata, fusca, gibbosa.

I. Atlanta peroni Rang. (Taf. I, Fig. 6 u. 7 ).

Diese Form, die schon wiederholt beschrieben wurde, ist leicht kenntlich durch die Schale, 
die fast $1 \mathrm{~cm}$. gross werden kann, sehr flach ist, mit nur lose aufgerollten Windungen, 4 oder 5 an der Zahl; die Spira ragt gar nicht hervor; der Kiel dringt ziemlich tief zwischen den Umgängen ein und verstreicht ganz vor der Mundöfnung; der Schlitz in der Aussenlippe ist sehr tief. Nur Zuwachsstreifen sind auf der Schale sichtbar.

Eine sehr gute Abbildung findet sich bei Viyssière, wo auch die Radula genau beschrieben worden ist.

Copie nach SOuleyet.

S. übrigens den zweiten Abschnitt.

Verbreitung: Die Art ist kosmopolitisch, in allen wärmeren Meeren verbreitet. Mittelmeer: Acton, Mac Andrew, Lo Bianco, Cantraine, Chun, Costa, Forbes, Gegenuadr, Graeffe, de Gregorio, Hope, Jeffreys, Krohn, Leuchart, Monterosato, Oberinimer, Phimippi, Tiberi, Vayssière, Verayy. Östl. Atl. Oz.: Vayssière. Nord- und Süd-Atl. Oz.: Suithi, Souleyet. Pazif. Oz.: Smith, d'Orbigny. Neu-Guinea: Simth.

2. Allanta lamanoni (Eschscholtz). (Taf. I, Fig. S).

Die Abbildung von Eschscholtz gibt keine Aufklärung über die von ihm aufgestellte Art. Vielleicht ist sie mit $A$. mediterranea Costa identisch. Der Kiel scheint bis zur Mundöffnung sich zu erstrecken.

Copie nach Eschscholtz.

Verbreitung: Pazif. Oz.: Eschscholtz.

3. Atlanta helicialis Sowerby.

Die ganz fluichtige Zeichnung ${ }^{1}$ ) Sowerby's lässt nichts mit Sicherheit erschliessen. Vielleicht ist die Art mit A. lesueuri Souleyet identisch.

Verbreitung : ?: SOWERBY.

4. u. 5. Atlanta sp. Gray. (Taf. I, Fig. 9-io).

Nach Zeichnungen von Hooker sind von GRAY zwei Atlanta-Arten abgebildet worden, von welchen die eine (Fig. 9) O. keraudroni, die andere $A$. peroni sein kann.

Copie nach Grax.

Verbreitung: ?: Gray.

6. Atlanta planorboides (Forbes).

"Testa pellucida, alba, laevis, compressa, carinata, exalata, anfractibus 4. Diam. O1/12". Weiter wissen wir gar nichts. Die Beschreibung ist gänzlich ungenigend.

Verbreitung: Ägäisch. Meerbusen: Forbes.

I) Leider habe ich die Abbildung Sowerby's nicht einsehen können, und muss mich hier auf die Angaben Surtr's verlassen. 
7. Atlanta turriculata d'Orbigny. (Taf. I, Fig. I I-I2).

Die leicht kenntliche Art hat eine zierliche Schale mit dünner, deutlich hervorragender Spira. Die ursprüngliche Beschreibung d'Orbigxy's wurde später von Souleyet wesentlich ergänzt. Durchm. $2 \mathrm{~mm}$.

Näheres s. im zweiten Abschnitt.

Copie nach Souleyet.

Pazif. Oz.: d'Orbigny, Souleyet. Ind. Oz.: Soulexet.

8. Atlanta lesuenri Souleyet. (Taf. I, Fig. I3-16).

Spira klein, nur wenig Umgänge. Letzte Windung sehr gross. Kiel sich bis zum Mund. rande erstreckend, mehr oder weniger tief zwischen den Umgängen eindringend. Leicht kenntlich an den queren Rippen auf der Schale. Durchm. $6 \mathrm{~mm}$. Bei der Varietät (Souleyet) verstreicht der Kiel allmählich am Mundrande (Fig. 15).

Copie nach Soulexet und Vaysière.

Verbreitung: Atl. Oz.: Souleyet. Nord-Atl. Oz.: Smith. Monaco und Gibraltar: Vayssière.

9. Atlanta involuta Souleyet. (Taf. I, Fig. I 7-IS).

Schale flach, 6 Umgänge, Spira sehr wenig nach hinten geneigt; Schlitz in der Aussenlippe nicht tief; vorletzte Windung ein wenig nach links gedreht. Durchm. $3 \mathrm{~mm}$.

Copie nach Souleyet.

Verbreitung: Pazif. Oz.: Souleyet.

Io. Atlanta inflata Souleyet. (Taf. I, Fig. I9-20).

Spira hervorragend, 7 Umgänge. Kiel niedrig. Schlitz in der Aussenlippe wenig tief. Durchm. 5- I0 $\mathrm{mm}$.

Näheres s. im zweiten Abschnitt.

Copie nach Souleyet.

Verbreitung: China: Souleyet. Nord-Atl. Oz.: Simth.

I I. Atlanta gibbosa Souleyet. (Taf. I, Fig. 21-22).

Characterisiert durch ihre dicke, kreiselförmige Schale, bei welcher eine Misverhältniss zwischen Spira und letzter Windung weniger sichtbar ist. Durchm. "microscopisch" (Souleyet).

Näheres s. im zweiten Abschnitt.

Copie nach Souleyet.

Verbreitung: Atl. Oz.: Souleyet.

12. Atlanta helicinoides Souleyet. (Taf. I, Fig. 23-24).

Diese Art sieht $A$. inflata sehr ähnlich, ist aber verschieden durch grössere Spira, die etwas mehr hervorragt; der letzte Umgang ist verhältnissmässig etwas kleiner. Durchm. 2 mm.

Copie nach Souleyer.

Verbreitung: Pazif. Oz.: Souleyet. 
13. Atlanta inclinata Souleyet non Vayssière. (Taf. I, Fig. 25-26).

Eine gut characterisierte Form mit grosser, deutlich nach hinten geneigter Spira, 7 Windungen. Durchm. 5-6 $\mathrm{mm}$.

Näheres s, im zweiten Abschnitt.

Copie nach Souleyet.

Verbreitung: Pazif. u. Atl. Oz.: Souleyet. Nord- und Süd-Atl. Oz.: Smrtr. Nord-Pazif. Oz.: Simtir. Torres-Strasse: Smith.

14. Atlanta inclinata Vayssière non Souleyet. (Taf. I, Fig. 27-27a).

Die von VAyssière unter diesen Namen beschriebene Form weicht in mancher Hinsicht von der Darstellung Sovleyet's ab, weshalb ich die beiden Arten nicht für identisch halten kann. Die Spira zeigt vor Allem weniger Windungen, und ist gar nicht nach hinten geneigt, der Kiel erstreckt sich bis zum Mundrande. Ausserdem bildet VArssière eigentümliche, querverlaufende Knotenreihen (Fig. I2 $a$ ) auf der Schale ab. Ich habe im Londoner Museum, als ich die Originalexemplare Souleyet's untersuchte, bei starker Vergrösserung nichts von solcher Sculptur wahrgenommen. Auch ist die Radula ganz anders gebaut.

Copie nach VAYSSIÈRE.

Verbreitung: Azoren und Canar. Inseln: VAyssière.

15. Atlanta gaudichandi Souleyet. (Taf. I, Fig. 28-29).

Schale sehr flach, mit niedriger Spira, die nur aus $3^{1 / 3}$ Windungen besteht. Kiel niedrig, vor der Mundöffnung verstreichend, mit einer rötlichen Linie an der Basis. Durchm. 5-6 mm.

Die Art ist nicht sehr kenntlich, im zweiten Abschnitt wird eine nähere Beschreibung gegeben werden.

Copie nach Souleyet.

Verbreitung: Pazif. Oz.: Soulevet. Westl. Pazif. Oz.: Surrm. Torres-Strasse: Suith.

16. Atlanta fusca Souleyet. (Taf. I, Fig. $30-33$ ).

Schale mit 5 oder 6 Windungen. Spira etwas hervorragend, schlank; Kiel, obwohl allmählich verstreichend, sich bis zur Mundöffnung erstreckend, Schlitz in der Aussenlippe also kaum merkbar. Schalen, wo der Kiel gar nicht die Innenlippe von der vorletzten Windung abhebt (Fig. 32-33), wurden von Soulevet als Varietät betrachtet.

Wie Sмптн hervorhebt, ist ein sehr gutes Merkmal in den spiraligen Linien gelegen, die an beiden Seiten der Schale sichtbar sind. Durchm. $2 \mathrm{~mm}$.

Näheres s. im zweiten Abschnitt.

Copie nach SOUleyet.

Verbreitung: Kosmopolitisch: Souleyet. Nord- und Süd-Atl. Oz.: Simth. Fidschi-Ins., Torres-Strasse: Smith. Nord. Pazif. Oz.: Smith. Mittelmeer: Monterosato, Obermimer. 
17. Atlanta depressa Souleyet. (Taf. I, Fig, 34-35).

Spira mit 5 IVindungen, flach, nur wenig hervorragend. Kiel hoch, Schlitz in der Aussenlippe ziemlich tief, keilförmig. Durchm. $2 \mathrm{~mm}$.

Copie nach Souleyet.

Verbreitung: Pazif. Oz.: Souleyet.

\section{Atlanta rosea Souleyet. (Taf. I, Fig. 36-37).}

Diese Art hat viel Ähnlichkeit mit A. peroni; die Schale ist aber nicht so ganz flach, die Windungen schliessen fest aneinander, die Spira ragt ein wenig hervor, und der Kiel, der vor der Mundöffnung verstreicht, hat an der Basis eine rötliche Linie, wie A. gaudichaudi. Durchm. 40,5 mm.

Näheres s. im zweiten Abschnitt.

Copie nach SOUleyet.

Verbreitung: Atl. Oz.: Souleyet. Mittelmeer: Acton, fide Monterosato, Jeffreys, OBERTIMIIER.

19. Atlanta quojana Souleyet non Vayssière. (Taf. I, Fig. 38-39).

Spira flach, mit $4^{1 / 2}$ Windungen, alle aneinander schliessend, Spira etwas hervorragend, Mundrand stark eingebuchtet (Fig. 2 I). Zuwachsstreifen auf der letzten Windung. Durchm. kaum $2 \mathrm{~mm}$.

Copie nach Souleyet.

Verbreitung: Paz. Oz.: Souleyet. Mittelmeer: Lo Bianco, Chun, fide Schiemenz, Oberwimmer.

20. Atlanta quoyana Vayssière non Souleyet. (Taf. I, Fig. 40).

Ich kann VAyssik̀RE in der Identifizierung dieser Form mit der vorhergehenden nicht beistimmen. Namentlich ist die Spira viel grösser, und zeigt regelmässig an Grösse zunehmende Windungen. Auch der Kiel ist anders gebaut, sehr hoch und, ohne zu verstreichen, bis zur Nundöffnung reichend. Durchm. ${ }^{1 / 2}-\mathrm{I}^{1} / 2 \mathrm{~mm}$.

Copie nach VAYSSIÈrE.

Verbreitung: Santa Cruz, Azoren: VAyssière.

21. Atlanta mediterranea Costa. (Taf. I, Fig. 4I).

Diese sehr ungenügend bekannte Art ist merkwürdig dadurch, dass der Kiel am Nundrande nicht verstreicht, sondern hoch bleibt; die Windungen schliessen alle aneinander, und die Innenlippe ist nicht abgehoben. Am ehesten möchte sie mit A. lesueuri identisch sein, obwohl von Querrippen nichts erwähnt wird, und auch die Form der Spira etwas anders ist. Durchm.?

Copie nach Costa.

Verbreitung: Neapel: Costa. 
22. Atlanta violacea Gould. (Taf. I, Fig. 42-43).

"Shell violaceous, nautiloid, whorls four, the last volution rot rapidly enlarging, and unusually. distended; keel nearly as broad as the whorl at the aperture, which is elliptical, about twice as long as broad, rounded at the extremities. Colour violaceous, deeper at the spire. Diam. $3 /$ inch".

Copie nach Drayton (in Gould's Atlas).

Verbreitung: Lat. $3^{\circ}$ S., Long. $20^{\circ} \mathrm{W}$. : Gould.

23. Atlanta tessellata Gould. (Taf. I, Fig. 44).

"Shell nautiloid, compressed, the last whorl somewhat rapidly enlarging; whorls four, with a very narrow keel around the angle; aperture narrow, oval, rounded at the inner extremity, acute at the outer angle; colour yellowish, with a series of square, violaceous spots following around the middle of the spire. Diam. "/4 inch".

Eine so deutliche Zeichnung von quadratischen, violetten Tüpfeln, wie sie hier angegeben wird, scheint diese Art wohl zu den am meisten markirten zu machen.

Copie nach Gould.

Verbreitung: Lat. $3^{\circ}$ S., Long. $20^{\circ} \mathrm{W}$ : Gould.

24. Atlanta primitia Gould. (Taf. II, Fig. 45).

„Shell nautiloid, ovate, very faintly umbilicate on the left side, of about three whorls; the lip of the aperture convex in profile, the aperture itself narrow, elliptical, acute at extremities. It has a thin, broad, membranous carina at the angle of the shell. Colour violaceous, especially on the spire". Durchm. ?

Wenn auch von Querrippen gar nicht die Rede ist, so glaube ich doch, dass wir hier wieder $A$. lesucuri vor uns haben.

Copie nach Daxa (in Gould's Atlas).

Verbreitung: Trop. Atl. Oz.: Gould.

25. Atlanta cunicula Gould. (Taf. II, Fig. 46).

"Shell very delicate, with a keel, nearly as broad as the shell itself, nearly circular, compressed, quite simple, merely exhibiting very faint lines of growth". Durchm. 4 mm.

Nan möchte fragen, ob diese Art mit $A$. quoyana Vayssière identisch sei. Der sehr hohe Kiel gibt dafür einige Wahrscheinlichkeit, wenn auch die Fundorte weit auseinander liegen.

Copie nach Dana (in Gould's Atlas).

Verbreitung: Westl. Sandwich-Ins.: Gould.

26. Atlanta souleyeti Smith. (Taf. II, Fig. 47-49).

Diese Art wurde erst von Souleyet unter den Namen A. lamanoni beschrieben, später von Surin in $A$. soulcyeti umgetauft, weil der frühere Namen schon von Escrischoltz gebraucht worden war. 
Die Schale zeigt bei oberflächlicher Betrachtung viel Ähnlichkeit mit O. kerandreni; die Art wurde denn auch von Macdonald zu Oxygyrus gezählt. Die Mundöffnung ist rundlich, gar nicht so flach wie bei den meisten Atlanta-Arten. Auch der Kiel sieht dem von Oxygyrus sehr ähnlich, und ist, ebenso wie diese, von horniger Consistenz. Die Schale ist aber überall kalkig, und besitzt zudem eine deutlich nach rechts hervorragende Spira; auch das Operculum (Fig. 40) ist ganz Atlanta-ähnlich. Immerhin haben wir hier eine sehr kenntliche Art vor uns, die ein Bindeglied zwischen Oxygyrus und Atlanta darzustellen scheint. Durchm. 2 mm.

Copie nach SOUleyet.

Verbreitung: Atl. Oz.: Souleyet, Smith.

27. Atlanta stcindachneri Oberwimmer. (Taf. II, Fig. 50-51).

,Die ersten Umgänge sind sehr klein, und bilden ein kleines, stumfkegelförmiges Gebilde, welches vom letzten, sehr vergrösserten, und nach rechts vorgezogenen Umgange umgeben wird. Der letzte Umgang ist bis zu seinem halben inneren Umfang von den übrigen losgelöst, so dass der vordere Abschnitt desselben mit seinem Innenrande den vorletzten Umgang nicht beruhrt. Er ist mit einem breiten Kiele versehen, welcher etwas oberhalb der Mündung beginnt, den ganzen letzten Umgang umgibt, und bis an den vorletzten Umgang reicht, wobei er allmählich schmäler und zarter wird, bis er am vorletzten Umgange verschwindet.... Der letzte, sehr glänzende Umgang ist radial mit bald stärkeren, bald schwächeren, schwach $S$-förmig gekrümmten Linien gestreift". Durchm. 2,8-3,5 mm.

Diese kleine Art ist also durch den sehr tief zwischen den Windungen eindringenden Kiel, den die Innenlippe der Mundöffnung nicht berührt, zur Genüge gekennzeichnet.

Copie nach OBERWIMMER.

Verbreitung: Östl. Mittelmeer: Oberwimmer.

Das hier besprochene zusammenfassend, möchte ich noch bemerken, dass, so viel ich sehe, synonym sind:
A. lamanoni (Eschscholtz).
A. mediterranea Costa.
A. lesueuri Souleyet.
A. primitia Gould.

Weiter:

A. quoyana Vayssière.

A. cunicula Gould.

Gänzlich unbestimmbare Arten sind:

A. helicialis Sowerby.

A. sp. (I u. 2) Gray.

A. planorboides (Forbes).

Im zweiten Abschnitte werden die folgenden Arten noch einer näheren Besprechung unterzogen werden: 
O. keraudroni (Rang).

O. rangi (Souleyet).

"Hclicophlegma candei" d'Orbigny.

A. peroni Lesueur.

A. turriculata d'Orbigny.

A. inflata Souleyet.

Dorthin verweise ich noch für die Beschreibung zweier neuen Arten.
A. gaudichandi Souleyet.

A. fusca Souleyet.

A. rosca Souleyet.

A. gibbosa Souleyet.
A. inclinata Souleyet.

Familie II. Cartinariddae.

Diese Familie enthält die Arten, welche zwar eine Schale besitzen, sich aber darin nicht zurückziehen können. Diese ist kalkig, sehr dünn und spröde, und bedeckt entweder den ganzen Eingeweidesack, den Nucleus, oder nur einen sehr kleinen Teil desselben. Am Tiere ist die oft sehr stark entwickelte Cutis bemerkenswert, so dass der ganze Körper wie aufgebläht erscheint, wenigstens am Rumpfe. Tentakel, sowie ein Saugnapf, kommen beiden Geschlechtern zu.

Innerhalb der Gruppe sind drei Gattungen unterschieden worden: Carinaria, Pterosoma und Cardiapoda.

\section{Carinaria Lamarck isor.}

Diese Gattung hat die folgenden Merkmale. Die Schale hat eine Capulus-ähnliche Gestalt: sie ist am ehesten mit einer Atlanta-Schale zu vergleichen, bei welcher die letzte Windung sich nicht um die vorhergehenden aufrollt, sondern gerade gestreckt ist, und dabei, im Vergleiche mit der Spira, enorm vergrössert. An diesen geraden Teile setzt sich ein sagittaler Kiel an. Am freien Vorderrande der Schale ragen die Kiemen hervor; der Eingeweidenucleus wird durch die Schale umfasst, und ist mit einem kurzen Stiele mit dem übrigen Korper verbunden. Der Rumpf ist sehr umfangreich, der enorm entwickelten Cutis wegen; der Rüssel ist etwas schmäler. Der Schwanz trägt oft mediane oder laterale Flossen. Die Schwimmflosse, mit grossem Saugnapfe, ist stark entwickelt, und zeigt eine sehr deutliche Musculatur; im conservirtem Zustande ist freilich die Flosse, wie auch der ganze Körper, stark zusammengeschrumpft, und ihre Form oft unkenntlich.

Die Gattung Carinaria hat in früheren Zeiten das grösste Interesse der Conchyliologen erregt, weil ihre zierliche, milchweisse Schale für äusserst wertvoll gehalten wurde. Wenigstens war dies mit $C$. cristata der Fall, deren Schale mit fabelhaften Summen bezahlt wurde. Im achtzehnten Jahrhundert, als die Gruppe der Heteropoden überhaupt wissenschaftlich noch unbekannt war, wurde die Carinaria-Schale mit dem Namen Patella, Nautilus, Argonauta von Linné, Martixi, Schroeter belegt. Das Exemplar nach welchem Martini seinen "Nautilus exiguus vitreus dictus" beschrieb (1769), wurde 1824 in Amsterdam für mehr als Iooo Mark verkauft. Später galt es unter den Conchyliologen als ein grosses Ereigniss, als REeve zum ersten Male die "C. gracilis" aus der Sammlung Ryder's, des damaligen Residenten der Molukken, aus Holland nach England brachte. 
Ein wissenschaftliches Studium des Tieres wurde von Cuvier begonnen, und in mancher Hinsicht von Poli, Quoy und Gamiard, delle Cimije, Souleyet und Gegenbaur ergänzt. Trotzdem ist es eine auffallende Tatsache, dass die Art des Mittelmeeres, die den Forschern fast ausschliesslich zum Untersuchungsobject diente, fast ohne Ausnahme, ungenau beschrieben wurde, und sogar bis jetzt noch keine Abbildung besteht, die ganz genau den Habitus des Tieres darstellt. Auch die Schale ist oft nur mangelhaft dargestellt worden.

Die Arten sind die folgenden:

1. Carinaria cristata (Linné).

1 a. Carinaria cristata var. gracilis (Reeve).

2. Carinaria lamarcki Péron et Lesueur.

2a. Carinaria lamarcki var. oceanica Vayssière.

3. Carinaria fragilis Bory de Saint-Vincent.

4. Carinaria depressa Rang:

5. Carinaria australis Quoy et Gaimard.

6. Carinaria cithara Benson.

7. Carinaria galea Benson.
8. Carinaria punctata d'Orbigny.

9. Carinaria atlantica Adams et Reeve.

10. Carinaria gaudichaudi Souleyet.

I 1. Carinaria cormucopia Gould.

12. Carinaria sp. Smith.

13. Carinaria elata Sowerby.

14. Carinaria grimaldi Vayssière.

15. Carinaria pseudo-rugosa Vayssière.

16. Carinaria sp. Warlomont.

Ausserdem wird noch im zweiten Abschnitt eine neue Art hinzugefügt werden.

Zwar wurde neuerdings ( 1893 ) eine kritische Revision von SowERBY gegeben, eine erneute Besprechung der Arten wird hier aber am Platze sein.

1. Carinaria cristata (Linné). (Taf. II, Fig. 52-52a).

Schale hoch, nur schwach gekrümmt, ventrale Kante fast gerade, die dorsale schwach convex, mit einem doppeltblättrigen Kiel versehen, der, ebenso wie die Schale, deutlich quergerippt ist. Schale an der Spitze umgebogen und hier mit einer kleinen Spira versehen, die also gleichsam an der Schale "aufgehängt" ist.

Das Tier wurde bis jetzt, freilich nach einem verstümmelten Exemplar, nur von Swith beschrieben. Die Flosse ist rund, der Schwanz zeigt einen gleich am Nucleus anfangenden, dorsalen Kamm. Der Rumpfteil ist mächtig entwickelt. Wie verschiedene Forscher (SмIтн, Sowerby) vermuten, wird das Tier, nach den Schalen zu urteilen, bedeutende Dimensionen erreichen können.

Diese wenigen Worte müssen vorläufig hier genügen; ich werde im zweiten Abschnitt noch ausführlich über die Art zu sprechen haben.

Copie nach SmTH.

Verbreitung: Nur von den Molukken bekannt: Favanne, Sumtir ${ }^{1}$ ), Sowerby.

I a. Carinaria cristata var. gracilis (Reeve). (Taf. II, Fig. 53-54).

Diese, von REEve ursprünglich als besondere Art aufgefasste Varietät unterscheidet sich

I) Ich muss hier freilich bemerken, dass SwTu noch drei junge Exemplare dieser Art erwälınt, als zwischen den AdmiralitätsInseln und Japan erbeutet. Wie ich mich aber durch eigene Untersuchung iberzeugen konnte, ist ihre Zugehörigkeit zu C. cristata wenigstens sehr zweifelhaft. Ein Exemplar ist sogar ein Pterosoma. 
nur durch die im Allgemeinen schlankere Gestalt, noch geringere Convexitit der Dorsalkante der Schale, und durch eine, im Verhältniss zu dieser, noch kleinere Spira. Länge wie C. cristata. Copie nach ReEve.

Verbreitung: Molukken?: ReEve. Ein Exemplar im „British Museum”, das ich sah, hatte als Fundort: „Eastern Seas".

2. Carinaria lamarcki Péron et Lesueur (Taf. II, Fig. $55-58$ ).

Diese, fast immer unter den Namen C. mediteranea erwähnte Form, ist die allbekannte Art des Mittelmeers. Sie wurde von friheren Forschern eingehend beschrieben; aber trotzdem dass gewiss mehr als ein Dutzend Abbildungen der Art bestehen, sind leider noch immer einige Lïcken in der Diagnose geblieben. Oft wurde nicht zwischen Tuberkeln, auf der aufgequollenen Cutis, und zwischen Hautflecken unterschieden. Beide kommen nämlich vor, und sie wurden offenbar, auch bei anderen Arten, oft verwechselt, weil die kleinen, scharf umschriebenen Flecken irrtimlich für Tuberkel gehalten wurden. Diese sind ziemlich gross, und kommen ebenso vor den Augen als auf dem Rumpfe und am Schwanze vor. Die Hautflecken sind kleiner und viel zahlreicher, überall zwischen den Tuberkeln zerstreut. Die Tentakeln sind gewöhnlich lang, oft aber stark zusammengezogen und kaum sichtbar. Auf der Höhe der Tentakel und Augen scheidet eine ziemlich tiefe Furche einen Kopf vom viel mächtigeren Rumpfteil ab. Die Flosse ist gross, rundlich, mit einem grossen Saugnapfe am Hinterrande. Eigentiimlich ist der Schwanz gebildet. Wie es vielen Beobachtern, mit Ausnahme von Gegenbaur und Kalide, entgangen zu sein scheint, findet sich an der Unterseite, nahe der Spitze des Schwanzes, eine eigentümliche, paarige, horizontale Ausbreitung der Cutis, die, indem die Ränder der rechten und linken Flosse sich verbinden, hier einen nach unten offenen, im Querschnitt ovalen Becher bildet, in dessen dünner Wandung isolierte Muskelbündel zu sehen sind. Ein derartiges Gebilde kommt fast in gleicher Form, oft aber dunkel pigmentirt, bei Cardiapoda vor, und ist dort schon öfter erwähnt worden. Der Schwanz endet in einer Spitze, die einen mehr oder weniger langen Faden trägt, der aber fast immer abgerissen ist. Eine Ruickenflosse, die eine bestimmte Strecke hinter dem Nucleus plötzlich als steil aufsteigende Firste anfängt und bis zur Spitze des Schwanzes verläuft, ist wohl ausgebildet, und zeigt zarte, vertikale oder etwas nach hinten geneigte Muskeln. Dickere Muskelbündel sind an beiden Seiten des Schwanzes deutlich sichtbar; nach vorn gehen sie in die allgemeine Körpermusculatur über. Merkwürdig ist, dass die oben erwähnte paarige Ausbreitung an der Unterseite des Schwanzes nur bei kleineren Exemplaren (bis zu $75 \mathrm{~mm}$.) deutlich entwickelt ist; bei grösseren ist sie sehr klein und winzig. Die Schale ist stark gekrimmt, mit stark niedergedrückter Spira; die Mündung ist ziemlich weit, ungefähr eiförmig; der Kiel auf der dorsalen Kante ist nicht sehr hoch, und besitzt, ebenso wie die Schale, Querrippen.

Länge des Tieres bis zu $220 \mathrm{~mm}$.; Höhe der Schale bis zu $4 \mathrm{I} \mathrm{mm}$.

Copie des Tieres nach Costa (Fig. 58 nach Reeve), der Schale nach Reeve.

Verbreitung: Mittelmeer, auch in der Adria: Aradas und Benoit, Lo Bianco, Cavolini, detle Chiaje, Costa, Döderlein, Doublier, Fahringer, Fol, Forbes, Gegenbaur, Gemellaro, Jefrereys, Leucrart, Macri, Michaud, Oberwimmer, Paneth, Payraddenu, Petit, Philipri, Poli, Reeve, Requien, Risso, Targioni-Tozzetti, Vayssière, Verany. Atl. Oz. ( $38^{\circ} \mathrm{N} ., 28^{\circ} \mathrm{W}$.): Vayssière. 
2a. Carinaria lamarcki var. oceanica Vayssière.

Diese neuerdings von VAIsSIĖRE abgetrennte Varietät unterscheidet sich durch eine viereckige Schwimmflosse und längere Tentakeln. Die Radula ist etwas abweichend gebaut, die drei Dornen an der Mittelplatte haben eine schlankere Gestalt, der Kamm an der Innenseite der Zwischenplatte ist etwas weniger kräftig entwickelt. Das Tier wurde nicht abgebildet. Länge 8 I mm.

Verbreitung: Östl. Atl. Oz. $\left(42^{\circ} \mathrm{N}\right.$., $14^{\circ} \mathrm{W}$.): VAyssière. Zweimal wurde ein Exemplar, jedesmal im Magen eines Thunfisches, gefunden, sodass aus den Fundorten, wie mir scheint, nichts Genaues ersehen werden kann.

3. Carinaria fragilis Bory de Saint-Vincent. (Taf. II, Fig. 59).

Die Schale ist deshalb merkwürdig, weil BORY DE SAINT-VINcent ihr, statt Querrippen, radiale Linien zuschreibt, die also sämtlich nach der Spitze verlaufen. Eine solche Structur ist niemals bei Carinaria beobachtet worden. Sowerby sprach neuerdings die Vermutung aus, dass der Forscher sich mit durchschimmernden Kiemen getäuscht haben könnte.

Wie dem auch sei, die Abbildung zeigt so grosse Ähnlichkeit mit C. lamarcki, dass wir wohl die beiden Arten für identisch halten können.

Verbreitung: Süd-Afrikanische Küste: BORY DE SAInt-VIxceNt.

4. Carinaria depressa Rang. (Taf. II, Fig. 60-6I).

Diese früher von Raxg ungenügend angedeutete Art, wurde neuerdings von SowErbY wieder beschrieben. Ein ausgezeichnetes Exemplar findet sich im „British Museum”. Die ganze Schale ist äusserst flach, die ventrale Kante ist kaum ausgebildet, sehr kurz, die dorsale aber deutlich convex, und ziemlich lang. Von oben gesehen, sind die Querrippen auf der Schale sichtbar, von dem medianen, kaum hervorragenden Kiel ausgehend. Die sehr kleine Spira ist stark nach rechts gebogen.

Länge des Tieres (nach RAxG) I IO mm.; Länge der Schale Io mm. (RAxG), 5-10 mm. (SOWERBY).

Die hier gegebene Abbildung ist nach einer Skizze von mir, nach dem Londoner Exemplar, angefertigt worden.

Verbreitung: Madagascar: Raxg. Ind. Oz.: Sowerby. Die von mir studierte Schale stammte ebenfalls aus dem Indischen Ozean.

\section{Carinaria australis Quoy et Gaimard. (Taf. II, Fig. 62-63).}

Diese Art zeichnet sich durch folgende Merkmale aus: der Körper ist ganz glatt und langgestrekt, vorn in einen ziemlich dünnen und kurzen Rüssel, hinten in einen hohen Schwanz übergehend, der, wie es scheint, in zwei horizontale Flossen endet, zwischen welchen ein Schwanzfaden sich anheftet, ganz wie bei Pterotrachea. Ein Kamm auf der Dorsalseite des Schwanzes, ganz nah am Nucleus anfangend, scheint deutlich vorhanden zu sein. Die Flosse ist scharf viereckig, mit einem Saugnapfe an der hinteren, freien Ecke. Die Schale is niedrig, fast ganz wie bei C. lamarcki.

Copie (Fig. 62) nach Quor und Gaimard. 
Die Beschreibung in der Voyage de l'Astrolabe wurde in nenester Zeit von VArssièr: ergänzt; wenn er aber, wie er vermutet, die Originalexemplare vor sich hatte, so zeigen doch die verschiedenen Abbildungen gar nicht denselben Habitus (vergl. Fig. 62 u. 63). In der Abbildung VAYsstère's (Fig. 63) sind die Tentakel länger, der Ruissel ist bei weitem nicht so dünn, an der Dorsalseite des Schwanzes ist gar kein deutlicher Kamm entwickelt, der Schwanz. endet einfach spitz, ohne horizontale Flossen. Der Eingeweidenucleus ist mit einem langen Stiele der Schwimmflosse gegenüber angeheftet. Letztere ist zwar deutlich vicreckig, zeigt aber nicht zwei, sondern drei freie Ecken. Die Radula hat eine Mittelplatte mit drei ungleich langen, sehr schmalen Dornen. Der ganze Körper ist glatt, ohne Tuberkel, zeigt aber, ülberall zerstreut, die kleinen, runden Hautflecken, wie sie überall bei Carinaria vorzukommen scheinen. Länge des Tieres $32-35 \mathrm{~mm}$., Höhe der Schale $6-7 \mathrm{~mm}$.

Ob die zwei hier gegebenen Beschreibungen sich auf dieselben Exemplare beziehen, steht dahin.

Verbreitung: Süd-Pazif. Oz. (zwischen Australien und Neu-Seeland): Quor und Gamrard.

\section{Carinaria cithara Benson. (Taf. II, Fig. 64).}

„Testa dextra, ultimo anfractu recto, compresso-conico, versus spiram gradatim et eleganter attenuato, spiram terminalem fere amplectente, rugis obliquis ornato; apertura obliqua, oblongoovata, versus carinam coarctata, carina mediocri, striis sub-rectis signata".

Aus der undeutlichen Beschreibung Benson's geht so viel hervor, dass die Schale ganz gerade ist, ohne jegliche Krümmung, unten schräg abgestutzt, mit niedrigem Kiele. Neuerdings wurde diese Art wieder von Sowerby beschrieben und zum ersten Nale auch abgebildet. Ein ganz tadelloses Exemplar findet sich im "British Museum”, und die hier gegebene Abbildung ist nach dieser Schale gemacht worden. Die Schale ist gerade, die kleine, elegante Spira oben aufgesetzt; die Hinterseite ist länger als die Vorderseite, weil die Schale unten wie schräg abgestutzt erscheint. Querrippen laufen parallel dem Mundrande und setzen sich in derselben Richtung auf den niedrigen Kiel fort. Höhe der Schale 9-io mm.

Verbreitung: Trop. Ind. Oz.: Benson, Sowerby. Das von mir untersuchte Exemplar stammte ebenfalls dorther.

\section{Carinaria galea Benson. (Taf. II, Fig. 65).}

„Testa dextra, ultimo anfractu incurvo, compresso-conico, spiram terminalem fere amplectente, rugis transversis ornato, late carinato, carinae rugis perobliquis recurvatis; apertura transversa, ovata, versus carinam coarctata".

Die Schale ist an der Spitze gekrümmt, und hier heftet sich die kleine Spira an.

Es wurde auch diese Art von Sowerby wieder beschrieben, und eine Abbildung beigegeben. Da auch ein ganz schönes Exemplar sich im "British Museum” fand, so habe ich die nach dieser Schale angefertigte Skizze hier wiedergegeben. Die Schale ist ganz gerade, nur an der Spitze leicht gebogen, und hier findet sich die elegante Spira. Auch fängt schon dort der Kiel an, der weiter der ganzen Vorderseite der Schale entlang zieht, ziemlich hoch und mit sIgOg.t-ExpHDITIL L.T. 
Querstreifen versehen ist, die mit den Querrippen auf der Schale einen bestimmten Winkel. bilden. Der Mund ist nicht schräg abgestutzt, wie bei der vorhergehenden Art.

Nähere Besprechung im zweiten Abschnitt.

Verbreitung: Trop. Ind. Oz: Bexson, Sowerby. Auch das von mir gesehene Exemplar stammte dorther. Östl. Pazif. Oz. (bei den Galapagos-Inseln): Bexsor.

S. Carinaria punctata d'Orbigny. (Taf. III, Fig. 66-66a, b).

"Corps allongé, subfusiforme, acuminé à ses extremités, diaphane, gélatineux, couvert partout de petits points élevés, qui rendent toute sa superficie rugueuse, excepté la trompe qui est lisse". Die Flosse ist viereckig mit grossem Saugnapfe. Schwanz spitz zulaufend ohne laterale Flossen, ohne Kamm an der Rückenseite. Schale der von C. lamarcki sehr ähnlich, nur, wie es scheint, etwas mehr zusammengedriickt (Fig. 6Sb) und mit grösserer Spira. Wie D'Orbigny hervorhebt, ist diese Art durch die iberall auf dem Körper zerstreuten kleinen Dornen von C. australis verschieden. Ich möchte noch hinzufügen, dass auch die Form des Schwanzes und der Schwimmflosse die Art D'Orbigny's von.C. australis trennen. Länge des Tieres 90-100 mm.

Copie nach D'ORBIGay.

Verbreitung: Östl. Pazif. Oz. (bei Juan-Fernandez): D'ÓRBIGNY.

9. Carinaria atlantica Adams et Reeve. (Taf. III, Fig. 67).

Die Beschreibung und Abbildung dieser Art ist so eigentümlich, dass, vorausgesetzt dass die Angaben richtig sind, die Aufstellung eines neuen Genus gerechtfertigt wäre. Erstens sind Eingeweidenucleus und Flosse einander nicht gegenubergestellt, wie sonst ganz allgemein bei Carinaria vorkommt, sondern die Flosse ist noch dazu "sharply triangular", was sonst nie bei Heteropoden überhaupt der Fall ist. Am ehesten wäre aber ungenaue Beobachtung anzunehmen. Der Körper ist langgereckt und schlank, mit stumpfem Schwanze; eine deutliche Einschnuirung, gleich vor den spitzen Tentakeln, trennt den kurzen Rüssel vom übrigen Körper. Schale klein, zusammengedriickt, mit hohem Kiele. Grösse des Tieres wird nicht angegeben.

Copie nach ADAus.

Nord-Atl. Oz.: Adaws.

I0. Carinaria gaudichaudi Souleyet. (Taf. III, Fig. 68-69).

„La coquille est très élevée, en forme de bonnet phrygien, comprimée latéralement et marquée de sillons transverses comme dans les autres espèces, très fragile et d'une grande transparence; son sommet représente une petite coquille discoide, munie de trois tours, faisant une légère saillie à droite et ombiliquée du côté gauche; le dernier tour, qui forme presque toute la coquille, est munie antérieurement d'une très large carène qui se retrécit progressivement vers sa partie supérieure et qui se termine au sommet. L'animal se rapproche beaucoup des Carinaroides par la disposition du pédoncule nucléal qui est situé plus en arrière que dans les autres espèces, et par le développement moins considérable de son extremité postérieure ou 
caudale; sa surface est recouverte, dans toute l'étendue du corps, de petites éminences ou aspérités, comme dans les autres Carinaires".

Die hier gegebene Beschreibung wurde später von MACDoNald in so weit ergänzt, dass er nachwies, dass die kleinen Tuberkel auf dem Körper in Wirklichkeit subcutane Hautflecken vorstellten, wie sie allgemein bei Carinaria vorkommen. Die Abbildung MLcDovald's (Fig. 69) zeigt merkwürdigerweise den Saugnapf nahe an der Basis der Schwimmflosse. Der Schwanz ist etwas stumpfer.

Trotzdem wird es leicht sein, in C. gaudichaudi dieselbe Art zu erblicken wie C. galca. Die Schalen, mit der leicht gebogenen Spitze und dem breiten Kiele, kommen ganz iiberein. Die Priorität gehört also dem Namen Bexsox's. Auch Sowerbr sprach sich fiir die Identitait der beiden Arten aus.

Länge des Tieres $25 \mathrm{~mm}$.; Höhe der Schale $6 \mathrm{~mm}$. (Souleyet).

Copie nach Soulexet (Fig. 68) und Macdoxald (Fig. 69).

Verbreitung: Philippinen: Souleyet. Trop. Pazif. und Atl. Oz.: Micdoxald.

\section{Cerinaria cornucopia Gould.}

„Testa parva, hyalina, elongata, subtriangularis, compressa, plicis angulatis reclivibus ad cristam retrorsum inclinatis ornata; apice spirali anfractus 4 dextrorsum, unicum sinistrorsum volventes monstrante; crista elevata, lunata, spiram haud attingente. Apertura angusta, ovata.

The unusual length of the shell, the very elevated crest, equalling half the major diameter, and the waved, almost plicate surface make this a strongly marked species".

Trotz der letzten Bemerkung möchte ich an den Schluss der Beschreibung, durch keine Abbildung verdeutlicht, ein Fragezeichen stellen. Sowerby vermutet, dass ebenfalls C. cornucopia mit C. galea identisch sei.

Höhe der Schale Io $\mathrm{mm}$.

Verbreitung: Süd-Ǩarolinen-Inseln : Gould.

12. Carinaria sp. Smith. (Taf. III, Fig. 7o).

Der Körper ist überall mit kleinen Hautflecken bedeckt, auch am Schwanze und auf dem Rüssel; dazwischen kommen Höcker vor. An die Rückenseite des Schwanzes heftet sich, eine bestimmte Strecke hinter dem Eingeweidenucleus anfangend, ein Kamm an, der bis zur Spitze reicht. Die Flosse ist abgerundet; der Nucleus niedrig, mit Kiemen am freien Rande, besonders an der linken Seite.

Nach meiner Überzeugung muss diese Form zu C. lamarcki gestellt werden, besonders mit Rücksicht auf den Schwanz, die Flosse und den Nucleus. Ich hatte im „British Museum” Gelegenheit das Originalexemplar zu studieren, und fand meine Vermutung nur bestätigt. Die kleinen Hautflecken und Tuberkel sind, ganz wie bei der Art des Nittelmeers, uiberall zerstreut. Als ich die Radula untersuchte, fand sich, dass die Zwischen- und Seitenzähne ganz mit denen von C. lamarcki übereinstimmten, in der Mittelplatte zeigten sich aber die drei Dornen viel schlanker und langgestreckt, während sie bei C. lamarcki dicker und kürzer sind. 
Höchstens kann man es hier mit einer Varietät der mediterranen Art zu tun haben. lediglich mit Ruicksicht auf die Radula. Die Varietät oceanica ist jedenfalls eine andere.

Von Smith und Sowerby wurde vermutet, dass diese Form mit C. punctata identisch sein könnte.

Länge des Tieres $35 \mathrm{~mm}$.

Copie nach Sirth.

Verbreitung: Westl. Ausgang der Strasse von Gibraltar: Smith.

13. Carinaria elata Sowerby. (Taf. III, Fig. 71).

Die Schale ist sehr hoch, höher noch als bei $C$. cithara, zugleich auch schlanker, unten schräg abgestutzt, stark zusammengedrückt. Die Spira war abgebrochen, aber sehr wahrscheinlich der Spitze der Schale aufgesetzt, ganz wie bei C. cithara. Auch der Verlauf der Querrippen auf der Schale und der Streifen auf dem niedrigen Kiel ist in beiden Arten ähnlich.

Höhe der Schale $16 \mathrm{~mm}$; Breite $6 \mathrm{~mm}$; Querdurchmesser der Mundöffnung $3 \mathrm{~mm}$.

Copie nach Sowerby.

Verbreitung: West-Pazif. Oz.: Sowerby.

14. Carinaria grimaldi Vayssière. (Taf. III, Fig. 72).

Körper langgestreckt und überall. mit kleinen Stacheln besäet, welche das Tier, wie mit einem sammetähnlichen Kleide, überziehen. Rüssel mächtig entwickelt, fast ebenso dick wie der Rumpf; Augen sehr gross; Tentakeln klein, kaum sichtbar. Flosse klein, fast viereckig, mit einem Saugnapfe in der hinteren, freien Ecke. Die Schale fehlte, ist aber, nach der Form des Eingeweidenucleus zu urteilen, sehr niedrig; die Spira ganz dem Körper des Tieres anliegend, mit nur zwei Windungen, die aber schon zusammen einen beträchtlichen Teil der ganzen Schale bilden. Schwanz einfach, in eine Spitze auslaufend. Radula der von C. lamarcki sehr ähnlich; der Kamm an der Innenseite des Zwischenzahnes ist aber etwas abweichend gebaut. Wie sonst bei Carinaria kommen auch hier kleine, rundliche. Hautflecken vor, subcutan gelegen; sie sind aber meist gänzlich verdeckt unter den vielen kleinen Stacheln an der Oberfläche des Körpers.

Wenn auch das Vorkommen von Stacheln von vorne herein zugegeben werden muss, so möchte ich doch die Vermutung äussern, dass es sich hier um ein Artefact handeln kann. Bei der Fixierung mit Pikrin-Schwefelsäure wird die Kalkschale aufgelöst und es kann nachher, in Alkohol, ein Niederschlag von ganz kleinen Gypskrystallen entstehen, welche sich uberall festheften, und so ein stachliges Kleid vortauschen. Wie das Tier conserviert wurde, ist aber nicht angegeben worden.

Wenn immerhin die kleinen Nadeln sich auch beim lebenden Tiere zeigten, würden wir darin ein ganz schönes Merkmal dieser Art zu erblicken haben.

Länge des Tieres $12 \mathrm{~mm}$.

Copie nach VAYSSIÈRE.

Verbreitung: Azoren: VAyssière. 
I5. Carinaria pseudo-rugosa Vayssière. (Taf. III, Fig. 73).

Diese kleine Art erinnert in ihrem Habitus sehr an C. lamarcki; der ganze Körper scheint mit kleinen Tuberkeln ibersäet zu sein, aber bei genauer Betrachtung erweisen sich die vermeintlichen Tuberkel als von drüsiger Natur; sie sind einfach rundliche, subcutane Hautflecken, und echte Höcker kommen gar nicht vor. Der Körper ist schwach rötlich angehaucht. Augen sehr gross, hervorragend; Rüssel in der Mitte stark eingeschnürt. Der Schwanz ist klein und entbehrt ganz irgendwelcher vertikalen oder horizontalen Kämme, nur an der Oberseite, da wo der Schwanz in einen langen Faden endet, ist eine schwarzpigmentierte Stelle. Die Schwimmflosse ist verhaltnissmässig sehr klein, abgerundet, mit kleinem Saugnapfe am Unterrande, etwas nach hinten verschoben. Der Eingeweidenucleus mitsamt der Schale fehlten gänzlich. In der Radula sind die drei Dornen der Mittelplatte gleich lang, die Äusseren sehr leicht nach aussen gekrummt an der Spitze, und alle von schlanker Gestalt.

Länge des Tieres $\mathrm{I}_{4} \mathrm{~mm}$.

Copie nach VAYSSIÈRE.

Verbreitung: Azoren: VAYSSIÈRE.

16. Carinaria sp. Warlomont. (Taf. III, Fig. 74).

Diese Form zeichnet sich aus durch ihren ausserordentlich kräftigen Rüssel, und überhaupt durch die mächtige Entwicklung des vorderen Rumpfabschnittes. Die Augen sind sehr gross. Der Nucleus und der Schwanz sind nur ganz unbestimmt angegeben worden, der letzte endet in zwei sehr grosse laterale, horizontale Ausbreitungen; die Flosse ist rundlich und trägt einen Saugnapf am Hinterrande. Nöglich ist es allerdings, dass wir in dieser Form nur ein Jugendstadium irgendeiner schon bekannten Carinaria zu erblicken haben.

Die Länge des Tieres beträgt nur $7 \mathrm{~mm}$.

Copie nach WARLOMONT.

Verbreitung: Villefranche: WARLOMoxt.

Pterosoma Lesson i 830.

Die Gattung Pterosoma wurde zuerst von Lessox errichtet, freilich ohne irgendwelche Andeutung, wo ihr systematischer Platz wäre; sie wurde, man möchte sagen, zufällig, in die Nähe von Pterotrachea gestellt. Ihre systematische Stellung blieb lange Zeit zweifelhaft; Fischer hielt sie fuir eine pelagische Nemertine. Erst in neuerer Zeit gelang es MIoseley, namentlich aber Hedley den Nachweis zu liefern, dass die Gattung Pterosoma zu den Heteropoden zu stellen wäre. Von CRosse wurde diese Behauptung näher begrindet. Das Originalexemplar Lessox's war offenbar verstümmelt, sonst wäre ihm die Ahnlichkeit mit Carinaria wohl nicht entgangen. Eine nähere, freilich nur kurze, Diagnose verdanken wir HEDLEx.

Ich selbst hatte das Glück, ein Pterosoma untersuchen zu können, und zwar aus der Sammlung der Challenger. In seinem Rapport über die Heteropoden des Challenger werden 
von Sinth drei sehr kleine Exemplare erwähnt, die von ihm zu C. cristata gestellt wurden. Als ich jüngst diese drei kleinen Formen untersuchte, stellte es sich heraus, dass zwei derselben wirklich zu Carinaria gehören, die dritte aber ein Vertreter der Gattung Pterosoma ist.

Man kann Pterosoma auffassen als eine Carinaria, deren Flanken, am Rumpfe wie am Schwanze, sich stark horizontal ausgebreitet haben, so dass das ganze Tier eine flache Scheibe darstellt, welche vorn eingekerbt ist, und an dieser Stelle den Rüssel frei herabhängen lässt, hinten aber sich allmählich verschmälert und in einen langen, dünnen Schwanzfaden endet. Der Nucleus ist etwás weiter nach vorn verschoben, und nicht der Flosse gegenüber, wie bei Carinaria.

Eine Skizze, von mir, während meines Aufenthaltes zu London, angefertigt, ist auf Taf. III, Fig. 75 wiedergegeben. Man sieht, dass der ganze Körper sich zu einer dünen, flachen Scheibe abgeflacht hat, die überall mit kleinen Hautflecken bedeckt ist. HeDLEy erwähnt ausserdem noch kleine Höcker. Die Scheibe ist ganz durchsichtig, ganz wie die Cutis bei Carinaria, am Rande nicht dünner, oder doch nur sehr wenig, als in der Mitte, und im Ganzen gestreckt. herzförmig, also vorn, zwischen den Augen, eingekerbt, hinten sich verjïngend, hier mit deutlichen schwach convergierenden Muskelbündeln versehen, und in einen langen Faden auslaufend. Der cylindrische, kräftige Rüssel, mit grosser Buccalmasse, hängt frei herab; da, wo er sich an die Scheibe heftet, finden sich die Tentakel (von weichen ich nur den linke sah) und die Augen, welche ganz wie die Sehorgane von Carinaria gebaut sind, und ebenfalls eine breite Basis und eine im Ganzen dreieckige Gestalt besitzen. Mitten auf der Scheibe ruht ein sehr flacher Nucleus, der allerdings stark beschädigt war, und dessen Schale fehlte. Kiemen sind am Vorderrande und an der linken Seite entwickelt; sie sind sämtlich von gleicher Gestalt und sehr kurz. HEDLEy beschreibt einen viel höheren Nucleus, der, gerade der Flosse gegenüber, in der Mitte der Scheibe gelagert war; von der Schale sagt er noch: „the shell is carried with its spiral end posteriorly; it is $4,5 \mathrm{~mm}$. long, I,5 $\mathrm{mm}$. broad and high, apically consisting of a spiral, smooth, purple shell of $2^{1} / 2$ whorls, at right angles to which extends the adult, boat-shaped shell, white, glassy, shining, most brittle, ornamented by a double, lamellar keel running from the embryonic shell along its periphery; from keel to margin curved growth-lines undulate the side of the shell". Es geht daraus hervor, dass die Schale im Ganzen der von Carinaria ähnlich ist.

Etwas weiter nach hinten verschoben, also nicht dem Nucleus gegenüber, findet sich die grosse, dünne Flosse, deren Basis eingeschnürt ist und welche am Hinterrande einen deutlichen Saugnapf trägt. Zwei deutlich gesonderte Muskelsysteme, wie sie auch bei Carinaria vorkommen, und die sich fast rechtwinklig kreuzen, geben der Flosse ein gegittertes Aussehen, lassen aber den sehr diinnen, membranösen Unterrand fast gänzlich frei.

Die Radula ist fast ganz wie bei Carinaria gebildet. Die Mittelplatte trägt drei fast gleich lange, schlanke Dornen; der Zwischenzahn hat an der Innenseite einen deutlichen Kamm, ganz Carinaria-ähnlich, und die beiden Seitenzähne sind stark gekrimmt.

In der phylogenetischen Reihe erscheint also Pterosoma als einseitig entwickelter Zweig des Carinaria-Stammes, der sich besonders dadurch kennzeichnet, dass der Rumpf sich zu einer Scheibe abgeflacht hat. 
Da die Ehre des Wiederauffindens dieser Gattung der Challenger-Expedition gehört, so schlage ich fur die hier beschriebene Form den Namen Ptorosoma challengcri ${ }^{1}$ ) vor.

Lesson giebt als Länge des Tieres $80 \mathrm{~mm}$. an; Hrinliy fand nur $30 \mathrm{~mm}$. (von den Augen bis zum Schwanze), der Rumpf selbst war is $\mathrm{mm}$. lang, I $3 \mathrm{~mm}$. breit. Das von mir untersuchte Exemplar war kleiner, die Scheibe hatte eine Länge von $9 \mathrm{~mm}$.

Verbreitung: Zwischen den Molukken und Neu-Guinea: Lisson. Zwischen Australien und Neu-Seeland: Hedury. Das Exemplar der Challenger-Expedition wurde auf dem Traject Admiralitäts-Inseln-Japan erbeutet. Die Siboga-Expedition hat keinen Vertreter der Gattung gefunden.

\section{Cardiapoda d'Orbigny 1836 .}

Eine zu dieser Gattung gehörige Art wurde zwar 1830 von Lisson aufgefunden, ihr abweichender Habitus aber nicht erkannt, weshalb sie einfach zu Pterotrachea gezogen wurde. D'Orbigny aber wies nach, welche grosse Unterschiede zwischen Ptorotrachea und der betreffenden Form von LESSon tatsächlich bestehen, und stellte deshalb die Gattung Cardiapoda auf, welchen Namen Soulzyet dann wieder in Carinaroida umzutauschen versuchte. Zwar wurde unsre Kenntniss der Gruppe durch die Beschreibungen d'Orbigny's, Souleyet's und Macdonald's wesentlich erweitert, aber doch ist noch jetzt von den verschiedenen Gattungen der Heteropoden, Pterosoma ausgenommen, das Genus Cardiapoda am wenigsten bekannt. Es rührt dies wohl daher, dass Cardiapoda im Mittelmeer gar nicht vorkommt, und deshalb auch nur sehr selten zur Untersuchung gelangte.

Ich werde im zweiten Abschnitt noch Gelegenheit haben, auf viele Eigentuimlichkeiten der Gattung zuriickzukommen; da es sich hier nur um rein systematische Interessen handelt, so genügt eine Diagnose von Cardiapoda mit ihren bis jetzt bekannten Arten.

Der allgemeine Habitus ist wie bei Carinaria; die Cutis ist etwas weniger dick auf dem Rumpfe, der Rüssel ist kräftig ausgebildet, vorn rechtwinklig abgestutzt; eine Einschnürung, die den Kopf vom übrigen Körper trennt, kommt nicht vor. Die Augen sind sehr gross, ganz wie bei Carinaria ausgebildet, Tentakel kommen ebenfalls vor und zwar bei beiden Geschlechtern. Der Nucleus ist nach hinten verschoben und wird auf einem mehr oder weniger langen Stiele getragen; die Schale ist sehr klein, spiralig aufgewunden, und bedeckt nur einen verschwindend kleinen Teil der Leber, sonst ist der Nucleus ganz nackt, und entweder auf dem ganzen freien Rande, oder nur an der Vorderseite mit Kiemen versehen. Der Stelle gegenüber, wo der Stiel des Nucleus aus dem Körper entspringt, heftet sich die sehr grosse Flosse an; bisweilen ist sie aber etwas nach vorn verschoben. Die Muskelbindel in der Flosse sind hier weniger deutlich als bei Carinaria; der Saugnapf ist entweder an der Unterseite oder aber am Hinterrande befestigt, ist fur gewohnlich ziemlich klein und kommt beiden Geschlechtern zu. Der wenig entwickelte Schwanz, ohne deutlichen Kamm, verjüngt sich allmählich (wenigstens oft) in einen Schwanzfaden und trägt bisweilen an der Unterseite ein ovales, sehr dünnwandiges, becherförmiges Gebilde; da wo der Schwanzfaden sich am Schwanze festheftet, findet sich bei einigen Arten eine kleine, horizontale Ausbreitung der Spitze, mit eingebuchteten Rändern. 
Die Arten von Cardiapoda sind sehr ungenügend beschrieben worden; MACDonald glaubte sogar, die beschriebenen Formen wären alle in einer Art zu vereinigen, und SuIth hält diese Ansicht für gerechtfertigt. Der letztgenannte Autor war der Meinung, dass die Geschlechter nur durch die Kiemen angedeutet würden, so dass Arten wie C. placenta das Weibchen, C. carinata das Männchen einer und derselben Art vorstellten. Die Untersuchung des SibogaMateriales und auch der Sammlung des „British Nuseums”, hat mich aber gelehrt, dass diese Auffassung aufgegeben werden muss. VAYSSIÈrE schreibt nur den Männchen einen Saugnapf zu, aber auch diese Behauptung betrachte ich als einen Irrtum.

Am bequemsten wird es wohl sein, die Arten in zwei Gruppen zu verteilen, $A$ : mit Kiemen am ganzen freien Rande des Nucleus, $B$ : mit Kiemen nur am Vorderrande.

$\mathrm{Zu} A$ gehören :

I. Cardiapoda placenta (Lesson).

2. Cardiapoda placenta (Souleyet).

3. Cardiapoda placenta Smith.

4. Cardiapoda pedunculata d'Orbigny.

5. Cardiapoda sp. Gray.

Zu $B$ gehören :
6. Cardiapoda carinata d'Orbigny.
7. Cardiapoda caudina Rang.
8. Cardiapoda caudina (Souleyet).
9. Cardiapoda sp. Macdonald.
Io. Cardiapoda richardi Vayssière.

1. Cardiapoda placenta (Lesson). (Taf. III, Fig. 76).

Die sehr unvollständige Beschreibung Lessox's giebt nur wenig Aufschluss; der Körper ist cylindrisch, vorn in einen ziemlich langen Rüssel, hinten in einen spitzen Schwanz uibergehend, der, wie es scheint, keine Anhänge trägt. Mit dem Schwanze von gleicher Länge ist der Stiel, an dessen Ende sich der Eingeweidenucleus findet, der am ganzen Hinterrande mit Kiemen besetzt ist. Gerade dem Stiele gegenuiber heftet sich an der Unterseite die Flosse an, die von abgerundeter Gestalt ist und an der Wrurzel sich nur wenig verschmälert. Ein Saugnapf, sowie Augen und Tentakel, sind nicht angegeben, aber sehr wahrscheinlich übersehen worden.

Länge des Tieres $50 \mathrm{~mm}$.

Copie nach LEsson.

Verbreitung: Neu-Guinea: Lessox.

\section{Cardiapoda placenta (Souleyet). (Taf. III, Fig. 77).}

Diese von SOUleyet mit der vorhergehenden Art identifizierte Form unterscheidet sich namentlich dadurch, dass der Nucleusstiel viel kürzer ist als der Schwanz. Weiter ist der Nucleus selbst viel umfangreicher, mit Kiemen am ganzen freien Rande. Der Schwanz endet in ein schwarzpigmentiertes, lappenförmiges Gebilde; die Flosse ist etwas mehr nach vorn gelegen als der Nucleusstiel, sehr gross, abgerundet, an der Basis eingeschnürt, mit sehr kleinem Saugnapfe 
an der Unterseite, etwas nach hinten verschoben. Der Riussel ist krïftig, ebenso wie bei Carinaria; Augen und Tentakeln (diese sehr lang) sind vorhanden.

Länge des Tieres $35 \mathrm{~mm}$.

Copie nach Soulever.

Verbreitung: Sandwich-Inseln u. trop. Atl. Oz.: Souleyet,

3. Cardiapoda placenta Smith. (Taf. III, Fig. 78).

Die von der Challenger-Expedition gefundene Form hat wirklich mit der Art Soutryer's die grösste Ähnlichkeit, jedoch möchte ich sie lieber getrennt beschreiben, da immerhin gewisse Unterschiede bestehen. Der Rüssel ist kürzer, ziemlich spitz zulaufend, der Rumpf dagegen mächtig entwickelt und in einen kleinen Schwanz übergehend, der an den Seiten deutliche, longitudinale Muskeln zeigt und, nach einer geringen Einschnürung, bandförmig wird, um schliesslich in ein sehr kleines eingekerbtes Gebilde zu enden. Letzteres, sowie der Nucleusstiel, der Nucleus selbst mit den Kiemen und die grosse, breit angeheftete Flosse, stimmen mit den entsprechenden Teilen der vorhergehenden Art fast ganz überein. Ein kleiner Saugnapf kommt auch hier vor und zwar ebenfalls ein wenig nach hinten gerückt.

Ich hatte im „Britisch Museum” die Gelegenheit, das Originalexemplar zu studiren, und damit die Angaben Sxптн's zu bestätigen. Nur muss ich noch hinzufügen, dass die Mittelplatte der Radula drei gleich lange, ziemlich weit von einander abstehende Dornen trägt.

Länge des Tieres $77 \mathrm{~mm}$.

Copie nach Smith.

Verbreitung: Aru-Inseln: Suith.

4. Cardiapoda pedunculata d'Orbigny. (Taf. III, Fig. 79).

Rüssel kurz, wahrscheinlich stark zusammengezogen; Rumpf nur wenig dicker, Tentakeln lang, Schwanz schlank, allmählich sich verdünnend, ohne membranöse Ausbreitungen. Nucleusstiel sehr lang und dünn; Nucleus selbst sehr umfangreich mit einer Reihe Kiemen am ganzen Hinterrande. Die Flosse ist nicht gerade der Ansatzstelle des Stieles gegenuiber gestellt, sondern etwas nach vorn gerückt, klein, an der Wurzel stark eingeschnürt, mit grossem Saugnapfe, gerade in der Mitte der Unterseite.

Nach Souleyet wäre diese Art dieselbe wie seine C. placenta, der Nucleus ist aber grösser, der Stiel länger, der Schwanz einfach und ohne flossenartige Bildungen, und besonders die Flosse ist kleiner, deutlich eingeschnürt, indem der Saugnapf nicht am Hinterrande liegt, sondern nach vorn gerückt ist.

Länge des Tieres $30-40 \mathrm{~mm}$.

Copie nach D'Orbigny.

Verbreitung: Trop. Atl. Oz.: D'Orbigny.

5. Cardiapoda sp. Gray. (Taf. III, Fig. 80).

Die Abbildung, von Gray nach einer Zeichnung von Hooker angefertigt, zeigt nur SIROGA-EXPENITLE LI. 
Weniges deutlich, wenn auch der allgemeine Typus von C. placonta, im weiteren Sinne, unverkennbar ist. Der Schwanz geht hier merkwürdigerweise in ein langes, plattes Band über.

Die Länge des Tieres wird nicht angegeben.

Copie nach Gray.

Verbreitung: Unbekannt: GRAX.

Die Arten, welche die Kiemen nur am Vorderrande des Nucleus tragen, nähern sich dadurch im äusseren Habitus sehr dem Carinaria-Typus, und diese Ähnlichkeit wird noch erhöht durch die Beschreibungen der Schale, wenigstens in einigen Fällen.

6. Cardiapoda carinata d'Orbigny. (Taf. III, Fig. 8I-8I a).

Rüssel kräftig, ohne Einschnürung vor den Augen, Tentakeln sehr lang; Rumpf cylindrisch, mit einem ganz kurzen Stiele, der den kleinen Nucleus trägt. Dieser Nucleus ist von einer membranösen Hülle umgeben (vom Verfasser als Schale betrachtet, da er die kleine, spiralige Kalkschale noch nicht kannte) „de la forme d'une nacelle, et carénée en dessous comme la Carinaire". Am Vorderrande dieser Hülle ragen die Kiemen hervor. Wahrscheinlich ist hier eine mantelähnliche Hautduplicatur gemeint. Der Schwanz läuft allmählich spitz zu und hat an der Unterseite zwei schwarze Linien. Die grosse Flosse ist deutlich nach vorn gerückt, abgerundet, an der Basis stark eingeschnürt, am Hinterrande mit einem grossen (im Texte klein genannten) Saugnapfe.

Länge des Tieres $25 \mathrm{~mm}$.

Copie nach D'Orbigny.

Verbreitung: Süd-Atl. Oz.: d'Orbigny.

\section{Cardiapoda caudina (Rang). (Taf. III, Fig. 82).}

Diese Art zeigt im Allgemeinen denselben Habitus, aber die Flosse ist noch weiter nach vorn verschoben, und gerade in der Mitte zwischen dem kurzen Nucleusstiele und den Augen gelagert; an der breiten Basis finden sich kleine rötliche Flecke, die auch am Schwanze vorkommen. Der Nucleus ist klein, wird auf kurzem Stiele getragen, und ist an der Oberseite mit Kiemen versehen. Die Flosse besitzt noch einen winzigen, etwas hinterwärts verschobenen Saugnapf.

Länge des Tieres $80 \mathrm{~mm}$.

Copie nach RANG.

Verbreitung: Trop. Atl. Oz.: Rang.

8. Cardiapoda caudina (Souleyet). (Taf. III, Fig. 83-84).

'Trotz unleugbarer Ähnlichkeit mit der vorhergehenden Form, hat doch die Art Souleyet's gewisse Merkmale, welche nach meiner Meinung, eine gesonderte Besprechung rechtfertigen. Der Nucleus ist verhältnissmässig viel umfangreicher, die Flosse ist hinterwärts gerückt, mit grossem Saugnapfe am freien Hinterrande. Der Schwanz endet in ein sternförmiges, eingekerbtes Gebilde und trägt an der Unterseite einen ovalen, dünnwandigen, schwarz pigmentirten Becher. 
Ein junges Exemplar von Cardiapoda, von Souleyet zu der hier besprochenen Art gerechnet, unterscheidet sich nur durch den spitz zulaufenden Schwanz und einen grossen, schwarzen Fleck, statt des Bechers, an dessen Unterseite.

Das Originalexemplar war im „British Museum”, leider aber ganz eingetrocknet, weshalb ich keine weiteren Untersuchungen anstellen konnte.

Nach Souleyet wäre diese Art dieselbe wie C. carinata; letztere unterscheiclet sich aber, abgesehen von der Schale, durch die Form der Flosse, und durch den grösseren, zudem noch anders gestalteten Schwanz. Eine Identität wäre freilich möglich.

Länge des (erwachsenen) Tieres $35 \mathrm{~mm}$.

Copie nach Souleyet.

Verbreitung: Atl. und Pazif. Oz.: Souleyet.

9. Cardiapoda sp. Macdonald. (Taf. III, Fig. 85).

Diese Art zeigt im Allgemeinen denselben Habitus wie die vorhergenannte, aber doch sind deutliche Unterschiede vorhanden. Die breit angeheftete, niedrige Flosse, ist dem Nucleusstiele gegenüber gelegen, und besitzt, ganz hoch am Hinterrande, einen grossen Saugnapf, del sich sogar von dem übrigen Teil der Flosse deutlich abhebt. Der Schwanz trägt einen ovalen Becher an der Unterseite, setzt sich hinter diesen, mit ziemlich plötzlichem Übergang in ein schmales Band fort, ohne eingekerbtes. Gebilde an der Spitze. Die Schale ist, nach der Beschreibung, sehr merkwürdig. MACDONaLd sagt wörtlich: „numerous branches, with a plain external surface and a zig-zag internal fold, protruded from beneath the dorsal lip of the shell which was semicartilaginous, shallow, or scoop-shaped, with an involute nucleus, and a deep but very thin and delicate keel". Man möchte hier fast an Carinaria denken, wenn nicht die Radula, deren Mittelplatte drei ungleiche Dornen besitzt, und deren Zwischenzahn an der Innenseite einen distal nicht zugespitzten Kamm trägt, ganz Cardiapoda-ähnlich wäre. Erwähnenswert ist weiter noch der stark entwickelte Penis, der sonst bei Cardiapoda klein bleibt.

Länge des Tieres $18 \mathrm{~mm}$.

Copie nach Macdonald.

Verbreitung: S.W. Pazif. Oz.: Macdonald.

I0. Cardiapoda richardi Vayssière. (Taf. III, Fig. 86).

Rüssel sehr gross, mit dem Rumpfe ohne Einschnürung verbunden, zusammen einen cylindrischen Körper darstellend, an dessen Ende sich der Nucleusstiel und der Schwanz finden. Der Nucleus wird auf kurzem Stiele getragen, ist sehr umfangreich, und besitzt am Vorderrande acht lange, dünne Kiemen. (Was der merkwirdige, konische Zapfen an der rechten Seite des Nucleus bedeutet, wird nicht angegeben. Ein Penis wäre an anderer Stelle zu suchen). Der Schwanz ist anfangs sehr hoch, verschmälert sich dann plötzlich, in ein langes Band übergehend: an der Übergangsstelle findet sich, was der Verfasser nennt: „une grande expansion membraneuse à bords sinueux et noirâtres" von schwerlich definirbarer Gestalt. Die sehr grosse, breit angeheftete, rundliche Flosse, die deutliche Muskelbündel zeigen soll, ist dem Nucleusstiele 
gegenüber gestellt, und entbehrt merkwürdigerweise des Saugnapfes; wenigstens wird seine Existenz geleugnet; mehr wahrscheinlich aber ist er, seiner Kleinheit wegen, übersehen worden. Die Augen sind weit auseinander, lateralwärts, gerückt, und jedes trägt einen starken Tentakel an der Vorderseite. Der ganze Körper ist allseitig mit kleinen, ovalen, länglichen oder birnförmigen Hautflecken bedeckt. Die Mittelplatte der Radula zeigt drei Dornen, von denen der mittlere länger ist als die beiden anderen; der Kamm auf der Innenseite des Zwischenzahns ist distal nicht so scharf zugespitzt wie bei Carinaria.

Länge des Tieres $17 \mathrm{~mm}$.

Copie nach VAYSSIÈRE.

Verbreitung: Westl, von den Azoren: VArssière.

Am Schlusse der systematischen Besprechung der Carinariidae, möchte ich noch einige Formen ganz kurz erwähnen, deren Beschreibungen und Abbildungen entweder nach verstümmelten Exemplaren angefertigt wurden oder welche doch auf anderer Weise ganz unkenntlich sind.

Von älteren Autoren sind hier Cuvier, und Quoy und Gamard zu erwähnen. Die "Pterotrachea" von Cuvier (Taf. III, Fig. 87) ist eine verstümmelte Carinaria. Ebenso sind Monophora cylindracea und Timorienna firoloides, beide von Quov und Gamard beschrieben, nur abgerissene Schwanzteile irgendeiner Carinaria.

Später wurden noch von RatrRay einige Formen beschrieben. Erstens eine Carinaria (Taf. IV, Fig. 88) deren Nucleus abgerissen war, mit auffallend langem Schwanze. Weiter noch zwei zu Cardiapoda gehörige Formen, von denen die erste (Taf. IV, Fig. 89) mit ziemlich langem Nucleusstiele, Kiemen am Vorderrande des Nucleus, breit angehefteter Flosse, mit etwas nach hinten gerücktem Saugnapf, zu C. pedunculata gerechnet wurde (wie mir vorkommt, aber mit Unrecht), indem die zweite (Taf. IV, Fig. 90) deren Schwanzteil an den von C. cristata erinnert, einfach als "Carinaroides" bezeichnet wird. Die hier gegebenen Copien stellen die natüliche Grösse dar. Alle stammen aus dem östl. Pazif. Ozean.

Im zweiten Abschnitt werden die folgenden Arten noch ausführlicher besprochen werden: Carinaria lamarcki Péron et Lesueur.

Carinaria cristata Linné.

Carinaria galea Benson.

Ich habe dort noch eine neue Art hinzufügen müssen.

Die zu Cardiapoda gehörigen Tiere habe ich als drei neue Arten bezeichnet.

\section{Familie III. Pterotracheidae.}

Solche Arten, bei welchen gar keine Schale nachweisbar ist, werden zu der Familie der Pterotracheidae vereinigt.

Die älteste Beschreibung einer zu dieser Gruppe gehörigen Art und einer Heteropode überhaupt, stammt von ForSkíL, der I 775 zum ersten Male kurze Diagnosen gab von vier sogenannten "Arten". Diese Beschreibungen sind aber ausserordentlich mangelhaft, und dasselbe 
gilt in mehr oder wenig hohem Grade von fast allen seinen Nachfolgern. Sehr oft wurden einfach die secundären Geschlechtscharactere (die natirlich noch nicht als solche erkannt waren) als Artmerkmale verwendet, in anderen Fällen hat man das Fehlen des Kopfes oder des Schwanzfadens benutzt, um neue Arten oder sogar neue Gattungen aufzustellen. Die systematische Litteratur ist aber noch ganz besonders complizirt dadurch, dass viele Formen vier- oder finfmal mit demselben Namen belegt wurden, ohne die Identität mit den ursprunglichen Beschreibungen genügend festzustellen. Die Verwirrung, welche in der Systematik der Heteropoden ijberhaupt herrscht, ist in dieser Gruppe am grössten und der Forscher, der sich die Aufgabe gestellt hat, die bisher beschriebenen Arten zu besprechen, findet hier gewiss die schwierigste Arbeit.

Es nuitzt nichts, hier wieder die Klagen zu wiederholen, welche schon öfter von verschiedenen Seiten angehoben wurden; wir haben nur die ganze Bürde der ungenügenden Beschreibungen hinzunehmen und zu versuchen, tant soit pou einige Lichtstrahlen in die Finsternis unsrer systematischen Kenntnis zu senden.

Wie ich nach eigenen Beobachtungen nur bestätigen kann, zeigt die ganze Familie eine höchst einförmige Gestalt. Mit grosser Zähigkeit behalten die Arten immer und immer wieder die Grundzüge ihres Baues bei. Überall derselbe cylindrische Körper, ganz durchsichtig und vollkommen an die pelagische Lebensweise angepasst; dieselbe Flosse, derselbe Schwanz, ja, sogar die vier Muskelstreifen, zu beiden Seiten des Schwanzes von Ptcrotrachea, wiederholen unveränderlich den gleichen Verlauf. Bei solcher Sachlage ist es begreiflich, dass nur bei ganz genauer Betrachtung Unterschiede gefunden werden können - eine Aufgabe die offenbar den meisten Beschreibern, wenigstens hier, zu beschwerlich war.

Die Pterotracheidae wiederholen im Allgemeinen den Habitus, wie sie die vorhergehende Familie zeigt; der Körper ist aber schlanker, vollkommen durchsichtig, Tuberkeln kommen zwar vor, aber sie sind klein, und bleiben vereinzelt; Hautflecken sind grösser, rundlich, immer, wenn vorhanden, an der Ventralseite, besonders in der Nähe der Flosse, gelagert. Der Rumpf geht vorn ohne Einschnürung in den cylindrischen Rüssel iiber, hinten in einen Schwanz, in dessen Gestalt hauptsächlich die Unterschiede zwischen den beiden Gattungen gelegen sind. An der Grenze zwischen Rumpf und Schwanz findet sich der Eingeweidenucleus, von birnförmiger Gestalt, eingebettet in die hyaline Körperbedeckung. Die rundliche Flosse, mit etwas eingeschnürter Basis, ist etwa auf halber Länge zwischen den Augen und dem Nucleus angebracht.

Die Familie zerfällt in zwei Gattungen, Pterotrachea und Firoloida.

\section{Pterotrachea Forskâl 1775 .}

Die Gattung unterscheidet sich durch folgende Merkmale: der Rüssel ist kräftig, vor den Augen kommen keine Tentakeln vor, welche ganz fehlen, aber statt dieser, finden sich bisweilen, an ihrer Stelle, einige kleine, nach vorn gerichtete Dornen auf der Stirn. Die Cutis ist ganz hell und durchsichtig, die Flosse gross, rundlich, und fast genau in der Mitte des convexen Unterrandes mit einem Saugnapfe versehen, der nur den Männchen zukommt, bei den Weibchen aber ganz fehlt. Der Eingeweidenucleus ist fast ganz in der durchsichtigen Körpersubstanz eingebettet, nur der spitze, obere Teil ragt hervor, und ist hier am Vorderrande und 
an der linken Seite mit Kiemen versehen, welche vorn sehr klein sind, nach links aber allmählich an Grösse zunehmen. Der Schwanz ist beiderseits zusammengedrückt und überall fast ganz hyalin, mit Ausnahme der schon oben erwähnten, ganz constanten, longitudinalen Muskelbündel, von denen das zweite, namentlich aber das dritte (von der Dorsalseite aus gerechnet) die grössten sind. Eine ausfuhrliche Beschreibung dieser Bündel und ihrer schliesslichen Verschmelzung ist hier nicht am Platze. Sie ist ausserdem schon von Anderen (Leuckart, Kalide u. A.) gegeben worden; es genügt hier zu constatiren, dass die Muskelstreifen zusammenstossen und schliesslich ganz am Ende des.Schwanzes sich vereinen. Hier sind noch zwei, rechts und links gelegene, kleine horizontale Ausbreitungen der Cutis zu beachten, welche zusammen eine herzförmige nach hinten also eingekerbte Figur bilden; in der Einkerbung ist der lange, bewegliche, sehr zarte, perlschnürförmige Schwanzfaden angebracht ("tacnia” Forskâl).

Die Schlundmasse ist im Grossen und Ganzen nach dem allgemeinen Typus bei den Heteropoden gebaut und besitzt eine kräftige Reibeplatte: was aber diese Gattung von den übrigen noch unterscheidet, sind die merkwürdigen Chitinzähne am Dache der Mundhöhle. Sie wurden zuerst von MACDONALD beschrieben, dann in neuerer Zeit wieder von VAyssière. Es handelt sich um zwei longitudinale Reihen, jederseits von der Medianlinie gelegen, am Rande einer dorsalen Grube in der Mundhöhle, und von vorn nach hinten an Grösse zunehmend. Die Zähne sind zäpfenförmig, leicht nach hinten gerichtet; ihre Zahl ist in beiden Reihen nicht immer die gleiche, gewöhnlich sind deren sechs oder sieben vorhanden. Zudem kommen noch nach VAyssière, wenigstens bei einigen Arten, Peribuccalzähne vor, welche im Kreise den Eingang der Mundöffnung an der Innenseite umgeben. Es sind kleine, stark gekrümmte Häkchen, welche sämtlich nach innen gerichtet sind. Alles dies weist auf die äusserst räuberische Lebensweise der Pterotrachea-Arten hin.

Wenn man die verschiedenen, bereits sehr zahlreichen, Abbildungen betrachtet, die sich auf Pterotrachea beziehen, kommt man leicht zu der Vermutung, dass Fehler in der Beobachtung sich oft eingeschlichen haben müssen. Besonders die Lage der Kiemen um dem Nucleus herum, und auch der Schwanz, sind in den Figuren oft abenteuerlich gestaltet, und man möchte meinen, dass in dieser Hinsicht eine grosse Mannigfaltigkeit besteht. Dem ist aber nicht so. Wie schon oben gesagt wurde, ist der Körper bei Pterotrachea immer nach demselben Typus gebaut. Wer genügendes Vergleichsmaterial zu seiner Verfügung hat, wird sich von dieser Tatsache leicht überzeugen können. Ich habe, während fünf Monaten, an der zoologischen Station zu Neapel, eine grosse Menge Exemplare zu studiren Gelegenheit gehabt, aber bei diesen, ebenso wie bei dem reichen Material der Siboga-Expedition, habe ich immer nur bestätigt gefunden, dass die Kiemen, der Schwanz, überhaupt der ganze Körper höchst einförmig sich gestaltet. W or in, meiner Ansicht nach, eigentlich die (freilich geringen) Unterschiede bestehen, hoffe ich im zweiten Abschnitt noch ausfïhrlich zu erörtern, hier habe ich nur die Einförmigkeit constatiren wollen, um es von vornherein verständlich zu machen, dass ich die eigentümlichen Gestaltungen in den Abbildungen auf Beobachtungsfehler zurückführen muss und nicht als spezifische Merkmale berücksichtigen kann.

Es ist aus der Litteratur die stattliche Zahl von 37 Arten zu verzeichnen, von denen Io gänzlich unkenntlich sind, die übrigen aber, wie ich glaube, auf fünf oder sechs Formen zu reduziren wären. 
Diese Arten sind:

I. Ptcrotrachea coronata Forskal.

2. Pterotrachea cuviera (Lesueur).

3. Pterotrachea peronia (Lesueur).

4. Pterotrachea gibbosa (Lesueur).

5. Pterotrachea frederica (Lesueur).

6. Pterotrachea frederici (Blainville).

7. Pterotrachea friderici(ana) delle Chiaje.

8. Pterotrachea fredericia Cantraine, Gegenbaur, Carus.

9. Pterotrachea forskalia (Lesueur).

10. Pterotrachea mutica (Lesueur).

I I. Pterotrachea mutica Cantraine, Gegenbaur, Keferstein, Carus.

12. Pterotrachea mutica (Vayssière).

I3. Pterotrachea mfa Quoy et Gaimard.

I 4. Pterotrachea lesuenri Risso.

15. Pterotrachea lesueuri (Macdonald).

16. Pterotrachea adamastor Lesson.

17. Pterotrachea hippocampus Philippi.

18. Pterotrachea hippocampus (Vayssière).

i9. Pterotrachea quoyana (d'Orbigny).
20. Pterotrachica edwardsi (Deshayes).

21. Pterotrachea umbilicata delle Chiaje.

22. Pterotrachea keraudreni Souleyet.

23. Ptcrotrachea scutata Gegenbaur.

24. Ptcrotrachea sp. Smith.

25. Ptcrotrachea souleyeti (Vayssière).

26. Ptcrotrachea gegenbauri (Vayssière).

27. Pterotrachea talismani (Vayssière).

28. Pterotrachea hyalina Forskal.

29. Pterotrachea hyalina (cristallina) delle Chiaje.

30. Pterolrachca aculcata Forskâl.

31. Pterotrachea pulmonata Forskal.

32. Pterotrachea (Anops) peroni d'Orbigny.

33. Ptcrotrachea (Anops) sp. Rattray.

34. Pterotrachea keraudreni Rattray.

35. Pterotrachea sp. Gray.

36. Hypterus appendiculatus Rafinesque-

Schmaltz.

37. Hypterus crythrogastor Rafinesque-

Schmaltz.

\section{Pterotrachea coronata Forskal. (Taf. IV, Fig. 91).}

Diese sehr oft beschriebene Art ist leider bis jetzt nur mangelhaft bekannt. Dass sie von späteren Forschern, trotz der rohen Abbildung Forskís's erkannt werden konnte, liegt eigentlich nur daran, dass die Art auffallend gross werden kann, sogar bis $250 \mathrm{~mm}$. Hinter solchen Dimensionen bleiben die übrigen Pterotrachea-Arten weit zurück.

Der kräftige Rüssel zeigt vor den Augen $6-8$ starke, nach vorn gerichtete Dornen, gewöhnlich in zwei distal divergirenden Reihen gestellt. Die Cutis ist glatt, fast ganz ohne Dornen, an der Bauchseite finden sich, wie bei Pterotrachea überhaupt, grosse, rundliche Hautflecken, wie sie schon zu wiederholten Malen, so von Gegrnbaur und Vayssière, besprochen wurden. Die Flosse ist sehr gross, rundlich, etwas mehr dem Nucleus als den Augen genähert. Der Nucleus selbst zeigt eine langgestreckte Gestalt, die Kiemen wechseln stark in Zahl; der Schwanz zeigt nichts besonderes.

Panetr machte die merkwürdige Entdeckung, dass bei dieser Art Saugnapf und Penis, sonst nur Zeichen des männlichen Geschlechtes, gelegentlich auch beim Weibchen vorkommen. Besonders ist der Saugnapf an der Flosse des Weibchens sogar ziemlich häufig ${ }^{1}$ ). Paneth meinte, dass die secundären Geschlechtsunterschiede des Männchen gelegentlich auch auf das Weibchen

I) CANtraise sagt von dieser Art: „disco pedis nullo aut subnullo"; wahrscheinlich hat er dann nur normale Weibchen, oder solche mit männlichen Merkmalen gesehen, denn der Saugnapf ist beim Männchen sehr gross. 
ibertragen werden konnten; GRoBben aber, und, wie ich meine, mit Recht, vermutet, dass bei Pt. coronata das secundäre Geschlechtsmerkmal, der Saugnapf, noch nicht in dem Masse nur dem Männchen eigentümlich sei wie sonst bei Pterotrachea, dass also die hier besprochene Art eine Anfangsstufe sei, wo sich das betreffende Merkmal noch in statu nascendi befinde. Diese freilich anregende Tatsache sei hier nur kurz erwähnt.

Wenngleich die Art öfter als irgend eine andere abgebildet wurde, hat noch kein Forscher auf die wesentlichen spezifischen Merkmale hingewiesen. Keinem scheint es aufgefallen zu sein, dass die Augen (wenn auch oft, von Leuckart, Gegenbaur, Grenacher, Hesse beschrieben) sich in ganz besonderer Weise von denen der anderen mediterranen Arten unterscheiden. Das Auge ist nämlich mehr oder weniger cylindrisch, weil die schmale Retina nur kurz ist, nicht lang ausgezogen, wie sonst. Zwar ist diese Tatsache vielen Forschern nicht entgangen, nie aber, wie es scheint, als Artmerkmal hervorgehoben worden. Ich betrachte diese Form der Augen als einen wesentlichen Unterschied von den übrigen Arten des Mittelmeeres; ja, diese Eigenschaft kommt, nach meiner Erfahrung, immer combinirt vor mit einer schlanken, langgestreckten Gestalt des Nucleus, weshalb in der Gattung zwei distincte Gruppen unterschieden werden können. Im zweiten Abschnitt werde ich alles dies ausführlicher begründen.

Am Dache der Mundhöhle stehen jederseits $7-8$ Buccalzähne, von denen die drei vorderen sehr klein sind, distal aber an Grösse zunehmen. Die Mittelplatte der Radula ist deshalb merkwürdig weil in der Mitte drei Dornen auf gemeinschaftlicher Basis angebracht sind.

Die hier gegebene Copie ist nach VAyssière.

Verbreitung: Nittelmeer: Lo Bianco, Cantraine, delle Chiaje, Fol, Forbes, Gegenbaur, Krohn, Leuckart, Oberimimer, Paneth, Risso, Vayssière, Verany.

\section{Pterotrachea cuviera (Lesueur). (Taf. IV, Fig. 92).}

${ }_{n}$ Body destitute of the vermiform organ ${ }^{1}$ ) and cup. Tail with an appendage.

Body subequal, larger and transversely wrinkled before, with a dorsal groove ${ }^{\circ}$ ). Colour pale violaceous, tubercles rosaceous, irregularly disposed; one on each side of the dorsal fin larger and transverse, with two longitudinal ones placed upon the tail. Gelatinous points ${ }^{3}$ ) eight, four in a transverse line, surmounted by four others in two transverse lines".

Copie nach Lesueur.

Verbreitung: Mittelmeer: Lesueur.

\section{Pterotrachea peronia (Lesueur). (Taf. IV, Fig. 93).}

"A vermiform organ, cup on the dorsal fin, and caudal appendage. Gelatinous points none. Body cylindrical, diaphanous, spotted with white at the base of the dorsal fin, tubercles none". Copie nach Lesueur.

Verbreitung: Mittelmeer: Lesueur.

1) Es ist damit der Penis gemeint.

2) In den Beschreibungen LesueuR's wird stets die beim Schwimmen nach oben gekehrte Seite (also in Wirklichkeit die ventrale) als dorsale bezeichnet.

3) Dornen ror den Augen. 
4. Pterotrachea gibbosa (Lesueur). (Taf. IV, Fig. 94).

„Body furnished with a vermiform organ, no cup ${ }^{1}$ ) or caudal appendage.

Body gibbose above the nucleus, narrowed behind the eyes, and emarginate at the base of the dorsal fin. Gelatinous points disposed in a single semi-circular row. Colour pale blue, with two lateral fillets of rosaceous tubercles, base of the dorsal fin yellow".

Diese Art wäre, nach VAYssière, dieselbe wie seine "Firola mutica".

Copie nach Lesueur.

Verbreitung: Mittelmeer: Lesuevr.

5. Pterotrachea frederica (Lesueur). (Taf. IV, Fig. 95).

"A cup on the dorsal fin, a caudal appendage. Vermiform organ none" ").

Die Form wurde von VAyssike mit seiner "Firola hippocampus" identifiziert.

Copie nach Lesueur.

Verbreitung: Mittelmeer: Lesueur.

6. Pterotrachea frederici Blainville. (Taf. IV, Fig. 96).

Über die hier gegebene Form lässt sich nichts mit Sicherheit entscheiden. Es finden sich deutliche Dornen vor den Augen, der Schwanz ist gross, die Horizontalflossen sind wahrscheinlich iibersehen worden.

Copie nach de Blatyville.

Verbreitung: Mittelmeer: DE Brainville.

7. Pterotrachea friderici(ana) delle Chiaje $^{3}$ ). (Taf. IV, Fig. 97).

Nach der Abbildung wäre diese Art, wenigstens auf der vorderen Hälfte des Rumpfes, ganz regelmässig mit Tuberkeln bedeckt. Die Flosse ist dem Nucleus ganz nahe gerückt und besitzt einen Saugnapf in einer leichten Einbuchtung des Randes. Der Penis ist klein.

Copie nach delle Chiaje.

Verbreitung: Mittelmeer: Delle Chiaje.

8. Pterotrachea fredericia Cantraine, Gegenbaur, Carus.

"Corpore hyalino, verrucoso, dilute violaceo-purpureo ${ }^{4}$ ), tuberculis frontalibus usque ad sex" (Cantraine, Gegendaur).

Länge des Tieres bis zu $95 \mathrm{~mm}$.

Verbreitung: Mittelmeer: Cantraine, Forbes, Gegenbaur, Leuckart, Oberiwimmer, Risso, Verany.

1) Da ein Penis vorhanden ist, scheint das Fehlen des Saugnapfes bemerkenswert.

2) Hier scheint wieder ein Saugnapf, aber kein Penis vorzukommen.

3) Von Philipri, auch von Surth, ganz unrichtig zu Pt. hippocampus th. gestellt.

4) Dies bildet einen kleinen Unterschied mit der Art CuLje's.

SIBOGA-EXPEDITIE LI. 
9. Pterotrachea forskalia (Lesueur). (Taf. IV, Fig. 98).

"Body with a vermiform organ, and a cup on the dorsal fin. No caudal appendage.

Body cylindrical, subequal, with a dorsal groove. Colour pale violaceous, a lateral row of rosaceous tubercles, double before. Cup resembling a small basket, with four radical threads, passing between the muscles of the fin. Fin somewhat elongated behind. Gelatinous points six, disposed by opposite pairs in two longitudinal rows".

Diese Art wäre nach VAyssière identisch mit der soeben besprochenen Form Pt. gibbosa. Diese aber besitzt einen Penis, aber keinen Saugnapf, während letzteres Organ gerade bei Pt. forskalia sehr gross ist.

Copie nach Lesueur.

Verbreitung: Mittelmeer: Lesueur.

ı. Pterotrachea mutica (Lesueur). (Taf. IV, Fig. 99).

„No vermiform organ, no cup on the dorsal fin, no caudal appendage.

Substance firm, diaphanous, tuberculated, rosaceous; tubercles irregularly placed, and of a deeper colour. Dorsal fin nearer the nucleus, placed in a groove. Trunk wrinkled, and with the region of the dorsal fin spotted with white. Gelatinous point six, disposed as in the foregoing species".

Copie nach Lesueur.

Verbreitung: Mittelmeer: Lesueur.

II. Pterotrachea mutica Cantraine, Gegenbaur, Keferstein, Carus. (Taf. IV, Fig. I0o).

„Corpore laevi, hyalino, purpureo-maculato, fronte laevigata" (Cantraine, Gegenbaur).

Diese Art zeichnet sich also von der vorhergehenden dadurch aus, dass, abgesehen von den purpurnen Flecken, der Stirn glatt, ohne Dornen, ist. Sie ist also nicht mit der gleichnamigen Art Lesueur's identisch. Es besteht, beim Fehlen der Dornen vor den Augen, ein gewisser Anklang mit Pt. peronia.

Länge des Tieres $90 \mathrm{~mm}$.

Copie nach Keferstein.

Verbreitung: Mittelmeer: Cantraine, Chun, Gegenbaur, Krohn, Leuckart, Paneth, Verany.

I 2. Pterotrachea mutica (Vaysière). (Taf. IV, Fig. IOI).

An der Rückenseite des Körpers hat das Tier etwa zwölf rötliche Querbänder, seitlich und ventral finden sich grosse Flecken von derselben Farbe; grössere und kleinere Dornen sind namentlich an den Flanken und am Rüsel zerstreut; vor den Augen sind deren 4 oder 6 vorhanden; der Nucleus hat etwa ein Dutzend Kiemen; Schwanz wie gewöhnlich gestaltet, also mit Horizontalflosse und Schwanzfaden versehen.

Die Querbänder auf dem Rücken würden schon ausreichen, diese Art vor den anderen auszuzeichnen. Soviel ich weiss, hat man eine derartige, regelmässige Zeichnung noch nie bei 
Pterotrachea, und bei Heteropoden überhaupt, beobachtet. Die Farbe hatte sich, trotz mehrjähriger Aufbewahrung in Formol, nur wenig verwischt, beim lebenden Tiere wiirde sie also ganz besonders deutlich sein. Trotzdem ist sie von den vielen Forschern, welche Ptcrotrachaca lebend studiren konnten, nie erwähnt worden.

Nach VAyssière wäre die Art identisch mit den beiden Arten Llisulur's Pt. gibbosa und Pt. forskalia. Diese sind aber nicht nur unter einander verschieden (man vergl. Fig. 94 und 98 ), sondern zeigen auch keineswegs irgendwelche Ähnlichkeit mit dem hier besprochenen Tiere.

Länge des Tieres bis zu $90 \mathrm{~mm}$.

Copie nach VAYSSTÈrE.

Verbreitung: Mittelmeer (Monaco): VAyssiÈRE.

13. Pterotrachea rufa Quoy et Gaimard. (Taf. IV, Fig. IO2).

Die sehr unvollständig beschriebene Form zeigt einen ausserordentlich langen Schwanz, die Flosse ist den Augen ganz nahe gerückt. Ein Nucleus ist nicht einmal angegeben worden, oder ist der kleine Körper in der Mitte des Schwanzes als ein solches Organ zu betrachten? In diesem Falle würde allerdings die von Quoy und Gamard beschriebene Form einen höchst aberranten Typus darstellen. Gewiss aber handelt es sich um einen Beobachtungsfehler.

Copie nach Quoy und Gaimard.

Verbreitung: Ind. Oz.: Quoy und Gaimard.

14. Pterotrachea lesuenri Risso. (Taf. IV, Fig. I03).

Auch von dieser Form lässt sich nichts mit Gewissheit sagen. Flosse und Schwanz sind freilich abenteuerlich genug gestaltet, die Abbildung zeigt aber so deutlich die Folgen ungenauer Beobachtung, dass weitere Besprechung ganz nutzlos ist.

Copie nach Risso.

Verbreitung: Mittelmeer: Risso.

15. Pterotrachea lesueuri Macdonald. (Taf. IV, Fig. IO4).

Macdonald hat sich nur zweifélnd iber die Identität seiner Art geäussert. Die Flosse ist in der Mitte zwischen Augen und Nucleus gestellt und trägt einen sehr grossen Saugnapf, ganz an der Unterseite. Der Nucleus ist rundlich, der Schwanz endet in eine Spitze; möglich ist es freilich, dass keine Horizontalflosse vorhanden war; einem so guten Beobachter wie MACDONALD würde sie sonst wohl schwerlich entgangen sein.

Länge des Tieres etwa $100 \mathrm{~mm}$.

Copie nach Macdonald.

Verbreitung:

16. Pterotrachea adamastor Lesson. (Taf. V, Fig. 105).

Der Rumpf dieser Art ist massig, der Rüssel dagegen nur schwach entwickelt und, nach 
der Abbildung, dorsal mit kleinen Dornen besetzt, welche sich auch in stärkerer Ausbildung vor den Augen finden. Die Flosse, dem Nucleus gegenüber, ist niedrig, breit angeheftet. Der Schwanz ist mit einer Horizontalflosse ausgestattet. Wahrscheinlich ist die Art mit Pt. coronata identisch, wie LEsson selbst zugibt.

Länge des Tieres etwa $200 \mathrm{~mm}$.

Copie nach Lesson.

Verbreitung: Kap der Guten Hoffnung: Lessox.

\section{Pterotrachea hippocampus Philippi. (Taf. V, Fig. 106.}

„Pt. capite elongato, porrecto, pinnula centrali, ventre et cauda seriebus duabus tuberculorum, coronula frontis aculeis sex, asperis". Es geht daraus hervor, dass zwei Reihen Hautflecken (denn als solche sind die „Tuberkel" wohl zu betrachten) existiren an der Ventralseite des Tieres; wenn Philipr, und in gleicher Weise Smith, die Art mit Pt. friderici delle Chiaje identifiziren, so ist, meiner Meinung nach, der Unterschied darin gelegen, dass die letztgenannte Art über den ganzen Rumpf mit Dornen bedeckt ist.

Länge des Tieres etwa $90 \mathrm{~mm}$.

Copie nach Philippi.

Verbreitung: Mittelmeer: PhiLippi.

18. Pterotrachea hippocampus Vayssière. (Taf. V, Fig. iо7).

Diese Art besitzt vor den Augen 6-8 Dornen, in zwei Reihen gestellt; an beiden Seiten finden sich 4 oder 5 Reihen rundlicher „Tuberkel”, besonders in der Nähe der Flosseninsertion; letztere ist deutlich etwas mehr den Augen als dem Nucleus genähert; der Nucleus trägt I'2-I 4 ziemlich lange Kiemen; der Schwanz ist niedrig, mit sehr grossen Horizontalflossen, zwischen welchen ein langes, segmentirtes Filament anfängt. Jeder der Knoten dieses Fadens zeigt distal eine schleierartige Verlängerung. Der Penis (natürlich nur bei den Männchen) ist cylindrisch, an seiner Basis inseriren sich drei Hautlappen.

Nach der Ansicht VAyssière's ist diese Art dieselbe wie Pt. lesueuri Risso und Pt. frederica Lesueur, ohne aber irgendwelchen Grund für seine Meinung anzuführen.

Länge des Tieres $120 \mathrm{~mm}$.

Copie nach VAyssiÈRE.

Verbreitung: Mittelmeer (Monaco): Vayssière.

19. Pterotrachea quoyana d'Orbigny. (Taf. V, Fig. Io8-iog).

Vor den Augen ragt bei dieser Art, wenigstens nach der Abbildung, ein ganzes Bündel dichtgedrängter Dornen hervor. Die Flosse ist stark eingeschnuirt und der Saugnapf nach hinten geriickt, was sonst nicht bei Pterotrachea der Fall zu sein pflegt. Merkwürdig ist noch der Nucleus, welche ziemlich frei aus der Cutis hervorragt, mit Kiemen an der Vorderseite, als wäre 
hier eine Annäherung an Cardiapoda gegeben. Der Schwanz endet spitz. In wie weit wir hier wirklich eine aberrante Form vor uns haben, lassen Beschreibung und Abbildung D'Orbigny's ganz unentschieden. Ungenaue Beobachtung möchte auch in diesem Falle ihren Einfluss geibt haben.

Länge des Tieres $50-60 \mathrm{~mm}$.

Copie nach D'Orbigny.

Verbreitung: Süd-Atl. Oz.: d'Orbigny. Mittelmeer: OBERwimmer.

20. Pterotrachea edvardsi (Deshayes). (Taf. V, Fig. I Io).

Die Abbildung zeigt offenbar viele Ungenauigkeiten, und eine Beschreibung wurde nicht beigegeben. Der allgemeine Habitus, besonders die Dornen vor den Augen, und der langgestreckte Nucleus, auch die Grösse des Tieres, weisen auf die im Mittelmeere gar nicht seltene Pt. coronata hin.

Länge des Tieres etwa $200 \mathrm{~mm}$.

Copie nach Deshayes.

Verbreitung: Mittelmeer: Deshayes.

21. Pterotrachea umbilicata delle Chiaje. (Taf. V, Fig. I I I).

Diese Form zeigt, schon der Grösse wegen, grosse Ähnlichkeit mit Pt. coronata. Besonders aber fällt die sehr grosse Flosse auf, die einen kräftigen Saugnapf besitzt. An der ventralen Seite sind hier und da rundliche Hautdrüsen zerstreut. Bemerkenswert ist die sehr regelmässige Reihenfolge der Kiemen, welche ganz symmetrisch gelagert zu sein scheinen, auf einem gemeinschaftlichen Stiele getragen, einer Kiemenvene, die das Blut zum Herzen leitet. Ob eine derartige Symmetrie der Kiemen wirklich bei Pterotrachea möglich wäre, lasse ich dahingestellt; von vornherein scheint es mir, auf Grund eigener Wahrnehmung sehr unwahrscheinlich. Der Schwanz endet in zwei Horizontalflossen. Nach Delle Chiaje ist der ganze Körper schwach violett angehaucht "come la ulva porfiria".

Länge des Tieres etwa $350 \mathrm{~mm}$.

Copie nach delle Chiaje.

Verbreitung: Mittelmeer: delle Chiaje.

22. Pterotrachea keraudreni (Souleyet). (Taf. V, Fig. I I 2).

In mancher Hinsicht zeichnet sich diese Form vor anderen aus. Die ganze Oberfläche ist rauh, die Cutis ist auf dem Rumpfe und dem Rüssel stark entwickelt, so dass das Tier wie in einer Gallertmasse eingehüllt erscheint. Der Rüssel selbst ist kurz und gerade gestreckt, die Stelle vor den Augen ist ganz glatt. Flosse sehr gross, rundlich, dem Nucleus nahe gerïckt. Der zur Hälfte frei hervorragende Nucleus trägt etwa I 4 Kiemen, sämtlich, wie es scheint, von gleicher Länge. Am merkwürdigsten ist der Schwanz gestaltet, der eine derartige Abweichung vom gewöhnlichen Typus aufweist, dass man, wenn es sich nicht um einen sehr sorgfältigen Wahrnehmer handelte, wie Souleyet, fast an die Wahrheit seiner Angaben zweifeln möchte. 
Der Körperteil hinter dem Nucleus zeigt eine deutliche Cutis, die sich von der unterliegenden Körpermuskulatur scharf abhebt. Die subcutane Muskelwand ist dorsal und ventral fein quergestreift. Eine Horizontalflosse oder ähnliche Bildung besteht nicht; der Schwanz geht mit deutlicher Übergangsstelle in ein plattes Band über.

Nach Macdosald wäre die Art das Männchen von Firoloida desmaresti Lesueur. Erstens aber ist sie gar keine Firoloida, des deutlichen Schwanzes wegen, zweitens ist sie ein unzweifelhaftes Weibchen, weil weder Penis noch Saugnapf zu bemerken sind.

Länge des Tieres $50 \mathrm{~mm}$.

Copie nach Souleyet.

Verbreitung: Trop. Atl. Oz.: Souleyet.

23. Pterotrachea scutata Gegenbaur. (Taf. V, Fig. i i 3 - I I4).

„Pt. hyalina, parte anteriore scutiformi tuberculis serialibus asperis; fronte laevigata".

Die Abbildung lässt leider an Genauigkeit viel zu wïnschen übrig. Die örtliche Verdickung der ganz durchsichtigen Cutis, welche besonders bei Ventralansicht des Tieres auf dem vorderen Drittel des Rumpfes mächtig entwickelt ist, scheint nach hintenzu plötzlich aufzuhören; es sind distal gar keine Details eingezeichnet worden. Nur so viel geht hervor, dass der Nucleus ganz in der Cutis eingebettet ist und etwa acht sehr lange Kiemen trägt. Penis und Saugnapf sind beide verhältnismässig klein. Der Schwanz endet in Horizontalflossen.

Länge des Tieres $105-120 \mathrm{~mm}$.

Copie nach Gegenbaur.

Verbreitung: Mittelmeer: Chun, Gegenbaur, Oberwhmer

24. Pterotrachea sp. Smith. (Taf. V, Fig. I I 5-I I5a, b).

Körper langgestreckt, glatt, an der Basis der Flosse einige rundliche Drüsenkörper. Die Flosse ist dem Nucleus mehr genähert als den Augen, klein, und ganz von der gewöhnlichen Form, mit einem Saugnapfe in der Mitte der Unterseite. Nucleus nach den Angaben Swith's langgestreckt, mit etwa zwölf Kiemen. Der Schwanz zeigt hier nichts besonderes. Rüssel ziemlich lang; vor den Augen nur zwei symmetrisch gelagerte Dornen. Was Sirth sonst noch von dieser Form beschreibt, ist ganz allgemein für alle Pterotrachca-Arten zutreffend. Als ich das Originalexemplar im „Britisch Museum” untersuchte, stellte sich noch heraus, dass die Augen ganz wie diejenige von Pt. coronata gestaltet sind, dass nur sechs Kiemen, an der linken Seite des Nucleus, ziemlich lang sind, dass weiter ein Penis vorhanden ist, der von Smith weder beschrieben noch abgebildet wurde. Die Conservirung war übrigens ziemlich schlecht. Der Mitteldorn in der Mittelplatte der Radula hatte eine breite Basis. Mit diesen verschiedenen Angaben als Stütze, habe ich mit der von Sмтн beschriebene Form eine andere der Siboga-Expedition identifiziren können, ich werde daher darüber noch im zweiten Abschnitt zu sprechen haben.

Länge des Tieres etwa $170 \mathrm{~mm}$.

Copie nach Surth.

Verbreitung: Banda: Siritr. 
25. Pterotrachea sonleyeti (Vayssic̀re). (Taf. V, Fig. I 6 ).

Körper langgestreckt, Ruissel ziemlich lang, kleine Dornen, nicht nur an der Unterseite des Rüssels, sondern auch an der vorderen Rumpfhälfte, meist ventral gelagert, einzelne Hautflecken nahe der Basis der Flosse Cutis vor dem Nucleus verdickt, und hier einige Kiemen tragend, meist sehr kurz und etwa 6 oder 7 an der Zahl. Nucleus aufgeschwollen, kurz. Schwanz mit sehr grossen Horizontalflossen, zwischen welchen sich ein Schwanzfaden inserirt, der nur als Fragment erhalten war und eine längliche, manchettenartig den Faden umfassende Anschwellung zeigte. Dornen vor den Augen sind nicht vorhanden. Saugnapf (selbstverständlich nur beim Männchen) sehr gross. Penis distal gerichtet, mit lappenförmigen Gebilden an der Basis, in einen Knopf (wahrscheinlich umgekrempelte Ränder) endend. Am Dache der Mundhöhle kommen links 6, rechts 4 Buccalzähne vor. Die Radula wiederholt im Allgemeinen den gewöhnlichen Typus bei Pterotrachea.

Länge des Tieres $49 \mathrm{~mm}$.

Copie nach VAYSSIÈRE.

Verbreitung: Zwischen Madeira und den Azoren: VAyssière.

\section{Pterotrachca gegenbauri Vayssière. (Taf. V, Fig. I I 7).}

Diese Art scheint deshalb merkwürdig, weil sie sehr reichlich mit Dornen besetzt ist. Diese sind über den ganzen Rumpf zerstreut, kleiner und zahlreicher sind sie auf den jederseits herabhängenden Falten der Cutis, welche sich ventral an der vorderen Rumpfhälfte, also zwischen Ruissel und Flosse vorfinden. Wenn Vayssière diese Falten als Artmerkmal gelten lassen will, so muss ich doch bemerken, dass ein solcher Kehlsack schon von Forskî ( guzla") erwähnt wurde, und dass ein derartiges Gebilde ganz allgemein bei Ptcrotrachea vorkommt, ja, nach meiner Erfahrung, bei keiner Art vollständig fehlt. Wirkliche Stirndornen sind nicht vorhanden. Vor dem Nucleus bildet die Cutis dorsal zwei longitudinale, fein gezähnelte Kämme. Der Nucleus ragt nicht hervor, die Zahl der Kiemen beträgt mehr als 20, sämtlich klein und sehr kurz. Die Horizontalflossen des Schwanzes sind sehr klein, ein Schwanzfaden war nicht mehr nachweisbar. Die Flosse ist ganz klein, beim Männchen mit einem deutlichen Saugnapf ausgestattet, der noch vor der Medianlinie der Unterseite geruickt ist. Es bestehen jederseits in der Mundhöhle 5 Buccalzähne, ausserdem kommen noch um die Mundöffnung herum zwei oder drei unregelmässige Kränze von kleinen Zähnchen vor, welche besonders lateral und dorsal zahlreich sind. In der Radula ist noch erwähnenswert, dass die Mittelplatte, jederseits vom Mitteldorne, nur zwei oder drei kleinere Dornen trägt; sonst ist diese Zahl bei Pterotrachca fast immer grösser.

Länge des Tieres etwa $100 \mathrm{~mm}$.

Copie nach VAYsSIÈrE.

Verbreitung: Östl. Atl, Oz.: VAyssik̀re.

\section{Pterotrachea talismani Vayssière.}

Körper mit Dornen besetzt, etwa $1_{5}$ Kiemen in der Nähe des Nucleus, Flosse ziemlich gross, rundlich. Wie bei der vorhergehenden Art bestehen hier zahlreiche Peribuccalzähne, am 
Eingang der Mundhöhle, sämtlich nach innen gerichtet und an der Spitze gekrümmt. Eine Horizontalflosse konnte am Schwanze nicht aufgefunden werden; möglich scheint es allerdings, da keine Spur von Verstümmelung sichtbar war, dass dieses Gebilde wirklich fehlt.

Länge des Tieres $5 \mathrm{I} \mathrm{mm}$.

Die jetzt folgenden, noch in der Litteratur erwähnten Formen sind nur wenig bekannt, und es wird wohl niemals gelingen ihre Selbstständigkeit oder Zugehörigkeit zu anderen Arten zu begründen. Mehrere sind allerdings nach verstümmelten Exemplaren beschrieben wurden. Nur der Vollständigkeit halber sollen sie hier noch erwähnt werden.

Erstens eine Art Pt. lyalina Forskal (Taf. V, Fig. I I8), die nach der Abbildung, wie schon von Sirrm vermutet wurde, eine kleine Firoloida darstellt, wenngleich auch die Stelle des Nucleus nicht angegeben ist. Zweitens Pt. hyalina (cristallina) (delle Chiaje) (Taf. V, Fig. x I9), welche vor den Augen „con coppia di sottili tentacoli" (?) ausgestattet ist und dadurch wieder an Firoloida erinnert, durch die unterständige Lage des Saugnapfes, die deutlichen Kiemen, und den Schwanz, übrigens den Typus von Pterotrachea zeigt. Pt. pulmonata Forskal (Taf. V, Fig. I 20) weicht besonders dadurch ab, dass der Rüssel ganz kurz, nicht cylindrisch, sondern von stumpfkegelförmiger Gestalt ist. Pt. peroni (d'Orbigny) (Taf. VI, Fig. I 2 I-122) entbehrt der Augen und des ganzen Rüssels und wurde, weil das Tier beim Fange sich lebhaft bewegte, von D'Orbigny als Vertreter einer besonderen Untergattung Anops betrachtet. Offenbar handelt es sich hier um eine verstümmelte Pterotrachca, über die sich sicheres nicht sagen lässt. Auch Pt. sp. Rattray (Taf. VI, Fig. I 23), als eine Form von Anops bezeichnet, ist nur der Rumpfteil irgendeiner grossen Pterotrachea, welche Augen und Rüssel, auch Nucleus und Schwanz, verloren hat. Jeder, der Pterotrachea lebend beobachten konnte, weiss, dass derartige verstummelte Tiere trotzdem sich lebhaft bewegen können, und durchaus den Eindruck lebensfähiger Wesen machen. Mir sind solche Exemplare in Neapel ziemlich oft vorgekommen. Pt. aculeata Forskâl ist ebenfalls nur ein abgerissenes Schwanzstiick einer Pterotrachea, wahrscheinlich der grossen Pt. coronata. "Firoloides keraudreni" Rattray (Taf. VI, Fig. I24) hat einen walzenförmigen Körper, Tentakeln vor den Augen, einen sehr kurzen Schwanz; wenn dadurch Anklänge an Firoloida bestehen, weisen die deutlichen Kiemen wieder auf Pterotrachea hin, während die Lage des Saugnapfes, am Hinterrande der Flosse, Cardiapoda-ähnlich ist. Die „Firola sp." von Gray (Taf. VI, Fig. 125) ist eine verunstaltete Firoloida; ebenso die „Firola sp. jun." Quoy und Gaimard (Taf. VI, Fig. 126). Schliesslich sind noch zwei Arten zu erwähnen:

$I^{0}$ Hypterus appendiculatus Rafinesque-Schmaltz, nach DELLE CHIAJE mit seiner Pt. friderici, nach VAYsSIÈRE mit seiner Pt. hippocampus synonym;

$2^{0}$ Hyptemes erythrogaster desselben Autors, welche von DELLE CHIAJE und VAyssière als identisch mit $P t$. coronata betrachtet wird.

\section{Firoloida Lesueur 1817.}

Die hierher gehörigen Arten wurden unter verschiedenen Gattungsnamen, namentlich Firoloida, Cerophora und Firolella beschrieben. Die Ursache des Irrtums liegt darin, dass die secundiaren Geschlechtsmerkmale, die Tentakeln, Listetr unbekannt blieben; und, als D'OrnigNY 
später Formen mit Tentakeln fand, glaubte er zu der Aufstellung einer Untergattung Corophora berechtigt zu sein. Später übersah Troschel wieder die ursprüngliche Diagnose Lesulur's und errichtete für zwei tentakellose Formen das Genus Firolella.

Firoloida unterscheidet sich von Pterotrachea hauptsächlich darin, dass der Schwanz sehr klein bleibt, der Rumpf sich also, distal vom Nucleus, nur eine ganz kleine Strecke fortsetzt und dann in einen Schwanzfaden ïbergeht (der allerdings sehr oft abgerissen und also verschwunden ist). Der Rumpf ist langgestreckt und cylindrisch, ganz glatt, nach vorn allmählich ohne Einschnürung in den schwachen, ziemlich kurzen Rüssel übergehend. Die Flosse ist rundlich. Am Ende des Rumpfes findet sich der kurze Nucleus.

Nur dem Männchen kommen Tentakeln und Saugnapf zu, und begreiflicherweise hat man lange Zeit solche Tiere, welche mit Tentakeln ausgestattet waren, für besondere Arten gehalten. Eine Erörterung dieser Verhältnisse wurde von Surı gegeben, der, nach sorgfältiger Studirung der in der Litteratur bestehenden Abbildungen zu dem Resultat kam, dass die Anwesenheit von Tentakeln ein secundäres Geschlechtsmerkmal der Männchen darstelle und nicht als Artunterschied verwendet werden könne. Das gleiche gilt von dem Saugnapf, der lange Zeit unbekannt blieb, erst von MACDONaLD entdeckt (nach der Abbildung wäre er bei seiner Art ausserordentlich gross), dann noch mehrere Male erwähnt wurde; merkwürdig ist aber, dass der wirkliche Sitz des Saugnapfes an der Flosse sogar einem Beobachter wie GEGEnbaur nicht auffiel ${ }^{1}$ ). Dieser Forscher sagt: „disco suctorio pinnae marium ad marginem posteriorem”. Erst Ratrkay zeichnete den Saugnapf, freilich nur als dünne Linie, an richtiger Stelle, am Vorderrande der Flosse.

Tentakeln, ebenso wie Saugnapf, sind also, um es noch einmal hervorzuheben, secundäre Geschlechtscharactere des Männchens; sie gehen also dem Weibchen ab. Freilich ist von FEwkes angegeben worden, dass bei den Weibchen von Firoloida lesueuri ein Saugnapf vorkommt. Diese Behauptung scheint mir näherer Begründung zu bedürfen. Die oben erwähnte, schon von Sirth ausgesprochene, Meinung habe ich bei meinen eigenen Untersuchungen immer, ohne Ausnahme, bestätigt gefunden. Ich habe aus dem Material der Siboga-Expedition mehr als hundert Exemplare studiren können, auch im „British Museum” untersuchte ich eine Menge Tiere, zu Firoloida gehörig; stets aber fand sich die Behauptung Swith's bestätigt.

Kiemen sind von einigen Forschern angegeben worden; so haben LESUEUR, D'ORBIGNY und Souleyet sogar sehr grosse Kiemen abgebildet, kaum kleiner als die nämlichen Gebilde bei Pterotrachea. Diese Angabe ist aber gänzlich verfehlt; Forscher wie Gegrnbaur und Huxlex: haben, trotz ihrer genauen Untersuchung, besondere Respirationsorgane bei Firoloida gar nicht wahrnehmen können; nur MAcDoxald giebt, vor dem Nucleus, eigentümliche, winzige Läppchen an, welche als Kiemen gedeutet werden können; und in neuerer Zeit sagt VAyssière in seiner Diagnose der Gattung: „des digitations branchiales très petites, peu visibles”, ohne indessen dies durch irgendwelche Tatsache näher zu begründen. Ich werde über die Atmungsorgane von Firoloida noch im zweiten Abschnitt zu sprechen haben, und constatire hier nur, dass Kiemen, sehr klein und wenig zahlreich, wirklich bisweilen vorkommen.

I) In seinen Untersuchungen ïber Pteropoden und Heteropoden behauptet GEGeNBaUk aber (S. 156), der Sauguapf bei Firoloida finde sich am Vorderrande der Flosse.

SIBOGA-EXPEDITIE LI. 
Die Unterscheidung der bisher bekannten Arten ist ausserordentlich schwierig, und in den meisten Fällen wird wohl die Frage nach der Existenzberechtigung irgendwelcher Form unentschieden bleiben. Männchen und Weibchen sind als verschiedene Arten beschrieben worden, wie schon oben erörtert wurde, und mit den undeutlichen Beschreibungen ist meist nur wenig anzufangen. So weit meine Erfahrung reicht, sind die zu der Gattung Firoloida gehörigen Tiere sehr einförmig gebaut, und gruppiren sich, ebenso wie in der Gattung Pterotrachea, mit unbedeutenden Abweichungen alle um denselben Typus herum. Mit Sirth möchte ich annehmen, dass nur zwei oder drei etwas variirende Formen bestehen; hier aber wird es meine Aufgabe sein, das uns bisher bekannt gewordene zusammenzufassen.

Wir können dann unterscheiden:

I. Firoloida demarestia Lesueur.

2. Firoloida desmarestia Souleyet.

3. Firoloida desmarestii Huxley.

4. Firoloida desmaresti Vayssière.

5. Firoloida blainvilleana Lesueur.

6. Firoloida aculeata Lesueur.

7. Firoloida lesueuri (d'Orbigny).
8. Firoloida gaimardi (d'Orbigny).

9. Firoloida lesueuri (Souleyet).

I0. Firoloida gracilis (Troschel).

I I. Firoloida vigilans Troschel.

12. Firoloida sp. Macdonald.

I 3. Firoloida kowualecuskyi Vayssière.

I. Firoloida demarestia Lesueur. (Taf. VI, Fig. 127).

"Body long, glabrous, hyaline, acuminated at each extremity; no gelatinous points".

Die langgestreckte Form des ganzen Tieres fällt besonders auf. Wie Lesueur selbst erwähnt, ist noch beachtenswert, dass die nach vorn verlängerte Flosse den Augen viel näher gerückt ist, als in Pterotrachea, wo der Abstand zwischen Flossenbasis und Nucleus immer kleiner als der zwischen Flossenbasis und Augen ist, oder doch die beiden Abstände höchstens einander nahezu gleich sind. Das abgebildete Exemplar ist ein Weibchen, also ohne Saugnapf und Tentakeln, mit einer sehr langen Eierschnur; wie aber der kurze Schwanz gestaltet ist, wird nicht angegeben. Die von Lesueur angegebenen Kiemen müssen wohl nur in seiner Fantasie bestanden haben.

Länge des Tieres $50 \mathrm{~mm}$.

Copie nach Lesueur.

Verbreitung: Martinique: Lesueur. Mittelmeer: Chun, Fol, Gegenbaur, Leuckart, Risso, Troschel, Verany.

2. Firoloida desmarestia Souleyet. (Taf. VI, Fig. I28).

„Cette Firoloïde a le corps fusiforme, lisse dans toute son étendue, terminé postérieurement, en dessous du nucléus, par un petit prolongement, qui se rétrécit en un appendice filiforme plus ou moins long. La tête n'offre aucune trace de tentacules en avant des yeux, ni de pointes cartilagineuses entre ces organes. La nageoire est placée au milieu du corps, à égale distance de ses deux extrémités".

Ein grosser Unterschied mit der vorhergehenden Art besteht in der viel gedrungeneren 
Körpergestalt; der Rumpf geht nach vorn in den kurzen Riissel über und ist mit diesem ganz in der dicken, gallertigen Cutis eingehillt. Wichtig ist noch der Umstand, dass die sehr grosse, rundliche Flosse sich in der Mitte zwischen Augen und Nucleus inserirt. Der Schwanz ist in seiner Form deutlich angegeben worden. Eine lange Eierschnur hängt aus dem Nucleus des abgebildeten Tieres (selbstverständlich ein Weibchen) hervor. Nur des Fehlens der Tentakel wegen hat Souleyet seine Art mit der Lesueur's identifizirt; eine Ahnlichkeit besteht sonst nicht.

Länge des Tieres $30 \mathrm{~mm}$.

Copie nach Souteyet.

Verbreitung: Sandwich-Inseln und trop. At1. Oz.: Souleyet.

3. Firoloida desmarestii Huxley. (Taf. VI, Fig. 129).

Die von Huxley mit diesem Namen belegte Form hat Tentakeln und gehört also gewiss nicht hierher. Der Körper ist cylindrisch, die Flosse zeigt eine stark eingeschnürte Basis und ist sehr gross, ganz symmetrisch gestaltet, der Abstand zu den Augen ist kleiner als zu dem Nucleus. Letzterer hat keine Kiemen; unter dem Nucleus ragt ein dünner Schwanz hervor, der nach kurzem Verlauf in ein plattes Band, ohne Knoten oder Einschnürungen, übergeht. Ein Penis ist vorhanden; dies, zusammen mit dem Besitz von Tentakeln weist auf ein Männchen hin.

Länge des Tieres $25 \mathrm{~mm}$.

Copie nach Huxley.

Verbreitung: ?: HuXLEY.

4. Firoloida desmaresti Vayssière. (Taf. VI, Fig. I30-I $30 a$ ).

Körper langgestreckt, cylindrisch, ganz glatt; Flosse nahezu in der Mitte zwischen Augen und Nucleus, aber ein wenig nach hinten gerückt, mit eingeschnürter Basis; Nucleus klein, am Ende des Rumpfes; Rüssel kurz, gerade gestreckt, in der Axe des Körpers. Weiter werden die Tentakeln beim Männchen beschrieben, im weiblichen Geschlecht sind sie: na peu près atrophiés"; ich muss bekennen, dass ich niemals bei Firoloida-Weibchen Tentakeln, auch nicht eine Spur derselben, habe beobachten können. Ein kleiner Saugnapf findet sich am Vorderrande der männlichen Flosse. Der Schwanz soll bei den Männchen einen kleinen stumpfen Fortsatz bilden, der in einen von Abstand zu Abstand verdickten Faden übergeht. Im weiblichen Geschlecht dagegen bestehen sehr eigentümliche Verhältnisse. Der Schwanz setzt sich hier nur aus zwei kleinen, lanzettförmigen Läppchen zusammen, der Schwanzfaden dagegen heftet sich direkt, proximal von diesem Schwanze, dem Nucleus an und ist deutlich gegliedert, ganz wie die Tarsalglieder eines Insektes. Ein derartiges Verhalten scheint mir dem Körperbau bei Firoloida ganz zuwider; abgesehen von der Gliederung des Anhanges, ist die Trennnng von Schwanzanhang und Schwanz selbst, und die Teilung dieses letzteren Organes in zwei isolirte Stückchen so etwas abweichendes, dass man wirklich die Richtigkeit der Beobachtung anzweifeln möchte. Bemerkenswert ist noch der Umstand, dass Schwanz und Faden sich nicht wie sonst an der Hinterseite, sondern am proximalen Rande des Nucleus inseriren, und beide nach vorn gerichtet sind. Die Mittelplatte der Radula hat grosse, schwach nach innen gekrümmte Seitenhörner und 
trägt 6-7 symmetrisch gestellte Dornen am distalen Rande. Einen ernsten Fehler macht VAyssrÈRE; wenn er in seiner Abbildung den Herzventrikel (oder vielleicht die Niere?) als Anhang des männlichen Genitalapparates bezeichnet.

Länge des Tieres bis zu I $5 \mathrm{~mm}$.

Copie nach Souleyet.

Verbreitung: Azoren: VAYSSIÈRE.

\section{Firoloida blainvillana Lesueur. (Taf, VI, Fig. I $3 \mathrm{~J}$ ).}

„Body short, glabrous, posterior extremity thicker and truncated; dorsal ${ }^{1}$ ) fin equidistant between the eyes and the nucleus".

Das Tier unterscheidet sich von $F$. demarestia desselben Autors durch mehr gedrungene Gestalt; der Rüssel ist dünn, der Schwanz ist als kleiner Fortsatz distal vom Nucleus bemerklich, eine. Eierschnur ist vorhanden. Kleine Kiemen sind auch hier angegeben worden.

Länge des Tieres $35 \mathrm{~mm}$.

Copie nach Lesueur.

Verbreitung: Martinique: LesUeUR.

\section{Firoloida aculeata Lesueur. (Taf. VI, Fig. I32).}

"Body subequal, glabrous, hyaline, wrinkled above the eyes. Dorsal fin equidistant from the extremities, longer behind..... One elongated, gelatinous point beneath the eyes, and another, much shorter, before them".

Offenbar hatte Lesueur ein männliches Tier vor sich; denn der Fortsatz vor den Augen ist ohne Zweifel ein Tentakel; freilich spricht er von zwei Hervorragungen in der Nähe jedes Auges, auch sind männliche Geschlechtsorgane nicht abgebildet worden. Dagegen kommen hier wieder ziemlich grosse Kiemen vor, aber, wie schon gesagt, scheint mir ihre wirkliche Existenz sehr zweifelhaft.

Die Länge des Tieres wird nicht angegeben; wenn aber die Figur die natürliche Grösse darstellt, so erreicht die Art eine Grösse, wie sie sonst bei Firoloida nicht vorkommt.

Copie nach Lesueur.

Verbreitung: Martinique: Lesueur.

\section{Firoloida lesueuri (d'Orbigny). (Taf. VI, Fig. 133-1 $33 a$ ).}

„.... deux tentacules coniques, contractiles, aigus, en avant des yeux, sur les côtés du corps; trompe buccale très mince, diminuant tout-à-coup en partant de la tête; nucléus presque terminal, de forme acuminée, munie en avant de nombreux lobes branchiaux; en arrière du nucléus, pour toute queue, une partie élargie, à deux lobes arrondis, au milieu desquels est une saillie aiguë très courte; aile petite, sans aucune ventouse apparente; intestins à peine visibles par la transparence de l'animal".

1) Lesueur war der Meinung, dass die beim Schwimmen nach oben gekehrte Seite die dorsale vorstellte, weshalb er auch in sämmtlichen Figuren das Tier mit nach oben gekehrter Flosse abbildete. 
Die Form des Schwanzes, wie sie hier beschrieben worden, und wie sie besonders deutlich in Fig. $133 a \mathrm{zu}$ sehen ist, ist diejenige, welche wirklich ganz allgemcin bei Firoloida vorkommt, nur sind die Verhältnisse der Teile unter einander etwas anders. Zu beachten ist noch der dünne, schmächtige Rüssel; wenn Souleyet dies auf Zusammenschrumpfung in Alkohol zurückführt, so scheint mir doch, nach der Beschreibung d'Ornigny's, die Beobachtung an lebenden, frisch gefangenen Tieren gemacht worden zu sein. Das Vorkommen von Tentakeln weist auf männliche Merkmale hin. Auch bei dieser Art sollen Kiemen vorhanden sein.

Länge des Tieres $25-30 \mathrm{~mm}$.

Copie nach d'Orbigny.

Verbreitung: Süd-östl. Pazif. Oz, : D'Orbigny.

8. Firoloida gaimardi d'Orbigny. (Taf. VI, Fig. I34-134a).

„.... partie céphalique un peu moins large que le milieu du corps, munie d'yeux non saillans, et, de chaque côté en avant de ces derniers, d'un tentacule conique et aigu; trompe buccale presque conique, très mince à son extremité, fortement contractile; nucléus presque terminal, sessile, ovale; et, en arrière du nucléus, il n'y a, pour queue proprement dite, qu'une partie conique, étroite, aiguë, sans lobes, ni appendices; l'aile est médiocre, pédonculée, sans ventouse apparente; l'intestin est très visible, se renfle un peu en arrière des yeux, se rétrécit ensuite pour se renfler de nouveau en arrière de l'aile, avant de se diriger vers le nucléus".

Der Schwanz ist also etwas einfacher gestaltet als bei der vorhergehenden Art, und nicht lappig ausgebildet, sondern nur einen kleinen, konischen Zapfen darstellend. Merkwürdigerweise wird hier von Kiemen nichts erwähnt. Sonst ist die Übereinstimmung der beiden Arten D'Orbigny's sehr gross. Die Meinung Souleyet's dass wir in F. gaimardi das Weibchen von $F$. lesueuri zu erblicken hätten, muss, der deutlichen Tentakeln wegen, bestritten werden.

Länge des. Tieres $25-30 \mathrm{~mm}$.

Copie nach d'Orbigny.

Verbreitung: Trop. Atl. Oz.: D'Orbigny.

\section{Firoloida lesuenri Souleyet. (Taf. VI, Fig. I 35).}

Der Körper dieser Art zeigt dieselbe gedrungene Gestalt wie F. desmarestia desselben Autors. Die Flosse ist sehr gross, rundlich, ohne Saugnapf; zwei lange Tentakeln stehen vor den Augen, dieser von Souleyet als Artmerkmal benutzte Umstand ist natülich nur ein Zeichen des Männchens. Äussere primäre Sexualcharactere sind ausserdem angegeben worden. Der Schwanz geht in einen gegliederten Faden über, der einige Ähnlichkeit besitzt mit dem gleichnamigen Organe des Weibchens von $F$. desmaresti, wie oben geschildert wurde. Auch hier sollen wieder ziemlich deutliche Kiemen vorkommen. Souleyet hat die hier beschriebene Art mit den beiden Formen D'Orbigny's identifizirt; ob mit Recht, lässt sich nicht entscheiden.

Länge des Tieres $20 \mathrm{~mm}$.

Copie nach Souleyet.

Verbreitung: Süd-Atl. und Süd-Ind. Oz.: Sovleyet. 
10. Firoloida gracilis Troschel. (Taf. VI, Fig. I36).

Rüssel kurz, vorn abgestumpft, gerade gestreckt, Augen nicht hervorragend; Flosse ein wenig vor der Körpermitte, klein und, wie es scheint, mit ziemlich gerader Unterseite. Rumpf cylindrisch, nicht lang ausgezogen, sondern ziemlich gedrungen. Schwanz nicht angegeben. Eine lange Eierschnur, als Zeichen des weiblichen Geschlechtes, hängt aus dem Nucleus heraus.

Diese kleine Art zeigt nichts besonderes, was zur näheren Beschreibung dienlich sein könnte. Namentlich wird die Form des Schwanzes leider nicht beschrieben. Vielleicht könnte die nach vorn gerückte Lage der Flosse, so wie die eckige Gestalt derselben, als Merkmal dienen.

Länge des Tieres $16 \mathrm{~mm}$.

Copie nach Troschel.

Verbreitung: Messina: Troschel.

\section{I1. Firoloida vigilans Troschel. (Taf. VI, Fig. I37).}

Bei dieser Form fallen in erster Linie die grossen Augen auf, welche wie auf kurzen Stielen getragen, aus dem Körper hervorragen; es scheint mir aber dieses Merkmal auf Schrumpfung der gallertigen Cutis zu schieben zu sein. Der Rüssel ist kurz, vorn abgestumpft, gerade gestreckt. Die Flosse, in der Rumpfmitte gelegen, ist verhältnissmässig gross. Der Rumpf selbst ist etwas bauchig, distal dünner werdend. Unter dem Nucleus ragt der männliche Begattungsapparat hervor; Tentakeln, welche man im männlichen Tiere erwarten sollte, sind aber nicht verzeichnet worden; es ist dies wohl der Jugend des Tieres zuzuschreiben. Weiter sagt Troschel noch: „vorn und über dem Nucleus liegt ein einfacher, flacher, abgerundeter, ganzrandiger Lappen, welcher flimmert. Er muss wohl, da er ganz dieselbe Lage hat, wie die Kiemen bei Pterotrachea, gleichfalls als eine solche betrachtet werden. Eine solche einzelne Kieme steht freilich in der Familie der Firolaceen ganz ohne Beispiel da. Ob vielleicht, da Firolella gracilis kiemenlos zu sein scheint, dieser einzelne Kiemenlappen später bei vortschreitendem Wachstum verkümmert, oder ob er eine Eigentümlichkeit dieser Species bildet, muss vorläufig unentschieden bleiben". Die erste Vermutung scheint mir wahrscheinlicher.

Das Tier misst nur $3,5 \mathrm{~mm}$.

Copie nach Troschel.

Verbreitung: Messina: Troschel.

12. Firoloida sp. Macdonald. (Taf. VI, Fig. 13 8 ).

Rüssel schwach gekrümmt; Tentakeln vor den Augen; Flosse gross, den Augen genähert, mit convexer Unterseite; Saugnapf am Vorderrande, sehr gross (im Texte aber klein genannt); Rumpf cylindrisch: l'enis auf langem stiele: Schwanz allmählich in einen langen, fadenförmigen Anhang übergehend, welcher von Abstand zu Abstand Verdickungen zeigt.

Länge des Tieres etwa roo mm.

Copie nach Macdonald.

Verbreitung: Ind. Oz.: Macdoxal.D. 
I3. Firoloida kowalcuskyi Vayssière. (Taf. VI, Fig. 139--139a).

Körper ziemlich gedrungen, nach vorn in einen dünnen Rüssel übergehend; Flosse in der Mitte des Rumpfes, der immer schwach nach unten gekrummt erscheint. Schwanz aus drei Lappen bestehend (Fig. I39a), von denen der mediane länger ist als die beiden seitlichen: diese letzteren inseriren sich ein wenig dorsal am Schwanze und sind mit ihren spitzigen Enden nach hinten gerichtet. Aus der Unterseite des Nucleus tritt eine Eierschnur hervor, die, am Anfang zart und dünn, sich allmählich erweitert, und eine grosse Menge Eier birgt. Die Oberfläche der Schnur zeigt eine schwache Ringelung. Weiter erwähnt VAyssibris noch (beim weiblichen Tiere!) Tentakeln, welche allerdings undeutlich sind. Dies würde ein höchst wichtiges Merkmal sein, wenn wirklich Tentakeln bei beiden Geschiechtern dieser Art vorkommen ${ }^{2}$ ). Die Form des Schwanzes ist sehr characteristisch, und ich werde darüber im zweiten Abschnitt noch näher zu sprechen haben.

Länge des Tieres $22 \mathrm{~mm}$.

Copie nach VAYSSIÈRE.

Verbreitung: Westl. Canar. Inseln: VAyssiÈRE.

Zum Schlusse möchte ich noch ganz kurz eine Form erwähnen (Fig. I 40), welche von Rattray verzeichnet wurde. Das Fehlen des Schwanzes weist allerdings auf Firoloida hin; die Flosse zeigt aber eine abenteuerliche Gestalt, wie sie nie bei Heteropoden vorkommt; sie ist äusserst stark eingeschnürt an der Basis, und zeigt einen Saugnapf auf besonderem Stiele! Ungenaue Beobachtung wäre hier wohl am ehesten anzunehmen.

Beim Rückblick am Ende dieser systematischen Übersicht, zeigt sich die Untersuchung der Litteratur über die Pterotracheiden bei weitem am unfruchtbarsten. Irgendwelchen festen Anhaltspunkt bieten nur die wenigsten Abbildungen. Mit einiger Gewissheit habe ich nur die Pterotrachea sp. Smith unter den Heteropoden der Siboga-Expedition wiederzuerkennen geglaubt, während Firoloida kowalewskyi Vayssière, wenigstens in einigen Punkten, mit den zu dieser Gattung gehörigen Tiere meines Untersuchungsmateriales ibereinstimmte. Sonst aber habe ich bei der systematischen Bearbeitung der Pterotracheidae fast nie in der früheren einschlägigen Litteratur einen Lichtpunkt finden können.

I) Leider ist diese Beobachtung nur mit grösster Reserve aufzunehmen; ich habe bei den Weibchen derselben Art (s. den zweiten Abschnitt) nie Tentakeln gesehen. 


\section{ABSCHNITT II. \\ DIE HETEROPODEN DER SIBOGA-EXPEDITION.}

Das von der Siboga gesammelte Heteropodenmaterial umfasst die drei Familien, welche innerhalb dieser Molluskengruppe sich begrenzen lassen. Mit Ausnahme der sehr seltenen Gattung Pterosoma sind sämtliche Genera in der Sammlung vertreten, also: Oxygyrus, Atlanta, Carinaria, Cardiapoda, Pterotrachea und Firoloida.

\section{Familie I. Atrantrdae.}

Die Untersuchung der kleinen, zu dieser Gattung gehörigen Arten gab mir Gelegenheit hier eine Bemerkung zu machen über eine Angabe VAyssière's, der neuerdings den Atlantiden "mâchoires lamelleuses latérales et rudimentaires" zuschreibt. Eine solche Entdeckung hätte allerdings mehr verdient als eine nur fluichtige Constatirung der Tatsache; denn weder von Leuckart, noch von Huxley, Gegenbaur, Souleyet oder Troschel sind je Kiefer bei Heteropoden beobachtet worden. Die Abbildung der Kiefer von Oxygymus, welche Vayssière seiner Beschreibung zufügt, lässt aber stark vermuten, dass der Zungenknorpel, wie er sehr allgemein bei Prosobranchiern vorkommt, mit Kiefern verwechselt wurde. Der Knorpel unterhalb der Reibplatte kommt in ähnlicher Ausbildung auch bei Atlanta vor (Taf. VI, Fig. I). Es handelt sich um zwei birnförmige, distal sich etwas erweiternde Gebilde, die zu beiden Seiten der Radula gelagert sind, und sich aus einem Gewebe von blasigen Bindegewebszellen zusammensetzen, die wie Pflanzenparenchym aussehen. An der Unterseite jedes Stückes setzt sich eine Muskel an mit einer langen, schmalen, longitudinalen Insertion; diese Muskeln sind nach vorn und nach der Medianlinie gerichtet und in der Nähe dieser letzteren finden sie an der Leibeswand ihr Ende. Offenbar dienen sie der Retraction des Rüssels.

Kiefer muss ich also den Atlantiden entschieden absprechen. Das Vorhandensein von Zungenknorpel wurde von TROschel bei Carinaria, von Huxley bei Firoloida constatirt.

Die Radula der Atlantidae ist besonders kräftig entwickelt, mehr als in den anderen Familien; man zählt bisweilen 70 und mehr Querreihen. Die Gestaltung der einzelnen Glieder einer Querreihe ist nicht nur in den beiden Gattungen Oxygyrus und Atlanta verschieden, sondern zwischen den einzelnen Arten bestehen in dieser Hinsicht oft noch erhebliche Differenzen, weshalb solche auch vorteilhaft systematisch verwertet werden können. 
Oxygyrus Benson 1835 .

Die unzweifelhaft urspringlichste Gattung der Heteropoden ist in der Sammlung der Siboga durch eine einzige Art vertreten.

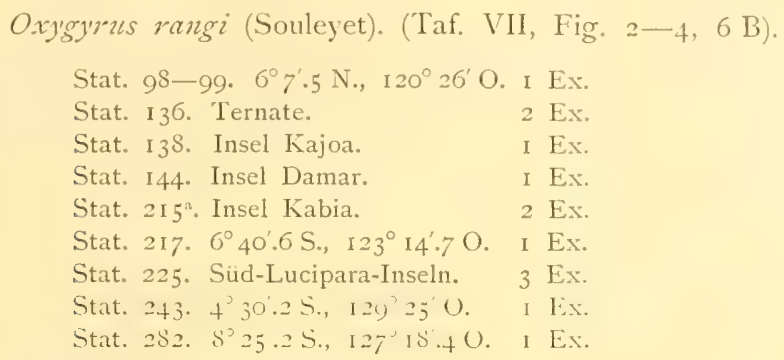

Die Schale besitzt einen hohen Kiel, der nur bei den grössten Exemplaren ( $4 \mathrm{~mm}$.) sich auch bis auf die erste Hälfte der letzten Windung erstrekt. Dịe sehr kleine Schale von Stat. 243 hat noch gar keinen Kiel. Dieser Kiel und die zweite Hälfte des letzten Umganges sind hornig, die übrigen Windungen aber kalkig, und mit sehreigentümlichen, spiraligen Wellenlinien versehen. Die ganze Schale ist fast farblos, ganz durchsichtig, im kalkigen Teile schwach bräunlich angehaucht. Mundöffnung ein gleichseitiges Dreieck bildend, wie bei $O$. keraudroni, mit einem kleinen Schlitz, der sich in den Kiel hinein erstrekt.

Operculum mehr abgerundet als bei $O$. keraudreni (Fig. $6 \mathrm{~A}$ u. 6 B), mit breiterer Rachis.

Radula stark entwickelt, mehr als 70 Querreihen. Die Mittelplatte (Fig. 3) hat drei, fast gleich lange Dornen; an der convexen Aussenseite des Zwischenzahnes findet sich ein wohl ausgebildeter Kamm, der sich mit einem Dorne gegen die Hauptspitze des Zwischenzahnes abgrenzt; ein Aussendorn an dem concaven Innenrande der intermediären Platte, wie er oft bei Atlanta sichtbar ist, kommt bei Oxygymus nicht vor. Die Seitenzähne sind schwertförmig gestaltet, fast gleich lang, besonders an der Spitze gekrümmt.

Wenn wir nun Fig. 3 mit Fig. 5 (die Radula von 0 . keraudrenzi) vergleichen, so fällt gleich der Unterschied in den Mittelplatten auf. Während die seitlichen Dornen der Mittelplatte bei der letzten Art kurz bleiben und an der Spitze durch eine kleine Einkerbung gespalten erscheinen ${ }^{1}$ ), sind alle drei Dornen bei O.rangi gleich gross. Durchmesser der Schale $\mathrm{I}^{1} / 2-4 \mathrm{~mm}$.

Ich hatte im „British Museum” Gelegenheit die Originalexemplare Souleret's zu untersuchen. Auch hier zeigten sich die spiraligen Wellenlinien auf der Schale, und die Radula stimmte ebenfalls ganz im Bau mit der der Siboga-Exemplare überein. Die Art ist durch die beiden hier erwähnten Merkmale scharf von O. keraudroni unterscheiden.

Es wurde von MacDONald eine Art Oxygyrus beschrieben, die, wie schon im ersten Abschnitt erwähnt wurde, mit der hier genannten identisch ist. Auch hier findet man die

r) Die Abbildung der Radula von O. kiraudroni durch VArssìke, weicht in einigen Punkten, namentlich im Bau der seitlichen Dornen der Mittelplatte, und des Kammes am medianen Rande der Zwischenplatte, von der meinigen ab, welche mehr der Darstellung Troschel's entspricht. Die Beschreibung, welche Lovìx von der keibplatte von . Allanth lesucuri" gab, bezieht sich ganz gewiss auf Atlanta, nicht auf Oxygyrzs, wie von Troscher und SmTrm vermutet wurde. 
spiraligen Wellenlinien auf der Schale (vergl. Fig. 5 im ersten Abschnitt), der Kiel ist hoch, setzt sich auf der letzten Windung eine kleine Strecke fort und hört dann ziemlich plötzlich auf. Nit dieser Abbildung stimmt das kleine Exemplar der Siboga fast ganz überein, nur ist hier kein Kiel vorhanden. Bekanntlich kommt aber bei Oxygyrus ein Bellerophina-Stadium vor. In der Jugend haben wir dann: eine in ihrer ganzen Ausdehnung kalkige Schale, mit IVellenlinien, ohne Kiel (Ex. von Stat. 243); später tritt ein Kiel auf, zuerst ganz nahe der Mündung; es bildet sich zugleich der hornige Teil, der beim ausgewachsenen Tiere die zweite Hälfte des letzten Umganges ausmacht (Stadium von MACDONaLd beobachtet). Zuletzt wird dann der Zustand erreicht, wie er auf Taf. VII, Fig. 2 abgebildet worden ist: eine teils kalkige, teils hornige Schale, mit einem hornigen Kiele, der sich allmählich auf die erste Hälfte des letzten Umganges ausdehnt. Die Abbildung der Radula, welche MACDonald gab und welche ebenfalls drei fast gleich lange Dornen an der Mittelplatte zeigt, schliesst jeden Zweifel über die Identität seiner Art und $O$. rangi aus.

Anhang: Unter dem Namen "Helicophlegma cande"” wurde von D'Orbigry eine kleine, nautiloide Schale beschrieben, die zu der hier besprochenen Gattung gehören sollte. Die Schale zeigte aber einige Eigentümlichkeiten, welche D'Orbigny dazu veranlassten, ein Genus Brozunia für die Aufnahme dieser Form vorzustellen.

In der Siboga-Sammlung sind einige Schalen vorhanden, welche in den meisten Punkten mit der Beschreibung D'Orbigny's ubereinstimmen. Die Schale ist in einer Ebene aufgerollt, involut, und in ihrer ganzen Ausdehnung hornig, biegsam und weich, ohne die geringste Spur kalkiger Substanz. Die Mundöffnung ist niedrig aber breit, viereckig; auf der Aussenseite, wie auf den Flanken sind drei Doppelreihen vorspringender, gezähnelter Leisten sichtbar. In dieser Schale steckt ein sehr kleines Tier, das gar nicht an der Wandung befestigt ist; man kann einen quergefalteten Fuss unterscheiden, distal in einen lang ausgezogenen Schwanz ibergehend, einen Kopf mit kurzem Rüssel, zwei kleine Tentakeln, an deren Basis sich die winzigen Augen finden, weiter eine dorsale Mantelhöhle mit Ctenidium. Auf dem Kopfe sieht man ganz deutlich ein in vier Lappen geteiltes, tief eingeschnittenes Velum.

Wir haben hier offenbar eine Embryonalschale vor uns, welche wahrscheinlich zu der von KROIN beschriebenen Echinospira gehört. Diese Form scheidet innerhalb ihres hornigen Gehäuses eine definitive Kalkschale ab, und die ursprüngliche Umhüllung wird dann abgestreift. Echinospira wurde ïbrigens neuerdings von Lo Braxco aus dem Mittelmeer verzeichnet.

\section{Atlanta Lesueur I\& 17 .}

$\mathrm{Zu}$ der im ersten Abschnitt gegebene Diagnose fügen sich noch einige Merkmale hinzu, welche dem Tiere eigentümlich sind. Im Unterschiede mit Oxy'gymus, ist der Saugnapf verhältnissmässig klein, und ist bedeutend reducirt, zu Gunsten der, übrigens ebenso wie bei Oxygyrus vom Saugnapf gesonderten Flosse. In dieser Ausbildung macht sich also schon ein Fortschritt kenntlich in der Richtung, wie sie die höheren, mehr specialisirten Heteropoden eingeschlagen haben. Aber noch in anderer Hinsicht bestehen Unterschiede. Der Rüssel ist schwächer entwickelt, 
und oft kürzer, als bei Oxygyrus, die Tentakeln dagegen sind länger, die Augen sind, abgesehen von ihrer allgemeinen Gestalt, noch dadurch merkwirdig, dass sich an ihrem medianen Rande, vorn an der Cornea, eine kurze, tentakelförmige Papille findet (Fig. $\%$ ), deren Bedeutung umbekannt ist, und welche sonst an den Augen der Heteropoden gar nicht vorkommt. Von den die Augenkapsel umspinnenden Muskelfasern, treten einige in den konischen Fortsatz ein, sodass er wahrscheinlich contractil ist und als innerer Tentakel aufgefasst werden könnte, den morphologischen Wert eines wirklichen Tentakels hat er aber gewiss nicht. Die hier erwähnte Papille ist schon von Raxg beschrieben, später auch von Soulryet, Geglimatr und Micdoxat.D angezeigt worden, von den beiden letzteren Autoren wurde sie auch abgebildet, eine Meinung über ihre mögliche phylogenetische Bedeutung aber nicht ausgesprochen.

Die Radula hat mit dem gleichnamigen Organ von Oxygy'rus die sehr hohe Zahl der Querreihen gemein (es kommen bis zu 75-So Reihen vor), sonst aber zeigt sie deutliche Unterschiede. Während bei Oxygymus die Grösse der einzelnen Glieder in der Transversalreihe. von vorn nach hinten, allmählich beträchtlich zunimmt, ist eine solche Differenz bei Allanta viel weniger bemerkbar, die ganze Radula hat die Gestalt eines langen, platten Bandes, welches sich nach hinten zu kaum wahrnehmbar verbreitert. Die Mittelplatte der Radula besitzt nicht drei Dornen, sondern immer nur einen einzigen, die Seitenhörner der Platte, welche bei Oxy'gyrus stark nach innen gekrümmt sind, sind hier fast gerade, und viel schwächer entwickelt; der Kamm am convexen, medianen Rande der Zwischenplatte endet nicht mit einer distal gerichteten Spitze.

Beachtenswert ist weiter ein vorderes Paar Speicheldriisen, welche, wie es scheint, nur der Gattung Atlanta zukommen, und ganz vorn in der Mundhöhle ausmuinden (Fig. 8). Ich habe diese Speicheldriisen, oder vielleicht besser: Lippendrüsen, wenigstens bei $A$. peroni aufgefunden. Bei Betrachtung des Rüssels von der ventralen Seite fallen hier zwei lange, cylindrische Schläuche auf, die sich proximal mittels eines dünnen Ausführungsganges in die Mundhöhle öfnen; die Wandung der Drüsen ist aus sehr kleinen Zellen zusammengesetzt, welche sich mit Carmalaun sehr tief färben; einen besonderen Inhalt konnte ich freilich in den Schläuchen nicht nachweisen. Die Drisen sind auch hier schon von RAxG beschrieben worden, seitdem wurden sie aber nie wieder erwähnt, und Soulexet sprach die Meinung aus, dass RAxG sich mit den Buccalganglien geirrt haben möchte.

Die eigentlichen Speicheldrüsen, wie sie allen Heteropoden zukommen, liegen ganz hinten, und münden, etwa auf der Höhe der Radulascheide, aber ein wenig dorsal von dieser, also an der nämlichen Stelle wie bei Prosobranchiern überhaupt, in die Buccalhöhle aus. Sie haben keulenförmige Gestalt, so dass der Ausführungsgang (der bei Atlanta etwas kuirzer ist als bei Oxygyrus) ziemlich deutlich vom eigentlichen Drüsenkörper gesondert ist. Die Zellen, welche die Wandung der Drüsen bilden, sind hier etwas grösser als bei dem vorderen, oben erwähnten Paare.

Näheres ist hier, wo hauptsächlich die systematischen Zwecke im Vordergrunde stehen, nicht am Platze.

Bei der Bestimmung der Atlanta-Schalen, welche in namhafter Zahl von der Siboga heimgebracht wurden, war ich in der Gelegenheit, die Sammlung Souleret's im „British Museum” untersuchen zu können, und seine Originalexemplare mit den meinigen zu vergleichen. Freilich sind nicht alle von Souleyet beschriebene Arten im „British Museum” vorhanden - eine grosse 
Zahl findet sich, wie mir Prof. L. Joubin freundlichst mitteilte, in Paris; aber doch war es mir möglich fast alle Arten der Siboga-Expedition mit Hilfe der genannten Sammlung zu bestimmen. Hier fühle ich mich also auf sicherem Boden. Die von Sovleyet vor fast 7o Jahren gesammelten Schalen waren trocken aufbewahrt und aufgeklebt worden; etwaige Färbung war allerdings nirgends mehr vorhanden, und viele Exemplare zeigten sich stark zerstuickelt. Jedoch habe ich 8 Arten des Siboga-Materiales wieder erkannt; es blieben nur zwei Arten übrig, welche sich in keiner Hinsicht mit denjenigen Souleyet's vereinigen liessen und auch mit den sonst aus der Litteratur bekannten Formen keine Ähnlichkeit zeigten.

Die Sammlung im „British Museum” umfasste:
A. souleyeti Smith.
A. peroni Lesueur.
A. rosca Souleyet.
A. inflata Souleyet.
A. gaudichandi Souleyet.

Im Siboga-Material fanden sich:
A. peroni Lesueur.
A. rosea Souleyet.
A. inflata Souleyet.
A. gaudichaudi Souleyet.
A. lesueruri Souleyet.
$A$. helicinoides Souleyet.
A. inclinata 'Souleyet.
A. turriculata d'Orbigny.
A. fusca Souleyet.

Ausserdem als neue Arten:

$$
\begin{aligned}
& \text { A. affinis n. sp. } \\
& \text { A. oligogyra n. sp. }
\end{aligned}
$$

Atlanta peroni Lesueur. (Taf. VII, Fig. I, 7, 8).

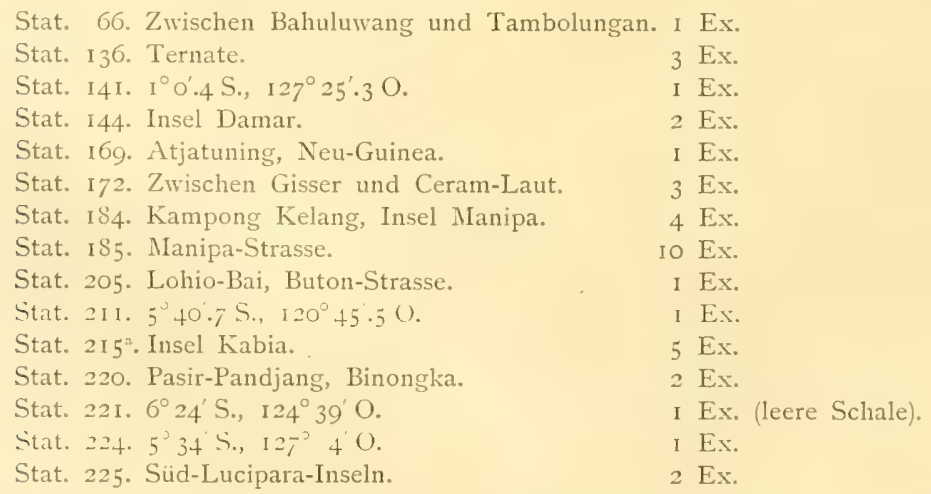

Über diese allbekannte Art ist nichts Besonderes zu erwähnen; sie ist durch das tiefe Eindringen des Kieles zwischen die Umgänge und durch die kleine, flache Spira kenntlich genug. Die leere Schale zeigt kaum sichtbare Querstreifung auf der letzten Windung; diese ist aber, wie auch VAYSSIÈRE hervorhebt, nie, wie bei $A$. lesueuri, wellig. 
Die Schalen sind sämtlich klein, nur wenige erreichen die Grösse von 5 mm.; D'ORIBTGXY machte ubrigens schon die Bemerkung, dass die Art im Atlantischen Ozean zu bedeutenderer Grösse heranzuwachsen scheint. Exemplare im Utrechter Museum, welche aus dem Atlantischen Ozean stammen, erreichen die für Atlanta ganz ansehnliche Dimension von io mm.

Die Art ist im ostindischen Gébiet iuberall häufig, ob sie aber, wie andere von der Siboga erbeutete Arten, in Schwärmen auftreten kann, würde man aus obiger Liste nicht schliessen können.

Atlanta affinis n. sp: (Taf. VII, Fig. $9-10$ ).

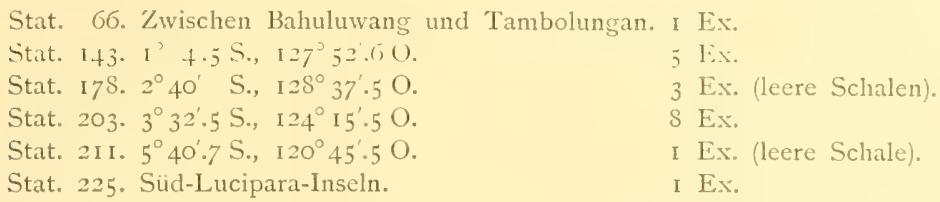

Die hier beschriebene neue Art zeigt grosse Ähnlichkeit mit A. peroni; auch hier findet man einen Kiel, der bis zum Schlitz in der Aussenlippe reicht und vor der Mundöffnung also verstreicht; ebenso wie bei der vorhergehenden Art, dringt der Kiel hier zwischen die Windungen ein, und zwar ziemlich tief, sodass mehr als die Hälfte der vorletzten Windung von der letzten geschieden ist. Die Schale ist ganz flach und besteht aus 6 Windungen, von denen die letzte weitaus die grösste ist; die Spira zeigt dieselbe Form wie bei $A$. peroni, steht aber nicht aufrecht, sondern ist stark nach vorn geneigt; hierin liegt das wesentliche Merkmal der hier besprochenen Art. Weiter zeigt der letzte Umgang, besonders deutlich bei den leeren Schalen, regelmässige Querstreifen, welche bisweilen den Eindruck von Furchen machen, wenn sie in Wirklichkeit auch dünnere Stellen der Schale vorstellen, zwischen denen breite, undurchsichtige Streifen gelegen sind. Die Mundöffnung ist niedrig, eiförmig, ganz wie bei $A$. pcroni, mit tiefem Schlitz in der Aussenlippe, dessen Ränder nach aussen zu nicht divergiren.

Die Art stellt gewissermassen ein Bindeglied dar zwischen A. pcroni, mit der sie die flache Schale und den tief zwischen die Windungen hineinreichenden Kiel gemein hat, und A. lesueuri, deren Querstreifen auf der Schale (man vergleiche besonders Fig. I6 im ersten Abschnitt) in derselben Weise auftreten, allerdings sich auch auf die Spira selbst fortsetzen. Von beiden Arten ist sie aber genügend verschieden.

Die Radula (Fig. Io) zeigt im Ganzen die grösste Ähnlichkeit mit der von A. peroni. In der Form der Mittelplatten ist kein wesentlicher Unterschied zu bemerken. Auch die Zwischenplatten sind ganz ähnlich gestaltet, nur kommt der Aussendorn, wie er sich bei $A$. teroni an der concaven Aussenseite der Platte findet, bei A. affinis nicht vor. Die Seitenzähne, welche in Grösse untereinander gleich sind, erreichen gar nicht die Länge der Zwischenplatte; ein derartiges Verhalten ist allerdings in der Gattung Atlanta ganz allgemein.

Der grösste Durchmesser der Schale betrug bei einem Exemplare (leere Schale) $7 \mathrm{~mm}$; in den meisten Fällen aber wird $2-4 \mathrm{~mm}$. erreicht.

Die Art scheint, etwa in gleicher Zahl wie $A$. peroni, überall im Archipel vorzukommen. 
Atlanta gandichandi Souleyet. (Taf. VII, Fig. II-13).

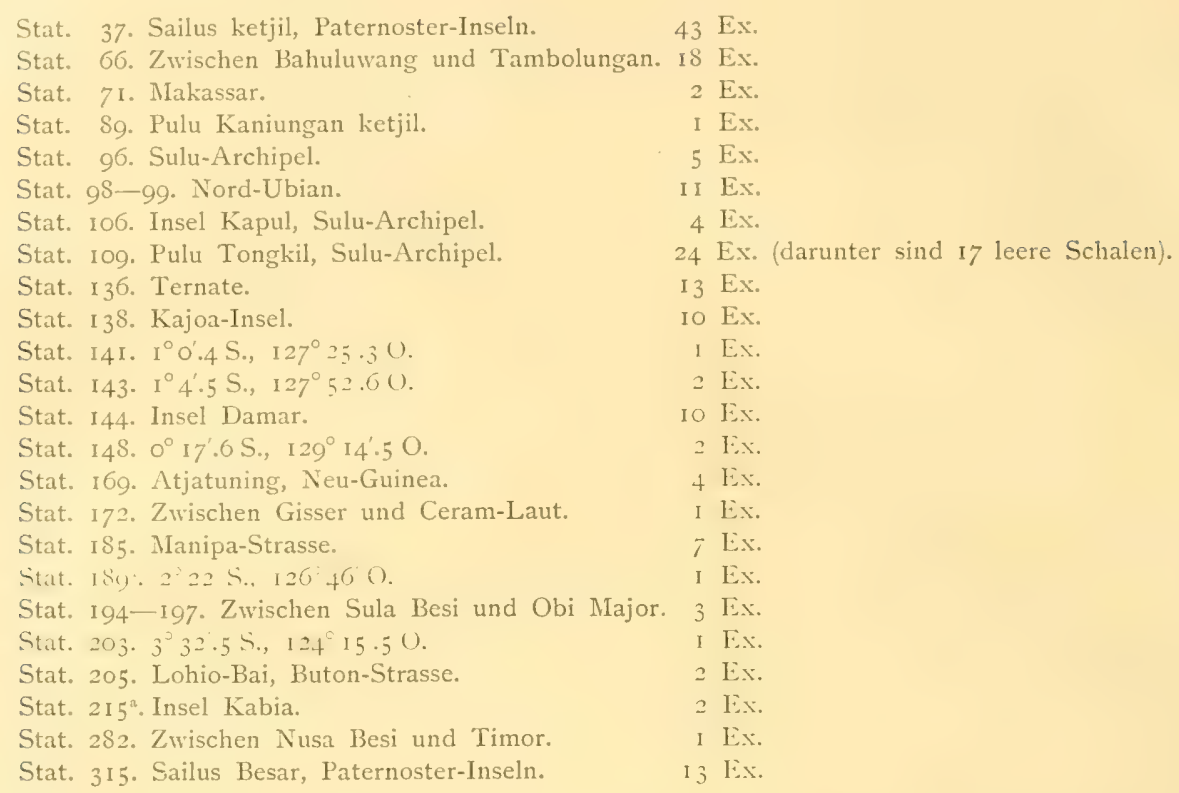

Die Form der Schale entspricht fast ganz der von A. peroni, nur schliessen die Windungen in den meisten Fällen fest aneinander; bei den grössten Schalen (4,5 mm.) aber ist die Innenlippe ein wenig abgehoben und dringt der Kiel in den Zwischenraum zwischen Innenlippe und Schale ein. Die Windungen sind $4^{1 / 2}$ an der Zahl und bilden zusammen eine sehr flache Schale, mit rundlicher Mundöffnung (Fig. I 2), tiefem Schlitz in der Aussenlippe und einer braunen Linie an der Ansatzstelle des Kieles; diese Linie setzt sich noch ein wenig weiter nach innen auf die Sutur fort, ist also, bei Betrachtung der Schale von der Mundöffnung aus, durch die duinne Innenlippe hindurch, sichtbar. Diese Linie, welche ich nirgends vermisste, war schon Souleyet aufgefallen.

Das Tier besitzt einen langen Rüssel; demgemäss ist auch die Radula ziemlich stark entwickelt. Die Mittelplatte ist fast ganz wie bei $A$. peroni gestaltet, nur ist der Dorn etwas kleiner, und etwa von gleicher Länge wie die seitlichen Fortsätze der Platte. Die Zwischenplatte zeichnet sich noch durch das Fehlen des kleinen Aussendorns aus; die Seitenplatten sind stark gekrümmt, die zweite steht der andere ein wenig an Grösse nach.

Diese Art scheint ganz häufig im Inselreich vorzukommen, und wurde an einigen Stationen sogar in grosser Menge gefunden. Bisher war sie nur aus dem Pazifischen Ozean bekannt.

Atlanta oligogyra n. sp. (Taf. VIII, Fig. I4-18).

Stat. 37. Sailus ketjil, Paternoster-Inseln. 44 Ex.

Stat. 66. Zwischen Bahuluwang und Tambolungan. 2 Ex.

Stat. 96. Sulu-Archipel. 5 Ex. 
Stat. 106. Insel Kapul, Sulu-Archipel. , T:

Stat. 136. Ternate. 3 Ex:

Stat. 138. Insel Kajoa. I Ex.

Stat. 144. Insel Damar. 6 Ex.

Stat. 165. Insel Daram. 4 Ex.

Stat. 169. Atjatuning, Neu-Guinea. 2 Ex.

Stat. 172. Zwischen Gisser und Ceram-Laut. 7 Ex.

Stat. $203.332 .5 \mathrm{~S}, 12+15.5() .3 \mathrm{Ex}$.

Stat. 205. Lohio-Bai, Buton-Strasse. 3 Ex.

Stat. 224. $5^{\circ} 34^{\prime} \mathrm{S}$., $\mathrm{I} 27^{\circ} 4^{\prime} \mathrm{O}$. $4 \mathrm{Ex}$.

Stat. 225. Süd-Lucipara-Inseln. I Ex.

Stat. 282. Zwischen Nusa Besi und Timor. 3 Ex.

Die meistens sehr kleine Schale ist durch eine sehr kleine Spira ausgezeichnet; es sind im Ganzen nur 3/2 Windungen vorhanden, die letzte ist weitaus die grösste und bildet allein schon fast die ganze Schale; diese ist ganz flach, mit ovaler Mundöffnung, in deren Aussenlippe sich ein Schlitz findet, der zwar untief ist, aber nach aussen zu stark divergirende Ränder hat. Der ziemlich hohe Kiel dringt, je nach dem Alter der Schale, mehr oder weniger tief zwischen den Umgängen ein (man vergleiche Fig. 14 und Fig. I7, welche bei derselben Vergrösserung gezeichnet sind). Die Ansatzstelle des Kieles ist auch hier durch eine braune Linie markirt, weniger deutlich aber als bei $A$. gaudichaudi.

Die Schale ist gänzlich ohne Skulptur, sehr feine Zuwachsstreifen sind auf dem letzten Umgange sichtbar. Ebensowenig ist irgend eine Farbe zu bemerken, das Ganze ist glashell und durchsichtig. Grösster Durchmesser der Schale $2 \mathrm{~mm}$., die meisten Exemplare sind aber kleiner.

Das Tier, mit kräftigem Rüssel und wohlausgebildeten Tentakeln ausgerüstet, besitzt eine lange, bandförmige Radula, an der ich 65 Querreihen zählen konnte. Der Dorn der Mittelplatte (Fig. I6) ist sehr kurz, kleiner als die seitlichen Fortsätze dieser Platte; dem Zwischenzahn fehlt der Aussendorn, die Seitenzähne von nahezu gleicher Grösse sind an der Spitze hakenförmig gekrümmt.

Ich habe mich wohl entschliessen müssen, hier eine neue Art aufzustellen, da ich weder mit den im "British Museum" aufbewahrten Typen Souleyet's, noch mit anderen in der Litteratur beschriebenen Formen genügende Übereinstimmung fand. Nur mit der von Souleyet als Varietät seiner A. lesueuri (Fig. I5 im ersten Abschnitt) bezeichneten Form besteht eine gewisse Ähnlichkeit, aber, abgesehen von den bei letztgenannter Art sehr deutlichen Querstreifen, ist hier die letzte Windung, mit den übrigen verglichen, verhältnissmässig noch grösser als bei A. oligogyra. Auch in der Grösse bestehen beträchtliche Unterschiede, da A. lesueuri einen Durchmesser von $6 \mathrm{~mm}$. erreicht.

Die Art ist im ganzen Gebiet häufig und tritt bisweilen (wohl passiv von Seeströmungen verschleppt) schwarmweise auf.

Atlanta inflata Souleyet. (Taf. VIII, Fig. Iy-2I).

Stat. 37. Sailus ketjil, Paternoster-Inseln. 6 Ex.

Stat. 66. Zwischen Bahuluwang und Tambolungan. I Ex.

Stat. 98-99. Nord-Ubian, Sulu-Archipel. 20 Ex. 
Stat. I36. Ternate.

7 Ex.

Stat. I3S. Insel Kajoa.

Stat. $148.0^{\circ} 17^{\prime} .6$ S., $129^{\circ} 14^{\prime} .5$ O.

4 Ex.

Stat. 165. Insel Daram.

$2 \mathrm{Ex}$.

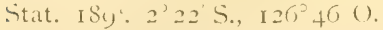

I Ex.

Stat. I94-197. Zwischen Sula Besi und Obi-Major. I Ex.

Stat. $203 \cdot 3^{\circ} 32^{\prime} .5$ S., $124^{\circ} 15^{\prime} .5$ O. I Ex.

Stat. $215^{\pi}$. Insel Kabia. 4 Ex.

Sitit. $223 \cdot 5+4.7 \div, 12027 \cdot 3 \mathrm{O} . \quad$ I Ex.

Stat. 224. $5^{\circ} 34^{\prime}$ S., $127^{\circ} 4^{\prime}$ O. 3 Ex.

Stat. 225. Süd-Lucipara-Inseln. 4 Ex.

Stat. 243. $4^{\circ} 30^{\prime} .2$ S., $129^{\circ} 25^{\prime}$ O. 4 Ex.

Stat. $245.4^{\circ} 16^{\prime} .5$ S., $130^{\circ} 15^{\prime} .8$ O. 4 Ex.

Stat. 282. Zwischen Nusa Besi und Timor. 5 Ex.

Mit dieser Art verlassen wir den Formenkreis der $A$. peroni, d. h. die ganz niedrigen, flachen Schalen, bei denen die Spira gar nicht hervorragt, und der Kiel mehr oder weniger weit zwischen den Umgängen eindringen kann. Zwar ist damit nicht eine deutliche Gruppe bezeichnet, welche etwa als Untergattung aufzufassen wäre; denn in dieser Hinsicht zeigen sich die Zungenbewaffnungen der Atlanta-Arten unter einander so sehr verschieden, dass z.B. bei so nahe verwandten Formen wie $A$. peroni und $A$. gaudichaudi an der Zwischenplatte der Radula der Aussendorn vorkommen kann oder fehlen.

Die Schale der $A$. inflata zeigt zunächst nicht die Disproportion zwischen Spira und letzter Windung; die Umgänge nehmen von der Spitze nach abwärts ganz regelmässig an Grösse zu; es sind im Ganzen 5 Umgänge vorhanden; die ersten vier sind gewöhnlich durch eine dunkelbraune oder violette Farbe unterschieden, was als deutliches Artmerkmal gelten könnte, wenn nicht bei einigen Schalen diese Farbe ausnahmsweise fehlte. Von der Seite betrachtet, zeigt sich die rundliche Mundöffnung, in deren Aussenlippe sich ein Schlitz findet mit stark auseinander weichenden Rändern; die Innenlippe, welche nie von der Schale abgehoben ist, da ein Eindringen des niedrigen Kieles zwischen die Windungen nicht vorkommt, ist bräunlich angehaucht. Ein sehr schönes Merkmal der Art, das sie freilich mit anderen gemein hat, ist in den feinen Spirallinien gegeben, welche bei starker Vergrösserung parallel der Sutur auf den ersten Windungen sichtbar sind (in Fig. I9 sind sie nicht abgebildet worden). Auf der letzten Windung kommt eine solche Skulptur nicht vor, ebenso wenig an der Nabelseite der Schale. Die bei Seitenansicht ziemlich stumpf erscheinende Spira ist schwach nach hinten geneigt.

Als ich die Originalexemplare Souleyet's im „British Museum” untersuchte, konnte ich auch hier die oben erwähnte Skulptur feststellen.

Grösster Durchmesser der Schale kaum $\mathrm{I}^{1} / 2 \mathrm{~mm}$.

Das Tier besitzt einen ziemlich langen Rüssel, aber bei der Kleinheit dieser Art sind die einzelnen Glieder der Radula schwierig zu sehen. Ich habe einige Querreihen der Reibplatte herauspräparirt, hierbei erwies sich dann (Fig. 2I) die Mittelplatte als ganz klein, mit kleinem Dorn und kaum entwickelten seitlichen Fortsätzen. Die Zwischenplatte weist hier merkwürdigerweise wieder den allerdings kaum sichtbaren Aussendorn auf, wie er bei $A$. poroni vorkommt; die hakenförmig gebogenen Seitenzähne sind deutlich kürzer als die Zwischenplatte.

Erwähnenswert ist weiter der Umstand, dass der männliche Begattungsapparat mit 
seinem Anhang ganz dunkel, fast schwarz pigmentirt ist, wie durch die dünne, durchsichtige Schale hindurch direct sichtbar ist. Diese Eigentümlichkeit war übrigens auch schon SoulrytT nicht entgangen.

A. inflata gehört im ost-indischen Inselreich gewiss zu den häufigsten Arten. Namentlich im Norden des Gebietes, in dem Sulu-Archipel, wurde sie, gemeinschaftlich mit A. rosea, in grosser Menge erbeutet.

Atlanta rosea Souleyet. (Taf. VIII, Fig. 22-24).

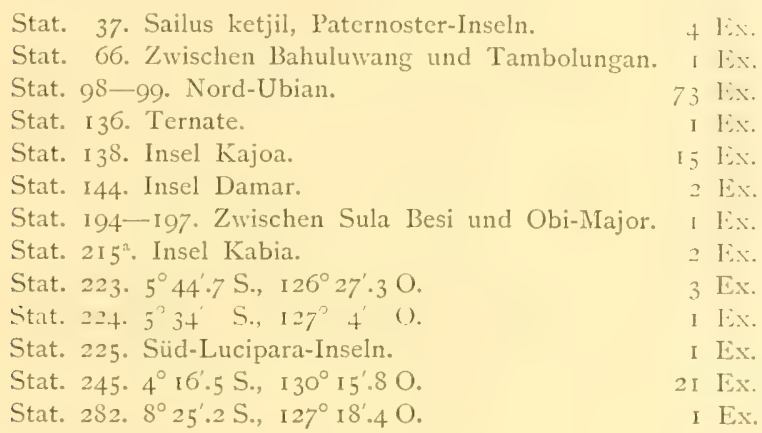

Bei erster Betrachtung ist die Ähnlichkeit der Schale mit cler von A. inflata eine ausserordentlich grosse (vergl. Fig. I 9 und 22); jedoch sind einige Unterschiede zu verzeichnen, welche A. rosea als gesonderte Art abtrennen. Die Grössenzunahme der verschiedenen Windungen $\left(5^{1 / 2}\right)$ ist nicht ganz regelmässig; die vorletzte und die drittletzte Windung zeigen in dieser Hinsicht einige Eigentümlichkeiten, welche am besten aus der Abbildung selbst zu ersehen sind. Besser noch als von oben betrachtet, tritt der Unterschied hervor bei Seitenansicht der Schale (vergl. Fig. 20 und 23). Die Spira der A. rosea ist etwas dünner und schlanker und ragt nur ganz wenig hervor. Das ganze Gehäuse ist farblos, und ein Farbenunterschied wie bei $A$. inflata, wo die Spira dunkler gefärbt ist als der letzte Umgang, kommt hier nicht vor. Die Mundöffnung ist etwas mehr niedergedrückt, die Innenlippe ist glashell, wie die ganze Schale, die Aussenlippe ist tief eingeschlitzt, mehr noch als bei $A$. inflata. Der Kiel ist sehr niedrig; ein Eindringen zwischen den Umgängen wurde nirgends beobachtet. Ein schönes Merkmal, allerdings auch bei A. inflata vorkommend, sind die äusserst feinen Spirallinien, welche auf den ersten drei Windungen sichtbar sind, ganz in derselben Weise, wie. es oben für $A$. inflata erwähnt wurde. Auch bei $A$. rosea ist von diesen Linien an der Nabelseite der Schale nichts zu erblicken.

Grösster Durchmesser der Schale kaum $\mathrm{I}^{1} / 2 \mathrm{~mm}$. Nach Souleyet erreicht diese Art eine Grösse von $4-5 \mathrm{~mm}$.

Da der Rüssel des Tieres sehr kurz ist, ist die Radula ausserordentlich winzig, und nur bei sehr starker Vergrösserung sind.an den Platten (Fig. 24) Einzelheiten wahrzunehmen. Die Mittelplatte ist wie bei $A$. inflata gebildet, also auch hier mit einem kurzen Dorn ausgestattet, der nur etwa ebenso lang ist als die beiden seitlichen Fortsätze der Platte. Die Zwischenplatte 
trägt einen kleinen Aussendorn an der convexen Seite. Die beiden säbelartig gekrümmten Seitenzähne stehen an Grösse ziemlich weit hinter der Zwischenplatte zurück.

IVie schon bei der Besprechung von $A$. inflata erwähnt wurde, ist A. rosca im ganzen von der Siboga durchforschten Gebiete eine uiberaus häufige Erscheinung.

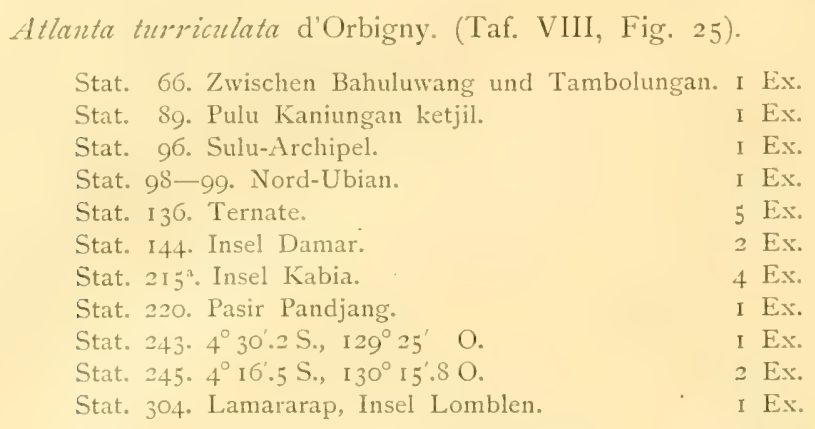

A. turriculata ist sehr leicht kenntlich an der eigentümlichen Spira, welche sehr schlank und hoch ist und sich besonders deutlich von der letzten Windung abhebt, nicht nur durch die Farbe, da die Spira dunkelgelb oder braun gefärbt ist, sondern auch dadurch, dass der letzte Umgang, während die vorhergehenden IVindungen schraubenförmig abwärts steigen, sich fast in einer Ebene aufrollt, so dass die Spira wie ein Kegel aus einem niedrigen Talkessel hervorragt. Aus den Abbildungen D'Orbigny's, besser aber noch aus denjenigen Souleyet's (Fig. I I-I2 im ersten Abschnitt), ist die Art ohne Weiteres zu erkennen und gehört, mit den hier folgenden $A$. gibbosa, $A$. inclinata und $A$. fusca zu den am besten characterisirten Formen der Gattung; ich habe deshalb eine nochmalige Abbildung der Schale hier unterlassen. Der Beschreibung Souleyer's möchte ich nur hinzufügen, dass die Spira nicht ganz aufrecht steht, sondern sehr schwach nach hinten geneigt ist, weiter, dass die Aussenlippe der Schale tief gespalten ist.

Das Tier besitzt einen sehr kurzen Rüssel und dementsprechend ist, bei der Kleinheit des ganzen Tieres (der grösste Durchmesser der Schale beträgt kaum $\mathrm{I}^{1}{ }_{4} \mathrm{~mm}$.), die Radula ausserordentlich schwierig zu untersuchen. Nur so viel lässt sich sehen dass die Zwischenplatte (Fig. 25) einen bedeutenden Aussendorn trägt, der fast dieselbe Länge erreicht wie die Hauptspitze der Platte; in so weit besteht ein Unterschied mit allen von mir untersuchten Arten. Von den beiden Seitenzähnen ist die erste grösser als die zweite.

Diese Art scheint zwar im ganzen Archipel vorzukommen, ist aber nirgends in solcher Menge erbeutet worden, wie z.B. A. inflata oder $A$. rosea. Vielmehr tritt sie zwar überall, fast immer aber nur vereinzelt auf.

Atlanta inclinata Souleyet. (Taf. VIII, Fig. 26).

$\begin{array}{lll}\text { Stat. 37. Sailus ketjil, Paternoster-Inseln. I Ex. } & \text { I Ex. } \\ \text { Stat. } 138 \text {. Insel Kajoa. } & 2 \text { I Ex. } \\ \text { stat. } 185.3^{\circ} 20^{\prime} \text { S., I } 27^{\circ} 22^{\prime} .9 \text { O. } & \end{array}$


Stat. 220. Pasir Pandjang.

1 Ex.

Stat. 225. Süd-Lucipara-Inseln. I Ex.

Stat. 304. Lamararap, Insel Lomblen. I Ex.

Die Schale hat eine kreiselförmige Spira, welche sehr deutlich nach hinten geneigt ist, von schwach rötlicher Farbe, während die letzte Windung farblos ist. Die characteristische Form der Spira, deren Windungen allmählich an Grösse zunehmen, ist dieser Art eigentiimlich, weshalb sie unmöglich mit anderen verwechselt werden kann. Die mir vorliegenden Schalen zeigen genau das Bild wie es von Souleyet gegeben wurde (Fig. 25-26 im ersten Abschnitt). Die Innenlippe der Schale ist bräunlich angehaucht, die Aussenlippe zeigt einen tiefen Schlitz: dementsprechend verstreicht der Kiel schon in ziemlicher Entfernung vor dem Muncrande. Die Innenlippe ist infolge des Eindringens des Kieles zwischen den Umgängen, von der Schale ein wenig abgehoben.

Im ersten Abschnitt wurde schon auseinandergesetzt, weshalb ich die von VAYSSIÈRE mit dem Namen $A$. inclinata bezeichnete Art nicht als dieselbe Form wie die von Souleyet halten kann. Ausserdem habe ich die von der Siboga-Expedition gesammelten Schalen mit den Originalexemplaren Souleyet's vergleichen können.

Wenn auch keine Skulptur der Schale bemerkbar ist, so ist doch die Art durch die umfangreiche, auf den letzten Umgang nach hinten zurückgeschlagene Spira kenntlich genug.

Der grösste Durchmesser der von mir untersuchten Schalen war $3 \mathrm{~mm}$., während SoulexeT eine Grössé bis $6 \mathrm{~mm}$. angibt.

Im sehr kleinen, schwachen Rüssel, der von den langen Tentakeln von oben ganz bedeckt ist, ist die Radula verborgen, welche sich von den bis jetzt Beschriebenen nicht wesentlich unterscheidet. Am meisten gleicht sie der Reibplatte von A. oligogyra (vergl. Fig. 26 und I6). Die Seitenhörner der Mittelplatte sind ziemlich stark entwickelt und schwach nach innen gekrümmt; der einzige Dorn der Nittelplatte steht hinter den beiden seitlichen Fortsätzen an Grösse nicht zurück. Einen Aussendorn an der hohlen Seite der Zwischenplatte kommt hier nicht vor. Die Lateralzähne haben die allgemein bei Atlanta vorkommende Gestalt; ein Unterschied in der Grösse besteht zwischen ihnen kaum.

A. inclinata ist zwar an verschiedenen Stationen erbeutet worden, tritt aber nur vereinzelt auf, und von solchen Scharen, wie sie z.B. A. oligogyna, A. inflata und A. rosea bisweilen aufweisen, ist hier gar nicht die Rede. Dies gilt übrigens noch mehr von den beiden nachfolgenden Arten.

Atlanta gibbosa Souleyet. (Taf. VIII, Fig. 27).

Stat. 220. Pasir Pandjang. 3 Ex.

Stat. $245.4^{\circ}$ I6 $.5 \mathrm{~S}_{0}, 130^{\circ}$ I5'.8 O. I Ex.

Diese Art steht in gewissem Gegensatz zu den anderen, weil die Spira sehr dick und kreiselförmig ist und diese nicht, wie sonst, im Vergleich mit der letzten Windung, einen verschwindend kleinen Teil der Schale ausmacht, sondern säntliche Umgänge ganz regelmässig an Grösse zunehmen. Man vergleiche ibrigens Fig. 2 I und 22 im ersten Abschnitt. Die Spira ist stark nach vorn geneigt, und ganz farblos; die Schale ist glashell, durchsichtig, und besteht 
aus 7 Umgängen, welche sämtlich fest aneinander schliessen. Der Kiel ist ziemlich hoch; ein deutlicher Spalt ist in der Aussenlippe des Mundrandes vorhanden.

Grösster Durchmesser der Schale $\mathrm{I}^{1} \frac{1}{2} \mathrm{~mm}$.

Souleyet hat gezweifelt, ob er unter dem Namen $A$. gibbosa wirklich eine existenzberechtigte Form beschrieb; denn er nennt die Schale „presque microscopique", und dazu kommt, dass bekanntlich die Atlanta-Arten in der ersten Jugend eine regelmässig aufgewundene, turmförmige Schale besitzen, welche erst später jenen fast allgemeinen Gegensatz zwischen Spira und letzter Windung aufweist. Allein die Art besitzt einen ausgebildeten Penis, und zudem ist die Schale nicht ganz regelmässig kreiselförmig, sondern die Spira ist ein wenig auf die letzte IVindung herabgebogen.

Die Radula gleicht fast ganz der von A. inclinata. Nur ist clie Mittelplatte (Fig. 27) insoweit verschieden, dass ihr Dorn kürzer und breiter ist, auch sind die seitlichen Fortsätze der Platte kleiner und nicht gekrümmt. Die Zwischenplatte weist einen kleinen Aussendorn auf, während die Seitenzähne von etwa gleicher Grösse sind.

A. gibbosa war bis jetzt nur aus dem Atlantischen Ozean bekannt. Im ost-indischen Inselreich kommt sie zwar vor, scheint aber sehr selten zu sein.

Atlanta fusca Souleyet. (Taf. VIII, Fig. 28-30).

Stat. $215^{2}$. Insel Kabia. 2 Ex.

Die Art hat einige Ähnlichkeit mit A. gibbosa, die Spira ist aber sehr viel dünner und kleiner, im Vergleich mit der letzten Windung, und auch gar nicht so stark nach vorn gebogen. Dies ist auch bei Betrachtung der Schale von oben ganz deutlich sichtbar (Fig. 28). Der Kiel ist niedrig und setzt sich, den sehr engen Spalt in der Aussenlippe des Mundrandes zwischen die beiden niedrigen Lamellen fassend aus welchen er sich hier zusammensetzt, bis zur Mundöfnung fort. Die Schale ist ganz farblos und durchsichtig. Sehr characteristisch sind die feinen, der Sutur parallel gehenden Spirallinien auf der Spira, welche sich auf die letzte Windung nicht fortsetzen; hier aber zeigt die Schale mehr oder weniger deutliche Querbänder. Eine solche Skulptur kommt, wie oben erwähnt, auch bei $A$. inflata und $A$. rosea vor; ein Unterschied mit der hier besprochenen Art besteht aber darin, dass bei $A$. fusca diese Linien auch an der Nabelseite der Schale sichtbar sind. Es wurde diese Schalenzeichnung schon von Siıth erwähnt, und ich hatte im „British Museum" nur Gelegenheit seine Angaben zu bestätigen.

Als Varietät deutete Souleyet ein Exemplar, (Fig. 30 und 3 I im ersten Abschnitt), an welchem der Kiel eine Strecke weit zwischen den Umgängen eingedrungen ist, und wo der Spalt in der Aussenlippe etwas weniger tief erscheint. Die von der Siboga-Expedition gesammelten Schalen nehmen beide eine Mittelstellung ein, weil die Windungen alle fest aneinander schliessen, und der betreffende Spalt sehr seicht ist.

Grösster Durchmesser der Schale kaum $\mathrm{I}^{1} / 2 \mathrm{~mm}$.

Souleyet fand die Art in allen Meeren und bezeichnet sie als häufig, auch wurde sie von der Challenger-Expedition in ziemlicher Menge erbeutet. Dagegen scheint sie nach den Befunden der Siboga-Expedition im ost-indischen Archipel sehr selten zu sein. 
Da von den beiden mir zur Verfügung stehenden Excmplaren, nur eines ganz gut erhalten war, das andere aber deutliche Spuren von früherer Eintrocknung zeigte, habe ich die Radula nicht untersuchen können.

Notizen ïber Lebensweise und Verbreitung der Atraxtid.AE.

Die Heteropoden bieten in ihrer phylogenetischen Anfangsstufe: den Atlantiden, den ersten Beginn der Entıvicklung dar, welche allmählich auf die vollkommene Anpassung an das durchweg pelagische Leben hinausläuft, wie sie sich besonders bei den Pterotracheiden kundgiebt. Sowie Orygyms und Atlanta in ihrem Körperbau, besonders hinsichtlich der hohen Ausbildung des Saugnapfes, im Vergleich mit der Flosse, nur wenig specializirt erscheinen, so zeigen auch ihre Bewegungen noch nicht die ganze Erfüllung der Bedingungen, welche das treibende Leben auf hohem Neere, ohne irgendwelchen Anhalt, den pelagischen Wesen stellt. Eine lebende Atlanto, in einem Gefässe beobachtet, schwimmt ziemlich schnell, die Schale nach unten gekehrt, mit kurzen, stossweisen Bewegungen, und macht durch das lebhafte Hin- und Herschlagen ihrer Flosse einen bei Mollusken sonst ungewöhnlichen Eindruck. Bei dem Vorwärtskommen zeigt sie aber wenig Ausdauer. Bald werden die Bewegungen eingestellt, das Tier zieht sich ganz in die Schale zurück, schliesst die Öffnung mit dem Deckel, und sinkt zu Boden. Hier bleibt es oft lang unbeweglich, um sich dann wieder hervorzustrecken und die Bewegungen von neuem anzufangen. Im Freien scheint den Tieren eine gewisse Ruhe dadurch ermöglicht zu sein, dass sie sich mittels ihres Saugnapfes an Fremdkörpern anheften können, ja, sie sind sogar im Stande eine gewisse Strecke fortzukriechen, nach Art der Platypoden, wie es von Souleyet beobachtet wurde. Ich selbst konnte (in Neapel) etwas derartiges nie wahrnehmen.

Die Atlantidae scheinen von den Heteropoden nicht nur am weitesten verbreitet zu sein, sondern auch dann und wann scharenweise aufzutreten; letzteres geht nicht nur aus den Angaben Souleyet's und den Erfahrungen in Neapel, sondern auch aus den Befunden der Siboga-Expedition hervor. Die Heteropoden sind durchaus Bewohner der wärmeren Meereszonen, und können, durch Strömungen in kühlere Gewässer verschleppt, wahrscheinlich ihr Leben nicht lange fristen. Doch wurde Atlanta von M'INTosh noch aus den englischen Meeren verzeichnet.

Wie überall, so nimmt auch im ost-indischen Gebiet, die Gattung Atlanta, sowohl an Arten- wie an Individuenzahl den ersten Rang ein. Oxygymus kommt zwar an vielen Stellen, fast immer aber nur vereinzelt vor. Im Mittelmeer dagegen halten beide Gattungen einander ziemlich das Gleichgewicht, und hier kann, wenigstens an einigen Stellen, Oxygymus, wie Atlanta, in grossen Schwärmen angetroffen werden.

Familie II. Carinaridde.

Da die Carinariidae eine Mittelstellung zwischen den beiden anderen Familien der Heteropoden einnehmen, bieten sie ein besonderes Interesse. Angesichts der Tatsache, dass die Vertreter der hier genannten Gruppen, in Vergleich mit anderen Heteropoden, weitaus seltener 
sind, kam man die Ausbeute der Siboga-Expedition auch in dieser Hinsicht als ein befriedigendes Resultat betrachten. Allerdings wurde die nur wenig bekannte Gattung Ptcrosoma nicht gefangen, wenngleich sie auch im ost-indischen Gebiet wohl vorkommen mag, Carinaria aber und Cardiapoda sind beide vorhanden, und ihre vorzigliche Erhaltung gestattete eine eingehende Untersuchung, welche hier freilich hauptsächlich systematischen Zwecken diente.

Carinaria Lamarck ISOI.

Die Diagnose der Gattung ist schon öfter gegeben worden, nur möchte ich einige anatomische Befunde, welche teils mit denjenigen meiner Vorgänger nicht übereinstimmen, teils auch neu sind, hier wenigstens kurz erwähnen.

Carinaria unterscheidet sich durch die beträchtliche Entwicklung, welche die gallertige Bindesubstanzmasse genommen hat; namentlich der Rumpf erscheint deshalb wie aufgequollen, aber auch der Kopfteil ist von einer Gallerthülle umgeben, welche sich durch eine tief einschneidende Furche von der des Rumpfes trennt. Der Schwanz ist, besonders am Anfang, rundlich im Durchschnitt, und läuft nach hinten spitz zu. Bei näherer Betrachtung zeigt sich, dass die durchsichtige Hülle überall mit grossen Höckern besetzt ist, die hauptsächlich durch eine örtliche Emporhebung der Haut entstehen, da wo sich die Gallertmasse reichlicher entwickelt hat. Die Haut selbst, welche aus kleinen, zackig in einander greifenden Zellen besteht, deren Grenzen sehr undeutlich sind, ist an der Spitze der Höcker etwas dicker und die Zellen stehen mehr gedrängt (Taf. IX, Fig. 3I). Die Tuberkeln ragen, wie bei Seitenansicht deutlich ist, oft wie Vulkankegel hervor; der Gipfel ist sehr stumpf. Dass die Höcker gewissermassen als Tastorgane betrachtet werden können, dürfte ein sehr zarter Nervenfaden erweisen, der in jeden von ihnen eintritt und von einem der grossen Nerven abstammt, welche den Körper namentlich in der Längsrichtung durchziehen.

Bei anderer Einstellung erblickt man unterhalb der Haut die Elemente des Bindegewebes: kleine, sternförmige Zellen, mit oft enorm langen Ausläufern, welche zwischen sich die glashelle, durchsichtige Bindegewebsmasse ausscheiden, wie sie bei so vielen pelagischen Tieren vorkommt.

Zwei Gebilde sind in der Grundsubstanz noch bemerkenswert. Erstens Anhäufungen von Pigment, die, bald kleiner, bald grösser, allerlei fremdartige Gestalt annehmen können, mehr oder weniger tief unter der Haut liegen, und sich aus kleinen, dunkeln Körnchen und helleren Bläschen zusammensetzen. Sie sind besonders am Schwanze verbreitet. Beim lebenden Tiere ist das Pigment meist leicht rosa-rot, beim Tode aber schwächen sich die Farben ab und verschwinden bei längerer Aufbewahrung des Tieres meist ganz. Zweitens kommen in überaus grosser Menge Zellagglomerate vor, ein Zusammendrängen äusserst kleiner Zellen, die einen deutlichen Kern erblicken lassen. Solche Flecken sind überall am ganzen Körper zerstreut (Fig. 32), sie sind viel zahlreicher als die Höcker; meist rundlich und regelmässig, zeigen einige eckige oder langgestreckte Gestalt.

Unterhalb des gallertigen Bindegewebes findet sich die Körpermusculatur. Diese wurde schon früher von Leuckart, Gegendaur und namentlich Kalide eingehend beschrieben. Ohne mich hier auf eine ausführliche Besprechung meiner Befunde, mit Bericksichtigung des schon bekannten, einzulassen, muss ich mich auf einige kurze Angaben beschränken, welche sich besonders auf die Behauptungen KaLIDE's beziehen. 
Kurz zusammengefasst lässt sich sagen, dass die Körpermusculatur bei Carinaria aus einzelnen Muskelbändern besteht. Ringsum der Buccalmasse verlaufen platte Muskelstreifen in der Längsrichtung; die dorsal gelegenen weichen distalwärts bald auseinander, um sich bei den Augen wieder zu nähern und hier ${ }^{1}$ ), einen schmalen Riickenstreifen zwischen sich frei lassend, im Zwischenraum der Augen nach hinten zu ziehen, wo sie sich von Abstand zu Abstand in platte Bänder aufösen, welche im flachen Bogen nach hinten und nach der Bauchscite gerichtet sind, wobei sie häufig Anastomosen bilden. Die Muskelstreifen an den Seiten des Rüssels und an der Unterseite treten zwar oft mit den dorsalen in Verbindung, nehmen aber einen anderen Verlauf wie diese. An der Ventralseite des Rüssels lassen sie eine longitudinale Linie frei, die aber distalwärts bald aufhört. Die Muskeln selbst setzen sich teils an der Unterseite des Rumpfes fort, geben aber in regelmässigen Abständen Bänder $a b$, die schräg aufsteigen und nach oben und nach hinten gerichtet sind; diese Bänder, welche häufig mit einander anastomosiren, verlaufen unterhalb der Muskelschicht, die, wie oben erwähnt, von der Rückenmusculatur abstammt und schräg nach hinten und nach unten gerichtet ist. So ergiebt sich das Bild zwei einander kreuzender Systeme auf dem Rumpfe, von denen das untere weitaus stärker und dicker ist. Auf der Höhe des Nucleus und der Flosse, also dort wo der Schwanz anfängt, vereinigen sich die isolirten Muskelbündel zu einer einheitlichen Schicht, welche nach hinten zu längsverlaufende Lücken zwischen sich lässt und dann in gesonderten Muskelstreifen auf den Schwanz übergeht, die häufig mit einander in Verbindung treten durch schräge Anastomosen und in einzelnen zarten Fäden enden; da, wo der Schwanz nach hinten zu mehr seitlich zusammengedrückt ist, vereinigen sich die Muskeln der rechten und linken Seite allmählich. Vom dorsalen Muskel im Schwanze spalten sich zarte Fäden $a b$, welche, häufig sich verästelnd und sich verbindend, erst fast senkrecht, später in immer mehr geneigtem Verlauf in die Schwanzflosse emporsteigen.

Mit der Erwähnung, dass dem männlichen Begattungsapparat ein Teil der Längsmusculatur zugeteilt ist, und dass diese Musculatur sich auch auf dem Nucleusstiel bis in den Eingeweidesack hinein fortsetzt, wäre die längsverlaufende Musculatur bei Carinaria genuigend besprochen, in deren Schilderung ich mich KALIDE anschliesse. Anders verhält es sich freilich mit den Ringmuskeln. Ich fand solche als einen kräftigen Sphincter um der Mundöffnung herum ausgebildet, die Längsmuskeln bedeckend, und sich noch eine kleine Strecke nach hinten fortsetzend. Die circulären Muskelbänder, von KALIDE ausdrücklich beschrieben und abgebildet, und nach ihm den ganzen Körper in regelmässigen Abständen, wie die Reifen ein Fass, umspannend, habe ich aber, trotz aller Bemühung, an ausgezeichnet erhaltenen Exemplaren von Carinaria, nicht auffinden können. Sie wurden übrigens weder von Leuckart noch von Gegexbaur erwähnt. Eine merkwürdige Quermusculatur besteht im Schwanze. Hier spannen sich zwischen den Längsmuskeln diagonal sich kreuzende Muskelfasern ${ }^{2}$ ) aus (Fig. 33). Nach der Spitze des Schwanzes bleiben nur die Muskelchen, welche die Richtung von oben schräg nach unten und nach hinten innehalten, bewahrt, stehen hier aber meist senkrecht; auf der Horizontalausbreitung an der

I) Es ist an dieser Stelle, dass die Muskeln einzelne Fasern hineintreten lassen in die vor den . Iugen an ihrer medianen Seite gelagerten Tentakel. Es konnte diese Muskulatur von KALIDE nicht untersucht werden.

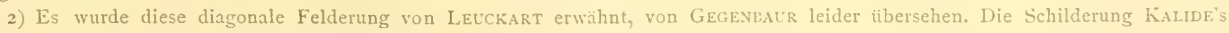
ist mir in dieser Hinsicht nicht deutlich; nach ihm sollen einzelne Querfasern auftreten, welche nach hinten zu sich verdicken und zu Bändern werden. 
Unterseite des Schwanzes von Carinaria sind sie in besonderer Zahl vorhanden. Der hier erwähnte Becher, wie er im ersten Abschnitt besprochen, früher auch von GEGENBAUR und KaLide beschrieben wurde, erhält iibrigens auch einzelne Streifen der an der Unterseite des Schwanzes nach hinten ziehenden Muskelbänder.

Sehr bemerkenswert ist der Umstand, dass die aus dem Nucleusstiele hinabsteigenden Muskeln, sich nur in die Flosse hinein fortsetzen, deren ganze Musculatur sie ausmachen. Diese ist also ein Derivat des Spindelmuskels und ist von der Körpermusculatur streng geschieden, eine Tatsache die auch von KaLide mit Frucht verwertet wurde zur Stitze seiner Behauptung, die Heteropoden-Flosse sei ein Organ sui generis und habe mit dem Kriechfuss der Gastropoden nichts zu schaffen. Ich kann darauf aber hier nicht näher eingehen ${ }^{1}$ ).

Der Penis ist an der rechten Seite des Körpers gelegen, unterhalb des Nucleusstieles; wie schon von Mitne Edwards, delle Chiaje und namentlich Gegenbaur, hervorgehoben wurde, besteht sie aus zwei Teilen, welche frei hervorragen, von einem gemeinschaftlichen Stamme. Dorsal findet sich der eigentliche Begattungsapparat (Fig. 34), der an der Oberseite eine Samenrinne zeigt, die Fortsetzung der beinahe geschlossenen Furche, welche aus dem Hoden herauskommend an der rechten Seite des Nucleusstieles und dann auf den Körper sich fortsetzt; in ihrer Nähe ist die gallertige Bindesubstanz beträchtlich verdünnt und zu einer diinnen Bekleidung reduzirt, welche der Körpermusculatur aufliegt. Die Furche $(S f)$ setzt sich also auf den Penis in die Samenrinne fort, die auf ihrem Boden einen Längswulst besitzt. Die Rinne ist an den Wänden rot-violett pigmentirt und zeigt hier Längsfalten; am Ende teilt sie den knopfförmig rerdickten Kopf des Penis in zwei Hälften. Der untere Abschnitt des Begattungsapparates ist länger, meist etwas gekrümmt, schwillt erst langsam an, um dann wieder dünner zu werden $(H a)$ und am Ende wieder knopfförmig anzuschwellen. Hier ist eine kleine Öffnung, welche in einen Blindsack hineinführt, dessen Wandungen von grossen Follikelzellen gebildet werden; diese scheiden ein klebriges Sekret ab, das durch die Öffnung am Ende des Organes nach aussen entleert wird. Die Ränder dieser Öffnung fand ich leicht umgestuilpt. Das schlauchförmige Organ ist mit grosser Wahrscheinlichkeit, mit GEgexbaur, als ein Haftapparat zu bezeichnen, der bei der Copulation der Geschlechter mit in die weiblichen Genitalien hineingeführt wird.

Der Schlundkopf bei Carinaria ist sehr umfangreich und wird, wie erwähnt, aussen durch einen kräftigen Sphincter, wenigstens an den Lippen, umgeben, während unterhalb desselben die Längsmuskelbänder anfangen, welche sich teils zwischen den Augen hindurch nach hinten richten, teils, wie die lateralen und ventralen Muskeln, namentlich schräg nach oben und nach hinten aufsteigen. Die eigentliche Schlundkopfmusculatur ist von den Längsmuskeln bedeckt. Die Mundhöhle selbst ist sehr geräumig und ganz von einem schwarz-violetten Pigmentepithel ausgekleidet. Am Dache der Mundhöhle findet sich eine tiefe Furche, welche sich nach aussen zu allmählich erweitert. Eine derartige Bildung kommt auch bei Pterotrachea vor, trägt aber hier kleine Zähne auf dem Rande, was bei Carinaria nicht der Fall ist; denn hier ist die Radula die einzige Bewaffnung in der Mundhöhle; Kiefer kommen hier also ebenso wenig vor wie bei den Atlantiden. Der Zungenknorpel ist sehr gross, die Form sowie der Bau dieser Stücke wurde schon von 
Troschel beschrieben. Die Radula auf deren Schilderung ich hicr nicht näher eingehe, ist zwar gut entwickelt, die Zahl der Querreihen ist aber bei weitem nicht so gross wie bei den Atlantiden. Es sind deren etwa 40 vorhanden.

Carinaria besitzt nur ein einziges Paar Speicheldrüsen, von cylindrischer Gestalt, am Hinterende immer ein wenig nach unten gebogen, vorn sich verdiinnend und mit einem kurzem Ausfiihrungsgang in die Mundhöhle, und zwar dorso-lateral, cinmündend. In gleicher Ausbildung kommen diese Speicheldrüsen bei Pterotracheiden vor; sie sind mit dem hinteren Paar bei den Atlantiden homolog, obwohl sie hier dicker sind und einen längeren, scharf vom Drüscnkörper gesonderten Ausfuihrungsgang aufweisen.

Die vorstehende Beschreibung bezieht sich ausschliesslich auf Carinaria lamarcki des Mittelmeeres. Wenn vieles nur fragmentarisch erscheint, so will ich bemerken, dass ich nur dasjenige erwähnt habe, was mir für C. lamarcki von systematischem Wert erschien, also dasjenige was dieser Art eigentümlich ist; wie wir gleich sehen werden, können die obigen Bemerkungen bei Besprechung der Formen der Siboga-Expedition ihren Nutzen haben.

Was von der Siboga gesammelt wurde, bestand fast nur aus Fragmenten: zerbrochenen Schalen, zerrissenen Schwanzstücken, oder verstümmelten Tieren. Trotzdem bietet die Untersuchung zahlreiche Aufschliusse, die eine deutliche Begrenzung verschiedener Arten ermöglichen. Es wurde die früher so hoch geschätzte $C$. cristata wiedergefunden, und zwar in Schalen ebenso wie in Tieren selbst, ausserdem die kleinere C. galca, und eine neue, ganz kleine Art, die allerdings nur durch ein einziges Exemplar vertreten war.

Carinaria cristata (Linné). (Taf. IX, Fig. 35-42. Taf. X, Fig. 43).

Leere Schalen:

Stat. 208. $5^{\circ} 39^{\prime}$ S.. $122^{\circ} 12^{\prime}$ O. I Ex.

Stat. $210^{\prime 2} .5^{\circ} 26^{\prime} \quad S^{\prime}, 121^{\circ} I^{\prime} \quad$ O. 1 Ex.

Tiere, ohne Schalen:

Stat. $227.44^{\circ} 50^{\prime} .5$ S., $127^{\circ} 59^{\prime}$ O. I Ex.

Stat. $266.5^{\circ} 56^{\prime} .5$ S., $132^{\circ} 47^{\prime} .7$ O. I Ex.

Stat. 27 I. $5^{\circ} 46^{\prime} .7$ S., $134^{\circ} \mathrm{O}^{\prime}$ O. I Ex.

Stat. $298.10^{\prime} 50^{\prime} .5$ S., $123^{\circ} 160$ O. I Ex.

Ich fange mit der Beschreibung der Schale an.

Das Exemplar von Stat. 208 war $45 \mathrm{~mm}$. hoch, an der Basis $52 \mathrm{~mm}$. breit, (in sagittaler Richtung). Die Spitze war leider abgebrochen und der Kiel nur in Resten vorhanden.

Das zweite Exemplar von Stat. $2 \mathrm{IO}^{\mathrm{a}}$ war $32 \mathrm{~mm}$. hoch, und die sagittale Breite an der Basis betrug $35 \mathrm{~mm}$. Die Schale war gut erhalten (Fig. 39), nur der Mundrand zeigte sich zerstuickelt, und auch hier war der Kiel nicht ganz intact erhalten.

Es fand sich. im Leydener Museum eine grosse Schale, zu dieser Art gehörig; von Dr. Horst wurde mir eine nach diesem Exemplare angefertigte Photographie freundlichst geschickt, und in Fig. 38 wiedergegeben. Die Breite an der Basis betrug $70 \mathrm{~mm}$; da die Spitze abgebrochen war, konnte als grösste Höhe nur $55 \mathrm{~mm}$. gemessen werden. 
Wie man aus den Abbildungen (Fig. 3 $8-40$ ) ersieht (siehe auch Taf. II, Fig. $52 a$, $53-54)$, ist die Schale hoch aufgerichtet, und zeigt sich dadurch scharf von der von C. lamarcki unterschieden. Die vordere Kante ist oben schwach convex, die Hinterseite etwas concav, nach unten aber ist die Schale vorn fast gerade und langgestreckt, weshalb auch die Mundöffnung, allmählich schmaler werdend sich weit nach vorn erstreckt. Das Gehäuse ist, wie überall bei Carinaria, mit deutlichen Querrippen versehen, welche oben, an der Spitze, sehr wenig tief sind, nach unten aber allmählich an Tiefe zunehmen, einen etwas welligen Lauf haben, und weiter auseinander liegen (in Fig. 38 scheint die Zahl der Querrippen, infolge von Lichtreflexen, höher als deren in Wirklichkeit vorhanden sind). Auf dem Kiele finden sich ebenfalls, besonders an der Basis, kurze, regelmässig einander folgende Querrippen, die einen schrägen Verlauf haben, und mit denen der Schale einen Winkel von etwa $60^{\circ}$ bilden.

Die Schale ist an der oberen Spitze leicht nach hinten gebogen, und hier setzt sich die sehr kleine, zarte Spira an, von der Schale selbst scharf geschieden. Die Spira ist ohne jegliche Zeichnung, besteht aus 4 Umgängen, die sämtlich fast in einer Ebene aufgerollt sind, und diese Ebene fällt mit der Symmetrie-Ebene der Schale zusammen. An der Unterseite der Spira, also von links betrachtet, ist ein deutlicher Nabel sichtbar. Dort wo die Spira sich an der Schale anhängt, ist wie gesagt die letztere scharf geschieden, und zwar nicht nur dadurch, dass die Rippen, wenn auch ganz undeutlich, hier schon anfangen, sondern auch durch einen deutlichen Übergang auf die hier scharf gebogene Oberseite der Schale. An dieser Oberseite, welche sich nach unten zu in die Vorderkante umwandelt, erhebt sich, eine gewisse Strecke weiter, der Kiel, der, erst niedrig, nach unten zu höher wird; nach dem Exemplar von Stat. $2 \mathrm{IO}^{\mathrm{a}}$ zu urteilen (Fig. 39), wo der Kiel fast nicht zerbröckelt ist, erreicht er keine beträchtliche Höhe.

Sämtliche Schalen zeigen am meisten Ähnlichkeit mit der Varietät gracilis (siehe den ersten Abschnitt); die Unterschiede mit der Hauptform sind aber unbedeutend.

Wenn ich jetzt zur Beschreibung des Tieres schreite, so muss ich eine kurze Bemerkung vorangehen lassen. Die oben beschriebenen Schalen gehören zwar gewiss zu C. cristata, da aber Tiere mitsammt Schale auf der Expedition nicht gefangen wurden, vielmehr mir nur Fragmente vorlagen, so konnte ich nur durch einen gliicklichen Zufall die Zusammengehörigkeit von Schale und Tier ermitteln; denn das Tier von C. cristata war, abgesehen von einer kurzen Angabe Sirth's (Taf. II, Fig. 52) gänzlich unbekannt. Es wurde mir nämlich von Prof. Weber freundlichst eine alte Abbildung zur Hand gestellt, welche hier Taf. IX, Fig. 37 reproduzirt ist, und, laut der sich darauf beziehenden schriftlichen Erörterung ${ }^{1}$ ), nach einem lebenden Tiere von "C. vitrea" in den naturlichen Farben angefertigt wurde. Diese Farben scheinen zwar etwas phantastisch, von grossem Nutzen war mir die Abbildung aber deshalb, weil ich mit der Schale,

I) Die Handschrift lautete, in's Deutsche übersetzt, folgendermassen:

Ein Exemplar Carinaria vilrea oder der Mönchshut, mit dem Tiere, auf Liquor.

Diese Schale, in der Bai von Amboina gefunden, ist eine grosse Seltenheit, und es wird das Tier auf Liquor besonders dadurch für die Wissenschaft von hohem Interesse sein, weil es, so weit bekannt, in keiner der wissenschaftichen Arbeiten über Conchylien und Schalen beschrieben und abgebildet worden ist.

Eine Zeichnung des Tieres und der Schale, nach dem Leben, wird hierbei angeboten an die Königl. Zool. Gesellschaft Natura Artis Magistra zu Amsterdam, von D. S. Hoent, Secretär des Districtes der Molukken. Amboina, 26 Oktober 1860. 
auch das Tier in seinem Habitus kennen lernte, und ich so die Carinaria-Fragmente der Siboga als C. cristata bezeichnen konnte. Später wurde mir noch das Originalexemplar, das sich in Amsterdam fand, geschickt, und die nähere Untersuchung ergab eine Bestätigung meiner Vermutung.

Was nun die Exemplare der Siboga betrifft, so muss ich allererst das riesenhafte Tier erwảhnen (Taf. IX, Fig. 35) das auf Stat. 227 erbeutet wurde. Die ganze Länge betrug $+20 \mathrm{~mm}$. Der Eingeweidenucleus, mitsammt der Schale, war leider abgerissen, schon als das Tier pelagisch, an der Oberfläche, gefangen wurde. Weiter zwei Schwanzsticke von Stat. 27 I und Stat. 298. Das erste mass $130 \mathrm{~mm}$., und gehört sehr wahrscheinlich zu einem Tiere von etwa $400 \mathrm{~mm}$., die Länge des zweiten Fragmentes betrug $190 \mathrm{~mm}$., und das dazu gehörige Ticr schätze ich auf $500 \mathrm{~mm}$.

Die häufige Verstümmelung bei Carinaria war schon bekannt; sie scheint of die Tiere, bis zu gewissen Grenzen, nicht am Leben zu hindern, wenn auch ein Tier, dem der Eingeweidenucleus fehlt, wohl schwerlich lange sein Dasein fristen kann. Der abgerissene Kopf von Stat. 266, dessen Länge $70 \mathrm{~mm}$. betrug, übertrifft aber alles, was man sich von der Zählebigkeit dieser Tiere vorstellen kann. Diesem Kopfe, oder vielmehr diesen Fragmente, (Taf. IX, Fig. 36) fehlte der vordere Teil, also die vordere Hälfte des Rüssels, ebenso war der ganze Körper etwa auf halber Höhe des Rumpfes abgetrennt worden. Doch zeigte das aufgefischte Überbleibsel des Tieres nirgends eine Öffnung. Vorn war die ganze Buccalmasse verschwunden aber nicht nur die Muskelschicht des Körpers, sondern auch die darauf gelagerte Gallertbekleidung, hatte die vordere Verwundung continuirlich abgeschlossen. Distal setzte sich die Cutis einfach in eine nach vorn und ventral eingekrümmte Spitze fort, und die Körpermusculatur setzte sich als ein geschlossener Sack, am Ende spitz auslaufend, eine Strecke weit darin forț. Das Tier bestand also: aussen aus der beträchtlichen Gallertmasse, allseitig geschlossen, dann aus der Körpermuskelschicht, ebenfalls eine zusammenhängende Wandung darstellend. Im Innern fanden sich gar keine Organe der Verdauung, der Darm war ganz verschwunden; nur waren noch die Augen sichtbar, mit Tentakeln, und die zwischen den Augen gelagerten, kleinen Cerebralganglien, mit abgerissenen Connectiven.

Es fragt sich nun, wie ein solches Tier hätte leben können, dem alle Gemeinschaft mit der Aussenwelt abgeschlossen ist, und dem auch der Darmkanal fehlt! Und trotzdem muss das Tier nach der starken Verletzung, welche es zerriss, doch einige Zeit gelebt haben, um die oben beschriebenen, höchst eigenartigen Verhältnisse ausbilden zu können!

Wenden wir uns jetzt zu der Betrachtung des grossen Exemplares von Stat, 227 (Taf. IX, Fig. 35), so können wir den allgemeinen Habitus folgendermassen beschreiben: Kopf stumpf, vorn wie abgestutzt, durch eine Einschnürung vor den Augen vom Rumpfe getrennt. Rumpf sehr dick, nach hinten noch etwas an Grösse zunehmend, dann an der Rückenseite niedriger werdend. Am Ende des Rumpfes, gerade der Flosse gegenüber, setzt sich der Nucleusstiel an. Da der Nucleus samt dem Stiele abgerissen war, kann ich weiter darüber nichts sagen ${ }^{1}$ ). Die Flosse ist sehr gross, rundlich, mit kräftigen Muskeln; ein grosser Saugnapf findet sich am Hinterrande. Der Körperteil zwischen Nucleus und Flosse ist seitlich zusammengedrückt, und dieses Verhalten

1) Nrch der Form der Schale wäre der Nucleus hoch aufger:chtet, ziemlich umfangreich, an der Spitze leicht umgebogen. 
geht auch auf den Schwanz über. Gleich hinter der Ansatzstelle des Nucleus steigt die dorsale Kante des Schwanzes ziemlich steil empor, um dann, nach einem Höhepunkt, der etwa auf gleichem Niveau mit der Höhe des Rumpfes liegt, in sanft gebogener Linie nach hinten auszulaufen. Der Durchschnitt des Schwanzes ist vorn dreieckig; der dorsale Teil ist zwar dünn, geht aber ohne Übergang in die Flanken des Schwanzes über, und es kommt hier nicht zu einer scharfen Trennung einer Rückenflosse vom Schwanze, wie bei C. lamarcki. Der Schwanz wird, nach hinten zu, allmählich niedriger, und behält dann die gleiche Höhe bei; der Querschnitt ist hier ein fast gleichseitiges Dreieck, am Ende fast rund.

Wenn die Schilderung der allgemeinen Leibesform in vieler Hinsicht einen deutlichen Unterschied von C. lamarcki ermöglicht, so weisen auch die Einzelheiten des Körpers manche Abweichungen auf.

Es finden sich iberall kleine Höcker, kleiner als bei C. lamarcki; sie sind namentlich an der Dorsalseite häufig, vereinzelt kommen sie an den Flanken vor, sind aber auf dem Schwanze zahlreicher, an der Unterseite sieht man sie fast gar nicht. Wenn man die Höcker mit starker Vergrösserung betrachtet, zeigt sich das Folgende (Taf. IX, Fig. 38). Wie überall, deckt den Körper ein einschichtiges Plattenepithel von kleinen, polygonalen Zellen, die an der Oberfläche der Höcker selbst ein wenig dicker und mehrschichtig erscheinen. Hier finden sich, unterhalb der Epithelschicht, eigentümliche sehr grosse, bräunliche Protoplasma-Schollen, welche einen helleren Kern durchscheinen lassen, und in einer mehr durchsichtigen Grundsubstanz eingebettet sind. Sie haben meist abgerundete Gestalt, oft liegen deren zwei aneinander, als ob sie aus einer Zelle durch Teilung hervorgegangen wären. $\mathrm{Ob}$ es sich hier um Knorpelzellen handelt, vermag ich nicht zu sagen. Weiter kann ich erwähnen, dass man, unterhalb des oberflächlichen Epithels, stark verästelte, dann und wann örtlich verdickte Fäden (Nerven) wahrnehmen kann, von denen einer immer in den Höcker eintritt. Eine mehr eingehende Untersuchung habe ich nicht vornehmen können. Unterhalb des Epithels lassen sich überall die Formelemente der Gallertmasse erkennen: mehrfach verästelte, oft spindelförmig gestaltete Zellen, welche mittels ihrer Ausläufer in Verbindung treten; in der Nähe der Höcker sah ich aber auch andersartige, rundliche Gebilde (Fig. $3 \delta, a$ ), Bläschen mit dunkleren Körpern im Innern, von rätselhafter Bedeutung. Ob sie durch Conservierung entstandene Kunstproducte oder irgendwie degenerirte Zellen, oder vielleicht auch einzellige Hautdruisen darstellen, weiss ich leider nicht ${ }^{1}$ ); einen Ausführungsgang habe ich jedenfalls nicht wahrnehmen können.

Wenn auch das hier Gesagte einen fragmentarischen Character trägt, so geht doch so viel daraus hervor, um es noch einmal hervorzuheben: dass die Höcker beträchtlich kleiner sind als bei C. lamarcki und zahlreich nur an der Rückenseite des Tieres sich finden. Auch haben sie eine andere Gestalt; sind namentlich nicht kegelförmig (siehe Taf. IX, Fig. 3I), sondern erheben sich auf dem Körper als rundliche Hervorwölbungen. Die Anhäufungen kleiner Zellen, wie sie bei C. lamarcki in Form grosser Tüpfel auftreten, sah ich bei C. cristata gar nicht. Noch ein anderer Unterschied ist erwähnenswert. Das Pigment kommt bei C. cristata nämlich nicht in der gallertigen Bindesubstanz vor, sondern zerteilt sich in grosser Masse im

1) Am wahrscheinlichsten sind sie Knorpelelemente, von ähnlicher Natur wie die oben erwähnten bräunlichen Zellen im Innern der Höcker. 
Plattenepithel der Haut, und zwar nur auf dem Schwanze, nicht am iibrigen Körper. Der Schwanz ist (Fig. 35) an der Dorsalseite dunkelbraun, fast schwarz; diese Farbe setzt sich etwas abgeschwächt, in mehreren hintereinander gelegenen, fingerförmigen Fortsätzen, welche schräg nach unten und nach vorn gerichtet sind, fort; nach hinten zu wird der allmählich niedriger werdende Schwanz ganz durch die dunkelbraune Farbe eingenommen. Da das Flächenepithel leicht abgerissen wird, so erklärt es sich, dass die Schwanzstücke von Stat. 27 I und 298 fast farblos sind und eine durchsichtige, hyaline Beschaffenheit aufweisen.

Da, wie gesagt, die Höcker dorsal ibberaus zahlreich sind, so kommen sie auf dem Schwanze, innerhalb des Gebietes von Pigment, häufig vor. Dass die winzigen Höcker sich aber gerade hier scharf von der Umgebung abheben, ist dem Umstand zu verdanken, dass eine kreisförmige Stelle um den Höcker herum pigmentfrei und also hell bleibt. Innerhalb dieses Kreises, gerade in der Mitte, zeigt sich der Höcker dadurch besonders deutlich, class er selbst wieder, der bräunlichen Masse wegen in dem Innern, dunkler erscheint. Die Höcker auf dem R.umpfe zeigen nur in einigen Fällen diese braune Anhäufung, meistens sind sie ganz farblos, und sind deshalb nur dann gut zu sehen (wie bei so vielen durchsichigen, pelagischen Tieren), wenn man den entsprechenden Körperteil aus der Flüssigkeit heraushebt.

Die Musculatur von C. cristata stimmt in ihren Lagerungsverhältnissen in den Hauptpunkten mit der von C. lamarcki überein, nur sind einige geringfügige Unterschiede zu erwähnen. Jenachdem die Muskeln im Rüssel, wo sie die Längsrichtung mehr oder weniger innehalten, entweder dorsal oder seitlich und ventral gelagert sind, ändern sie nach hinten zu ihren Lauf. Die dorsalen lassen ein breites Feld zu beiden Seiten der Rückenlinie des Rüssels frei, behalten aber, anders wie bei C. lamarcki, die gleiche Entfernung zwischen linken und rechten Muskeln, zwischen den Augen, und noch eine gewisse Strecke weiter rückwärts; hinter den Augen geben sie von Abstand zu Abstand ziemlich schmale, nur wenig miteinander in Verbindung tretende Muskelbänder $\mathrm{ab}$, welche schräg nach unten hinabsteigen. Die seitlichen und ventralen Muskeln aber steigen in Rumpfe in Gestalt breiter, vielfach anastomosirender Streifen, unterhalb der von oben kommenden Muskelschicht, schwach empor. Auf der Höhe des Nucleusstieles vereinigen sich die beiden Schichten; im Schwanze läuft die Musculatur, in einige sich distal zuspitzende Bänder aus, von denen der obere Streifen einzelne Verzweigungen in den dïnnen, dorsalen Teil des Schwanzes abgiebt; diese Verästelungen richten sich distal immer mehr nach hinten. Das Ende des Schwanzes ist nicht seitlich comprimirt, sondern fast rundlich und jegliche Andeutung eines Schwanzfadens oder einer membranösen Ausbreitung der Flanken fehlt durchaus. Eine Ringmusculatur kommt im Rüssel vor und bildet hier einen kräftigen, unmittelbar der Buccalmasse aufgelagerten Sphincter; weiter zeigen sich im Schwanze einige querverlaufende Muskelfasern (Fig. 39), welche die Längsmusculatur kreuzen und hauptsächlich in der Richtung von oben nach unten und nach hinten gehen, wenn auch einzelne Verzweigungen gerade einen entgegengesetzten Verlauf haben und, wie aus der Abbildung ersichtlich, mehrfache Anastomosen mit den erstgenannten Muskeln bilden. Man sieht diese Quermuskeln, wenn auch von oben betrachtet, von den longitudinalen Muskeln bedeckt, deutlich unterhalb dieser ihren Weg nehmen (die dunklen Stellen in der Abbildung rühren von Faltungen her).

Die Flossenmuskeln stehen mit denen im Innern des Nucleusstieles in directer Verbindung; 
ebensowenig wie bei $C$. lamarcki ist ein directer Zusammenhang mit der Körpermusculatur nachzuweisen, und das Ganze weist von dem schon von KALIDE dargestellten Verhältniss bei der uns als Vorbild dienenden Art des Mittelmeeres keine besondere Abweichungen auf.

$\mathrm{Da}$ das Exemplar von Stat. 227 weiblich war, habe ich hier keinen Penis untersuchen können, das von Amboina stammende Tier, in Fig. 37 dargestellt, war zwar ein Männchen, die Erhaltung war aber sehr schlecht, und die genaue Form des Penis konnte ich nicht ermitteln. Im Allgemeinen lässt sich sagen, dass hier das nämliche wie bei C. lamarcki vorkommt, das männliche Begattungsorgan ist aber verhältnissmässig kleiner und besteht aus zwei Teilen; der obere ist der eigentliche Penis, mit einer Samenrinne versehen und am Ende ein wenig angeschwollen; der andere Teil ist der bei der Begattung dienende Haftapparat, dessen druisenartig ausgebildeter Endabschnitt etwas dünner ist als die Wurzel des Organes, jedoch ohne Anschwellung, wie bei C. lamarcki; die Follikelzellen selbst schimmern schwärzlich hindurch.

Die Buccalmasse ist sehr umfangreich und zeigt die allgemeinen Charactere von Carinaria, nicht nur in den Speicheldrüsen und den Muskeln, welche zur Bewegung des Schlundkopfes dienen, sondern auch in der Furche am Dache der Mundhöhle. Auch die Radula entspricht, wenigstens in der allgemeinen Gestalt, der von C. lamarcki. Sie hatte bei dem Exemplar von Stat. 227 (420 mm. lang) eine Länge von $45 \mathrm{~mm}$., während die Breite in den unteren Reihen $20 \mathrm{~mm}$. betrug (Taf. X, Fig. 43); sie nimmt von vorn nach hinten allmählich an Grösse zu, um im letzten Drittel dieselbe Breite beizubehalten. Im Ganzen zählte ich 47 Transversalreihen. Die Mittelplatte (Fig. 43a) ist lang und schmal, leicht durchgebogen und trägt drei Dornen von annähernd gleicher Länge, ihr Basis ist breiter, und die Dornen selbst sind kürzer als bei C. lamarcki. Im Allgemeinen ist die mediane Seite der Seitendornen kürzer als die laterale; in den ersten Querreihen aber sind diese Seiten gleich. Die Zwischenplatte besitzt eine kräftige Spitze (Fig. 43b), welche nach unten, d. h. nach der Radulamembran hingebogen ist, also mit dem Körper der Platte nicht in derselben Ebene liegt. Ein Kamm ist auch hier vorhanden; er fängt oben (Fig. $43 b, a$ ) mit einem kleinen Höcker an, nach unten zu ist er durch einen deutlichen Dorn (b) von der Spitze der Platte geschieden. So verhält es sich in den meisten Querreihen der Reibplatte, nach vorn aber (Fig. 43c) ist die Zwischenplatte, und namentlich der Kamm, andersartig gestaltet, die beiden Stellen $a$ und $b$ sind hier weniger scharf ausgeprägt. Die Seitenplatten endlich sind beide ebenso gross wie die von ihnen überlagerte Zwischenplatte; sie sind stark gebogen, aber nur etwa in der Mitte ihrer Länge. Erwähnenswert ist weiter noch, dass die verschiedenen Platten, jenachdem sie an einzelnen Stellen mehr oder weniger dick sind, eine dunklere oder hellere Farbe aufweisen. Die Basis ist iberall schwarz, ausgenommen in der Mittelplatte; wie ubrigens diese Farbe in horngelb übergeht und schliesslich verschwindet, ist in den Abbildungen (Taf. X, Fig. $43 a-d$ ) durch verschiedene Schattierungen angegeben worden. Die Dornen der Mittelplatte sind sehr dünn und deshalb farblos. Dasselbe kommt allerdings bei $C$. lamarcki vor.

Was nun die Verbreitung von C. cristata betrifft, so zeigt sich, dass sie in der Banda-See, aus der sie auch schon früher bekannt war $^{1}$ ), von der Siboga-Expedition, wenn auch ziemlich 
vereinzelt, gefunden wurde. Sumtu erwähnt sie von den Aru-Inseln. Dass sie aber iber weitere Strecken ihr Gebiet ausgedehnt hat, diurfte eine Angabe Cruv's in der Beschreibung der Reise der Valdivia ${ }^{1}$ ) erweisen, während welcher Expedition ein Riesenexemplar von Carinaria bei Ceylon gefangen wurde, das eine Länge von $530 \mathrm{~mm}$. erreichte; wahrscheinlich wird sich das Tier als $C$. cristata herausstellen, und damit das grösste bekannte Exemplar dieser Art sein.

Carinaria galea Benson. (Taf. X, Fig. 44-45).

Leere Schalen:

Stat. 211.540 .7 . ., $120^{3} 45.5(1) 2 \mathrm{Ex}$

Stat. 22 I. $6^{\circ} 24^{\prime}$ S., $124^{\circ} 39^{\prime}$ O. I Ex.

Es wurden von dieser Art nur leere Schalen gefunden, leider alle mehr oder weniger zerbrochen. Die erste Schale von Stat. 2 I I mass an der Basis $61 / 2 \mathrm{~mm}$, die Höhe war $12 \mathrm{~mm}$, der Kiel war $2^{1 / 2} \mathrm{~mm}$. breit. Bei der zweiten Schale derselben Station waren die Dimensionen resp. $9 \%$, I I und $2 \mathrm{~mm}$. Da das erste Exemplar im Allgemeinen besser erhalten war, und namentlich der Kiel offenbar nur wenig gelitten hatte, auch die Spira keine Schädigung zeigte, ist nur diese Schale abgebildet worden (Fig. 44-45).

Das Exemplar von Stat. 22 I zeigte resp. die Dimensionen: 9, 10 und I mm.

Selbstverständlich haben diese Messungen nur deshalb relativen Wert, weil sie an verstümmelten Exemplaren vorgenommen wurden.

Wie Fig. 44 zeigt, ist die Schale hoch aufgerichtet, an der Spitze leicht nach hinten gebogen, wo die kleine, zierliche Spira aufgehängt ist. Dieselbe besteht aus 4 Windungen (Fig. 45) und besitzt keine Skulptur, nur auf dem vorletzten Umgange, sowie um dem Nabel herum, verlaufen einige deutliche Querstreifen. Da wo die Spira in die Schale übergeht, ist die Übergangsstelle ganz deutlich sichtbar durch eine plötzliche Erhöhung der dorsalen Kante (Fig. 45, a); auch fangen auf der Schale, erst noch unscheinbar, nach unten zu deutlicher, die Querrippen an, welche, ebenso wie bei der vorhergehenden Art, sanft gewellt sind und mit den deutlichen Querstreifen auf dem auffallend breiten Kiele, nicht in gleicher Richtung verlaufen.

Man möchte, bei erster Betrachtung, geneigt sein, die Unterschiede der hier besprochenen Art mit C. cristata nur darauf zurückzuführen, dass die Schale, wie sie in Fig. 44 dargestellt wurde, als das abgebrochene obere Fragment einer cristata-Schale aufzufassen sei. Dem ist aber nicht so, wenn auch die Ähnlichkeit beider Arten sehr gross ist. Während bei C. cristata die Spira in derselben Ebene wie die Symmetrie-Ebene der Schale liegt, ist die Spira bei C. galea, stark nach links gebogen, weshalb das ganze Gehäuse eine merkwürdige Asymmetrie zeigt. Erwähnenswert ist weiter noch, dass bei letzterer Art der Kiel nicht nur viel höher ist, sondern auch ganz oben an der Vorderseite anfängt (Fig. 45), während die zackigen Vorsprünge des Kieles bei $C$. cristata erst viel weiter nach unten beobachtet werden. Der Kiel besteht übrigens, wie überall bei Carinaria, aus zwei feinen Lamellen; ist also doppeltblättrig.

Das Tier von C. galea habe ich zwar nicht zu sehen bekommen, aus den Beschreibungen

I) Ans den Tiefen des Weltmeeres. Erste Auflage, S. 302 . 
Bexsoy's, Souleyet's und Macdonald's (siehe den ersten Abschnitt, auch unter dem Namen C. gaudichaudi) geht aber hervor dass keine Tuberkeln vorkommen und die. Haut überall mit rundichen Flecken überdeckt ist. Die Flosse besitzt eine abgerundete Gestalt.

Die kleine Art, die eine Länge von $40 \mathrm{~mm}$. wohl kaum erreichen wird, tritt nur ganz vereinzelt im ost-indischen Gebiete auf.

Carinaria macrorhynchus n. sp. (Taf. X, Fig. 46-5I).

Stat. 203. $3^{\circ} 32^{\prime} \cdot 5$ S., $124^{\circ} 15^{\prime} \cdot 5$ O. I Ex.

Diese kleine Art besitzt in ihrer ganzen Gestalt soviel Eigentümliches, dass sie von mir als neue Form aufgefasst wird.

Die Schale hat eine Höhe von $3^{1} / 2 \mathrm{~mm}$. und zeigt schwach angedeutete Querrippen, welche sich in derselben Richtung auf den Kiel fortsetzen. Dieser ist ziemlich hoch und zeichnet sich, wie aus Fig. 47 u. 48 ersichtlich, besonders dadurch aus, dass er nicht mit kleinen Erhebungen, wie sonst bei Carinaria, anfängt, sondern an der Stelle, wo die Spira sich an die Schale ansetzt, sich geradezu plötzlich, sogar mit scharf zurückgebogener Firste erhebt, und dann, annähernd die gleiche Höhe beibehaltend bis zur Mundöffnung verläuft, um hier mit abgerundeter Kante zu enden. Die Schale ist ganz gerade, Vorder- und Hinterseite also ohne jegliche Krümmung. Die Spira, welche im Verhältniss zur Schale ziemlich umfangreich ist, setzt sich oben an; der Übergang in die Schale ist auch hier scharf ausgeprägt. Man findet (Fig. 47,48) $3^{1 / 2}$ Umgänge, und die Ebene in welcher sie sämtlich aufgerollt sind, kommt mit der Symmetrie-Ebene der Schale ubberein. Eine Sutur ist tief eingeschnitten. Von unten gesehen ist ein deutlicher Nabel sichtbar, von welchem einige Querlinien ausgehen.

Das ganze farblose, ausserordentlich zarte Gehäuse zeigt einige Ähnlichkeit mit der Schále von C. cithara (Taf. II, Fig. 64). Auch hier ist die Schale ganz gerade, ohne irgendwelche Krimmung der beiden Seiten, und die Spira ist oben aufgesetzt. Erstens aber ist die Spira hier verhältnissmässig kleiner, und zweitens ist die Mundöffnung schräg abgestutzt, sodass die Vorderseite der Hinterseite an Länge nachsteht, während etwas derartiges bei C. macrorhynchus nicht vorkommt.

Wenn ich jetzt zur Beschreibung des Tieres übergehe, so fällt zunächst die ausserordentlich starke Entwicklung des Rüssels auf. Während das ganze Tier I I mm. misst, kommen davon etwas mehr als $4 \mathrm{~mm}$. auf den Rüssel. Die Augen erreichen ebenfalls eine beträchtliche Grösse. Hinter ihnen setzt sich die cylindrische Gestalt des Rumpfes ziemlich gleichmässig bis zum Nucleus fort. Der Eingeweidesack ist natürlich ganz in der Schale eingeschlossen, lässt aber nach vorn zu Platz für die Mantelhöhle mit den dazu gehörigen Organen. Vom Mantelrande hängen fünf oder sechs kleine Kiemen herab. Der ganze Nucleus wird auf kurzem Stiele getragen, diesem gegenüber findet sich die grosse viereckige Flosse; die Vorderecke ist abgerundet, die hintere aber deutlich ausgeprägt. Der Unterrand richtet sich von vorn nach hinten stark nach oben und trägt in der Mitte einen deutlichen Saugnapf. Der Schwanz endlich ist sehr kurz und entbehrt vollkommen der Anhänge; er ist stark seitlich comprimirt und spitzt sich am Ende scharf zu. 
Nach dieser kurzen Beschreibung der allgemeinen Leibesform, kann noch das Folgende hinzugefügt werden. Zunächst ist bemerkenswert, dass die gallertige Cutis, welche oft bei Carinaria zu beträchtlicher Entwickelung kommt, hier sehr diunn bleibt. Die Haut liegt auf dem Rüssel fast unmittelbar der Musculatur auf. Höcker oder sonstige Unebenheiten kommen gar nicht vor, wohl aber finden sich, überall auf dem ganzen Körper zerstreut, die kleinen rundlichen oder länglichen Flecken, welche in dieser Gattung oft beobachtet werden (Fig. 49). Sie liegen auch hier unterhalb der Haut in der Bindegewebsmasse, und man kann in dem optischen Querschnitt die zierlich verästelten Nervenzellen wahrnehmen, welche auch bei clen vorigen Arten gesehen wurden. Die Flecken finden sich, wie gesagt, auf dem ganzen Körper; auch am Ruissel sind sie, wenn auch ganz schwach, sichtbar. Der geringen Dicke der Cutis wegen, bedingt diese nicht, wie bei $C$. lamarcki und C. cristata die Körpergestalt, sondern das ganze Tier sieht schmächtig und schlank aus, und scheint dadurch einer rascheren Wendung fähig als die plumperen Arten. Der mächtige Rüssel und die grossen Augen weisen deutlich auf die räuberische Lebensweise hin.

Die Musculatur zeigt in so weit einen abweichenden Character, als hier keine Auflösung in einzelne, gesonderte Bänder stattfindet, sondern sämtliche Muskeln eine zusammenhängende Schicht bilden. Auf den Seiten des Rüssels ist schon der kreuzweise Verlauf der Muskeln sichtbar, und zwar unter Winkeln von fast $90^{\circ}$, während auf dem Rumpfe die Kreuzung der Muskeln (übrigens viel deutlicher sichtbar) unter scharfen Winkeln vor sich geht. Zu beiden Seiten der dorsalen Mittellinie verlaufen auf dem Rüssel starke longitudinale Muskeln; ein Mittelstreifen bleibt also frei, erweitert sich zwischen den Augen und hört dann bald auf. Erwähnenswert ist noch der Umstand, dass ich keine Spur des rechten Tentakels finden konnte, und ebenso wenig eine Verwundung, welche durch Zerreissung und Abtrennung des Organes entstanden wäre. Übrigens ist es mir mehrere Nale, auch bei der folgenden Gattung, aufgefallen, dass der rechte Tentakel erheblich kürzer ist als der andere; ob dies immer nur auf stärkere Zusammenziehung zurïckzuführen wäre, vermag ich nicht zu sagen. Auf der Höhe der Flosse geht die gekreuzte Musculatur in die Längsrichtung über und steigt einerseits am Nucleusstiele empor, andererseits zerfällt sie im Schwanze in einige sehr schwache Längsstreifen. Ringmuskeln habe ich nur am Rüssel beobachtet, und hier, abgesehen von der unmittelbaren Nähe der Mundöffnung, nur in isolirten, ganz kleinen Fibrillen, mit Ausnahme einer Stelle gerade vor den Augen, wo sie eine zusammenhängende Schicht darstellen. Die Muskeln der Flosse sind wie bei Carinaria überhaupt angeordnet, und auch hier treten sie in gesonderten Bändern auf. Die untere Schicht ist aber nur durch einige wenige, dafür wieder um so deutlichere, Streifen vertreten. Ein muskelfreier, membranöser Abschnitt am Unterrande kommt nicht vor. Die Flossenmuskeln durchsetzen die Körpermusculatur und treten, von dieser scharf getrennt, in den Eingeweidesack ein.

Das mir vorliegende Exemplar war ein Männchen, sodass ich auch den Penis untersuchen konnte. Dieser (Fig. 50) ist klein, und besteht aus den zwei üblichen Teilen: vorn ein kurzer, cylindrischer, hier stark zusammengezogener Abschnitt, der wohl als Haftapparat bei der Begattung aufzufassen wäre; und hinten der eigentliche Penis, auf welchem die rechts auf dem Nucleusstiele herabsteigende Samenfurche $(s f)$ sich als tiefe Rinne fortsetzt.

An der Buccalmasse fallen die zwei cylindrischen Speicheldrüsen auf. Innerhalb der geräu. migen Mundhöhle findet sich auch hier am Dache eine distal sich keilförmig zuspitzende Vertiefung. 
Die Radula (Fig. 5I) besteht aus 35 Querreihen und zeigt die gewöhnliche Ausbildung. Die nicht in der Mitte durchgebogene Mittelplatte besitzt drei Dornen, welche von ungleicher Länge sind. In allen Querreihen überragt nämlich der Mitteldorn die beiden seitlichen, von denen wieder der rechte um ein Geringes länger ist als der linke; die Spitzen dieser Dornen sind etwas nach aussen gerichtet. Der Kamm der Zwischenplatte ist sehr deutlich und schliesst nach der Spitze der langgestreckten Platte zu mit einem starken Dorne ab. Die beiden lateralen Platten endlich sind beide fast ebenso gross wie die Zwischenplatte; sie sind am Anfang gerade, dann aber stark gebogen. Im Unterschiede mit C. cristata ist die ganze Radula farblos.

Mit Rücksicht auf die Angaben W Wreomont's (Taf. III, Fig. 74) ist die Möglichkeit dass wir hier nur eine Jugendform irgendeiner Carinaria vor uns haben, nicht ausgeschlossen. Vorläufig aber muss die hier besprochene Form als neu betrachtet werden.

Die Länge des Tieres ist I I mm. (Rüssel $4^{1 / 3} \mathrm{~mm}$.), die Höhe der Schale $3^{1 / 2} \mathrm{~mm}$.

Da nur ein einziges Exemplar gefunden wurde, scheint die Art im ost-indischen Gebiete selten zu sein.

\section{Cardiapoda d'Orbigny 1836.}

Solche Formen wie die letztbeschriebene C. macror/nynchus leiten allmählich zu dem Typus Cardiapoda hinüber. Die Gallertschicht hat hier bedeutend abgenommen, das ganze Tier sieht also schlanker aus; der Stiel cles Nucleus hat sich verlängert, und die Ausbildung der bei Carinaria noch beträchtlichen Schale ist hier so weit zurückgeblieben, dass das kleine, spiralige Gehäuse nur einen sehr kleinen Teil des Eingeweidesackes bedeckt. Die Körpermusculatur ist nicht in Bänder aufgelöst, sondern stellt überall eine liuckenlose Schicht dar.

Wenn auch bezüglich der constanten Unterschiede, welche die hier besprochene Gattung Carinaria gegenüber besitzt, kein Zweifel bestehen, und somit eine Wiederholung der Diagnose unterbleiben kann, so sind wir doch, in Hinsicht auf die Anatomie von Cardiapoda, auf die älteren Angaben Souleyet's und D'Orbigny's beschränkt. Da von der Siboga-Expedition mehrere Exemplare von Cardiapoda erbeutet wurden und mir in trefflicher Erhaltung vorlagen, war allerdings die Verführung gross, eine mehr ausführliche Beschreibung zu geben. Eine eingehende anatomische Darstellung von Cardiapoda und der Heteropoden iberhaupt, mir an anderer Stelle vorbehaltend, ist es hier wohl am Platze, einige Angaben zu machen, welche ein ungefähres Bild der Gattung zu geben vermögen.

Die Musculatur des Körpers tritt, wie gesagt, nicht in isolirten Streifen auf. Auf dem starken, cylindrischen, annähernd überall die gleiche Dicke beibehaltenden Rüssel verlaufen die Muskeln der Hauptsache nach in der Längsrichtung, um sich erst in der Höhe der Augen, und dann weiter auf dem Rumpfe, in der bekannten Weise, wie bei Carinaria, zu kreuzen. Eine Einschniurung vor den Augen habe ich nirgends beobachtet. Die Rückenlinie des Rüssels bleibt muskelfrei, verengt sich nur sehr wenig zwischen den Augen und ist noch eine gewisse Strecke distal sichtbar. Am Ende des Rumpfes, also der Flosse und dem Nucleusstiele gegenüber, und an der Stelle wo (selbstverständlich nur beim Männchen) der Penis liegt, teilen sich die sich kreuzenden Körpermuskeln. Ein Teil behält den gleichen Lauf bei und setzt sich auf den Nucleusstiel, der somit nur als eine Verlängerung des Rumpfes erscheint, fort; der andere 
Teil aber wird ganz longitudinal und bildet die Schwanzmuskeln, welche sich nach hinten in die uiblichen, hier wenig deutlichen Streifen auflösen.

Die Musculatur der Flosse weicht in so weit von der bei Carinaria ab, dass einzelne Bänder nicht vorkommen ${ }^{1}$ ), sondern das Ganze einheitlich erscheint; nur am Unterrande zeigen sich einzelne Strecken muskelfrei. Die ganze Flosse besitzt übrigens die grösste Ähnlichkeit mit der von Pterotrachca, nicht nur in der Musculatur, sondern auch in der allgemeinen Gestalt. Kennzeichnend für Cardiapoda, wenigstens nach meinen jetzigen Erfahrungen, ist ihre sehr breite Basis. Ein kleiner, bisweilen kaum wahrnehmbarer Saugnapf findet sich am abgerundeten Unterrande, ein wenig nach hinten gerückt.

Der Schwanz ist zwar ziemlich langgestreckt, tritt aber, dem Rumpfteil gegeniiber, an Mächtigkeit sehr zurück. An der Spitze findet sich bei einigen Arten eine membranöse, oft schwarz pigmentirte Erweiterung mit eingekerbten Rändern. Im Bau des Schwanzes ergeben sich übrigens, ebenso wie bei Carinaria, wichtige systematische Merkmale, welche ausfihrlich bei den einzelnen Arten besprochen werden sollen. An das Ende eines mehr oder weniger langen Stieles setzt sich der Eingeweidenucleus an, der eine eiförmige, mit dem zugespitzten Pole nach unten gekehrte Gestalt zeigt und seitlich zusammengedrückt ist. Von der Mündung der Schale ausgehend, schlägt sich der Mantel über den Eingeweidesack hin, geht an den Seiten continuirlich in die allgemeine Körperbedeckung über und lässt nur vorn eine ziemlich weite Öfnung frei, welche in die geräumige Mantelhöhle hineinführt. Im rechten Rande dieser Öffnung mündet der Anus, links liegt ein merkwïrdiges, langgestrecktes, schwach S-förmig gekrümmtes Organ, in vertikaler Lage, das wohl als Hypobranchialdrise aufzufassen wäre, da es bei näherer Betrachtung sich als ein Complex grosser, einzelliger Drüsenzellen, mit ölartigem Inhalte, darstellt. In der Mantelhöhle liegt, links vom Nucleus, das Herz, dessen Atrium nach oben gerichtet ist. Die Kiemen sind Ausstülpungen des Mantels nach aussen; sie fangen an der Schalenmündung an, und sind hier sehr klein, um allmählich nach oben an Grösse zuzunehmen; an der Mantelöfnung werden sie wieder kleiner und steigen hier am linken Rande hinab. Es handelt sich um dreieckige Läppchen, welche alle median gelegen sind und wie die Meridionalreihen eines Ctenophors aufeinander folgen. Ohne auf den feineren Bau der Respirationsorgane hier näher einzugehen, bemerke ich nur, dass in jedem der Läppchen, an den Seiten ein zuführendes und ein abfuhrendes Kiemengefäss bemerkbar ist. Das erste steht in directer Verbindung mit einem grossen Venensinus, der der Basis der Kiemen entlang zieht und das aus dem Körper zufliessende Blut aufnimmt. In der Kieme wird das Blut durch quere Anastomosen in die Kiemenvene hinübergefuhrt, dann in einem grossen, langgestreckten Raum gesammelt, der dem Venensinus parallel liegt und allmählich in den Vorhof des Herzens übergeht.

Die Niere fällt besonders durch den ausserordentlich stark verästelten Bau auf, den der Boden des Organes besitzt, und erinnert somit stark an das entsprechende Organ der Chitonen. Die Wände bilden iberall kleine, sich oft noch teilende Aussackungen, deren dunkle Farbe an einzelnen Stellen wahrscheinlich durch Concretionen hervorgerufen wird. Das ganze Organ ist langgestreckt und liegt mit dem Ende hinter dem Herzen, also links vom Eingeweidenucleus, 
ganz nach hinten. Im weiteren Verlauf steigt die Niere in der Mantelhöhle empor, legt sich an dorsalen Rande des Nucleus über denselben hinüber, und kommt vorn an der rechten Seite zu liegen, wo sie mittels einer trichterförmigen Öffnung, am Mantelrande, dorsal vom Anus, nach aussen mündet; diese Stelle ist durch einen schwachen Sphincter angedeutet. Gleich dabei, aber etwas mehr zurück, liegt an der linken Nierenwandung, welche sich direct dem Pericard anschmiegt, die kleine, mit einem Ringmuskel versehene Renopericardialöffnung, mittels welcher also eine Verbindung von Excretionsorgan und Pericard hergestellt ist. Im Anschluss an die Niere möchte ich noch bemerken, dass das schon von delee Chiaje und Gegenbaur beschriebene Organ an der Flossenbasis, das später von FAHRINGER als „Speicherniere” eingehend besprochen wurde, fast in derselben Ausbildung wie bei Carinaria, auch hier zu finden ist. Nan sieht zwischen den aus der Flosse in den Körper ausstrahlenden Muskellamellen, gleich an der Flossenwurzel, zwei längliche, der Längsachse des Körpers folgende Streifen, welche von der Aorta caudalis in ganzer Länge durchsetzt werden. Wenn ich auch die innere Structur dieser Speicherniere nicht untersuchte, so scheint sie mir doch die Entwickelung, welche das Organ bei Carinaria besitzt, nicht zu erreichen; vielmehr ist hier nur ein dinner, wenn auch deutlicher Beleg von Drüsenzellen auf der Wandung des Blutgefässes nachweisbar.

Die Haut (Taf. X, Fig. 52) bei Cardiapoda zeigt das nämliche wie bei der vorigen Gattung, nur hat die gallertige Bindesubstanzmasse beträchtlich an Bedeutung abgenommen. Es kommen übrigens auch hier die rundlichen Flecke, bald mehr bald weniger an Zahl, vor, besonders auf dem Rumpfe, aber auch, und dies ist bemerkenswerth, an der Flosse. Höcker treten bisweilen auf, für gewöhnlich scheinen die Arten eine ganz flache Oberflächenbeschaffenheit der Haut zu besitzen.

Die Augen (Taf. XI, Fig. 53) haben den Carinaria-Typus, sind also an der Basis breit. Die Tentakeln, welche ihre Muskeln in ähnlicher Weise wie bei Carinaria beziehen, sah ich immer nur stark zusammengeschrumpft und deshalb in viele Faltungen gelegt; ihre Wurzel ist breit und membranös.

Der Penis ist, ebenso wie bei Carinaria ${ }^{1}$ ), aus zwei Teilen zusammengesetzt; die am meisten nach vorn gelegene Partie (Taf. XI, Fig. 54,a) ist der Haftapparat, in dem man den grossen Drisenschlauch ganz deutlich durch die dünne Wandung hindurchschimmern sieht; hinten, und etwas nach oben, liegt der eigentliche Penis $(p)$, der an der Hinterfläche (in der Zeichnung nicht sichtbar) die bis zur Spitze sich erstreckende Samenrinne zeigt, welche sich als sehr flache Furche (sf), der latero-ventralen rechten Seite des Nucleusstieles entlang ziehend, bis zum Nucleus selbst verfolgen lässt.

Am unteren Pole des Nucleus, der nicht vom Mantel bedeckt wird, findet sich die kleine gewundene Schale, welche leider in meinen Exemplaren entweder ganz verschwunden oder doch nur in Fragmenten vorhanden war. Ihre merkwürdigen dreieckigen Ausbreitungen am Mundrande, wie sie Souleyet beschreibt, habe ich also nicht auffinden können. Auch VAyssik̀re hat die Schale nicht zu Gesicht bekommen können.

Die Buccalmasse besitzt die beiden länglichen, cylindrischen Speicheldrüsen, welche wie bei Carinaria beschaffen sind. An der Oberseite fängt der Darmkanal an, der sich in der 
Höhe der Augen oder gleich nach hinten, zu einem spindelförmigen Gebilde erweitert (ebenso wie bei Carinaria und bei den Pterotracheidae), das als Magen aufaufassen wäre, wenn die Abwesenheit der nach dem Nucleus zuruckgedrängten Leber sich dieser Meinung nicht widersetzte. Der Darm verläuft dann weiter nach hinten, tritt, am Nucleus angelangt, linkerseits hinein, und zwar in der Höhe der Herzkammer, um schliesslich nach einer abermaligen, von der Leber umfassten Erweiterung im Nucleus, am rechten Rande der Mantelöfnung nach aussen zu münden; der Enddarm liegt frei.

In der Mundhöhle findet man die dorsale Rinne. Die Radula nimmt von vorn nach hinten ziemlich an Grösse zu. Es sind im Ganzen 37 Querreihen vorhanden (nach VAyssrèrE 40), welche denen von Carinaria sehr ähnlich sind.

Die drei Arten, welche von der Siboga-Expedition erbeutet wurden, sind sämtlich neu; ich habe wenigstens keine derselben mit den früher beschriebenen genügend gleichstellen können.

Cardiapoda trachydermon n. sp. (Taf. X, Fig. 52. Taf. XI, Fig. 53-56). Stat. 136 . Ternate. 2 Ex. $\left(\odot^{\circ}\right)$

Es wurden zugleich zwei Exemplare gefangen, beide Männchen, welche nahezu dieselbe Grösse haben, (etwa $35 \mathrm{~mm}$.).

Der Körper ist langgestreckt, cylindrisch, der kurze Rüssel geht ohne deutlichen Übergang in den Rumpf über, und dieser setzt sich wieder in den Nucleusstiel fort, während der dünne Schwanz unten angesetzt erscheint.

Das wichtigste Merkmal dieser Art ist in den Tuberkeln gegeben, welche ebenso wie bei Carinaria zerstreut sind, besonders zahlreich aber nur dorsal zwischen Augen und Nucleus auftreten, und ventral unmittelbar vor der Flosse. Übrigens kommen auch hier die rundlichen Flecken vor (Fig. 52, hf), welche aus Anhäufungen kleiner Zellen bestehen. Da wo die Gallertsubstanz eine kleine Hervortreibung der Haut bedingt und einen Höcker bildet, finden sich rundliche Zellen, in verschiedener Weise zusammengedrängt, überdies kommen diese Agglomerate auch sonst häufig in den Körperbedeckungen vor (Fig. 52, a) als einzelne, zersprengte Zellgruppen, meist nur aus 2-5 Zellen bestehend. Sie dienen als Knorpelgewebe.

Was oben von den Augen, den Tentakeln und dem Penis von Cardiapoda gesagt wurde (Fig. 53-54) trifft ganz bei der hier behandelten Art zu.

Die Flosse ist sehr gross, mit breiter Wurzel, mit Ausnahme des unteren Abschnittes ganz undurchsichtig (wenigstens im conservirten Zustande), und ist der von Pterotrachca sehr ähnlich. Der kleine Saugnapf ist ein wenig nach hinten verschoben.

Am Ende des Nucleusstieles liegt der Eingeweidesack (an dessen unterem Pole die kleine Schale nur noch an den Windungen der Leber zu erkennen ist), der an der Oberseite den Enddarm hervortreten lässt, welcher am rechten Mantelrande nach aussen muindet. Die Respirationsorgane sind stark entwickelt, und folgen einander in einer einzigen, medianen Reihe auf, welche aber an der Mantelöffnung ein wenig nach links ausweicht. Der Stiel des Nucleus, mitsammt diesem selbst, ist ein wenig kürzer als der Schwanz. Dieser ist klein und trägt am Anfang dorsal einen kleinen Kamm, der nach hinten zu allmählich verstreicht. Das Ende des Schwanzes 
verbreitert sich in ein membranöses Gebilde von symmetrischer Gestalt, mit gezackten Rändern. Einiges Pigment ist hier abgelagert, weshalb sich die Ausbreitung durch dunklere Farbe unterscheidet. In einer tiefen Einbuchtung am Hinterende heftet sich ein kurzer Zapfen an, der vielleicht den vorderen Teil eines abgerissenen Schwanzfadens darstellt.

Bezüglich der Radula (Fig. 56) kann erwähnt werden, dass die Mittelplatte nicht wie es bei Carinaria oft der Fall zu sein pflegt, nach unten eingebogen, sondern ganz gerade ist; der Vorderrand zeigt eine leichte Erhebung. Von den drei Dornen dieser Platte sind die beiden seitlichen ein wenig kürzer als der Mitteldorn und leicht nach aussen gebogen. Der Kamm an der convexen, medianen Seite der Zwischenplatte ist nur wenig entwickelt und trägt da wo er in die Hauptspitze, die ganz gerade ist, übergeht, nie einen Dorn, wie bei Carinaria. Die beiden Seitenplatten sind fast in derselben Weise wie bei der vorigen Gattung gestaltet.

Die Art scheint nur selten im Archipel vorzukommen.

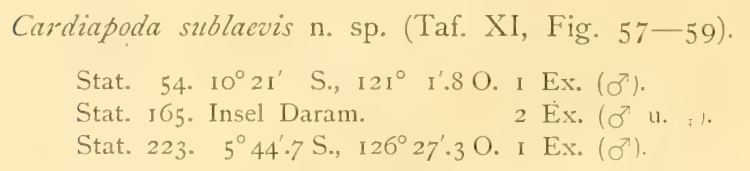

Diese Art ist durch 4 Exemplare vertreten, deren Länge $12-25 \mathrm{~mm}$. beträgt.

Es besteht die grösste Übereinstimmung mit der vorhergehenden Spezies; als entscheidendes Merkmal möchte ich aber bemerken, dass Tuberkeln der Haut oder sonstige Erhebungen hier gar nicht vorkommen. Die Oberfläche des Tieres erscheint vielmehr volkommen glatt, nur die rundlichen oder länglichen Flecken kommen in derselben Weise vor wie bei C. trachydermon. Der Rüssel zeigt eine wechselnde Gestalt, bald lang ausgezogen (Fig. 58), wie bei dem Weibchen von Stat. I65, bald stark zusammengezogen (Fig. 57). Der Rumpf ist cylindrisch, auf der Höhe der Flosse aber ist der Umfang etwas grösser als nach vorn zu. Die stielartige Verlängerung, in welche der Rumpf sich fortsetzt, trägt am Ende den Nucleus, wo am unteren Pole die Windungen der Schale nur noch an der Leber zu erkennen sind. Kiemen sind hier in derselben Ausbildung und in gleicher Reihenfolge, wie bei der vorigen Art vorhanden. Der Schwanz hat ebenfalls eine kleine, dorsale Crista am Anfang, während er in eine membranöse Ausbreitung (Fig. 57a) endet, welche bei den Exemplaren von Stat. 54 und 223 tiefschwarz gefärbt ist, sonst aber kaum Pigment besitzt. Die sehr grosse, lappige Flosse mit ihrer breiten Basis und dem nach hinten verschobenen Saugnapfe zeigt nichts Besonderes. Bisweilen treten auf der Flosse auch die Hautflecken auf, welche sich sonst nur auf den Körper selbst beschränken.

Die Mittelplatte der Radula zeigt drei genau gleich lange Dornen, deren Spitzen ziemlich weit aus einander stehen. Die Form dieser Mittelplatte, sowie der uibrigen Teile (Fig. 59) ist fast ganz wie bei der vorhergehenden Art.

Wenn auch die Unterschiede der beiden Arten nur unbeträchtlich erscheinen, so glaube ich doch zu der Aufstellung zweier gesonderter Formen berechtigt zu sein; denn nicht nur die glatte Beschaffenheit der Haut, sondern auch die Gleichheit der Dornen der Mittelplatte weisen, wie mir scheint, auf verschiedenartige Artmerkmale hin.

Auch $C$. sublaevis ist selten und wurde nur in 4 Exemplaren gefangen. 
Cardiapoda acuta n. sp. (Taf, XI, Fig. 60-63).

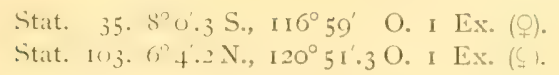

Die beiden zu dieser Art gehörigen Tiere waren Weibchen; das erste hatte eine Länge von $3 \mathrm{r} \mathrm{mm}$., das zweite von $17 \mathrm{~mm}$.

Die Art zeichnet sich besonders dadurch aus, dass der Schwanz hier jeglichen Anhang entbehrt und einfach in eine Spitze endet. Auch fehlt jede Andeutung eines Fadens.

Der kurze Rüssel geht in der Höhe der Augen in den Rumpf über, der über der Flosse am höchsten ist, sich dann einerseits in den Stiel fortsetzt, der den Nucleus trägt, andererseits den stark comprimirten Schwanz aus sich hervortreten lässt. Hier kommen noch einige geringfügige Unterschiede vor. Während bei dem Tiere von Stat. 35 (Fig. 6o) der Schwanz auf eine gewisse Strecke hin die gleiche Höhe beibehält, sich dann aber zu einer Scheibe umgestaltet, um schliesslich in ein plattes Band zu enden, ist bei dem Exemplare von Stat. 103 (Fig. 6I) das entsprechende Organ mehr gleichmässig gebaut, und die Höhe nimmt hier von vorn nach hinten allmählich ab, dorsal ist hier ein Kamm sichtbar mit grobgezacktem Rande.

Die Form der Flosse kommt, wie aus den Abbildungen ersichtlich, mit der der anderen Arten überein; auch die Stelle des Saugnapfes ist die nämliche. Die Kiemen sind zahlreich, und in derselben Weise angeordnet, wie oben beschrieben. Dass das Längenverhältniss des Nucleusstieles und des Schwanzes bei den beiden Tieren nicht gleich ist, darf wohl auf die verschiedene Zusammenziehung der entsprechenden Teile zuriickgefuhrt werden.

Nur beim kleinsten Tiere war der untere Pol des Nucleus vorhanden und zeigte hier zwei Umgänge; die nur in einzelnen Fragmenten sich hier anheftende Schale liess die Zahl ihrer Windungen nicht ermitteln.

Die Haut ist nicht glatt, sondern, besonders am dorsalen Rumpfteile mit zahlreichen, kleinen Höckern besetzt. Dass sie sich wenig bemerkbar machen, stammt daher, dass ihre Spitze nicht eine dunklere Farbe aufweist; das ganze Organ enthält (Fig. 62) kleine Zellgruppen (aus 2-8 Zellen zusammengesetzt), welche auch sonst iiberall auf dem Körper zerstreut sind. Bei C. trachydermon, wo derartige Gruppen ebenfalls vorkommen, finden sich in den Höckern Anhäufungen von 60 oder mehr solcher Zellen, weshalb eine derartige Stelle sich schärfer von der Umgebung abhebt. Einige Muskelbündel strahlen bei $C$. acuta in die Höcker aus.

Die Radula hat 37 Querreihen. In der Mittelplatte (Fig. 63) sind die drei Dornen fast gleich gross, die beiden seitlichen sind ein wenig nach aussen gerichtet ${ }^{1}$ ). Der Kamm der Zwischenplatte ist nach oben zu nicht scharf abgeschieden, sondern geht ohne Grenze in die obere Kante der Platte über; die Hauptspitze ist in allen Reihen nach innen gekrümmt. Die beiden Seitenplatten besitzen keine Merkmale, welche systematisch verwendet werden können.

Diese Art wurde nur an zwei, allerdings weit auseinander liegenden Fundorten gefangen.

I) In der Radula von Cardiapoda scheinen die Dornen der Mittelplatte eft verschiedene Verhältnisse aufzuweisen; wenigstens sind nach M.ıcDonatd und VAyssiére die beiden seitlichen beträchtlich kürzer als der Mittelfortsatz. 
Notizen uiber Verbreitung und Lebensweise der Carmarimat.

Die Familie der Carinariidae ist aus den Atlantiden abzuleiten, wenn man sich den Körper der Atlanta stark vergrössert vorstellt, sodass das Tier nicht mehr ganz in die Schale zurückgezogen werden kann, sondern nur der Eingeweidesack durch die dünne Schale bedeckt wird, deren letzter Teil sich nicht spiralig aufrollt, sondern mehr oder weniger gerade gestreckt ist, und dem gewundenen Teil gegeniiber, fast allein das ganze Gehäuse bildet. So ist es wenigstens bei Carinaria und auch bei Pterosoma; Cardiapoda dagegen, hat noch einen Fortschritt gemacht, insofern als die Schale, welche ganz gewunden, ohne geraden Endteil, nach dem unteren Pole des Eingeweidesackes hinabgedrängt ist und nur einen kleinen Teil der Leber bedeckt. Die letztgenannte Gattung leitet dann zu den Pterotracheiden hinüber.

Bezüglich der Häufigkeit stehen die Carinariidae weit hinter den beiden anderen Familien zurück. Wenn auch, wie die iibrigen Heteropoden in allen wärmeren Meeren verbreitet, gehören sie immer zu den Seltenheiten. Diese schon oft constatirte Tatsache wird auch durch die Befunde der Siboga-Expedition bestätigt; es wurden nur vereinzelte Exemplare gefangen, auch einige leere Schalen gefischt, von Schwärmen aber oder nur von kleineren Gruppen findet sich nie eine Spur. Ptcrosoma wurde gar nicht beobachtet.

Im Mittelmeer kommt nur die Gattung Carinaria vor, welche iberhaupt noch am weitesten verbreitet ist. Ptcrosoma und Cardiapoda scheinen auf die subtropischen und äquatorialen Meere beschränkt zu sein.

Die Carinariidae erheischen unser besonderes Interesse, nicht nur durch ihre of erhebliche Grösse (es wurde schon eine Carinaria von $53 \mathrm{~cm}$. gefunden), sondern auch durch ihre Vielgestaltigkeit, welche sich sowohl in der Schale wie im Körper ausdrückt, und eine schärfere Umgrenzung der Arten ermöglicht als es sonst bei den ziemlich einförmigen, um bestimmte Typen herum gruppirten Heteropoden der Fall zu sein pflegt.

Die beträchtliche Zunahme der gallertigen Bindesubstanz, welche bisweilen als eine dicke Schicht, namentlich den Rumpf einhüllt, hat schnelle Bewegungen und Biegungen des Körpers fast unmöglich gemacht. Die schwimmende Carinaria bewegt sich langsam, fast bedächtig, durch das Wasser, wobei die grosse Flosse regelmässig hin- und herschwingt. Diese ist immer nach oben gewendet beim lebenden Tiere; nur Costa behauptet, dass Carinaria beim Schwimmen die Schale nach oben kehrt. Nach einer Angabe Rang's heftet sich Carinaria gelegentlich an andere Gegenstände (Fucus) mittels des Saugnapfes fest.

Die langsame Bewegung, und infolge dessen die Hilflosigkeit beim Angriffe irgend eines Feindes mag wohl die Ursache sein, dass Carinaria oft verstimmelt gefunden wird, und ganze Körperteile, wie der Schwanz, oder der Nucleus, der durch dunklere Farbe natülich besonders die Aufmerksamkeit anderer Tiere erregt, fehlen können. Dass das so eingreifend verwundete Tier trotzdem eine grosse Lebenszähigkeit besitzt, dafür bieten die Funde der Siboga-Expedition einige Belege. 


\section{Familie III. PThrotracmeidas.}

Die P'terotracheidae bilclen die letzte und höchstentwickelte Familie innerhalb welcher die Anpassung an das pelagische Leben den Höhepunkt erreicht. Eine Schale fehlt dem ausgewachsenen Tiere ganz, und der ganze Körper ist so vollkommen durchsichtig, dass nur die Augen und der spindelförmige Eingeweidenucleus sichtbar sind, wenigstens wenn man von vereinzelten Pigmentflecken und Anfliigen absieht.

Es lassen sich die beiden Gattungen Ptcrotrachea und Firoloida unterscheiden.

\section{Pterotrachea Forskial 1775 .}

Beziiglich der allgemeinen Characteristik verweise ich nach dem ersten Abschnitt; es seien hier nur einige kurze Bemerkungen gemacht, welche z.T. systematisch wichtig sein dürten.

Die glashelle Körperbedeckung von Ptcrotrachea setzt sich aus den nämlichen Bindegewebszellen wie bei Carinaria zusammen, nur hat sie die knorpelartige Beschaffenheit verloren, und liegt wie eine ausserordentlich weiche Substanz der Musculatur auf, nur am Rüssel ist sie derber und fester, zugleich aber auch viel dünner. An einigen Stellen erheben sich grössere oder kleinere Höcker (Taf. XI, Fig. 64), welche einen Haufen kugeliger Zellen, mit körnigem Inhalt, enthalten; diese Zellen verleihen dem Höcker die nötige Consistenz, kommen aber auch sonst in der Körperbedeckung zerstreut vor. Die Oberfläche bekleidet ein Plattenepithel, das sich fetzenweise ablösen kann, und das an einzelnen Stellen Pigment enthält. Die eben erwähnten Höcker kommen vereinzelt besonders auf dem vorderen Rumpfteile vor, häufig aber finden sich einzelne grössere Höcker vor den Augen. Dass sie den bei Pterotrachaca fehlenden ${ }^{2}$ ) Tentakeln morphologisch nicht gleichzustellen sind, wie man wohl vermutet hat, geht daraus hervor, dass sie erstens viel weiter nach vorn gelegen sind, dann aber auch einen ganz anderen Bau aufweisen, und ausserdem unregelmässig auftreten, weil sie nicht nur auf beiden Seiten in verschiedener Zahl auftreten, sondern sogar rechts oder links vollkommen fehlen können, während sie auf der anderen Seite erhalten geblieben sind. Weiter machen sich, besonders an der Bauchseite weissliche, ziemlich grosse Flecken bemerkbar, deren Bau schon von Gegenbaur beschrieben wurde. Besonders fehlen sie nie in der Umgegend der Flossenbasis, weiter finden sie sich auch noch oft weiter nach vorn, bis an der Unterseite des Rüssels hinauf. Eine systematische Bedeutung ist ihnen, ihrer regellosen Zerstreuung zufolge, wohl schwerlich zuzumessen.

Der am Ende des Rumpfes gelegene Nucleus ist in die bindegewebige Körperbedeckung eingekeilt, und zwar derartig, dass unterhalb des Nucleus ein Raum bestehen bleibt, der hinter ihm, sich nach oben richtend, mit der Aussenwelt in Verbindung steht. Die Ränder dieser Ausmündung werden von dem dorsal crista-artig hervorragenden Schwanz gebildet (Taf. XI, Fig. 65); der rechte Rand ist höher als der linke, der zugleich einige Höcker tragen kann.

Ein Mantel kommt gar nicht vor; Niere ${ }^{2}$ ) und Herz sind in der gallertigen Bindesubstanz vor dem Nucleus eingebettet. Die Niere, deren Bau schon in Hauptziggen von Gegexbaur

1) Dock wurde noch in der neuen Auflage von LAxG's Lehrbuch d. vergl. Anatomie der Wirbellosen Tiere (Mollusca von Dr. K. Hescheler, S. I69) eine f'trotrachea mit Tentakeln abgebildet.

2) Eine "Speicherniere" geht den Pterotracheiden ab.

SHOGA-EXIEDITIE L.T. 
geschildert wurde, liegt oben und nach rechts gewendet; an ihrer rechten Seite liegt die mit einem Sphincter umgebene Öfnung, weIche nach aussen mündet; die innere Öffnung nach dem Pericardialraum liegt weiter nach unten. Die Vorkammer des Herzens liegt oberhalb des Ventrikels, mehr nach links gerichtet als die Niere, und weiter vom Nucleus entfernt. Die Kiemen, welche wie bei Cardiapoda beschaffen sind, sind Ausstullpungen der Leibeswand; gleich vor dem Nucleus, dorsal und median, steht ein kleines Bündel; an dem links vom Nucleus hinabsteigenden Kamm sind die Kiemen grösser und länger, unten aber werden sie wieder kleiner. Übrigens wechselt ihre Länge selbstverständlich nach dem Contractionszustande; bei den Individuen derselben Art kann auch die Zahl der Respirationsorgane anders sein. Ein langgestrecktes Osphradium liegt vor dem Nucleus, median, oder ein wenig nach links.

Die Musculatur von Pterotrachea wurde von Leuckart, Gegenbaur und besonders Kalide genügend beschrieben. Nur will ich bemerken, dass die drei Paare kurzer Muskelfortsätze, mit denen die Flosse in den Rumpf hineinragt, nicht nur in topographischer Beziehung, sondern auch in ihrem Bau von LEUCKarT ganz richtig beschrieben wurden, und KaLIDE in dieser Hinsicht sich irrt. Das erste Paar liegt nämlich ein wenig vor der Mitte der Flossenbasis, das zweite gleich dahinter, und das letzte am Ende. Das erste Paar divergirt nach oben, und heftet sich an die Körpermuskeln an, das zweite aber bildet nur eine nach oben geschlossene Schlinge, deren Seitenteile nahezu parallel gehen, während das dritte Paar bei Seitenbetrachtung zwar, wie LEuckart hervorhebt, eine kleine, viereckige Lamelle darstellt, bei genauer Untersuchung aber aus zwei Blättern zusammengesetzt erscheint, welche nicht in ihrer ganzen Ausdehnung sich an einander legen (LEUCKART), sondern stark convergiren, und sich nur an ihren oberen Enden vereinigen. Die Höhe dieser Stümpfe nimmt von vorn nach hinten ab. Einzelne, langgestreckte Bindegewebsfibrillen setzen die Muskelfortsätze mit den Rumpfmuskeln in Verbindung.

Von der Körpermusculatur sei hier nur erwähnt, dass iiberall die vier Paare von Längsmuskelbändern im Schwanze in grosser Einförmigkeit auftreten. Oben, dem dorsalen scharfen Rande des Schwanzes folgend, läuft ein sehr dünnes Paar (Taf. XI, Fig. 65, $a$ ), das vorn nicht mit der Rumpfmusculatur zusammenhängt, sondern frei endet. Die zwei Streifen, rechts und links, können in ihrem Verlaufe mit einander verschmelzen, nach hinten weichen sie aber wieder aus einander und vereinigen sich mit dem zweiten, stärkeren Paare (b), das (ebenso wie das dritte und vierte Paar) ganz duinn und schmal aus der unterhalb des Nucleus endenden Rumpfmusculatur seinen Ursprung nimmt, dann allmählich an Dicke zunimmt, sich mit dem ersten Paare vereinigt, und, nach der Vereinigung zu einem einzigen Strange zusammenfliessen, oder auch getrennt bleiben kann, um schliesslich in das dritte Paar (c) auszumünden, und zwar am Anfang der Horizontalflosse. Das dritte Paar ist uiberall das stärkste, bleibt in seinem ganzen Verlaufe getrennt, und vereinigt sich erst am Ende der Horizontalflosse, also dort wo sich der Schwanzfaden anheftet, mit dem vierten Paare (d), das meist iiberall gleichmässig dick bleibt und dem ventralen. Rand des Schwanzes folgt.

In der Horizontalflosse kommt eine Quermusculatur vor (Taf. XI, Fig. 65a); es stehen hier nämlich einzelne Müskelchen, welche das dritte und vierte Längsmuskelpaar durchsetzen, senkrecht auf ihre Richtung. Die dorsale Musculatur stammt vom dritten, die ventrale vom vierten der oben beschriebenen Längsbänderpaare $a b$; sie sind in ziemlich regelmässigen Abständen 
angeordnet. Wie aus der Figur ersichtlich, teilt sich noch an der Basis der Horizontalflosse das vierte Längsmuskelband, rechts und links; der innere Zweig behält den gleichen Verlauf, der äussere zieht in einen flachen, etwas nach oben gekehrten Bogen nach der Anheftungsstelle des Schwanzfadens hin, wo sich alle noch bis dahin getrennt verlaufenden Längsmuskeln vereinigen, und als zwei seitliche Bänder in den Faden eintreten.

In der hier gegebenen Beschreibung des Schwanzes habe ich mich nur auf eigene Beobachtungen gestützt, welche allerdings nur in untergeordneten Punkten von den Angaben LEUCKArT's, Gegevbaur's und Kalide's abweichen. Einige geringfügige Variationen können darin bestehen, dass bisweilen zwischen den Längsmuskelbändern verschiedenen Wertes Anastomosen auftreten können; solche Gebilde treten aber nur individuell auf und sind von keiner systematischen Bedeutung.

Dass der Schwanz, und überhaupt der ganze Körper, bei Pterotrachca sehr einförmige Gestalt zeigt, ist schon öfter hervorgehoben worden. Nach Angaben anderer Autoren, wie SoulexeT (bei Ptcrotrachea keraudreni) und VAyssière (bei Firola talismani) endet aber, wenigstens bei einzelnen Arten der Schwanz nicht in eine Horizontalflosse, sondern in eine einfache Spitze.

Wenn auch die Auffindung der Artmerkmale bei den immer denselben Habitus wiederholenden Pterotracheen, sich zu einer schwierigen Aufgabe gestaltet, so ist es immerhin möglich, zwei deutliche Gruppen innerhalb der Gattung anzuweisen, deren Unterschiede in einer Reihe constanter Merkmale angegeben werden kann.

Der erste Typus (Taf. XI, Fig. 66) ist der von Pterotrachea coronata Forskâl. Hier zeigt nämlich das Auge eine ganz characteristische Gestalt, wie besonders aus den Figuren Gri:NACHer's und Hesse's hervorgeht. Von oben oder von unten betrachtet, zeigt sich, dass linke und rechte Seite des Auges nahezu parallel verlaufen; der hintere Teil, wo sich die Schicht der Stäbchenzellen findet, ist nur wenig breiter als das Übrige; zudem kommen in der Pigmentbekleidung des Auges, namentlich dorsal, zahlreiche Lücken vor.

Ein anderes, leicht kenntliches Merkmal bei diesem Typus ist darin gelegen, dass der Nucleus hier sehr lang und dünn ist, ja, bisweilen nur einen ganz schlanken, sich nach oben schwach zuspitzenden Stab darstellt.

Der zweite Typus besitzt Augen, welche sich in ihrem Bau an die von Cardiapoda anschliessen. Die Stäbchenzellenschicht im Hintergrund des Auges ist viel grösser als der vordere Teil (Taf. XI, Fig. 67), und die Lücken in der Pigmentdecke sind weniger zahlreich. Der Nucleus ist kurz, breit, birnförmig.

Um diese beiden, genügend verschiedenen Typen herum, gruppirt sich eine Anzahl Arten, welche nur sehr wenig unter einander abweichen; man möchte daher fast geneigt sein, überhaupt nur zwei Arten zu unterscheiden, statt der beiden Typen. Im Interesse einer gewissenhaften Systematik werde ich letztere aber vorläufig als Untergattungen betrachten.

Da zu der ersten Gruppe gerade die schon längst bekannte Pt. coronata gehört, auf welcher Art die ganze Gattung aufgestellt wurde, so schlage ich für diese Gruppe den Namen Pterotrachea s. s. vor.

Wenn auch in der Litteratur zahlreiche Arten, welche zu der zweiten Untergattung gehören, beschrieben sind, so ist doch ihre Unterscheidung (vergl. den I $^{\text {en }}$ Abschnitt) ausserordentlich schwierig. Ich nenne diese Untergattung, mit den nach hinten breiter werdenden Augen, Euryops. 
Die Merkmale sind also die Folgenden:

Erstes Subgenus: Pterotrachica s. s. Augen schmal, d. h. linke und rechte Seite gehen parallel. Nucleus lang und dünn, spindelförmig. Das ziemlich scharf umschriebene Feld der Quermuskeln, an der Ventralseite des Rüssels, reicht bis zu dessen Basis hinauf.

Zweites Subgenus: Euryops. Augen breit, d. h. linke und rechte Seite divergiren stark nach hinten. Nucleus kurz, geschwollen, birnförmig. Das Feld der Quermuskeln reicht nur etwa bis zur halben Länge des Rüssels, nicht nur an der Unterseite, sondern auch an den Flanken:

Wie leicht nun auch irgendeine Pterotrachea der einen oder der anderen Gruppe zugerechnet werden kann, so sehr schwierig ist die Unterscheidung der Arten selbst, auch unter Berücksichtigung aller Verhältnisse. Unter dem Materiale der Siboga-Expedition habe ich so gut wie möglich nach Artmerkmalen gesucht; in wie weit aber meine Versuche das Richtige getroffen haben, werden künftige Vergleichungen mit Pterotracheen aus anderen Meeren erst entscheiden können.

Hier habe ich es für angezeigt gehalten, 6 Arten von Pterotrachea zu unterscheiden, von denen $3 \mathrm{zu}$ der Untergattung Pterotrachea s. s., 3 dem zweiten Subgenus Euryops zuzurechnen sind.

Es ist mir deutlich geworden, dass die spitzen Höcker, welche häufig vor den Augen wahrnehmbar sind weder an Zahl noch an Anordnung bestimmte systematische Mlerkmale abgeben. Bei Tieren, welche, meiner Meinung nach, ganz gewiss einer und derselben Art zugehören, kommen bald die betreffenden Höcker vor, bald ist die Stirne vollkommen glatt. Einerseits scheint dies vom Alter des Tieres abhängig zu sein, andererseits aber ist reiner Zufall mit im Spiele. Ein einzelner Höcker kann sich in verschiedene kleinere auflösen, und zwar geschieht dies oft nur an der einen, nicht an der anderen Seite. Diese Regellosigkeit ist, zusammen mit der ziemlich weit vor den Augen gelegenen Stellung der Stirndornen, der beste Beweis dafuir, dass letztere mit den Tentakeln der übrigen Heteropoden nichts zu schaffen haben. Reste von Tentakeln sind übrigens bei keinem der Geschlechter nachzuweisen.

Ebensowenig kann die Radula, wenigstens in ihrem feineren Bau, systematisch verwertet werden. Ich komme darauf gleich zurïck. Auch die Zahl der Palatinzähne am Dache der Mundhöhle wechselt stark.

Es erwies sich aber die relative Grösse des Saugnapfes und des Copulations-apparates (selbstverständlich nur bei den Männchen) von systematischem Werte. Ausserdem kann die Form: und Grösse der Flosse und des Schwanzes mit Vorteil berücksichtigt werden. In einem einzigen Falle kam noch die eigentümliche Gestalt des Auges dazu.

Subgenus Pterotrachea s. s. mihi.

Pterotrachea challengeri n. sp. (Taf. XII, Fig. 68-72).

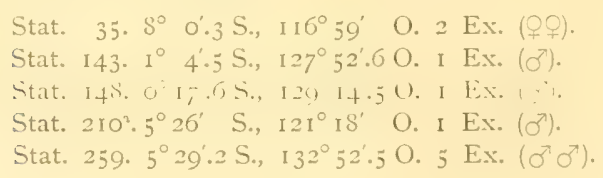


Der langgestreckte, cylindrische Körper trägt, etwa in der Nitte zwischen Augen und Nucleus, die rundliche Flosse, welche, bei den Männchen, mit einem sehr grossen Saugnapfe ausgestattet ist. Die gelblich-weissen Hautflecke sind, wie bei Ptorotrachea iberhaupt, ziemlich regellos zerstreut, immer aber in der Nähe der Flossenbasis vorhanden. Der Penis erreicht eine beträchtliche Grösse. Der Rüssel zeigt je nach dem Contractionszustande verschiedene Länge (vergl. Fig. 69 u. 70 ), ist aber immer gut ausgebildet, und einer beträichtichen Verlängerung fähig; denn bei einigen Tieren von Stat. 259 (Fig. 70) betrug seine Länge fast den halben Abstand zwischen Augen und Nucleus. Stirnhöcker habe ich zwar nirgends vermisst; oft aber ist ihre Zahl rechts und links verschieden; mehr als drei jederseits fand ich nie.

Die dorsale Medianlinie des Rumpfes erhebt sich vor dem Nucleus zu einen grähnelten Kamm. Die Kiemen sind gewöhnlich an der linken Seite des Nucleus sehr lang, ihre Zahl sowie ihre Länge ist aber bei den einzelnen Tieren vielen Änderungen unterworfen.

Characteristisch ist wieder die Form des kurzen Schwanzes, von gedrungener Gestalt, der natuirlich in eine Horizontalflosse endet.

Die Radula, welche sich aus 24 Querreihen zusammensetzt, hat eine breite Mittelplatte (Fig. 7 I u. 72) von der ublichen Gestalt, deren Mitteldorn bald eine breite Basis besitzt, bald auch schmäler und fast dolchartig sein kann, und im Übrigen sogar in clen verschiedenen Querreihen derselben Radula wechselnde Ausbildung zeigt. Jederseits stehen dam noch 6-8 kleine Dörnchen. Die Zwischenplatte zeigt an ihrer convexen Innenseite einen deutlichen Kamm, der vorn durch den Gebrauch oft zerbröckelt, hinten aber am distalen Ende mittels eines Fortsatzes sich von der Spitze der Platte abtrennt. Die Seitenplatten sind insoweit verschieden, dass die äussere an der Basis viel niedriger ist als die andere.

Die Palatinzähne stehen, jederseits 5 an der Zahı, am Rande der dorsalen Längsgrube in der Mundhöhle, welche den Weg zum Oesophagus andeutet. Die vorderen Zähne sind klein und kaum gebogen, die hinteren sind länger und distal gekrümnt.

Die hier beschriebene Art ist, wie ich hervorheben will, gekennzeichnet durch die kurze, gedrungene Gestalt des Schwanzes, und weiter durch die beträchtliche Entwicklung des Saugnapfes und des Penis.

Das grösste Exemplar hatte eine Länge von 1 io mm., ohne den Rüssel. Der Saugnapf war hier an der Basis $4 \mathrm{~mm}$. breit. Die anderen Tiere sind meist nur wenig kleiner.

Sehr wahrscheinlich ist diese Art dieselbe, welche von Sumti (Taf. V, Fig. 1 15) von Banda angegeben wurde. Seine Beschreibung passt sehr gut zu der meinigen; er erwähnt zwei Höcker vor den Augen, einen ziemlich umfangreichen Saugnapf und einen kurzen Schwanz. Die deutlich abgegrenzte Quermusculatur an der Unterseite des Rüssels und besonders der schlanke, spindelförmige Nucleus (der etwa ein Dutzend Kiemen tragen soll) macht die Zugehörigkeit zu Ptcrotrachea s. s. gewiss. Der Erhaltungszustand des Tieres, das ich jüngst im "British Museum" zu untersuchen Gelegenheit hatte, war derart, das von einem allgemeinen Habitus wenig zu erkennen war. Der centrale Fortsatz der Mittelplatte in der Radula hatte eine breite Basis, wie in Fig. 72. Ich habe daher geglaubt, mit cinigem Rechte der kurzgeschwänzten Art der Siboga-Expedition den Namen Pt. challengeri geben zu können. 


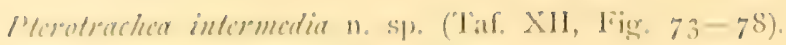

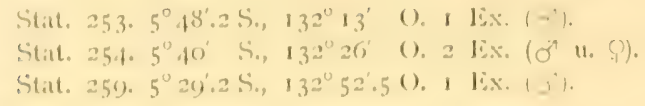

lis hat diese: Art die grösste Ahnlichkeit mit der vorhergehenden. Der allgemeine Körperban ist der gleiche; der Rissel hat etwa dieselbe Linge. Bei der Vergleichung der liguren 73 u. 75 muss man sich vergegenwirtigen, dass die erste Abbildung ein Tier, das in Formol aufbewalnt war, dasstellt, wihbend die zweite nach einem Alcoholexemplare angefertigt wurde, bei dem die urspringlichen Verhilunisse durch Schrumpfung viel geindert sind, und zudem die ganze körperbedeckmng anf dem Rumpfe: fohlte. Dataus lasst sich der ctwas abweichende Habitus erklaren.

1)as lixemplat von Stat. 2.59) (ligg. 73) wiederholt, von einigen wenigen Merkmalen abgesehen, dasjenige, was oben von I'\% challengeri gesagt wurde. Jederseits kommen 3 Stirnhöcker vor, die Tiere von Stat. 25.311 .25 .4 (Fïg. 76) zeigten aber im Ganzen nur zwei Stirnhöcker zwischen denen man dentich die: muskelfreie Riickenlinie hinchrchzichen sieht. Die Verteihng der rundlichen Hautlecke ist auch hier iberall unregelmissige (10ig. 7.3 11. 75), sie kommen lisweilen atuch auf dem Rissel vor. lïn gezihnelter liamm erhebt sich vor dem Nucleus, an dessen Vorderseite ein kleines Bisschel Kiemen steht, das isolirt von den langen këiemen, links vom Nuclens, liegt. Die Zahbl der Kiemen ist verschieden.

ber Sohwanz errecht eine relativ grossere Linge als bei P\%. challengeri und ist langerestreckter, die borsalseite ist nach hinten zn nicht convex, sondern gerade. Die Horizontalilosse am linde: trug bei einem lixemplare (lïg. 75) noch ein Stick des Schwanzfadens.

1) er Saturnap am Unterrande der grossen filosse stehe hinter dem der vorhergehenden

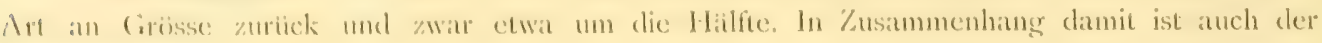
Penis klenener.

Dic: Radulat bieted anch hier keine Anhaltspunkte zn spezifischen Unterschieden. Der

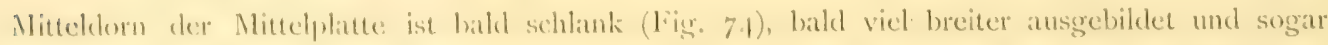
noch an den Seiten mit sehr kleimen lortsitzen ausgestatted (lïg. 7\%). An der Zwischenplatte lindet sich eine kleine (irube an der Stelle, wo der Lianm in die Spitze der Platte ibbergeht, aber die statk abenenuzten l'atten in den proximalen guereihen zeigen diese stelle wenig scharf makirt ( ligg. $7.19,77 a)$.

An Rande der dursalen Mundrinne stehen jederseits o oder 5 Chitinzilhne, deren Ban nichts bemerkenswertes zeigt (lig. 78$)$.

Die Lange des lioperts, ohne: den Risssel, betrug bei dem grössten fiere os mm.

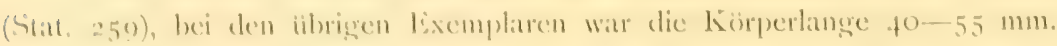

Diese An scheint mir erstens durch den lingeren und niedrigeren Schwanz, damn auch durch den kleineren und seluwieheren samgnapf gekennzeichnet zu sein, der hier nur an der

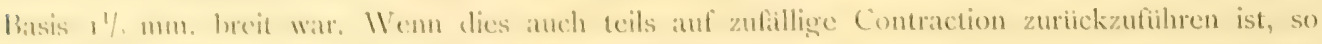
beible immerhin in dieser Hinsicht cin crwihnenswerter Interschied zwischen Pt. clublengeri und I'\% intramedtir bestehen.

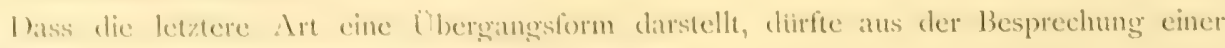
dritlen sperzies hervereschen, an eler wir jetat ibergehen. 


\section{$\therefore$,}

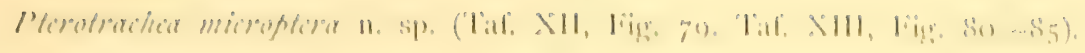

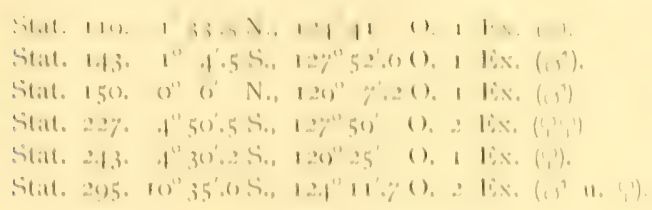

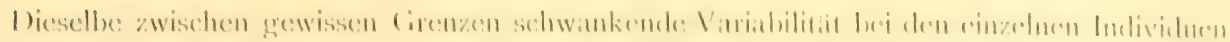

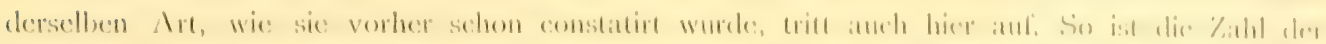

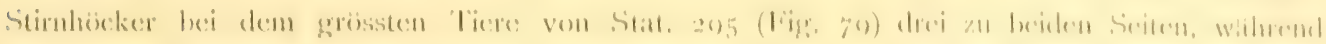

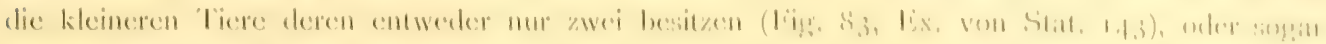

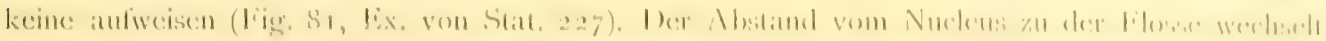

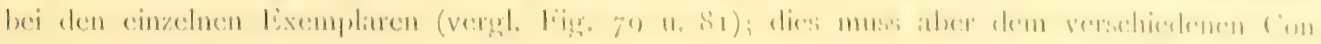

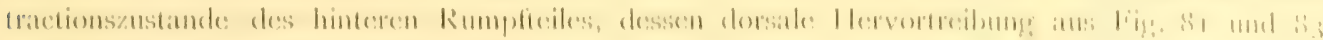
ersichelich ist, zugesselutichen werken.

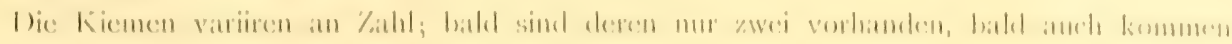
sereles oder sielen liemen vor:

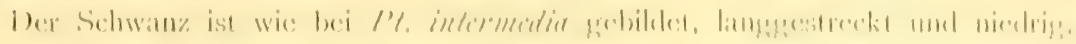

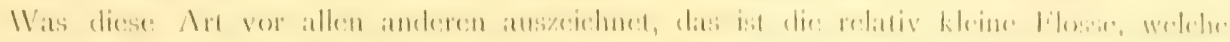

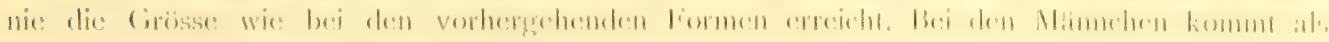

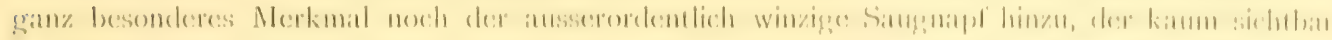

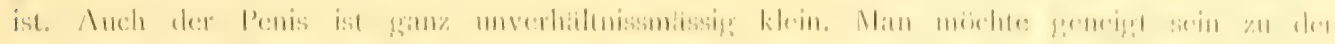

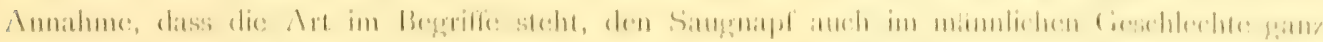

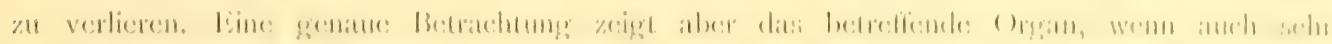

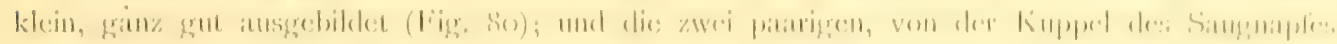

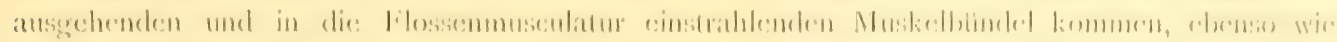

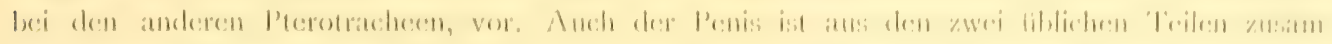

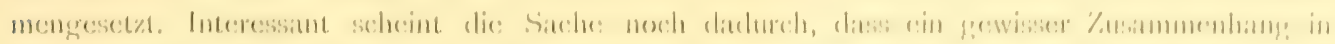

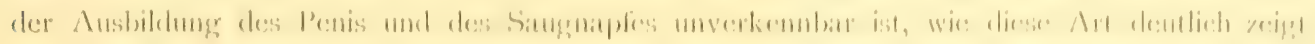

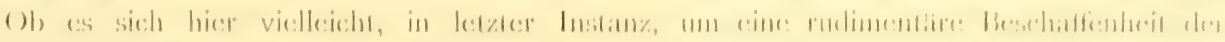

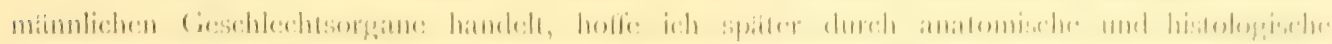

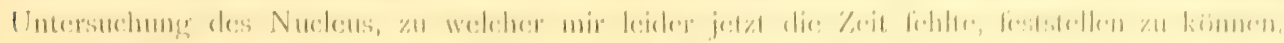

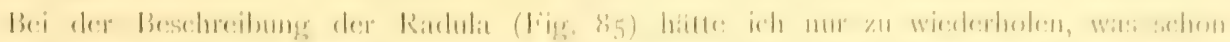

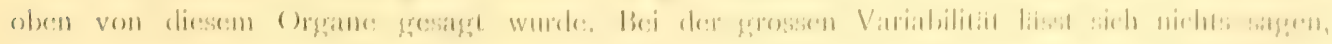

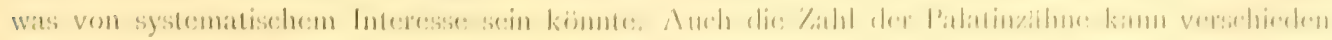

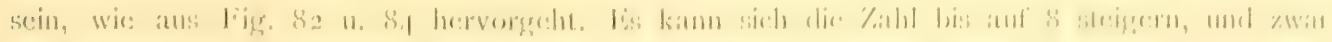

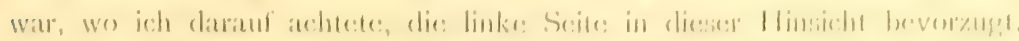

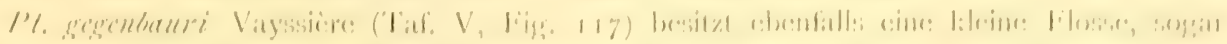

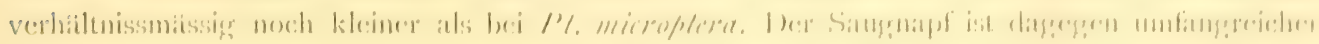

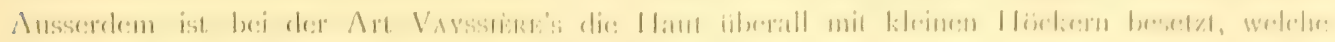

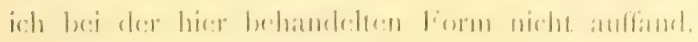


Subgenus Earyops mihi.

Pterotrachica (Euryops) mutabilis n. sp. (Taf. XIII, Fig. 86-89).

\begin{tabular}{|c|c|}
\hline 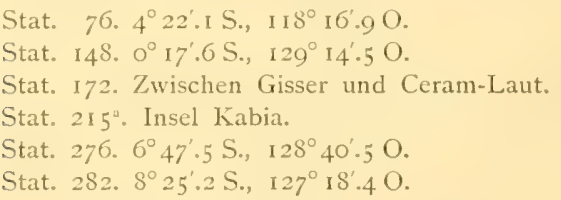 & $\begin{array}{l}\text { I Ex. }\left(\sigma^{7}\right) \cdot \\
\text { I Ex. }\left(\sigma^{7}\right) \cdot \\
\text { I Ex. }(9) . \\
5 \text { Ex. }\left(2 \sigma^{7} \sigma^{7}, 3 \text { Of }\right. \\
\text { I Ex. }(9) . \\
\text { I Ex. }(9) .\end{array}$ \\
\hline
\end{tabular}

Der Körper ist langgestreckt und geht vorn in einen gut ausgebildeten Rüssel über, der an der Basis keine Dornen aufweist, sodass die Stirne vollkommen glatt ist. Die Augen zeigen den breiten Typus (Fig. 67); in dieser Hinsicht sind bei Euryops noch ursprüngliche Verhältnisse bewahrt geblieben. Bei einem Tiere von Stat. $215^{2}$ (Fig. S6) fanden sich auf dem Rumpfe noch Reste von Pigmentflecken, welche freilich etwas verwischt aussahen, bei den anderen Exemplaren fand ich keine Spur von Pigment. Die Flosse ist ziemlich gross, bei den Weibchen etwas kleiner. Ein Saugnapf am Unterrande der Flosse, sowie der Penis sind gut ausgebildet. Der Nucleus ist kurz, birnförmig, von gedrungener Gestalt, an der linken Seite finden sich 8-ro Kiemen, welche sämtlich klein und kurz bleiben (wenigstens bei den mir vorliegenden Tieren). Der Schwanz ist klein und schwach, ziemlich langgestreckt, und, wie überall, mit einer Horizontalflosse abschliessend.

Auch hier bietet die Radula nichts, was von systematischem Nutzen sein könnte. Meist hat der Mitteldorn der Mittelplatte (Fig. 88) eine schlanke Gestalt, jederseits stehen 5-6 kleinere Zähnchen. Die Zwischenplatte (Fig. $88 a$ ) und die beiden Seitenplatten sind wie bei den vorhergehenden Arten gestaltet.

Die Zahl der Palatinzähne wechselt bei den einzelnen Tieren. Einmal betrug sie links 4, rechts 5 (Fig. 89); bei einem anderen Exemplare war das Verhältniss gerade umgekehrt.

Die Länge des Tieres betrug, ohne den Rüssel, $32 \mathrm{~mm}$. oder darunter.

Pterotrachea (Enryops) xenoptera n. sp. (Taf. XIII, Fig. 90-9I, 9Ia).

Stat. $203.332^{\prime} .5$ S., $124^{\circ}$ I $5^{\prime} \cdot 5$ O. I Ex. (q).

Der einzige Unterschied, der diese Art von der vorhergehenden auszeichnet, ist freilich sehr auffallend. Die kleine Flosse hat nämlich eine ganz eigentümliche Gestalt; denn, während sonst der Vorderrand convex, der Hinterrand aber nahe der Flossenbasis sich nach vorn richtet und dann sogar hohl werden kann, findet etwas derartiges hier nicht statt. Hinten fehlt die Einbuchtung, welche sonst bei Pterotrachec vorkommt, fast ganz, der Vorderrand dagegen ist scharf convex, mehr als gewöhnlich nach vorn reichend. In wie weit es sich hier um eine zufällige Anomalie handeln möchte, habe ich nicht entscheiden können, da ich nur ein einziges Tier sehen konnte, das hier als neue Art verzeichnet wird.

Sonst kommen keine Abweichungen vor, nur ist der Rüssel um ein weniges kürzer. Stirnhöcker fehlen. Der kleine, gedrungene Nucleus trägt an der linken Seite eine kleine Zahl winziger, kaum sichtbarer Kiemen. Der Schwanz endet auch hier in eine Horizontalflosse. 
Die Mittelplatte (Fig. 9I) der Radula zeigt einen schlanken Mitteldorn, der in den vorderen Reihen kuirzer ist als hinten. Jederseits stehen 5-6 kleinere Dornchen. Die Seitenplatten (Fig. 9I $a$ ) sind an der Spitze scharf gebogen.

Die Zahl der Zähne am Dache der Mundhöhle habe ich nicht festgestellt.

Die Körperlänge des Tieres beträgt $35 \mathrm{~mm}$.

Pterotrachea (Euryops) orthophthalmus n. sp. (Taf. XIII, Fig. 92-94).

Stat. $48.8^{\circ} 4^{\prime} \cdot 7$ S., II $S^{\circ} 44^{\prime} \cdot 3$ O. I Ex. (9).

Das Tier, das mir zur Aufstellung dieser neuen Art diente, war zwar in Allgemeinen der vorletzten Form sehr ähnlich, der Ruissel war aber beträchtlich kürzer. Im Bau der Augen zeigte sich ein bemerkenswerter Unterschied. Während das Auge von Euryops (Fig. 67) am Vorderrande eine concave Einbuchtung zeigt, ist dies bei der hier besprochenen Art nicht der Fall, sondern der Vorderrand ist ganz gerade (Fig. 93). Diese merkwürdige Abweichung würcle allerdings die Existenzberechtigung einer neuen Art beweisen, wenn es sich bewähren sollte, dass hier von keinem Zufalle die Rede ist.

Das Ende des Rumpfes ist dorsal, und zwar links, wo sich die kurzen Kiemen finden, stark aufgebläht, was wohl mit zufälliger Diastole des Herzens zusammenhängen mag. Der Schwanz ist wie bei der vorhergehenden Art gestaltet; am Ende findet sich die iibliche Horizontalflosse. Da, wie bei Pt. xenoptera, das einzige Exemplar weiblich war, habe ich keinen Saugnapf untersuchen können.

Die Radula (Fig. 94) wiederholt die Gestalt, welche das Organ bei Pt. xenopterc zeigt. Auch hier ist die Spitze der Seitenplatten scharf gekrümmt.

Die Gaumenzähne sind links 4, rechts 5 an der Zahl.

Das Tier, ohne Rüssel, misst $42 \mathrm{~mm}$.

Firoloida Lesueur 1817 .

Diese Gattung unterscheidet sich bekanntlich von Pterotrachea dadurch, dass der Schwanz sehr verkümmert ist, sodass der Nucleus fast am Ende des langen, cylindrischen Körpers gelagert ist. Der Rüssel ist viel schwächer und kürzer; die Flosse zwar gross, aber mit breitem, membranösem Unterrande versehen und nicht dem Nucleus, sondern den Augen genähert.

Trotz der zahlreichen Arbeiten, welche sich auf Firoloida in anatomischer Hinsicht beziehen (Lesueur, d'Orbigny, Souleyet, Gegenbaur, Macdonald, Huxiey u. A.), blieb noch Manches zu untersuchen übrig. Wenn auch das Material der Siboga-Expedition mir eine schöne Gelegenheit bot zu eingehendem anatomischem Studium der Gattung, so habe ich mich hier doch nur auf einige allerdings fragmentarische Bemerkungen beschränkt, welche hauptsächlich nur dazu dienen sollen den späteren Forschern die Unterscheiclung der Arten zu erleichtern.

Den ganzen Körper bei Firoloida iberzieht dieselbe weiche, ganz durchsichtige Bindesubstanz wie bei Pterotrachca. Höcker kommen aber niemals vor, auch auf der Stirne fehlen sie gänzlich. Nur hier und da finden sich kleine Zellenhäufchen, wie sie auch bei den Carinariiden beobachtet wurden (s. z.B. Taf, X, Fig. 52). 
Die Musculatur von Firoloida kommt in den Hauptzügen mit der von Pterotrachea, bei der die Verhältnisse am Genauesten von KaLide klargelegt wurden, überein. Nur ist sie schwächer ausgebildet, auch bilden die Fasern kein Netz.

Im Einzelnen lässt sich Folgendes sagen:

Auf dem Rüssel läuft die Musculatur longitudinal, ist aber zu beiden Seiten eines muskelfreien, schmalen Rückenstreifens etwas stärker beschaffen als sonst (Taf. XIV, Fig. 95). Die dorsalen Muskeln ziehen sich an der Basis des Rüssels zusammen und gehen als zwei dickere Stränge zwischen den Augen hindurch, um dann auf dem Rumpfe, wo der Rückenstreifen etwas breiter wird, die Längsrichtung beizubehalten. Auch die lateral und ventral dem Rüssel entlang ziehenden Muskeln bleiben auf dem Rumpfe longitudinal, und von einer Kreuzung zweier Schichten wie bei Pterotracha ist keine Rede. Ein muskelfreier Bauchstreifen kommt am Rumpfe, aber nicht am Rüssel vor (Taf. XIV, Fig. 96), bleibt bis zur Flosse ziemlich schmal, wird aber hinter ihr breiter und ist bis zum Schwanze zu verfolgen. Der oben erwähnte Rückenstreifen, der sich vorn auf dem Rumpfe deutlich erkennen lässt, wird allmählich breiter und weniger scharf auf der zweiten Hälfte. Am Ende des Rumpfes zieht sich der Hautmuskelschlauch zu einer dünneren Röhre zusammen und endet am Nucleus, ohne in den Schwanz einzutreten. Diesem kommen also keine Muskeln zu.

Die grosse, aber zarte Flosse besteht jederseits aus zwei uibereinander gelagerten Muskelschichten (Fig. 97, $f(m)$. Wie bei Pterotrachea verlaufen die Fasern der oberen Schicht von oben nach unten schräg nach vorn, und ziehen durchweg parallel, mit Ausnahme einer kleinen Stelle am Hinterrande, wo die Richtung fast senkrecht nach unten ist. Diese Schicht strahlt nach unten zu in einzelne, zarte Bündel aus, welche sich allmählich zuspitzen, und, am Rande der Flosse angelangt, sich dichotomisch spalten, um eine Verbindung mit den Bündeln der anderen Seite einzugehen.

Die untere Schicht ist schwächer und dünner, und kreuzt die obere fast rechtwinkelig; in den breiten, unteren Abschnitt der Flosse, der von den nach dem Rande ausstrahlenden, sich gabelnden Muskeln durchzogen wird, tritt diese zweite Schicht gar nicht ein.

Die Aufhängebänder der Flosse sind etwas anders beschaffen als bei der vorigen Gattung. Es kommen bei Firoloida nur zwei Muskelstimpfe vor (Taf. XIV, Fig. 97, a, b). Der vordere liegt in der Mitte der Flossenbasis und besteht aus den beiden kreuzweise verlaufenden Muskelsystemen $(a)$, welche, der Aussenseite der Rumpfmusculatur sich anschmiegend, in deren Fasern ausstrahlen, ohne aber irgendeine directe Verbindung mit ihnen einzugehen. Während das Ganze eine kleine, viereckige, nach aussen gebogene Lamelle darstellt, ist das zweite Band (b) andersartiger Gestalt und inserirt sich am Hinterrande der vorderen Lamelle. Es setzt sich nur aus den Fasern der oberen Flossenmuskelschicht zusammen, ist lang und platt und ist von den Rumpfmuskeln völlig getrennt. Die beiderseitigen Fortsätze convergiren nach oben, sind an ihren Spitzen, wo der Darmkanal über sie hinwegzieht, untereinander durch Bindegewebsfibrillen verbunden und, mittels ebensolcher Fäden, auch mit den dorsalen Rumpfmuskeln.

Wie schon im ersten Abschnitt dargetan wurde, kommt ein Saugnapf, mitten am Vorderrande der Flosse, nur dem Männchen zu. Wenn auch im Allgemeinen die drüsenartige Beschaffenheit des gleichnamigen Organes bei Ptorotrachea wiederholend, so ist er hier aber 
nicht nur viel kleiner, sondern entbehrt auch gänzlich der eigenen Musculatur, welche bei Pterotrachea in Gestalt zweier Paare von Muskelbuindeln, die sich mit der Flossenmusculatur nicht vermischen, beobachtet werden kann. Bei Firoloida konnte ich nichts Derartiges wahrnehmen.

Querverlaufende Muskeln kommen nur am Riissel vor, und zwar auf einem scharf umschriebenen Felde an der Unterseite. Es reicht von der Schlundmasse bis etwa zur halben Rüssellänge' (Taf. XIV, Fig. 96, gm ).

Die Tentakeln (Taf. XIV, Fig. 95, t) entspringen nicht an der Medianseite der Augen, wie bei Carinaria, sondern lateral, und ein wenig unterhalb des vorderen Abschnittes der Augen, welche in ihrem Bau der in Taf. XI, Fig. 66 angegebenen Gestalt bei Pterotrachea s. s. entsprechen. Bekanntlich kommen Tentakel nur beim männlichen Geschlechte vor und sind hier stattlich ausgebildet, während ich beim Weibchen keine Spur davon finden konnte, trotzdem dass sie hier nach VAYssière, wenigstens bei $F$. desmaresti und F. kowalcroskyi, wenn auch rudimentär, vorkommen sollen.

An der Oberfläche der Tentakel findet sich ein Pflasterepithel, das nach der Spitze zu allmählich höher wird aber einschichtig bleibt, und dessen Zellen sehr deutliche grosse Kerne enthalten. Unterhalb dieser Schicht breitet sich ein weitmaschiges Muskelnetz aus. Die unter den Augen vorbeiziehenden Muskeln (also nicht die zwischen den Augen hindurchgehenden Stränge, wie bei Carinaria) schicken einzelne Fasern in die Tentakel hinein. Hier verlaufen dieselben, sich mehrfach kreuzend und anastomosirend, bis zur Spitze des Organes. Die Höhle des Tentakels wird von einer glashellen Bindesubstanz ausgefillt, deren Formelemente sternförmige Zellen darstellen, und welche in der Längsachse einen Blutsinus erkennen lässt.

Dem Tentakel kommt ein eigener Nerv zu, der ihn in der Längsrichtung, ohne Verästelungen, gerade durchzieht, und an der Spitze in die cylindrischen Epithelzellen ausstrahlt. Zahlreiche Nervenfasern gehen vom Hauptnerven rechtwinkelig ab. Untersucht man den Ursprung des letzteren genau, so ergiebt sich, dass der Nerv unterhalb der Augenkapsel verläuft, um sich an der Vorderseite am Cerebralganglion, lateral und dorsal von der Abgangsstelle des Buccalconnectivs, zu inseriren.

Dieser Tentakelnerv wurde von Huxley und LeuckarT erwähnt; letztgenannter Forscher und Milne Edwards schreiben ihn auch Carinaria zu. Hier aber konnte Gegenbaur keine besondere Innervation nachweisen; mir selbst ist es ebensowenig gelungen.

Vor dem Nucleus, an der gleichnamigen Stelle wie bei Pterotrachea liegen Niere und Herz, die schon wiederholt (Huxley, Macdonald, Leuckart, Gegendaur) beschrieben wurden. Die Niere liegt auch hier (Taf. XIV, Fig. $98, n$ ) dem Nucleus am nächsten als ein länglicher Sack, dessen düne Wandung an verschiedenen Stellen kleine Zellenanhäufungen zeigt und an der rechten Seite eine mit deutlichem Sphincter versehene Öfnung nach aussen (no) besitzt, während am Vorderrand eine Communication mit dem Pericardialraum besteht. Das Atrium des Herzens $(a)$ ist nach oben gewendet, die $\operatorname{Kammer}^{1}$ ) $(v)$ entsendet zwei starke Äste, von denen der eine sich in den Nucleus hineinsenkt, der andere gerade nach vorn verläuft und den Vorderteil des Rumpfes versorgt. 
Dorsal, ganz an der Körperoberfläche findet sich ein hufeisenförmiges Organ, das mit dem länglichen Osphradium bei Pterotrachea übereinstimmt. Es wurde schon eingehend von Huxley, Leuckart und Gegenbaur beschrieben. Der Aussenrand (Taf. XIV, Fig. IO2, ar ) wird von einem mehrschichtigen Epithel gebildet, das lange Cilien tragen soll, welche ich aber bei meinen conservirten Tieren nicht wahrnehmen konnte. Unterhalb dieses Epithels und auch am Innenrande des Organes verlaufen hier und da dunklere Streifen, welche ich für Nervenpolster halte, während das Innere sich aus grossen, rundlichen Zellen zusammensetzt von drisenartiger Beschaffenheit. Der Aussen- und Innenrand sind wulstartig verdickt und heben sich deutlich hervor. Ein starker Nerv, der von dem, am unteren Pole der Herzkammer gelagerten Visceralganglion stammt, steigt links vom Herzen empor und inserirt sich mit einer ganglionären Anschwellung (gn) am Osphradium, und zwar am Innenrande desselben. Dieser Teil ist nach hinten gewendet und liegt unmittelbar an der Basis der sehr kleinen Kiemenblättchen, welche ich bei Firoloida auffand und deren Beschreibung unten gegeben werden soll.

Der Nucleus selbst ist zum grössten Teile ganz frei; und wird an den Seiten und hinten unmittelbar vom Wasser umspült. Die Analöffnung (Fig. 98, an) liegt wie bei Pterotrachea am oberen Pol. An der Unterseite findet sich, wie bei der eben genannten Gattung, ein kleiner Raum, der oberhalb des Schwanzes nach aussen muindet; der untere Pol des Nucleus ist also frei und nicht mit dem Schwanze verwachsen. Die Form des Eingeweidesackes ist rundlich, seitlich leicht zusammengedrückt; der Hinterrand ist etwas mehr convex als die Vorderseite.

Der Penis sitzt als kurzer, stumpfer Fortsatz der rechten Körperwandung auf, an der Stelle, wo die Rumpfmuskeln sich am Nucleus ansetzen (Taf. XIV, Fig. 98, p). Er ist sehr klein und hat an der medianen Seite eine tiefe Rinne, welche, als seichte Furche aus dem Nucleus herauskommend, sich allmählich vertieft und das Ende des Penis, welches knopfartig angeschwollen ist, einkerbt (Fig. IO3, sf). An der Basis des Penis und zwar an der Vorderseite inserirt sich ein langer, sehr dünnwandiger Schlauch (Fig. 98, $f$ ), der am Ende keulenförmig anschwillt und eine Menge fest verpackter Zellen einschliesst, deren Inhalt körnig beschaffen ist und welche noch einen Kern enthalten. Eine Öffnung nach aussen, welche von HuxLEy beschrieben wurde und äusserlich durch einen spitzen Fortsatz angedeutet werden soll, habe ich, ebensowenig wie Geginbaur, auffinden können; vielmehr stellte das Ganze nur einen allseitig geschlossenen, kugligen Körper dar, ohne Ausführungsöfnung und ohne centralen Hohlraum. Gegenbaur glaubte das Vorhandensein oder Fehlen einer Öffnung auf Altersdifferenzen zurückführen zu können und fasste das ganze Organ als Haftapparat auf, der bei der Copulation behülflich sei. Trotzdem dass kräftige Muskeln vollkommen fehlen und nur durch einzelne blasse Fasern auf dem dünnwandigen Schlauche ersetzt sind ${ }^{1}$ ), würde ich der Auffassung Gegenbaur's gewiss beitreten, wenn nicht ein einziges Männchen an der Aussenseite des Penis einen langen, nach hinten gerichteten, am Ende hakenförmig gekrümmten Fortsatz (Fig. IO3, h) aufgewiesen hätte, der ein ganz opakes Aussehen hatte und unter dem dünnen Epithel ein dichtes Netz von Längsund Quermuskeln zeigte. Drüsenfollikel gelang es mir nicht zu beobachten. Doch wäre, bei vergleichender Betrachtung der Verhältnisse bei den übrigen Heteropoden, dieser Fortsatz wohl

I) Zur Vervollständigung der Beschreibung sei noch erwähnt, dass in den Schlauch ein Nerv eintritt, der sich halbwegs gabelt, und sich an dem runden Knopfe verliert. 
als Haftapparat aufzufassen, was seine Lage und Gestalt einigermaassen wahrscheinlich macht. Dann wiirde allerdings der keulenförmige Körper als characteristisch für Firoloida zu betrachten sein. Merkwiirdig bleibt es, dass der eben erwähnte, cylindrische Fortsatz nur bei einem Exemplare vorkam, während alle übrigen Männchen keine Spur davon zeigten.

Die Buccalmasse am Ende des Rüssels ist nur wenig ausgebildet. Die Schlundkopfmuskeln, sowie der Zungenknorpel, bleiben klein und erreichen gar nicht die mächtige Grösse wie bei Pterotraclica. Am Rande der Gaumenrinne stehen keine Zähne; diese Schlundbewaffnung kommt also nur der vorigen Gattung zu. Die kurzen, cylindrischen, am Ende schwach angeschwollenen Speicheldrüsen münden vorn in die Mundhöhle, zu beiden Seiten der Radulatasche. Die Radula selbst ist relativ klein und nimmt von vorn nach hinten nur ganz langsam an Grösse zu, sodass der grösste Teil (etwa die letzten 20 Querreihen) sich nahezu gleich bleibt.

Die Platten der Radula wiederholen in vieler Hinsicht denselben Bau, der hei Pterotrachea beschrieben und abgebildet wurde; die Zahl der Transversalreihen ist etwas grösser, nämlich $27-28$.

Die vorstehenden, allerdings kurzen und fragmentarischen Beschreibungen der Gattung Firoloida beziehen sich sämtlich nur auf eine Art, welche von der Siboga-Expedition in grosser Zahl gefangen wurde. Dies ist die:

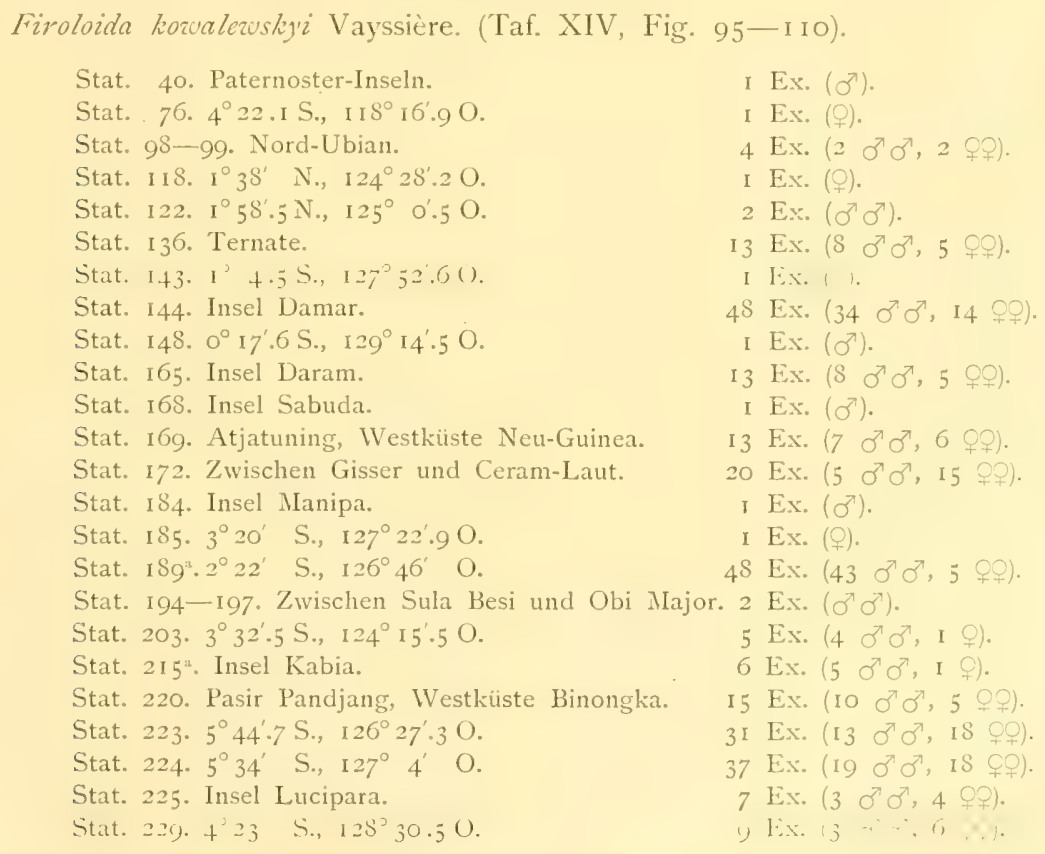

IVenn auch die verschiedenen Habitusbilder der Tiere (Fï. 104-I08) einige Differenzen aufweisen, so sind doch nur zufällige Zusammenziehungen oder Schrumpfungen in der Conservirungsflüssigkeit daran schuld, und sämtliche Exemplare stimmen im Wesentlichen überein. 
Der langgestreckte, drehrunde Rumpf geht vorn ohne Einschnürung in einen nur schwach ausgebildeten Rüssel über, während hinten, wo sich der Umfang des Rumpfes zwar gleich bleibt, der Hautmuskelschlauch aber beträchtlich enger wird, der Eingeweidenucleus den Körper abgrenzt, und nur ventral, unterhalb des Nucleus, der kurze Schwanz eine Fortsetzung des Leibes darstellt. Die Flosse ist nicht, wie bei Pterotrachea, dem Nucleus genähert, sondern im Gegenteil mehr nach vorn gerückt. Ihre Gestalt ist ziemlich symmetrisch und geht zur Genüge aus den Figuren 104-108 hervor.

Stirnhöcker oder sonstige Hartgebilde der Haut, sowie die grossen runden Flecken von Plerotrachea fehlen hier gänzlich. Die Oberfäche des Körpers überzieht ein niedriges Plattenepithel, dessen Zellen sich an einer Stelle ibereinander schichten, und zwar zwischen der Analöffnung und dem Osphradium, wo die Kiemen gelegen sind (Fig. 98-1OI, $k$ ). Es sind dies einfache Verdickungen der Haut, in’ denen ich Gefässe nicht wahrnehmen konnte. Erwähnenswert ist, dass sich auch hier ${ }^{1}$ ) ein Dimorphismus der Geschlechter bemerkbar macht; die Kiemen sind nämlich bei den Männchen (Fig. 98) nur wenig ausgebildet, oft kaum sichtbar, in den günstigsten Fällen sind nur zwei kleine Hervorragungen sichtbar, während beim weiblichen Geschlecht (Fig. 99-IOI) nicht nur die Zahl meist etwas grösser ist (man kann deren oft vier zählen, von denen dann die beiden seitlichen die kleinsten sind), sondern die Kiemen sind auch stets etwas besser entwickelt.

Wie im ersten Abschnitt erwähnt wurde, haben schon MAcDoxald, und neuerdings VArssière diese sehr kleinen Kiemen gesehen, und letztgenannter Autor hat sie auch als solche gedeutet, ohne indessen mehr als eine flüchtige Bemerkung im Text dieser Tatsache zu widmen. Für das Nähere kann auf das im ersten Abschnitt Gesagte verwiesen werden.

Die Musculatur des Leibes, sowie der Flosse wurde schon oben beschrieben und in Fig. 95-97 wenigstens teilweise wiedergegeben. Nur kann ich hinzufügen, dass sich vor dem Nucleus zuweilen eigentümliche Zusammenschnürungen des Rumpfes finden, von denen ein Fall in Fig. IO4 abgebildet wurde. Die vordere dieser Einschnürungen war zudem mit einer starken Torsion der Rumpfmusculatur verbunden, während die zweite (Fig. I I) nebst dieser Torsion die hier gelegenen Organe derartig verunstaltet hat, dass ich hier nur eine Herzkammer, aber kein Atrium beobachten konnte. Zweifellos sind solche Missbildungen nur zufällig und vielleicht dadurch entstanden, dass energische Entringungsversuche des Tieres, das am hinteren Körperende festgegriffen wurde, durch Drehungen um die Längsachse, die betreffende Stelle stark gedreht haben.

Nebst den Kiemen, von denen ich es dahingestellt sein lasse, ob sie auch bei anderen Firoloida-Arten vorkommen können, ist das hauptsächlichste Merkmal der Art in dem schon von VAYsSTÈre ganz richtig beschriebenen Schwanz gegeben. Er erwähnt nämlich „un prolongement charnu trilobé qui constitue l'extrémité caudale. Cette portion du corps de Firoloida Kowalewuskyi est assez caractéristique pour distinguer cette espèce de F. Desmaresti; sur le prolongement du corps nous avons d'abord un lobe médian, sorte de pyramide comprimée dont l'arête supérieure est seule distincte. Ce lobe médian offre de chaque côté, inséré un peu dor-

I) Weiter sind Geschlechtsunterschiede bekanntlich in Saugnapf und Tentakeln gelegen. 
salement, un lobe latéral plus petit en forme de denticule crochu à concavité interne et dont le bord externe englobe la partie inféro-antérieure du nucleus, puis va se perdre à la surface du corps".

Mit dieser Beschreibung, zu deren besserem Verständniss die Figuren 99- ro I dienen können, bin ich ganz einverstanden, mit dieser einzigen Einschränkung, dass sie nur für das Weibchen Gültigkeit hat. Hier findet sich wirklich ein dreilappiger Schwanz, dessen seitliche Fortsätze, je nachdem das Tier in Formol oder Alcohol aufbewahrt wurde, eine verschiedene Länge aufwiesen (vergl. z.B. Fig. 99 mit Fig. IOO u. IOI a). Beim Männchen ist der Schwanz. ausnahmslos einfacher gestaltet und wird hier nur durch den medianen, seitlich comprimirten Lappen des Weibchens repräsentirt (Fig. 98), an dessen Ende sich ein Schwanzfaden von sehr wechselnder Länge inserirt. Dieser Faden kommt zuweilen auch dem Weibchen zu (Fig. Ioo), scheint hier aber immer kleiner zu bleiben. Sein Aussehen ist variabel; bald stellt or nur ein einfaches plattes Band dar, mit unregelmässigen Anschwellungen (Fig. 98), bald erscheint er wie segmentirt (Fig. 108), indem die Knotenpunkte durch einen tiefschwarzen Ring umgeben sind. Segmentirungen, wie die Gliedmassen eines Arthropoden, wie sie Souleyet für F. lesucuri und VAyssière für $F$. desmaresti abbilden, habe ich nie gesehen. Bei starker Vergrösserung (Fig. 109) zeigt der Faden übrigens nahezu überall das gleiche Aussehen; an der Oberfläche liegt ein Plattenepithel, das sich bei der Zusammenziehung des Fadens in zahlreiche Querfältchen legt, darunter grobmaschiges Bindegewebe, während im Inneren sich Muskelfäden bemerkbar machen, die ich aber nie mit der Körpermusculatur in Verbindung treten sah, wie bei Pterotrachea, da der Schwanz gänzlich der Muskeln entbehrte. An einzelnen Stellen ist der Faden knotig verdickt. Das Ganze ist meist farblos; zuweilen kommt Pigment im Epithel vor.

Während beim Männchen, wie gesagt, der Faden immer vorhanden ist, fehlt er dem Schwanze bei den allermeisten Weibchen. Hier aber macht sich eine Eierschnur (Fig. 99-IO1) bemerkbar, welche zuweilen die Länge des Tieres erreicht und im Inneren eine Menge Eier birgt. Die Anordnung dieser Eier ist derartig, dass sie meist in drei um einander gewundene Spiralreihen innerhalb der Schnur liegen, am Anfang aber kommt oft nur eine einzige Reihe vor. Diese Stelle ist übrigens häufig zu einer dünnen Röhre verengt, welche die Verbindung mit einem Hohlraum am Hinterrande des Nucleus darstellt, dessen Epithel die Geschlechtsdriise darstellt.

Auffallend bleibt es, dass Schwanzfaden und Eierschnur einander zu vertreten scheinen. Kommt denn der Eierschnur die gleiche Function zu, wie dem Faden, dient sie also, wie dieser (wenigstens nach der Meinung verschiedener Forscher) zum Anlocken der Beute? Dies würde aber selbstverständlich die Fortpflanzung sehr beeinträchtigen; denn wenn die Schnur abgerissen wird, droht naturlich die Gefahr, dass die darin befindlichen Embryonen zu Grunde gehen. Die Schnur selbst, sowie die Eier, sind übrigens im Leben von glasheller Durchsichtigkeit, und das Ganze fällt also nicht durch Farbe auf. Eine feine, ziemlich regelmässige Querringelung lïsst sich an der Oberfläche der Schnur wahrnehmen.

Die aus 27 Querreihen zusammengesetzte Radula (Fig. I ro) zeigte, besonders bezüglich der Mittelplatte, zahlreiche individuelle Abweichungen; so gross aber, wie VArssière den Mitteldorn darstellt, der, nach ihm, fast die Länge der stark entwickelten Seitenhörner der Platte 
gleichkommt, fand ich diesen Fortsatz nie. Die am Vorderrande der Mittelplatte gelagerte "portion demi-membraneuse" (VAYssière), welche ich allerdings auch bei Pterotrachea nie vermisste, ist kein integrirender Teil der Radula, sondern nur eine Differenzirung der unterhalb der letzteren gelagerten Basalmembran. Zwischenplatte und Seitenplatten gleichen in ihrer Gestalt denen von Pterotrachea; die letztgenannten Platten aber sind etwas schlanker, habe eine flachere Krümmung, und zeigen an ihrer Basis einen zur besseren Befestigung dienenden, nach hinten und nach aussen gerichteten Fortsatz.

Gaumenzähne kommen bei Firoloida nicht vor.

Die Länge der Tiere wechselt von 4 bis zu $35 \mathrm{~mm}$., ohne den Rüssel einzurechnen.

Notizen über Lebensweise und Verbreitung der PterotracheidaE.

Innerhalb dieser Familie erreicht die Anpassung an die pelagische Lebensweise bei den Heteropoden ihre höchste Stufe. Der gallertige, äusserst wasserreiche Körper besitzt eine solche Durchsichtigkeit, dass sogar eine grosse Pterotrachea, im lebenden Zustande in ihrer natürlichen Umgebung, sich den Augen des Beobachters leicht entzieht. Nur bei den Bewegungen des Tieres wird man darauf aufmerksam gemacht. Das Schwimmen geschieht ziemlich rasch und in dieser Hinsicht besteht ein deutlicher Gegensatz zu den langsameren und plumperen Carinariidae. Bei starker Anstrengung werden die sonst energischen Schwingungen der Flosse fast ganz eingestellt und der ganze langgestreckte Körper bewegt sich schlängelnd im Wasser vorwärts. Dabei wird dann der lange Schwanzfaden, dessen Rolle im Leben des Tieres noch immer unsicher ist, nachgeschleppt. Beunruhigt man das Tier nicht, so sucht es mittels des sich ständig hin und her krümmenden Rüssels die Umgebung ab; freilich scheint das Benehmen mehr ein Tasten zu sein, und die grossen, complizirt gebauten Augen machen nicht den Eindruck, wesentlich mitzuhelfen, da, wie ich mich überzeugen konnte, das Tier, in gerader Linie fortschwimmend, gegen alle im Wege stehenden Gegenstände anprallt. Wird irgend eine Beute mit der Radula erfasst, so wird sie lange herumgetragen und allmählich, unter Mitwirkung der Palatinzähne (bei Pterotrachea wenigstens) verspeist. Die eigenen Artgenossen werden, wenn sie sich nicht erwehren können, ohne Gnade angefallen und getötet. Andererseits droht den Tieren die Gefahr, von den zahlreichen Feinden angefressen zu werden, und Pterotrachea, in allen Graden der Verstummelung, ist eine keineswegs seltene Erscheinung. Die energischen Bewegungen von Tieren, bei denen nur noch der Rumpf mit der Flosse übrig geblieben war, veranlassten d'Orbigny, und später Rattray, zu der Annahme einer Untergattung Anops.

Bezuiglich der Häufigkeit der Pterotracheidae scheint das Verhalten in verschiedenen Meeren nicht das Gleiche zu sein. Im Mittelmeer bilden sie unstreitig, wie schon Péron et Lesueur hervorheben, und alle Forscher in Neapel zugeben können, die Hauptmasse der Heteropoden iberhaupt und gehören zu den gewöhnlichsten pelagischen Tieren; ja, sie sind in dieser Hinsicht sogar den Atlantiden überlegen. Anders verhält es sich, wie es scheint, in den Tropen. Trotz der Angabe D'Orbigny's, der Pterotrachea hier in grosser Menge erbeutete, stimmen Huxter, 
Macdonald, Souleyet und Rattray in Anbetracht der relativen Seltenheit der schalenlosen Heteropoden ziemlich überein.

Die Befunde der Siboga-Expedition zeigen nun, dass im ost-indischen Gebiete die Pterotracheidae häufig auftreten. Die Arten von Pterotrachea wurden aber immer einzeln und nie zu grösseren Schwärmen vereinigt angetroffen. Bei Firoloida liegt allerdings die Sache anders; denn eine solche Menge, ein derartiges massenhaftes Auftreten dieser Gattung, und dazu noch einer einzigen Art, war noch nie verzeichnet worden.

Über den Verbreitungsbezirk der Arten lassen sich, bei der grossen Unsicherheit in der Systematik der Familie, zur Zeit noch keine zuverlässigen Angaben machen; nur ist clas Vorkommen von Firoloida kowalewskyi, welche Art ursprünglich von den Canaren verzeichnet wurde, im ost-indischen Meere erwähnenswert. 


\section{ABSCHNITT III.}

\section{DIE MORPHOLOGISCHE BEDEUTUNG DER HETEROPODENFLOSSE.}

Die Frage, ob das den Heteropoden zukommende Bewegungsorgan das in den verschiedenen Familien sehr verschiedene Ausbildung zeigt, mit dem sohligen Fuss der Gastropoden homolog sei, hat schon verschiedene Forscher beschäftigt, ist aber seit langer Zeit nicht wieder aufgenommen worden. Wenn ich es jetzt wage die Morphologie der Flosse zu besprechen, so will ich ausdrücklich hervorheben, dass wesentlich Neues hier nicht gegeben werden kann, vielmehr nur eine Combinirung zweier Theorieen versucht wird, welche Verbindung, wie ich meine, das Richtige trifft.

Die zwei wichtigsten Arbeiten, welche die morphologische Bedeutung der Heteropodenflosse einer eingehenderen Besprechung unterzogen, sind die fast gleichzeitig (I SS8) erschienenen Schriften Kalide's und Grobben's. Da besonders der Erstere sich auf eine ausführliche Darstellung der Ansichten seiner. Vorgänger einlässt und in den 18 Jahren, welche seitdem verflossen sind, soviel ich weiss, kein weiterer Versuch in dieser Richtung gemacht wurde, so kann ich mich darauf beschränken, hauptsächlich auf die Auseinandersetzungen KaLrDE's zu verweisen, wenigstens in historischer Hinsicht. Nur will ich ganz kurz angeben, welche Meinungen von den verschiedenen Autoren in Laufe der Zeit geäussert wurden.

Der Erste, der eine Homologisirung versuchte, war LEuckart, der die Flosse der Hetero. poden als den seitlich zusammengedruickten Gastropodenfuss auffasste, wobei der Saugnapf als Rudiment des Kriechfusses anzusehen wäre ${ }^{1}$ ).

Auch Huxley sprach sich in dieser Weise aus. Nach ihm wäre die Flosse als Propodium, der Saugnapf als Mesopodium zu betrachten, auch muisste der nach hinten hervorragende Schwanz ebenfalls als Teil des Fusses aufgefasst werden, der von ihm Metapodium genannt wurde. Alle drei Teile: Flosse, Saugnapf und Schwanz wären also Differenzirungen des Fusses, und zwar so, dass diese Dreiteilung den ursprünglichen Typus bei sämtlichen Weichtieren darstellte.

Die Ansicht Gegenbaur's stimmt fast ganz mit der von Leucrart und Huxley uiberein. Nur nennt er Flosse und Saugnapf zusammen das Propodium und fasst beide Gebilde somit als zusammengehörig auf. Der Schwanz wird auch hier als Metapodium bezeichnet. Später aber

1) Bezüglich der letzteren Meinung hat sich Leuckant aber nicht deutlich ausgesprochen. 
änderte Gegmadudr (Grundriss vergl. Anat, 1878) seine urspringliche Meinung dahin ab, dass die Flosse allein mit dem Gastropodenfusse zu vergleichen wäre, der Schwanz dagegen eine einfache hintere Fortsetzung des Körpers, rückwärts vom Fusse, darstelle und also nichts mit dem eigentlichen Fusse zu schaffen habe.

Die Stellung, welche Ray Lankesteir zu dieser Frage nahm ${ }^{1}$ ), wich in einigen Punkten ab. Er fasst die Flosse der Atlantiden als Propodium, aber teilweise auch als Mesopodium auf, während der Saugnapf als der andere Teil des Mesopodiums gedeutet wirc. Bei den Carinariiden und Pterotracheiden wird Flosse mit Saugnapf als Mesopodium bezeichnet; das Propodium aber bilde einfach die ventrale Fläche der vorderen Rumpfhälfte. Das Metapodium sei im Schwanze erhalten.

Kronx stützte sich vorwiegend auf seine an Heteropodenlarven gemachten Befunde. Err meint, dass der bei den Larven an der ventralen Seite, hinter dem Munde, auftretende Höcker, der hier ein Operculum trägt, den Gastropodenfuss darstelle; dieser Deckelträger bleibt nur bei den Atlantiden erhalten; bei den Familien aber, bei denen sich das Tier nicht in dic Schale zurückziehen kann oder gar keine Schale vorhanden ist, sei später der Deckel, und damit auch der Träger verschwunden.

FoL, der ebenfalls von entwicklungsgeschichtlichen Tatsachen ausgeht, sieht, ganz wie Kroms, den Deckelträger der Larve (und der ausgewachsenen Atlantiden) als Fuss an. Da die Flosse an einer scharf umschriebenen Stelle des Vorderrandes des Fusshöckers entsteht, kann sie, nach FoL, nicht als integrirender Teil des Gastropodenfusses, aufgefasst werden.

Letzterer Auffassung huldigte auch GrexAcher, der in einer ausfiuhrlichen Erörterung zeigte, „dass der Kielfuss als ein durchaus neues Gebilde, auch wenn er teilweise auf Kosten des Protopodiums entsteht, nicht mit dem Fusse der Gastropoden verglichen werden kann. Er ist ein Organ sui generis, characteristisch für die Heteropoden, und wir wollen ihn, im Gegensatz zum Protopodium, als Deutopodium bezeichnen". Die Protuberanz an der ventralen Fläche der Larve, der Deckelträger, ist, nach GREnacier, der eigentliche Gastropodenfuss, den er Protopodium nennt; dieses Protopodium ist bei den ausgebildeten Heteropoden nur bei den Atlantiden erhalten geblieben, bei den beiden anderen Familien aber nur im Larvenzustande erhalten und später ganz verschwunden.

Die Ansicht Grexacher's, dass die Flosse eine den Heteropoden eigentümliche Bildung darstelle, wurde nicht wenig verstärkt durch die anatomischen Befunde KaLide's, nach welchen die Flosse (wenigstens bei den Carinariiden und Pterotracheiden) eine Ausstrahlung des Spindelmuskels sei, und zu der Körpermusculatur in gar keiner Beziehung stehe. Eir sagt: ,während wir in dem Schwanze eine Ausstülpung des Körpers, hervorgegangen durch lokales Wachstum der Körperwände erblicken, müssen wir die Flossenbildung, wie sie uns bei.... Heteropoden entgegentritt, als eine Hervorsprossung des Spindelmuskels, oder eines Teiles desselben, auffassen". Die Flosse wird also als ein selbstständiges Organ betrachtet; und, in Übereinstimmung mit GrEAACIER, hält KALIDE den Saugnapf für unwesentlich, dem keine besondere morphologische Bedeutung beizumessen wäre.

I) Encyclopaedia britannica, $188_{3}$, vol. XVI, pag. 654 . 
Eine geringfügige Abänderung wurde dann noch von GrobBEx angebracht. Erstens ist nach ihm, die Heteropodenflosse zwar ein nur dieser Tiergruppe zukommendes Gebilde, nicht aber selbstständig entstanden, sondern eine Differenzirung des Protopodiums und deshalb nicht als Deutopodium, sondern als Pterygopodium anzusprechen, um damit eine gewisse Beziehung zum Fusse auszudruicken. Grobien hebt hervor, dass bei den Strombiden der Fuss sich in Deckelträger und in einen vom Körper scharf gesonderten, auf einem Stiele getragenen, Kriechfusse geteilt hat. Der Vorderrand dieses Stieles wäre dann bei den Heteropoden allmählich zu der Flosse ausgewachsen. Die phylogenetische Reihe der Heteropoden zeigt, nach Grobien, das Hervorwachsen dieser Flosse und das allmähliche Abdrängen des Kriechfusses (i.e. des Saugnapfes) in allen Stufen der Ausbildung. Bei dieser Wanderung des Saugnapfes verliert er immer mehr an Grösse, rückt vom Hinterrande der Flosse allmählich an die Unterseite und schliesslich sogar ganz nach vorn (bei Frroloida); bei den Pterotracheiden ist er ein secundäres Geschlechtsmerkmal geworden.

Aus dieser flüchtigen historischen Skizze geht hervor, dass die Meinungen der verschiedenen Forscher, wenn man zunächst nur die Flosse ins Auge fasst, in den folgenden zwei Sätzen zusammengefasst werden können:

I" Die Flosse der Heteropoden ist eine Differenzirung des ursprünglichen Gastropodenfusses, der seitlich zusammengedruckt ist, entweder in ganzer Ausdehnung, oder nur teilweise (Leuckart, Huxley, Ray Lankester, Gegenbaur).

2) Die Flosse ist ein vollkommen selbstständiges Organ, eine Bildung sui generis, welche nur den Heteropoden eigentumlich ist und hier als Deutopodium aufgefasst werden muss. Diese Meinung, auf die von KroHx und Fol gemachte Beobachtung sich stützend, nach welcher die Flosse bei der Larve an einer bestimmten Stelle vor dem Fusshöcker (Deckelträger) hervorwächst, wurde zuerst von GRENACHER geäusserst, später von KALIDE noch dadurch bestätigt, dass der Nachweis einer vollkommenen Unabhängigkeit der Flossenmusculatur einerseits und der Körpermuskeln andrerseits geliefert zu sein schien, indem die Flosse die Ausstrahlung des Spindelmuskels darstelle.

Wenn letztgenannter Autor zugibt: ${ }_{n}$ es ist wohl möglich, dass bei dem Hervorwachsen des Spindelmuskels aus dem Leibesraum diejenigen Gewebe, welche an der Stelle liegen, wo das Protopodium in den Körper übergeht, mit in die Neubildung hineingezogen werden, so dass es vielleicht den Anschein gewinnt, als ginge(n) die Flosse(n) aus dem Protopodium hervor", so nähert er sich damit der Ansicht Grobsen's, welche zwischen den beiden oben genannten Meinungen eine Mittelstellung einnimmt. Nach Grobsex wäre die Flosse am Vorderrande des Fussstammes entstanden, und stäncle somit in Beziehung zum Fusse, weshalb der Namen Pterygopodium vorzuziehen wäre. Einen Gegensatz zwischen Protopodium (= Kriechfuss der Gastropoden) und Deutopodium, wie Grenacher es will, weist Grobben somit zurück.

Bezigglich des Saugnapfes sind die Ansichten ebenfalls in zwei Gruppen zusammenzufassen: I" Der Saugnapf ist ein zufälliges Gebilde, dem keine morphologische Bedeutung zukommt (Grexacher, Kalide). Leuckart hat sich in dieser Hinsicht nicht bestimmt geäussert. 
20 Der Saugnapf gehört zum Gastropodenfusse und stellt entweder den ganzen Fuss clar (wobei seine Function noch fast ganz dieselbe bleibt) oder nur teilweise, indem ein Teil sich zudem noch in der Flosse, ein anderer Teil sich im Schwanze forterhält. Fï̈r diese Ansicht sprachen

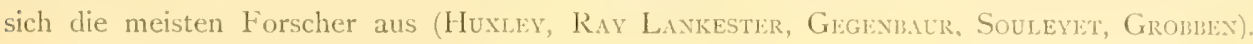

Was schliesslich den Schwanz betrifft, so muss von vornherein betont werden, dass es sich hier um ein Zusammenwerfen zweier verschiedener Begriffe handelt. Der Schwanz der ausgebildeten Carinariiden und P'terotracheiden ist deshalb demjenigen der Atlantiden nicht gleichzustellen, weil den letzteren 'Tieren ein gesonderter Deckelträgrer zukommt, cler den anderen Familien abgeht. Daher muss ich annehmen, dass dem Schwanze der Heteropoden nicht ïberall dieselbe Deutung zukommt, und werde diese Ansicht gleich näher begründen.

Am besten werden zuerst Flosse und Saugnapf zusammen besprochen.

Zunächst versuchen wir die Lösung der Frage: ist der Saugnapf ein accessorisches Gebilde. ohne besondere Bedeutung, oder aber haben wir in ihm den Gastropodenfuss zu erblicken?

Die Antwort kann, meiner Meinung nach, nicht allzu schwierig gefunden werden. Schon Grobber wies nach, dass der Saugnapf, bei den Atlantiden sehr gross und muskelreich (besonders bei Oxy'gyrus), und hier ganz nahe am Körper gelegen, allmählich bei den anderen Familien an Grösse verliert und dabei durch die sich immer mehr ausbildende Flosse vom Rumpfe abgedrängt wird. Aus dem Vergleich der Lage des Saugnapfes bei den phylogenetisch ältesten Formen (Atlantiden) und den nächsten Verwandten (Strombiden) geht hervor, dass der Saugnapf bei den Heteropoden den Kriechfuss der Gastropoden darstellt. Bei Oxygyrus und Atlanta ist die Function noch dieselbe geblieben, indem diese Tiere, nach den Angaben Souleyet's, sich mittels des Saugnapfes an fremde Gegenstände anheften können, ja, sogar zuweilen eine kurze Strecke kriechend zurücklegen, wie es die Gastropoden zu tun pflegen. Nach RAvg saugt auch Carinaria sich mit dem Saugnapfe an andere Körper fest.

Bei Carinariiden und Pterotracheiden tritt der Kriechfuss ontogenetisch sehr spät ${ }^{1}$ ) auf, kommt bei der letzten Familie nur den Männchen zu (in den allermeisten Fällen) und ist hier, wie ich mit Grobnex annehme, als secundäres Geschlechtsmerkmal aufzufassen ²); wenn er uiberhaupt noch zum Ansaugen benuitzt wird, wird dies wohl nur bei der Copulation stattfinden.

Der Kürze halber verweise ich hier auf die Beweisführung Gronbex's.

Jetzt fragt es sich aber: ist der Saugnapf allein der Kriechsohle der Gastropoden homolog? Mit anderen Worten: sind in anderen Teilen des Heteropodenkörpers vielleicht auch noch Reste des Fusses erhalten geblieben?

Zur Beantwortung dieser Frage muss nun die Besprechung der Flosse herangezogen werden. Erstens haben wir dann zu entscheiden, ob die Flosse einfach einen Fussteil darstelle oder eine Bildung sui generis sei.

Wäre das Erstere richtig, so müsste in der Flossenmusculatur, meiner Ansicht nach, nirgends eine Spur fremdartiger Muskeln gefunden werden; es miisste also die Hauptbedingung

1) Wenigstens nach den Angaben Kroun's. IVie sehr jungen Larven, welche ron l'ELsExEER abgebildet sind (s. weiter unten) weisen einen deutlichen Saugnapf auf.

2) Ein anderer Fall von Sexualdimorphismus, bei Mollusken sonst keineswegs bäufig, ist bei den Heteropoden noch in den Tentakeln der Firoloida-Männchen gegeben. 
gestellt werden: es kommen nur Fussmuskeln in der Flosse vor, und die Musculatur dieses letztgenannten Organes ist dem des Saugnapfes ganz ähnlich.

Dies ist nun aber keineswegs der Fall. Aus den Untersuchungen GEGENBaur's und Kilide's geht ïberzeugend hervor, dass die Flosse entweder ganz oder doch zum grössten Teile durch den Spindelmuskel gebildet wird; zudem wissen wir durch Krons und Fol, dass die Flosse gleich nach dem ersten Auftreten des Fusshöckers (der Deckelträger) als gesonderter Fortsatz entsteht.

Das Bewegungsorgan der Heteropoden ist somit eine Neubildung, aber es wird jetzt unsre Aufgabe sein, zu untersuchen, ob nicht etwa Reste von Fussmuskeln in der Flosse erhalten sein können. Dafür ist es nötig, den tatsächlichen Verhältnissen genau nachzugehen.

Die Flosse der Atlantiden lisst drei verschiedene Muskelschichten erkennen. Die beiden äusseren Schichten gehören der Körpermusculatur an und sind also wie diese, genau genommen, doppelt, indem sich die kreuzweise verlaufenden Faserzüge der Körpermuskeln ohne Weiteres auf die Flosse fortsetzen. Nur am freien Unterrande kommen diese Schichten nicht vor. Zu innerst strahlt der aus der Schale herabsteigende Spindelmuskel in die Flosse aus und durchsetzt sie bis zum Ende.

Die Körpermuskeln der Atlantiden setzen sich also continuirlich auf die Flosse fort. Diese Tatsache wurde schon ausdrücklich von Gegenbaur betont. Kalide der für die vollkommene Selbstständigkeit der Flossenmusculatur ganz bestimmt eintritt, citirt die diesbezügliche Stelle Gegevisaur's (er konnte selbst keine Atlantide untersuchen), und lässt darauf folgen: „man sieht ein, dass ich vollkommen geschlagen bin, sobald die von Gegenbaur gegebene Schilderung zutrifft.... Ich glaube, dass bei genauerer Untersuchung die Flosse von Atlanta dieselbe Beschaffenheit der Musculatur aufweisen wird wie die von Carinaria und Pterotrachea..... Es wird sich auch herausstellen, dass die Musculatur der Flosse nicht im Zusammenhang steht mit der Körpermusculatur, sondern irgendwie ihren Ursprung aus dem Spindelmuskel nimmt"

Da ich aus eigener Erfahrung die Angabe Gegenbaur's nur bestätigen kann, so muss ich diese Vermutung KALIDE's zuriickweisen.

Weiter wäre noch hinzuzufügen, dass die Muskeln des Saugnapfes nirgends mit der Flossenmusculatur in directem Zusammenhang stehen.

Bei Carinaria besteht die Flosse zu äusserst aus zwei Doppelschichten, welche deutlich vom Spindelmuskel herstammen. Sie gehen aus zwei Lamellen hervor, welche von der Basis der Flosse divergirend nach oben steigen und deren Fasern, zwischen welchen häufig Lücken zu sehen sincl, fast gerade emporsteigen, um oben zwischen den zu ihnen senkrecht verlaufenden Körpermuskeln auszustrahlen und keine Verbindung mit den letztgenannten Muskeln einzugehen. Nur am distalen Rande der oben erwähnten Muskellamellen gehen die liasern, ohne sich zwischen den Körpermuskeln zu verlieren, in die hintere WVand des gerade der Flosse gegeniber gestellten Nucleusstieles und von dort in den Eingeweidesack selbst über ${ }^{1}$ ).

Die beiden Muskelplatten sind offenbar aus dem Spindelmuskel entstanden zu denken, 
und zwar, wie ich annehme, derart, dass, im Interesse ciner besseren Zuriickichung der flosse in den Körper hinein, die T'asern des proximalen Teils der Mtuskelplatten sich secundia der Körpermusculatur angeschmiegt haben, olne aber, um es noch einmal hervorzuheben, mit iln in continuirliche Verbindung $\%$ treten.

In der Flosse teilt sich jede der mehrfach erwaihnten Platten in eine Inppeltschicht kreuzweise verlaufender lasem, deren Anordnung schon ganz genau von Kindn: geschiledert wurde und, wie ich bestitigen kann, der der Körpermusculatur gerade entgegengesetzh ist. Dic: beiden Aussenschichten der filosse von Carinaria sind also aus dem Sjjindelmuskel hervorgegangen und Körpermuskeln fehlen der Filosse gan\%.

Besonders wichtig scheint mir eine Angabe KAdub's, welche auch ich bestatigt, fancl. Er erwähnt nämlich, unterhalb der Doppeltschicht welche zu oberst liegt, „ein Muskelsystem. dessen zarte laserstränge parallel zu einander und in geringen Abstanden in der Richtung der Lïngsachse des Körpers verlaufen, vorn und hinten den Flossenrand erreichen und sich hien meist gablig spalten. Nach unten zu erstreckt sich dieses Stratum nicht ganz lis an den Rand der Flosse, sondern hört eine Strecke vor demselben auf". Wie Fasern dieser Mitic: I. schicht nun halte ich ganz bestimmt für Reste von Fussmuskeln. Firstens spricht dafiir ihre Anordnung in einer Richtung welche der Längsachse des Körpers parallel geht. Zweitens treten sie nicht mit den Aussenschichten in Verbindung, sondern bleiben durch eine Gallertschicht isolirt. Und endlich heften sie sich, wenigstens zum Teil, direct an den Saugnapf an. Dieser ist bekanntlich bei Carinaria unten am Hinterrande der Filosse gelegen.

Die Flosse wird also auswendig von den Ausstrahlungen des Spindelmuskels gebildet; zu innerst aber liegen noch Rudimente von Fussmuskeln.

Das Verhalten der Pterotracheiden ist bald besprochen. Die Flosse wird, wie schom wiederholt von anderen Forschern beschrieben worden, nach oben von drei Paar Muskclstimpfen (bei Pterotrachea) getragen (Reste des Riickzichmuskels), welche sich zwar auweilen (das vordere: Paar nämlich) der Körperwand anlegen, aber deren I'asern sich dann ganz aihnlich wie die des Vorderteils der Muskelplatten bei Carinaria verhalten und also zwischen den Körpermuskeln ausstrahlen. Das zweite und dritte Paar bildet cine Schlinge, deren Gipfel nur durch Jindegewebsfibrillen mit den Körpermuskeln in Verbindung tritt. Von den Stiimpfen wird weiter dic ganze Musculatur der lilosse geliefert; an der Aussenseite liegen hier also, rechts und links, Doppeltschichten, welche aber keine liussmuskeln zwischen sich fassen. Bei firroloida trifft das nämliche zu (s. S. 9o). Wo ein Saugnapf vorhanden (nur beim Männchen), sind dessen Muskeln wie besonders deutlich bei Pterolrachea ersichtlich ist, streng von der Flossenmusculatur greschiceden. Der Saugnapf liegt hier entweder in der Mitte des Unterrandes (Ptorotractica) oder an der Vorderseite der Flosse (Firoloida).

Fassen wir das über die Anatomie der Heteropodenflosse Gesagte kurz zusammen, so ergiebt sich das Folgende:

Die filosse ist eine den Heteropoden eigentümliche Neubildung, durch Ausstrahlung des Spindelmuskels entstanden. In dieser Hinsicht bin ich mit KarduE einig. Der Sipindelnuskel stellt das active Element dar, und treibt die vor ihm liegrenden Kijperteile vor sich her.

Ich stelle mir nun die phylogenetische Bildungsweise so vor: in Zusammenhang mit de: 
pelagischen Lebensweise entstand das Bedürfniss zu einem Fortbewegungsorgane. Dieses wurde dadurch geliefert, dass der Spindelmuskel, unabhängig vom Fụsse, aber zwischen diesem und der Basis des Rüssels die Körperwand vor sich her trieb und zwar derartig, dass nicht nur die gallertige Rumpfbedeckung, sondern auch die Körpermusculatur mit ausgestülpt wurde.

Die phylogenetisch älteste Familie (Atlantiden) zeigt noch jetzt dieses Verhalten.

KALIDE war der Ansicht, dass bei der Bildung der Flosse sich „nur die Epidermis und die gallertige Cuticula" (es ist dabei wohl die Cutis gemeint) auf sie fortsetzen. Das tatsächliche Verhalten bei den Atlantiden zeigt nun aber, dass ursprünglich auch die Körpermuskeln mit in die Flosse hineinbezogen wurden.

Bei den Carinariiden liegt die Sache anders. Erstens haben sich die Körpermuskeln von der Oberfläche der Flosse zurückgezogen, so dass jetzt die Aussenschicht durch den Spindelmuskel gebildet wird. Zugleich aber hat sich die Flosse hinten stark ausgebreitet und hat dabei den Fusstamm, der bei den Atlantiden noch unmittelbar mit dem Rumpfe zusammenhing, ganz in sich aufgenommen. Infolgedessen ist der Fuss (der Saugnapf) ziemlich weit vom Körper abgedrängt worden.

Ein wichtiger Beweis für diese Ansicht, welche zuerst von GrobBen ausgesprochen wurde scheint mir darin gegeben, dass die Fasern der Mittelschicht in der Flosse als Fussmuskeln gedeutet werden können, wie ich oben zu beweisen versuchte. Die Muskeln des Fussstammes sind also secundär in die Flosse hineinbezogen worden, und verhalten sich, in Gegensatz zum Spindelmuskel, ganz passiv.

Das Hineindrängen der Flosse zwischen Körper und Fuss ist bei den Pterotracheiden noch weiter gegangen, bei Firoloida liegt der Fuss (der Saugnapf) sogar in der Mitte des Vorderrandes der Flosse. Bei diesem Prozesse sind die Fussmuskeln, welche bei Carinaria die Mittelschicht der Flosse bildeten, gänzlich verschwunden; nur diejenigen Teile, welche mit dem Saugnapfe (bei Pterotrachea) zusammenhingen, sind erhalten geblieben und zeigen sich hier als ein vorderes und hinteres Paar kurzer Muskelbändchen, welche divergirend von der Oberseite des Saugnapfes nach oben steigen.

Das Letztere kurz zusammenfassend, können wir also sagen:

Die Heteropodenflosse ist eine Neubildung, durch Ausstrahlung des Spindelmuskels entstanden und zwar an einer Stelle unmittelbar vor der Basis des Fusses. Ursprünglich ist die Flosse noch mit der Körpermusculatur bekleidet. So tritt uns die Flosse bei den Atlantiden entgegen.

Später verschwindet die Körpermusculatur von der Flosse und diese drängt sich zugleich zwischen den hinter ihr gelegenen Fuss und den Körper hinein, wobei noch Reste von Fussmuskeln zwischen den beiden Platten des Spindelmuskels erhalten bleiben (Carinaria), oder, bei weiterer Abdrängung des Fusses vom Körper, diese Fussmuskeln nahezu oder ganz verschwinden (Pterotracheiden).

Die Flosse ist ursprünglich gänzlich unabhängig vom Fusse, tritt zu ihm später aber, secundär, in Beziehung. Sie ist somit ein Deutopodium, im Sinne Grexacher's und Kalide's, kein Pterygopodium, das, nach Grobben, aus dem Protopodium entsteht. Dem 
letztgenannten Forscher stimme ich aber ganz bei in der Deutung des Saugnapfes als Fuss, und in dem Abwärtsdrängen dieses Organes seitens der sich herausbildenden und immer mehr sich rückwärts vergrössernden Flosse.

Nach diesen Auseinandersetzungen fragen wir uns ab: was ist das Protopodium, der urspriingliche Fuss der Gastropoden, bei den Heteropoden? Wird dieser nur clurch den Saugnapf dargestellt, oder sind vielleicht noch andere Teile am Körper von ihm direct abzuleiten?

Zur Lösung dieser Frage müssen wir die Entwicklungsgeschichte herbeiziehen. Dank den Untersuchungen Krohn's, Gegensaur's und Fol's, wissen wir, dass bei der Larve, hinter dem Munde, ventral ein Höcker entsteht, der an der aboralen Fläche ein Operculum trägt; dieser Höcker oder Deckelträger ist ohne Zweifel als Protopodium (Grenacher, Grobien) zu deuten. Gleich vor ihm entsteht sehr bald, als beweglicher Fortsatz, die erste Anlage der Flosse. Es wächst dann der Körper des Tieres, als Schwanz, zwischen die Flosse und den Deckelträger hinein. Dabei stelle ich mich vor, dass das ursprünglich einheitliche Protopodium der Larve durch das erste Auftreten des Schwanzes in zwei Teile gespaltet wird: der vordere Teil wird der Saugnapf, der hintere, der noch lange das Operculum behält, bleibt bei den Atlantiden zeitlebens erhalten, verschwindet aber gänzlich bei den anderen Familien. Somit kommen Saugnapf und Deckelträger, welche zusammen das Protopodium bildeten, später durch das Hineindrängen des Schwanzes a us einander zu liegen.

Grenacher und Kalide, welche dem Saugnapfe keine Bedeutung beilegten, meinten den ursprïnglichen Gastropodenfuss n u r im Deckelträger erblicken zu müssen, und deshalb waren sie der Ansicht, dass das Protopodium den ausgebildeten Carinariiden und Pterotracheiden fehlte.

Eine wichtige Stütze für meine Auffassung, dass auch der Saugnapf zum Protopodium gehört, erblicke ich in einigen Figuren, welche Pelseneer in einer kürzlich erschienenen Abhandlung gab. Er hat (Taf. II, Fig. 3I, 36) zwei sehr junge, offenbar zu Pterotrachea ${ }^{2}$ ) gehörige Larven abgebildet, bei welchen die Schale und das sechszipfelige Velum noch in voller Ausbildung vorhanden sind. Der nach der Dorsalseite des hervorgewachsenen Schwanzes gedrängte Deckelträger besitzt ein grosses gewundenes Operculum. Bei diesen Larven ist an der Unterseite ${ }^{2}$ ) der beilförmigen Flosse schon der Saugnapf entwickelt. Ich nehme an, dass dieser Saugnapf an der Flosse nicht potentia, sondern ab origine tatsächlich vorhanden war, und, vor dem Auftreten des Schwanzes, mit dem Deckelträger zusammen, das Protopodium dargestellt hat. Diese Auffassung wäre aber nur durch genaue Beobachtung sehr junger Larven zu beweisen.

Der Schwanz der Atlantiden ist also aus zwei Teilen zusammengesetzt: I" aus dem Deckelträger (ein Teil des Protopodiums) und $2^{0}$ aus einer Fortsetzung des Körpers, dem eigentlichen Schwanze, unterhalb dieses Deckelträgers. Bei den iibrigen Heteropoden ist der Deckelträger verschwunden und nur der Auswuchs des Rumpfes bildet hier den Schwanz. Dass, wie Kalide vermutet, ein Rest des Deckelträgers, bei einigen ausgebildeten Carinariiden und Pterotracheiden, in den flossenförmigen Ausbreitungen am Schwanze, wie sie bei Carinaria-Larven

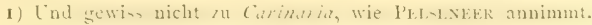

2) Die phylogenetische Bildungsweise der Flosse wird offenbar ontogenetisch beträchtlich verkiirzt.

SIBOGA-EXPEDITIE L. 
(nach IVirlonoxt und Pelseneer) und bei Cardiapoda vorkommen, zu erblicken wäre, kann ich nicht annehmen. Erstens liegen diese dünnwandigen, oft stark pigmentirten Gebilde an der Spitze des Schwanzes (Pterotracha, of auch Cardiapoda), oder sogar an dessen Unterseite ${ }^{1}$ ) (Carinaria, Cardiapoda). Zweitens besitzen sie entweder gar keine Musculatur, oder, wenn eine solche vorkommt, ist sie direct aus den eigentlichen Schwanzmuskeln hervorgegangen.

Allerdings dürte das ziemlich constante Vorkommen einer herzförmigen Flosse am Schwanzende, bei den Larven von Carinaria (Warlomont, Pelseneer), bei Cardiapoda und Pterotrachea in erwachsenen Zustande, auf eine gewisse Homologie dieses Organes hinweisen. Eine nähere Beziehung zum Protopodium ist aber meines Erachtens nicht nachzuweisen.

1) Nachgewiesenermassen drängt der hervorwachsende Schwanz den Deckelträger nach oben.

Zudem ist von PELSENEER (Fig. 31) eine junge Larve von Pterotrachea abgebildet worden, bei welcher der Deckelträger sich noch an der Riickenseite des Schwanzes findet, wo aber zugleich ventral am Schwanze zwei pigmentirte Läppchen zu sehen sind. 


\section{LISTE DER LITTERATUR.}

ADAMS und REEVE, s. REEVE.

Adasis, Genera of recent Mollusca, vol. II, 1855.

BENSON, Description of two new species of Carinaria, Journ. As. Soc. Beng, t. IV, IS35.

- Account of Oxygyrus, a new genus of pelagian Shells, Journ. As. Soc. Beng, t. IV, I\$ 35 .

Lo Branco, Le pesche pelagiche abissali eseguite dal „Maia” nelle vicinanze di Capri, Mitt. Zool. Stat. Neapcl, Bnd XV, 1902 .

Le pesche abissali eseguite da F. A. KRUP' col Yacht "P'uritan" nelle adiacenze di Capri ed in altre localitì del Mediterranco, Mitt. Zool. Stat. Neapel, Bnd XVI, I903.

DE Blainvilte, Manuel de malacologie et de conchyliologic, 1825 .

BOLL, Beiträge zur vergleichenden Histologie des Molluskentypus, 1869.

BORY DE SAINT Vincent, Voyage dans les quatre principales iles des mers d'Afrique, t. 3, iso4.

Bosc, Histoire naturelle des coquilles, $18{ }_{3} 6$.

BOVERI, Zellen-Studien. Uber das Verhalten der chromatischen Kern-Substanz bei der Bildung der Richtungskörper und bei der Befruchtung. Jen. 'Leitschr. für Naturw., Bnd 24, 1890.

Cantraine, Malacologie méditerranćenne, Nouv. Mém. Ac. Roy. Sci. 13rux., t. XIII, i\$4i.

CArus, Prodromus faunae méditerraneae, vol. II, p. II, 1890.

Delle Chinje, Mem. s. Stor. e not. d. an. s. vert., vol. IV, isz9.

- Descriz. e not. An. Invert. Sic., vol. II, 184 I.

_- Dei Molluschi P’teropodi c Etcropodi apparsi nel cratere napolitano, Rend. d. Ac. Borb. d. Sci. d. Napoli, vol. II, 1843 .

Nota iconografica intorno alla Carinaria mediterranea, Rend. d. Ac. Borb. d. Sci. d. Napoli, vol. III, IS4t

ClaUs, Das Gehörorgan der IIcteropoden, Arch. f. mikrosk. Anat., Bnd X11, 1876.

- - Über den acustischen $\Lambda$ pparat im Gehörorgan der Heteropoden, Archiv f. mikrosk. Anat., 13nd XV, 1878.

Costa, Note sur la Carinaire vitrée, Ann. d. Sci. Nat. t. XVI, i\$zg.

- Fauna Reg. Napoli, Eteropodi, 1852.

Crosse, History of Pterosoma with confirmation of Heteropod nature, Journ. Conch. vol. 44, I897.

Cuvier, Mémoire sur l'Haliotide et sur la l'térotrachée, Mém. p. scrv. ì l'hist. et l'anat. d. Mollusques, t. IV, 1817 .

Desinales, Cuviel's Règne Animal, Moll., 1836-1846.

Ednager, Die Endigung der Hautnerven bei Pterotrachea, Arch. f. mikrosk. Anat., Bnd XIV, $1 \$ 77$.

ESCHSCHOLT\%, in: OKEN'S Isis, I 825.

FAnRINGER, Über das Vorkommen einer Speicherniere bei Carinaria mediterranca, \%ool. Anz., 13nd 27, 1903.

FEIVKES, in: American Naturalist, vol. XVII, $188_{3}$. 
Fischer, IIanuel de chonchyliologie, $188_{3}-$ i $\$ 87$.

Fol, Sur le développement embryonnaire et larvaire des Hétéropodes, Arch. d. Zool. Exp., t. V, IS76.

FoRSKiL, Icones rerum naturalium, 1772.

- Descriptiones Animalium...., 1775.

GAIMARD, s. QUON.

GEgENBAUR, Über den Bau der Heteropoden, Zeitschr. wiss. Zool., Bnd IV, IS53.

Uber ein nierenartiges Excretionsorgan der Pteropoden und Heteropoden, Zeitschr. wiss. Zool., Bnd V, I 554 .

Über die Circulationsverhältnisse der Pteropoden und Heteropoden, Zeitschr. wiss. Zool., Bnd V, I 854.

Untersuchungen über Pteropoden und Heteropoden, 1855.

Gould, U. S. Exploring Expedition, vol. XII, I $\$ 52$.

- in: Proc. Bost. Soc. Nat. Hist., vol. VII, I86I.

GrAl, Fig. Moll. Anim. vol. IV, is 50.

GRENACHER, Zur Entwicklungsgeschichte der Cephalopoden, zugleich ein Beitrag zur Morphologie der höheren MIollusken, Zeitschr. wiss. Zool., Bnd XXIV, is74.

Abhandlungen zur vergleichenden Anatomie des Auges, T. II; das Auge der Heteropoden, Abhandl. Naturf. Gesellsch. Halle, Bnd XVII, I 886.

Grobeen, Zur Morphologie des Fusses der Heteropoden, Arb. Zool. Inst. d. Univ. IVien, Bnd VII, r887.

Hedley, Pterosoma Lesson claimed as a Heteropod, Proc. Malac. Soc. London, vol. I, IS95.

Hesse, Die Augen einiger Mollusken, Zeitschr. wiss. Zool., Bnd LXVIII, Igoo.

Hogx, (Lingual Dentition of Carinaria cristata) in: Transact. Roy. Micr. Soc. London, vol. XVI, IS68.

Huxley, Observations sur la circulation du sang chez les Mollusques des genres Firola et Atlanta, Ann. d. Sci. Nat. (3), t. XIV, I 850.

—- On the morphology of the cephalous Mollusca...., Philos. Transact, vol. I43, I852.

ILYIN, Das Gehörbläschen als statisches Organ bei den Pterotracheidae, Physiol. Russe, t. II, I900.

Das Gehörbläschen als Gleichgewichtsorgan bei den Pterotracheidae, Centralbl. Phys., Bnd I3, I90o.

JosEPII, Die vitale Methylenblaufärbungsmethode bei Heteropoden, Anat. Anz., I888.

KALIDE, Beitrag zur Kenntniss der Muskulatur der Heteropoden und Pteropoden, Zeitschr. wiss. Zool., Bnd XLIV, ISSS.

Keferstein, Heteropoda, in: Bronn's Thierreich, Bnd III, 2, rs66.

KROHx, Beobachtungen aus der Entwicklungsgeschichte der Pteropoden, Heteropoden und Echinodermen. Arch. f. Anat. u. Phys., 1856.

_- Beobachtungen aus der Entwicklungsgeschichte der Pteropoden und Heteropoden, Arch. f. Anat. u. Phys., I 857 .

Beiträge zur Entwicklungsgeschichte der Pteropoden und Heteropoden, IS60.

KRUkenberg, Die pendelartigen Bewegungen des Fusses von Carinaria mediterranea, Vergl. phys. Stud. I 880. DE Lamaxox, Mémoire sur les cornes d'Ammon, in: Voyage de la Pérouse....., I797.

LAMARCK, Système des Animaux sans vertèbres, ISor.

LESSON, Voyage de la Coquille..... t. II, Is 30.

Lesueur, Descriptions of six new species of the genus Firola, Journ. Ac. Nat. Sci. Philad., t. I, I\$I7.

- Character of a new genus, and descriptions of three new species upon which it is formed, Journ. Ac. Nat. Sci. Philad., t. I. ISI7.

Mémoire sur deux, nouveaux genres de Mollusques, Journ. Phys. Chim. et d'Hist. nat. t. S5, I8I7.

LEUCKART, Zoologische Untersuchungen, Heft 3, 1854.

LEvDig, Anatomische Bemerkungen über Carinaria, Firola....., Zeitschr. wiss. Zool., Bnd III, I85I.

LIxxÉ, Systema Naturae, Ed, XII, I766.

Lovèv, in: Öfversigt K. Vetensk, Ak.-Förhandlingar, I $\$ 47$. 
MAcdonald, On the Anatomy and Classification of the Heteropoda, Transact. Roy. Soc. Edinb., vol. XXIII, I $\$ 62$.

Discovery of buccal teeth in Firola, Quarterly Journ. Microsc. Sci. (I1), vol. 2, 187r.

Mandralisca, Monografia del genere Atlanta, Eff. sci. Sicil., vol. XXVIII, I840.

Mendelssom, Recherches sur les réflexes chez quelques Invertébrés, Compt. rend. Coners. Intern. de Méd., Paris, $190 \mathrm{I}$.

MiLne EDWARds, Observations sur la structure.... de quelques Mollusques, Ann. c. Sci. Nat. (2), t. XVIII, IS45.

M'Intosi, On a Heteropod (Altanta) in British waters, Ann. Mag. Nat. Hist., ISgo.

Moseley, Pterosoma (Lesson), Ann. Mag. Nat. Hist., I875.

Oberwimer, Zool. Ergebn. X, ges. v. S. M. Schiff „Pola”, Denkschr. Kais. Ak. Wiss. IVien, I3nd LXV, isoS. D'Orbigny, Hist. nat. des illes Canaries, t. II, I 836 .

_- Hist. phys., pol. et nat. de l'ile de Cuba, Mollusques, t. I, I84r.

Voyage dans l'Amerique méridionale, t. $\mathrm{V}, \mathrm{I} 8_{43}$.

PANCeri, Carinaria mediterranea (Lam.), in: Bullet. Assoc. Méd. Napl., is7.

PAneti, Beiträge zur Histologie der Pteropoden und Heteropoden, Arch. f. mikrosk. Anat., Bnd XXIV, 1885.

PEck, Heteropoda of the ${ }_{n}$ Albatross" Voyage, Proc. U.S. Nat. Mus., vol. XVI, 1893.

Pelseneer, Opercule des Hétéropodes, et syst. nerv. streptoncure des Hétéropodes, Bullet. Soc. Malac. Belg., I 892 (S. 35 u. S. $52-54$ ).

—_ Le syst. nerv. streptoneure des Hétéropodes, Compt. rend., T. CXIV, I 892.

- Biscayan Plancton collected during a cruise of H. M. S. „Research" 1900, Transact. Linn. Soc. London, vol. $\mathrm{X}$, Igo6.

Péron und Lesufur, Hist. du genre Firrola, Ann. Mus. d’Hist. Nat. Paris, t. XV, I810.

PFEFFER, in: Verh. Gesellsch. deutsch. Naturf. u. Aerzte, 63e Versamml., I89 I.

Philippi, Enumeratio Moll. Sicil., vol. I, I\$36.

- Fauna molluscorum..... utriusque Siciliae, vol. I, 1836.

- Handbuch d. Conchyl., I 853.

Poli, De Pterotracheae observatione in: velle CirAJE, Mem. s. storia e not. d. an. s. vert. d. regno di Napoli, vol. II, I 825 .

Testacea utriusque Siciliae, vol. III-IV, I $826-1828$.

Quoy und GAmard, Voyage de l'Uranie et de la Physicienne, t. 4, 1824.

-_ Description de dessins réprésentant la Carinaire de la Méditcranće, \nn. d. Sci. Nat., t. XVI, r\$29.

- - Voyage de l'Astrolabe, t. II, 1832.

RAFinesque-Schalatz, Précis des découvertes.... ISI4.

RANG, Observations zoologiques faites en juin 1826 à bord de l'Astrolabc, Bullet. Soc. d'Hist. Nat., t. XII, r827.

- - Observations sur le genre Atlanta, Mém. Soc. d’Hist. Nat. Paris, t. III, I827.

Sur la Firola caudina, Magasin de Zoologie, 1832.

RAxkF, Der Gehörvorgang und das Gehörorgan bei P'terotrached, Zeitschr. wiss. Zool., Suppl. Bnd XXV, I875.

RATTRAY, On the anatomy, physiology and distribution of the Firolidac, Transact. Linn. Soc. London, vol. XXVII, I87 I.

RAY-LANKESTER, in: Encyclopedia brittannica, vol. XVI, ISS3.

REEVE (ADAMS und --), Voyage ,Samarang", Mollusks, 1 S48.

- Description of a new species of Carinaria, Ann. Mas. Nat. Hist., IS42.

- Conch. Icon., vol. XV, I 865.

REtziUs, Zur Kenntniss des Gehörorgans von Pterotrachea, 13iol. Unters. Retzius, Bnd 10 , I902.

RI- (n), in: Hint. natt. Eirr., t. IV, is 25 , 
Smiti, Challenger Report, vol. LXXII, I88s.

Sulger, Zur Kenntniss des Gehörorgans von Pterotrachea, Schrift. naturf. Gesellsch., Danzig, Bnd I0, 1899. SOUleyet, Voyage autour du monde..... de la Bonite, t. II, i 852.

Sowerby, Notes on the genus Carinaria, with description of a new species, Proc. Malac. Soc. London, vol. I, I 895 .

Troschel, Zwei neue Heteropoden von Messina, Arch. f. Naturgesch. Jahrg. 21, Bnd I, I855.

Das Gebiss der Schnecken, Bnd II, I 856.

TRYON, Struct. syst. conch., vol. 11 , I883.

VArssière, Expéditions scientifiques du Travailleur et du Talisman, (Hétéropodes), I902.

Hétéropodes.... de l'Hirondelle et princesse Alice, Résult. d. camp. sci. Alb. d. Monaco, Fasc. 26, I 904.

VERANY, Journ. de Conchyl., t. IV, I853.

WaCkititz, in: Zool. Beiträge SchneIDer, Bnd 3, 1892.

WARLOMONT, Étude de quelques points sur la structure des Firoles, Journ. Anat. et Phys., t. XXII, ISS6.

IVoodward, Manuel de Conchyliologie, is7o. 


\section{REGISTER.}

\section{Atlanta}

A. affinis n. $\mathrm{sp}$.

A. cunicula Gould

A. depressa Souleyet

A. fusca Souleyet.

A. gaudichaudi Souleyet

A. gibbosa Souleyet

A. helicialis Sowerby

A. helicinoides Souleyet

A. inclinata Souleyet

A. inclinata Vayssière

A. inflata Souleyet

A. involuta Souleyet.

A. lamanoni (Eschscholtz).

A. lesueuri Souleyet

A. mediterranea Costa

A. oligogyra n. sp.

A. peroni Rang

A. planorboides (Forbes)

A. primitia Gould.

A. quoyana Souleyet

A. quoyana Vayssière

A. rosea Souleyet.

A. souleyeti Smith

A. steindachneri Oberwimmer

A. sp. (I) Gray.

A. sp. (2) Gray.

A. tessellata Gould

A. turriculata d'Orbigny

A. violacea Gould.

ATLANTIDAE .

$4,+5,61$

Cardiapoda d'Orbigny .

23,74

C. acuta n. sp.. . . . . . . . . . . 79

C. carinata d'Orbigny. . . . . . . . . 26

C. caudina Rang.......... . . 26

C. caudina (Souleyet) . . . . . . . . 26)

C. pedunculata d'Orbigny .
( . placenta (Lesson).

(. placenta Smith.

(. . placenta (Soulcyet)

C. richardi Vayssière.

C. sp. Gray .

C. sp. Macdonald .

C. sublaevis n. sp.

(.) trachydermon n. sp. .

\section{Carinaria}

CARINARIIDAE

I3, 6i, So

C. atlantica Adams et Reeve.

C. australis Quoy et Gaimard

C. cithara benson.

C. cornucopia Gould.

C. cristata Linné

C. cristata L. var. gracilis Reeve

C. depressa Rang .

C. elata Sowerby .

C. fragilis Bory de Saint-Vincent

C. galea Benson

C. gaudichaudi Souleyet

C. grimaldi Vayssicre

C. lamarcki Péron et Lesueur . . . . . 15, 1,2

C. lamarcki P. et L. var. oceanica Vayssière. 16

C. macrorhynchus n. sp.

C. pseudo-rugosa Vayssière

C. punctata d'Orbigny

C. sp. Smith.

C. sp. Warlomont.

Euryops (s. weiter unter Pterotrachea). $\delta_{3}$, it

\section{Firoloida}

F. aculeata Lesueur .

- 40 , siy

blainvilleana Lesueur ......... tt

F. demarestia Lesueur . . . . . . . . 42

F. desmarestia Souleyet . . . . . . . . 42

I. desmaresti Huxley . . . . . . . . . +3

F. desmaresti Vayssière. . . . . . . . 43 
F. gaimardi (d'Orbigny). . . . . . . . 45

F. gracilis (Troschel). . . . . . . . 46

F. lesueuri (d'Orbigny). . . . . . . . . 44

F. lesueuri Souleyet . . . . . . . . 45

F. kowalewskyi Vayssière. . . . . . 47, 93

F. vigilans (Troschel) . . . . . . . . 46

F. sp. Macdonald. . . . . . . . . 46

F. sp. Rattray . . . . . . . . . . . 47

"Helicophlegma candei" d'Orbigny. . . . 6, 50

"Monophora cylindracea" Quoy et Gaimard . 28

Oxygyrus Benson. . . . : . . . 4, 49

O. inflatus Benson. . . . . . . . . 5

O. keraudreni Rang . . . . . . . . . 5, 59 49

O. rangi Souleyet. . . . . . . . . 5, 5, 49

O. n. sp. Macdonald. . . . . . . 5, 49

Pterosoma Lesson . . . . . . 2 I

Pt. plana Lesson . . . . . . . . . 2 I

Pt. challengeri 12. sp. . . . . . . . . . 22

Pterotrachea Forskâl . . . . 29, SI

Pt. s. s. . . . . . . . $s_{3}, s_{4}$

Pt. aculeata Forskâl . . . . . . . . 40

Pt. adamastor Lesson . . . . . . . . . 40

Pt. (Hypterus) appendiculatus Rafinesque-Schmaltz. 40

Pt. challengeri n. sp. . . . . . . . . $\$_{4}$

Pt. coronata Forskål. . . . . . . . 3 I

Pt. cuviera (Lesueur). . . . . . . . . 32

Pt. edivardsi (Deshayes). . . . . . . . . 37

Pt. (Hypterus) erythrogaster Rafinesque-Schmaltz. 40

Pt. forstialia (Lesueur) . . . . . . . . . $3+$

Pt. frederica (Lesueur) . . . . . . . 33

Pt. frederici (Blainville) . . . . . . . . 33

Pt. friderici(ana) delle Chiaje. . . . . . 33
Pt. fredericia Cantraine

$\cdot 33$

Pt. gegenbauri (Vayssière). . . . . . . . 39

Pt. gibbosa (Lesueur) . . . . . . . . . 33

Pt. hippocampus Philippi . . . . . . . 36

Pt. hippocampus Vayssière . . . . . . 36

Pt. hyalina Forskâl . . . . . . . . . . 40

Pt. hyalina (cristallina) delle Chiaje . . . . 40

Pt. intermedia n. sp. . . . . . . . . . $\$ 6$

Pt. keraudreni Souleyet. . . . . . . . . 37

Pt. ("Firoloides") keraudreni) Rattray. . . . 40

Pt. lesueuri Risso. . . . . . . . . . 35

Pt. lesueuri Macdonald . . . . . . . . . 35

Pt. microptera n. sp. .. . . . . . . . . . $\$ 7$

Pt. (Euryops) mutabilis n. sp. . . . . . . Ss

Pt. mutica (Lesueur). . . . . . . . . . 34

Pt. mutica Cantraine. . . . . . . . . . $3 t$

Pt. mutica (Vayssière) . . . . . . . . . 34

Pt. (Euryops) orthophthalmus n. sp. . . . . So

Pt. peronia (Lesueur). . . . . . . . . . 52

Pt. („Anops") peroni d'Orbigny. . . . . . 40

Pt. pulmonata Forskâl . . . . . . . . 40

Pt. quoyana (d'Orbigny) . . . . . . . . 36

Pt. rufa Quoy et Gaimard. . . . . . . . 35

Pt. scutata Gegenbaur . . . . . . . . . $3 \mathrm{~s}$

Pt. souleyeti Vayssière . . . . . . . . . 39

Pt. sp. Cuvier . . . . . . . . . . 25

Pt. sp. Smith . . . . . . . . . $38, s_{4}$

Pt. ("Anops") sp. Rattray . . . . . . . 40

Pt. sp. Gray. . . . . . . . . . . . . 40

Pt. (Euryops) xenoptera n. sp. . . . . . . $\$ 8$

Pt. talismani (Vayssière) . . . . . . . . 39

Pt. umbilicata delle Chiaje. . . . . . . . 3T

Pterotracheidae . . . . . . 28, 8i, gr

"Timorienna firoloides" Quoy et Gaimard . . 2S 
TAFELN 


\section{TAFEL I.}

Wo bezuglich der Grösse nichts erwähnt wird, sind die Figuren unverändert wiedergegeben worden.

Fig. I-2. Oxy'gr'rus kerandreni (Rang). Nach OBERWIMMER.

Fig. 3-4. Oxy'grus rangi (Souleyet). Nach Sodleyet.

Fig. 5. "Oxygyrus n. sp." Macdonald. Nach Macdonald.

Fig. 6-7. Atlanta peroni Rang. Nach Soulevet.

Fig. 8. Atlanta lamanoni (Eschscholtz). Nach Eschscholtz.

Fig. 9-10. Atlanta sp. Gray.

Fig. 9 stellt wahrscheinlich O. keraudreni, Fig. IO A. peroni vor. Nach GRAY.

Fig. I I-I2. Atlante turriculata d'Orbigny. Nach Souleyet.

Fig. 13-16. Atlanta lesueuri Souleyet. Fig. I3-i5 nach Souleyet. Fig. I6 nach Oberwimmer.

Fig. 17-IS. Atlanta involuta Souleyet. Nach SOULEYET.

Fig. 19-20. Atlanta inflata Souleyet. Nach SouleyeT.

Fi:- 2I-22. Atlanta gibbosa Souleyet. Nach Souleyet.

Fig. 23-24. Atlanta helicinoides Souleyet. Nach Souleret.

Fig. 25-26. Attanta inclinata Souleyet. Nach Souleyet.

Fig. 27-27a. Atlanta inclinata Vayssière. Nach VAY'ssière.

Fig. 28-29. Atlanta gandichandi Souleyet. Nach Souleyet.

Fig. 30-33. Atlanta fusca Souleyet. Nach Souleyet. Fig. 32-33 Varietät (Soulevet).

Fig. 34-35. Atlanta depressa Souleyet. Nach Souleyet.

Fig. 36-37. Atlanta rosea Souleyet. Nach Souleyet.

Fig. 38-39. Atlanta quoyana Souleyet. Nach Souleyet.

Fig. 40. Atlanta quojana Vayssière. Nach VAYssière.

Fig. 4I. Atlanta mediterranea Costa. Nach CosTA.

Fig. 42-43. Atlanta violacea Gould, Nach DRAYTON.

Fig. 44. Atlanta tessellata Gould. Nach Gould. 
Sibigra-Expiditic. I.I. I. J. Tivit, Heteropoda.

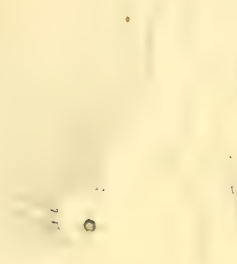

$12^{\prime}$

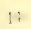

11

15

16

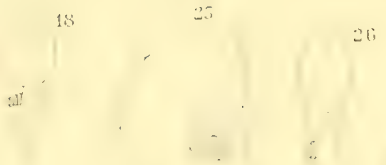

27.4

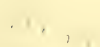

20

1:-

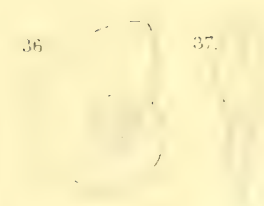

$\therefore 8$
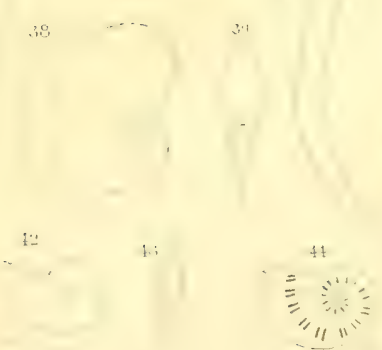




\section{TAFEL II.}

Iis. 45. Atlantia primitia Gould. Nach DANA.

I.is. 46. Atlanta cunicula Gould. Nach DANA.

lig. 47-49. Atlanta souleyeti Smith. Nach Souleret.

Fig. 49. Operculum.

IVis. 50-5I. Atlanta steindacleneri Oberwimmer. Nach OBER WmMar.

I.ig. 52-52a. Carinaria cristata (Linné). Nach SMith.

Fig. 53-54. Carinaria cristata var. gracilis Reeve. Nach REEvE.

Fig. 55-58. Carinaria lanarcki Péron et Lesueur. Fig. 55 nach ReEve, Fig. 56-58 nach Costa.

Fis. 59. Carinaria fragilis Bory de Saint-Vincent. Nach BORY DE SAINT-VINCENT.

Fis. 60-6I. Carinaria depressa Rang. Orig. 2 .

lig. 62-63. Carinaria australis Quoy et Gaimard.

Fig. 62 nach QUOY et GAIMARD, Fig. 63 nach VAYSSIÈrE.

Fis. 64. Carinaria cithara Benson. Orig. $\mathrm{I}^{1 / 2}$.

Fin. 65. Carinaria galea Benson. Orig. $1 \%$. 


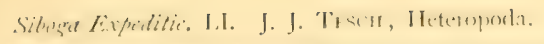

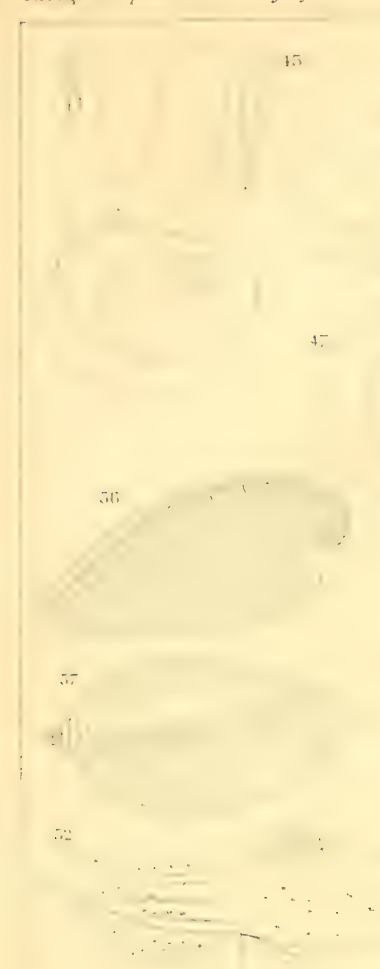

H:

1.. 




\section{TAFEL III.}

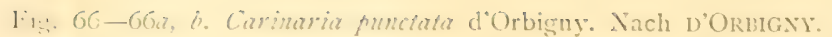

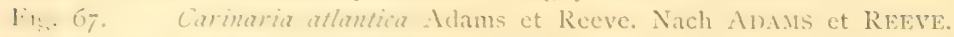

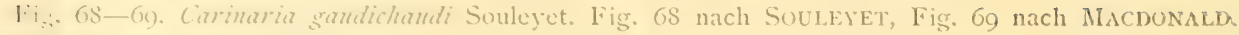

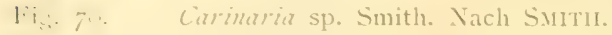

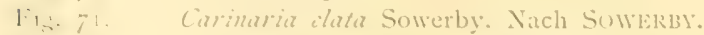

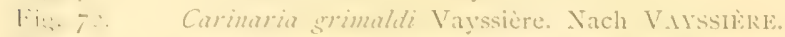

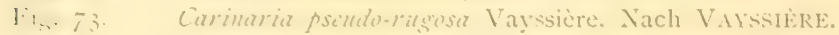

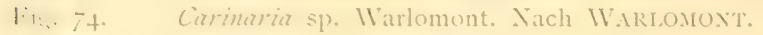

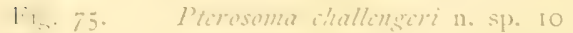

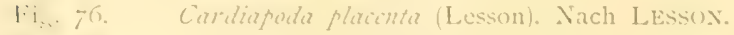

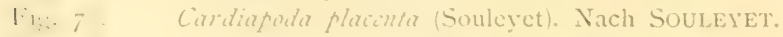

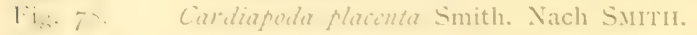

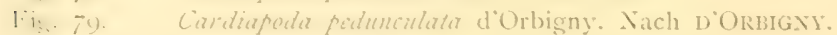

1... So. Cambiapoda sp. Gray. Nach Gray.

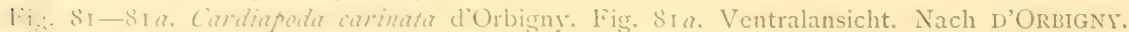

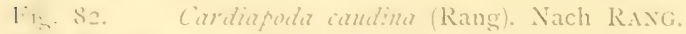

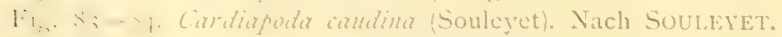

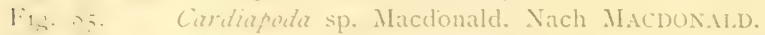

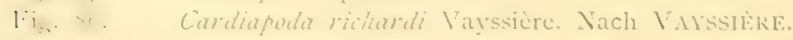

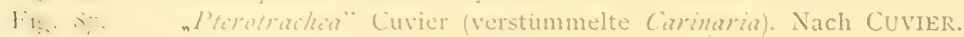


(.).

$=\quad \therefore+\cdots$

$\therefore \because$

,

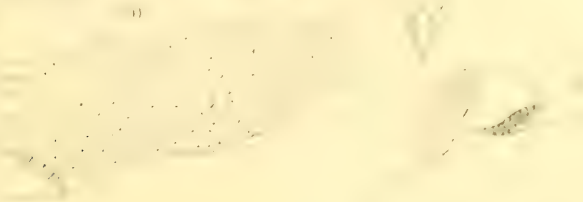

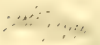

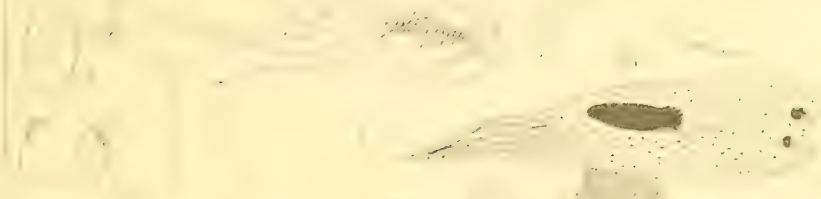

$+\cdots \cdots$

$-1$
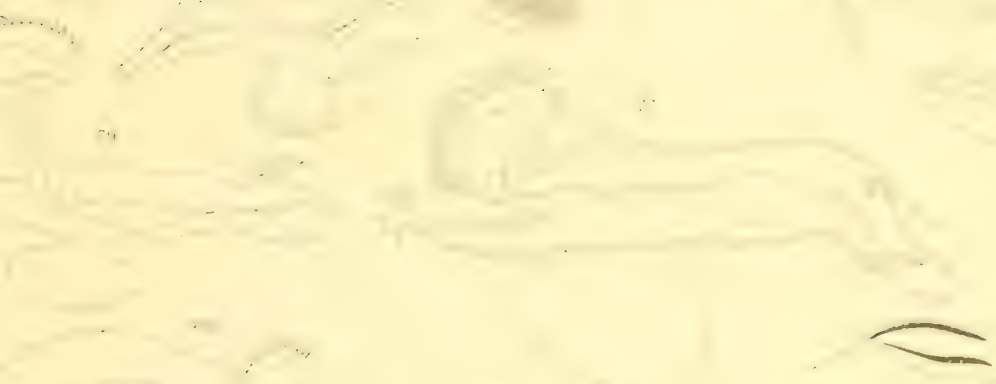

W.

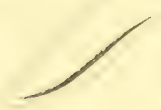

$\ldots$

, :

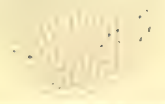






\section{TAFEL IV.}

Iis. SS. Carinaria sp. Rattray. Nach RATTRA:

Fis. Su. "Cardiapode fedunculata" d'Orbigny. Nach RATTRAs:

Jis. (w). "Carinaroides" sp. Rattray. Nach RAtTRAY.

Iive. y1. Pterotrachea coronata Forskâl. Nach VAYssière.

Iij. 92. Pterotrachea cuviera (Lesueur). Nach Lesueur.

Fis.s. 93. Pterotrachea peronia (Lesueur). Nach Lesueur.

lï.s. 4. Pterotrachea gibbosa (Lesueur). Nach Lesueur.

Tin. 155. Pterotrachea frederica (Lesucur). Nach Lesueur.

Fis. (1). Pterotractea frederici Blainville. Nach DE BLanvilue.

Iis... 1\%. Picrotrachea fridericilana) Chiaje. Nach Delde Chidje.

Fi... w. Pterotrachea forskalia (Lesueur). Nach Lesueur.

Iis. (m). Pterotrachea mutica (Lesueur). Nach LESUEUR.

Iiv. Iow. Pterotrachea mutica Cantraine. Nach Keferstein.

Fis. IOI. Pterotrachea mutica (Vayssière). Nach VAyssikre.

Fis. 102. Pterotrachea mufa Quoy et Gaimard. Nach QUOY et Gaimakd. 1/. X Fï. In. Pterotrachea lesuenri Risso. Nach Risso. 
Sibogr Expeditie. LI. J. J. Tescri, Heteropoda.

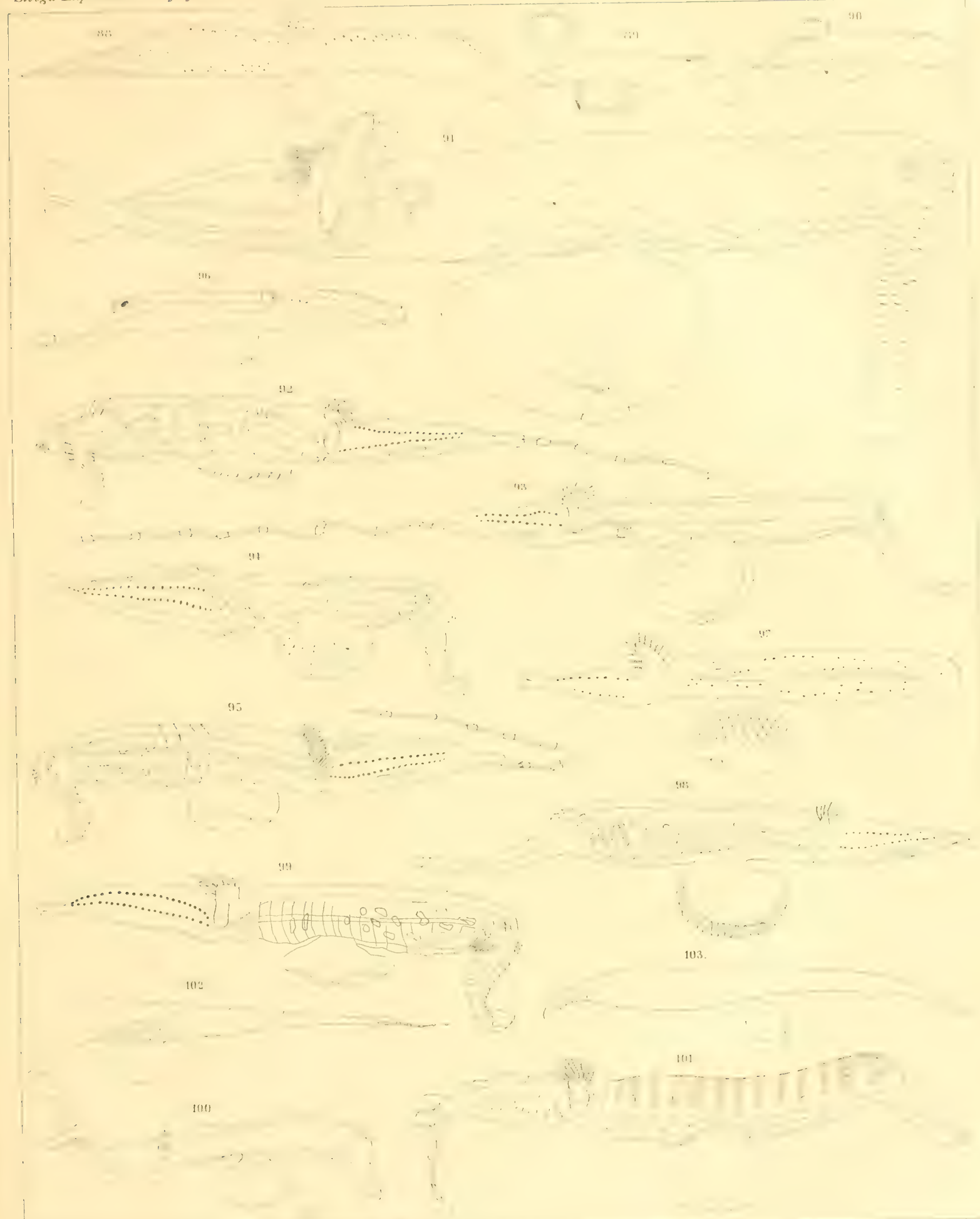






\section{TAFEL V.}

Iiis. 104. Pterotrachea lesuenri Macdonald. Nach Macdonald.

Iiv. 105. Pterotrachea adamastor Lesson. Nach Lesson.

Iiv. 106. Pterotrachea hippocampus Philippi. Nach PHILIPpI.

lis... 107. Pterotrachea hippocampus (Vayssière). Nach VAỴssière.

IFis. IOS- Iog. Pterotrachea quoyana (d'Orbigny).

Fig. Iog. Ventralansicht. Nach D'ORBIGNY.

I:is. I Io. Pterotrachea edwardsi Deshayes. Nach Deshares.

IF... II I. Pterotrachea umbilicata Chiaje. Nach CHIAje. 1/3

Iis. II 2. Pterotraclea keraudreni (Souleyet). Nach Souleyet.

Iiv. II3-I I4. Ptcrotrachea scutata Gegenbaur.

Fig. II4. Vorderteil, ventral. Nach GEgenBAUR.

Fin. II 5-i isa, b. Pterotrachea sp. Smith.

Fig. I 15a. Russel, von oben. Fig. I I5b. Hautfleck. Nach Sirtr.

Fig. I16. Pterotrachea sonleyeti (Vayssière). Nach VAYssière.

Fis. I17. Pterotrachea gegenbauri (Vayssière). Nach VArssière.

Fig. I 8 . Pterotrachea leyalina Forskal. Wahrscheinlich eine Firoloida. Nach Forskil.

Fis. I I9. Pterotrachea hyalina (cristallina) Chiaje. Nach Delle ChIAjE.

Fis.r. I20. Pterotrachea pulmonata Forskâl. Nach Forskil. 
Siluga Expertitic. I.I. J. J. Trsch, ITeteropoda.

i1.

115

tIII

117

114 




\section{TAFEL VI.}

I.i... I2 I-122. P'terotrachea (Ancps) peroni d'Orbigny.

Fig. I22. Ventralansicht. Nach D'ORBIGNY:

Fic. I23. Pterotrachea (Anops) sp. Rattray. Nach RATTRAl.

Fic. 124. "Firoloides keraudreni" Rattray Nach RATTRAY.

Fi... 125. "Firola sp." Gray. Wahrscheinlich eine Firoloida. Nach Grar.

Ii_. 126. "Firola sp. jun." Quoy et Gaimard. Wie die Vorige. Nach Quor et GaIMaRD.

1.1. 127. Firoloida demarestia Lesueur. Nach LEsueur.

Ii $;$ 128. Firoloida desmarestia Souleyet. Nach Souleyet.

1.... 129. Firoloida desmarestii Huxley. Nach Huxley.

Ii... I30-130a. Firoloida desmaresti (o') Vayssière. Nach VAyssiére.

Ií. I 3 I. Firoloida blainvilleana Lesueur. Nach LEsUEUR.

I.... I32. Firoloida aculeata Lesueur. Nach LESUEUR.

I.i. I33-I33a. Firoloida lesueuri (d'Orbigny).

Fig. $133 a$. Ventralansicht. Nach d'Orbigsy.

I.... 134-134\%. Firoloida gaimardi d'Orbigny.

Fig. I $34 a$. Ventralansicht. Nach D'ORIBGNI:

I i : I 35. Firoloita lesuewri Souleyet. Nach SoulereT.

Fi.. I36. Firoloida gracilis (Troschel), Nach TroscheL.

I'13. 137. Firoloida wigilans (Troschel). Nach TroscheL.

IFi... I 38 . Firoloida. sp. Macdonald. Nach Macboxald.

Irig. I39-139a. Firoloida kowalea'shi Vayssière. Nach VAlssière.

I: 140. Firoloida sp. Rattray. Nach RATTRAl: 


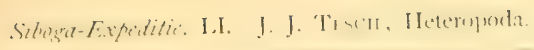
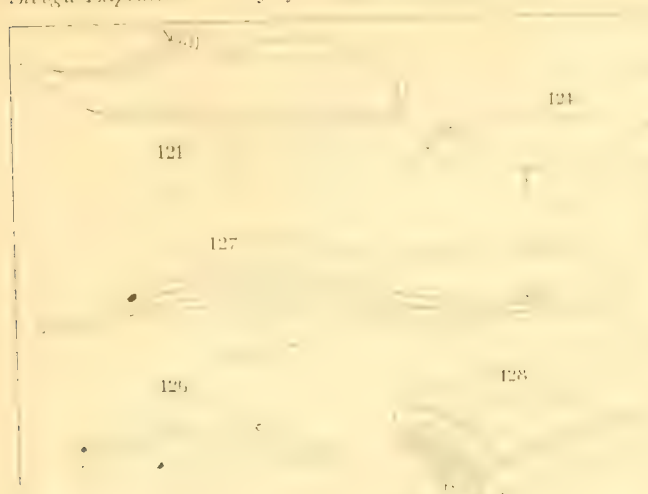

$1 \cdots$

i?

$=$

$1 \cdots:$

$1: 2$

1,1

$1 \div 4$

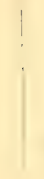

$1.3 t$

$1: 2$

Iis

$1: 1 \cdot 1$

$1: 31$

lis:

15:

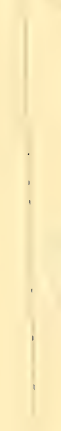






\section{TAFEL, VII.}

lig. I. Allanfa poroni Lesucur.

lit:. I. Zungenknorpel etc. von Atlank peroni Lesucur, $40 \times$; von unten. retr, Retractoren des Schlundkopfes; $z k$, 'Zungenknorpel; $r$, Radula.

Fig. 2-4. Oxygyrus rangi Souleyet.

lii... 2. Schale, $38 \times$; von oben.

fir.. 3. Radula, $290 \times$

fii.. I. Wellenlinien auf der Schale, $76 \times$.

I:is. 5. Radula von Oxygyms licrautrini Lesueur, $220 \times$.

lii... (1.l. Operculum von Oxygyrns licrandreni Lesucur, $10 \times$.

lia... h Operculum von Oxygyrus rangi Souleyet, $25 x$.

li: 7. Augen und Tentakel von Atlanta peroni Lesucur, $25 \times$; $t$, Tentakel; av, tentakelförmiger Fortsatz an der Innenseite der Augen.

lii... \&. Ruissel von Allanta peroni Lesueur $25 \%$, von oben. $k$, Zungenknorpel; esp, vorderste Speichelchriisen; r, Radula; $m$, Muskeln des Schlundkopfes; lsp, zwcites Paar Speicheldrüsen.

lig. 9-10. Atlanta affinis n. sp.

lii:. y. Schale, ro $\times$; von oben.

I.1... I0. Radula, 220>.

Fig. II-13. Allanta gaudichandi Souleyet.

Fi... II. Schale, $35 \times$; von oben.

li... 12. Dicselbe, $35 \times$; von der Mündungsseite.

Iin. 13. Raclula, 390 


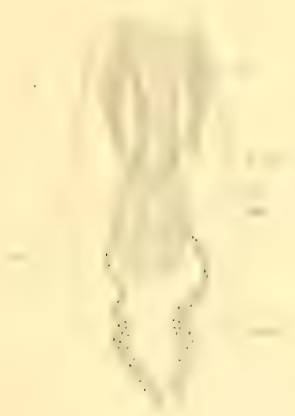



. 


\section{TAFEL VIII.}

Fig. 14-18. Athanta oligogyra n. sp.

Iix. 1.4. Schale, $35 x$; von oben.

Fis. I5. Dieselbe Schale, $35 \times$; von der Mündungsseite.

Ii... I6. Radula, $390 \%$

1F. I7. Eine andere, kleinere Schale, $35 \times$; von oben.

Fi... IS. Dieselbe, $35 x$; von der Mündungsseite.

Fig. 19-2r. Atlanta infata Souleyet.

Iif. 19. Schale, $35 \times$; von oben.

Fis 20. Dieselbe, $35 \times$; von der Mündungsseite.

Fis. 21. Radula, $390>$.

Fig. 22-24. Atlanta rosea Souleyet.

Ii... 22. Schale, $35 x$; von oben.

Fis. 23. Dieselbe, $35 \times$; von der Muindungsseite.

Iis. 24. Radula, $390 \times$.

Fi.. 25. Radula von Allanta turriculata Souleyet, 650 .

11 2\%. Radula von Itlanta inclinata Souleyet, 390

lis. 2,- Radula von Atlanta gibbosa Souleyet, 390 .

Fig. 2S-30. Atlanta fusca Souleyet.

I. 2S. Schale, $35 \times$; von oben.

lin. 21). Dieselbe, $35 \times$; von der Mündungsseite.

F... 3. Dieselbe, $35 \%$; von unten. 





\section{TAFEL IX.}

Fig. 31-34. Carinaria lamarcki Péron et Lesueur.

l:is. 31 . Höcker auf dem Körper, $52 \times$; zu jedem geht ein zarter Nervenfaden, uf; hf, Hautfleck.

liv. 32. Schwanzende, $2 \times$; von rechts. Es sind hier Höcker und Hautflecken gut auseinander zu halten. An der Unterseite, nahe dem Ende findet sich eine flügelförmige Ausbreitung.

I:iu. 33. Schwanzmuskeln, $52 \times$; lm, Längs-, qm, Quermuskeln; hf, Hautflecken.

Ii.s. 3.t. Begattungsorgane, IO $x$; $f$, Samenfurche, dic sich auf dem Penis, $P$, in eine tiefe Rinne fortsetzt. Ha, Haftapparat.

Fig. $35-42$. Carinaria cristata Linné.

Fig. 35. Exemplar von Stat. 227, 1/2 $\times$; das Tier wurde an der Oberfläche treibend gefunden, ohne Nucleus und Schale, und mass $42 \mathrm{~cm}$. Es wurde dann gleich eine farbige Skizze angefertigt, um die Farben, welche das lebende Tier besass, zu zeigen; da aber diese Zeichnung dem wirklichen Habitus des Tieres nicht ganz entsprach, habe ich eine neue Abbildung des Tieres gegeben, und darauf die urspriinglichen Farben, welche nach langer Conservierung fast ganz verschwunden waren, anbringen lassen.

Iiis. $3^{6}$. Exemplar von Stat. 266, I $\times$; stark verstümmelt und dennoch offenbar lebend aufgefunden. Weiteres s. im Text.

Fin. 37. Exemplar von Amboina, I $x$; es wurde mir von Prof. WEBER eine Abbildung geschickt, welche sich offenbar auf $C$. cristata bezieht, und in 1860 angefertigt wurde. Sie ist hier genau reproduzirt worden, ohne dass ich für die Farben selbstverständlich verantwortlich sein kann. WVeiteres s. im Text.

Fiv. 38 . Schale, I $x$; nach einer Schale im Museum zu Leyden, welche mir von Dr. Horst freundlichst zu Verfügung gestellt wurde. Das obere Ende war abgebrochen.

liv. 3\%. Schale der Siboga-Expedition, I

livis. 40. Dieselbe Schale, Spitze, 5 .

lis. 41. Höcker auf dem Körper, $220 \times$; $k z$, Knorpelzellen, welche das Innere ausfullen; $a$, isolirte Knorpelzellen. In der Nähe des Höckers ist das Flächenepithel, $f e$, verschwunden; unterhalb dieses Epithels liegen sternförmige Bindegewebszellen, bs, und die isolirten Knorpelzellen, $a$, weiter reich verästelte Nervenfäden, $n f$.

Fig. +2. Muskeln des Schwanzes, $52 x$; lm, Längs-, qm, Quermuskeln; die Letzteren treten an verschiedenen Stellen mit einander in Verbindung. 
Sibega Expeditie. 1.I. J. J. Тesch, Heteropoda.

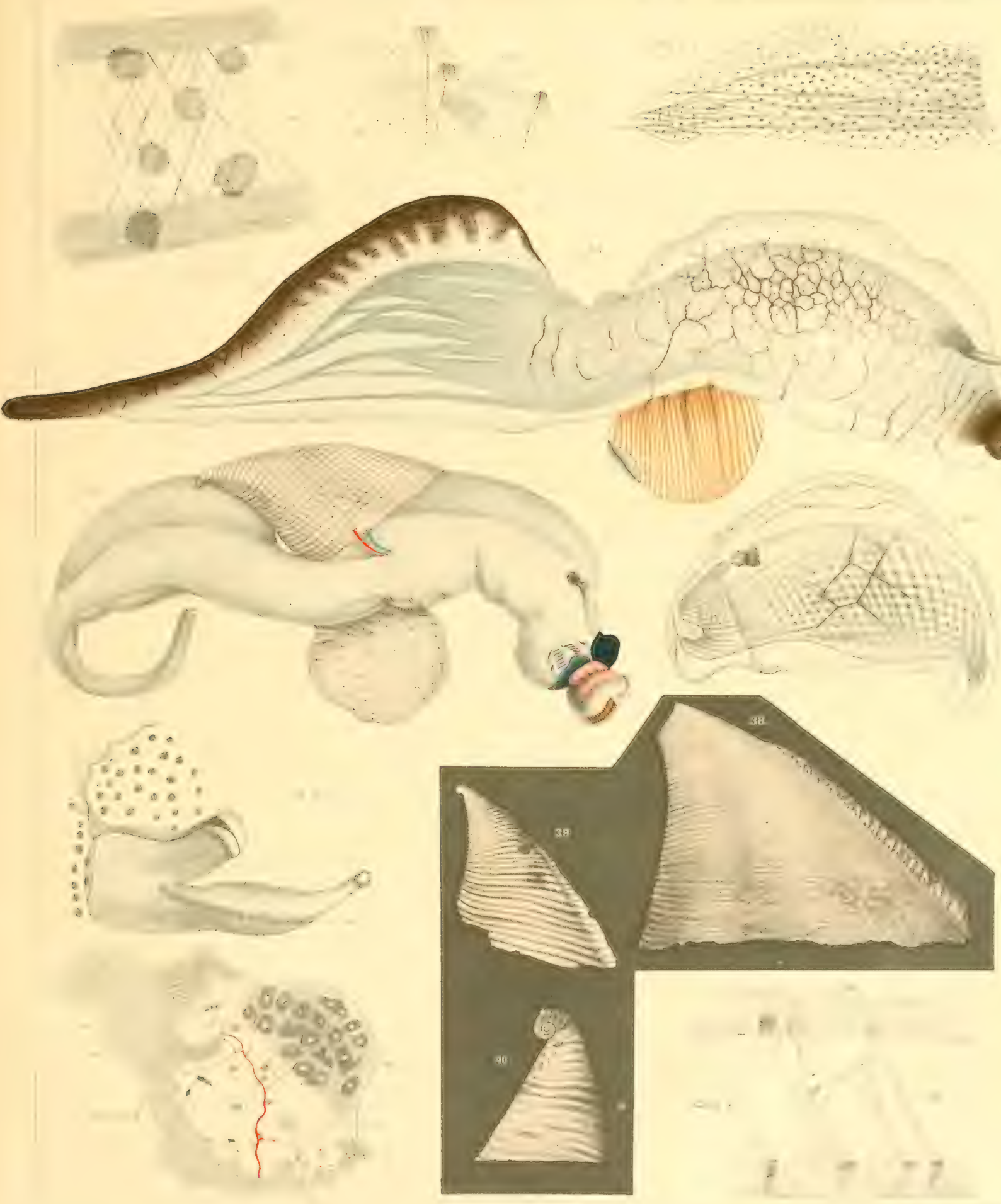






\section{TAFEL X.}

Fig. 43. Carinaria cristata Linné.

lig. 43. Umriss der Radula des Exemplares von Stat. 227 (Fig. 35), I $>$.

lig. $43 a, b, c, d$. Teile derselben Radula, $15>$.

Fig. $43 a$, Mittelplatte; Fig. $43 b$, Zwischenplatte; Fig. $43 d$, Seitenplatten; sämtlich aus der $4^{\text {en }}$ Querreihe. Fig. 43c, Zwischenplatte der $4^{\text {en }}$ Querreihe. In Fig. $43 b$ u. $43 c$ beachte man den Unterschied in der Strecke zwischen den Stellen $a$ und $b$.

Fig. 44-45. Carinaria galea Benson.

Iig. 44. Schale, $2 \times$; Stat. 2 II.

lig. 45. Spitze dieser Schale, 38\%; von rechts. Die kleine Spira liegt nach links in Hinsicht zur SymmetrieEbene der Schale; $a$ bezeichnet den Übergangspunkt zwischen Spira und Schale.

Fig. 46-51. Carinaria macrorlunnchus n. sp.

Fis. 40. Tier mitsamt Schale, $10 \times$.

Iiv. 47. Spitze der Schale, $38 \times$, von rechts.

I.ig. 4S. Dieselbe, $38 \times$, von links.

Fig. 49. Ein Teil der Haut, $220 \times$. hs, sternförmige Bindegewebszellen; hf, Hautflecken; $u s$, Nervenfäden und -zellen.

Figs. 50. Ein Teil der Leibeswand, in der Nähe des Penis; man sieht die gekreuzten Muskelbündel und die Hautflecken, $52 \times$. sf, Samenfurche; $p$, Penis; ha, Haftapparat.

Ii und Seitenplatten noch im Zusammenhang; zu unterst die Mittelplatte isolirt.

Fis. 52. Cardiapoda trachydermon n. sp.

Fig. 52. Cardiapoda trachydermon n. sp. Ein Teil der Haut; stellenweise finden sich flache Erhebungen, in deren Innerem sich ein Haufen Zellen findet, $a$, von knorpeliger Consistenz. Buchstaben übrigens wie in Fig. 49 . 
Sibona Expeditie. I.I. J. J. T'Fscr, IHeteropoda.
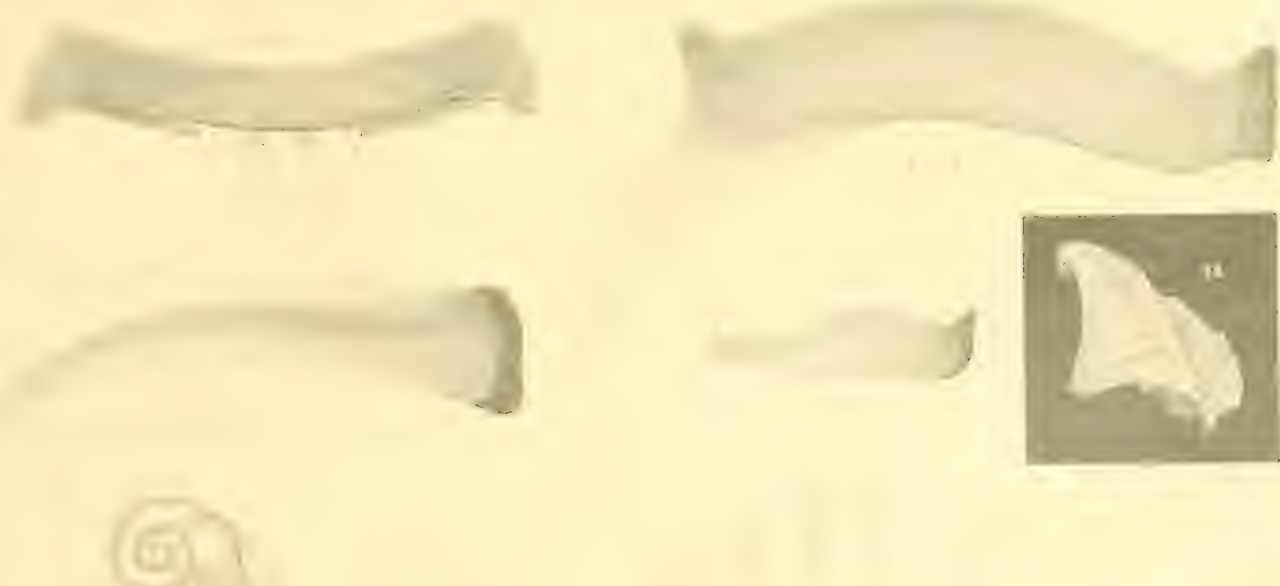

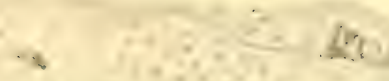

5

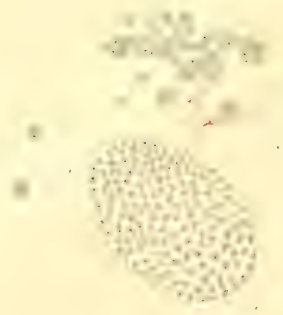






\section{TAFEL XI.}

Fig. 53-56. Cardiapoda trachydermon n. sp.

Fi... 53. Linkes Auge, innerhalb der Kapsel, und Tentakel, $t, 26$

1.j. 54. Teil des Leibeswand, nahe dem Penis. $13 \times$; sf, Samenfurche; $p$, Penis; $a$, Haftapparat.

Iivg. 55. Ganzes Tier, 07, $3 \times$. Stat. I 36 .

Fiv. 5\%. Teile der Radula, $52 \times$; 20. Querreihe. Links Mittelplatte, rechts Zwischenplatte u. Seitenplatten.

Fig. 57-59. Cardiapoda sublacvis n. sp.

Fis. 57. Ganzes Tier, 07. $7 \times$. Stat. 165. Fig. $57 a$. Schwanzende dieses Tieres, $10 \times$.

liv. 58. Ganzes Tier, $9,7 \times$. Stat. 165.

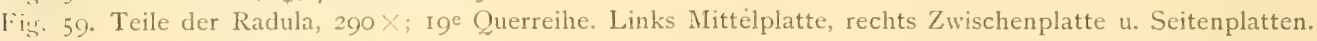

Fig. 6o-63. Cardiapoda acuta n. sp.

Fig. Go. Gimzes Tier. : 3 . Stat. 35 .

Fir. 61. Anderes Exemplar, 9 , $3 \times$. Stat. I03.

Fir. 62. Höcker, 290X; durch Haufen von kleinen Knorpelzellen, $k s$, auf der Haut hervorgerufen; $m$, Muskelstreifen; die Nervenfäden sind rot bezeichnet.

IFis. 6,3. Teile der Radula, $52 \times ; 28$. Querreihe. Links Mittelplatte, rechts Zwischenplatte u. Seitenplatten.

Fig. 64-67. Pterotrachea.

Fig. 64. Structur der Stirndornen von Pterotracleea, $290 \times . f e$, Plattenepithel, nur stellenweise erhalten; $k z$, Knorpelzellen; $n z$, verästelte Nervenzellen.

Fig. 65. Schwanz, $3 \times . a, b, c, d$, die vier Muskelbündel. Die blauen Linien bezeichnen ein sich ganz nach hinten erstreckendes Blutgefäss, überall durch einen Nervenfaden (rot) begleitet, der auch in den Schwanzfaden hinubertritt. Fig. $65 a$, Flosse des Schwanzendes, $3 \times$; von unten, mit der Endigungsweise des vierten Muskelbuindels.

Fig. 66. Typus des Auges von Pterotrachea s. s., $22 \%$.

Fig. 67. Typus des Auges von Euryops, $44 \times$. 
Sibega-Expeditie. I.I. J. J. Trscir, IIeteropoda.
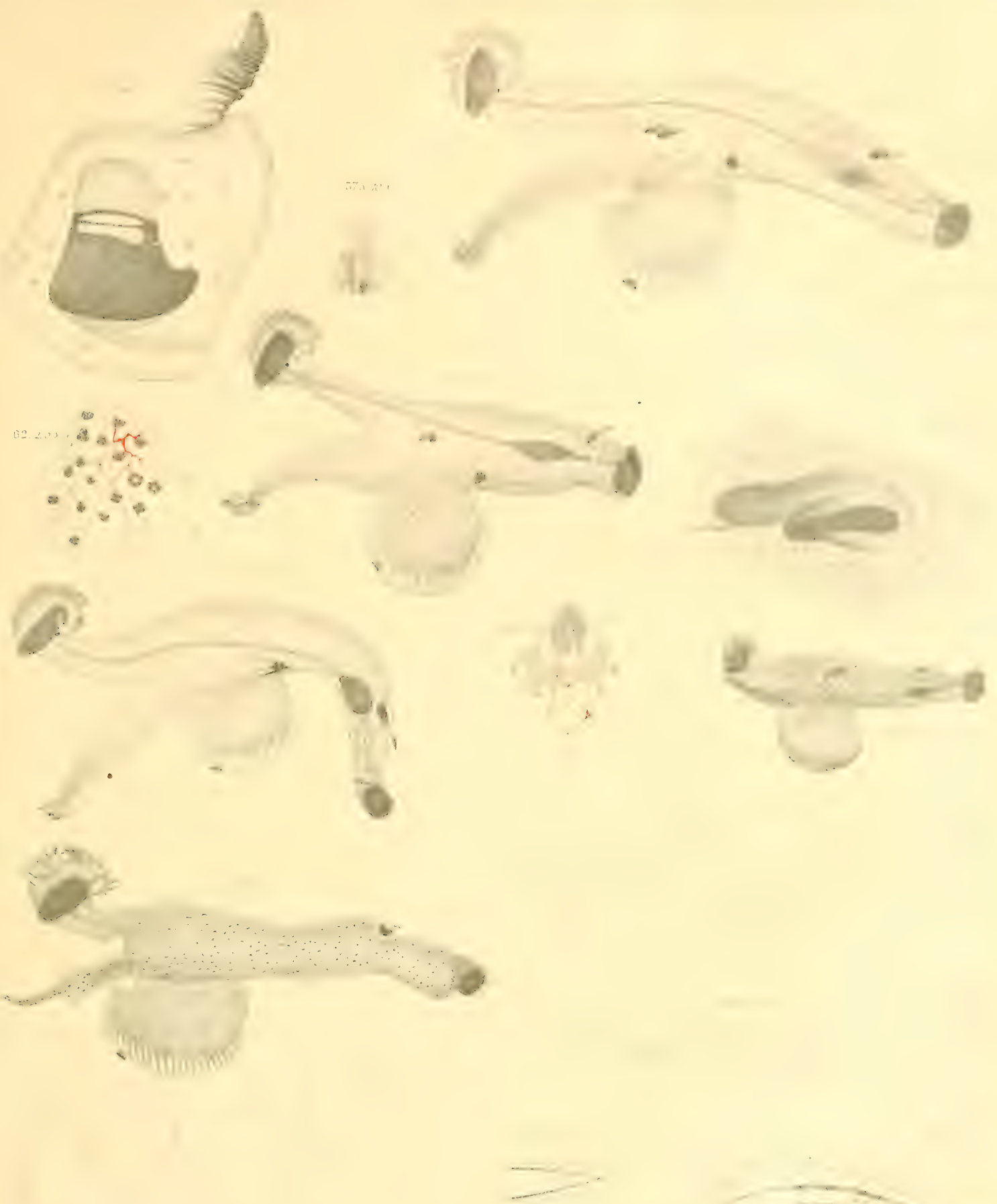




\section{TAFEL XII.}

Fig. 68-72. Pterotrachea cluallengeri n. sp.

Fin. 68. Ganzes Tier, $9, \mathbf{1} \times$. Stat. 35.

Fig. (x). Ganzes Tier, or, I $\times$. Stat. 148.

Fis. 70. Gauzes Tier, 07, I $\times$. Stat. 259.

Fis. 71 . Mittelplatte der Radula (Querreihe 16) des Tieres v. Fig. 69, $290 \times$.

Fis. 72. Mittelplatte der Radula (Querreihe 12) des Tieres v. Fig. 70, 290 X.

Fig. 73-78. Pterotrachea intermedia n. sp.

Fis. 73. Ganzes Tier, 07, I X. Stat. 259.

Fi. .7. Mittelplatte der Radula (Querreihe 12) dieses Exemplares. $290 \times$. Fig. 74a. Zwischenplatte derselben Reihe. 290 X.

Fir. 75. Ganzes Tier, 07, I $\times$. Stat. 253.

Fin. -7 . Kopf und Rüssel eines Tieres von Stat. 254. $3 \times$; Dorsalansicht.

Fin. 77. Mittelplatte der Radula (Querreihe 20) dieses Exemplares. $290 \times$. Fig. $77 a$. Zwischenplatte derselben Reihe. 290 .

Fis. 7 S. Palatinzähne desselben Tieres. $56 \times$.

Fig. 79. Pterotrachea microptera n. sp.

Fir. ; y. Ganzes Tier, 07, $2 \times$. Stat. 295. 




\section{TAFEL XIII.}

Fig. So-S5. Pterotrachea micropiera n. sp.

Fis. So. Saugnapf des Exemplares von Taf. XII, Fig. 79. $44 \times$.

Fis. \$1. Ganzes Tier, o7, $4 \times$. Stat. 227.

Iis. S2. Linke Reihe der Palatinzähne desselben Tieres, $290 \times$. Die Linie an der linken Seite der Figur deutet den linken Rand der dorsalen Mundrinne an.

Fin. 83 . Ganzes Tier, $\sigma^{7}, 1^{1} / 5 \times$. Stat. 143 .

Fiv. St. Palatinzähne des Weibchens v. Stat. 295. $56 \times$.

Fir. S5. Mittelplatte, Zwischenplatte und Seitenplatten der Radula (Querreihe Io) dieses Tieres. $290 \times$.

Fig. 86-89. Pterotrachea (Euryops) mutabilis n. sp.

Fin. S6. Ganzes Tier, o, $2 \times$. Stat. $215 a$.

Iig. S-. Ganzes Tier, $q, 2 \times$. Stat. 276.

Fis. S.. Mittelplatte der Radula (Querreihe I5) eines Tieres v. Stat. 172. 290×. Fig. SS $\alpha$. Zwischenplatte und Seitenplatten derselben Reihe. $290 \ldots$

Fis.s. Sy. Palatinzähne des Exemplares v. Stat. 2S2. $290 \times$. Der Abstand zwischen den beiden Reihen etwa um $1 / 3$ verkleinert.

Fig. 90-91. Pterotrachea (Euryops) xenoptera n. sp.

Fis. 90. Ganzes Tier, $+2 \times 2 \times$. Stat. 203.

1Fig. 91. Mittelplatte der Radula dieses Tieres (Querreihe S), 290x. Fig. 9I a. Zwischenplatte und Seitenplatten derselben Reihe, $290 \times$.

Fig. 92-94. Pterotracliea (Euryops) orthophthalmus n. sp.

Fiv. 12. Ganzes Tier, ( , $2 \times$. Stat. 48.

Fig. 93. Auge dieses Tieres, in Umriss, 56

Iig. 94. Ein Teil der $7^{\text {en }}$ Querreihe der Radula des Tieres, $290 \times$. Links die Mittelplatte, rechts Zwischenplatte und Seitenplatten. 


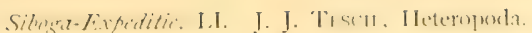
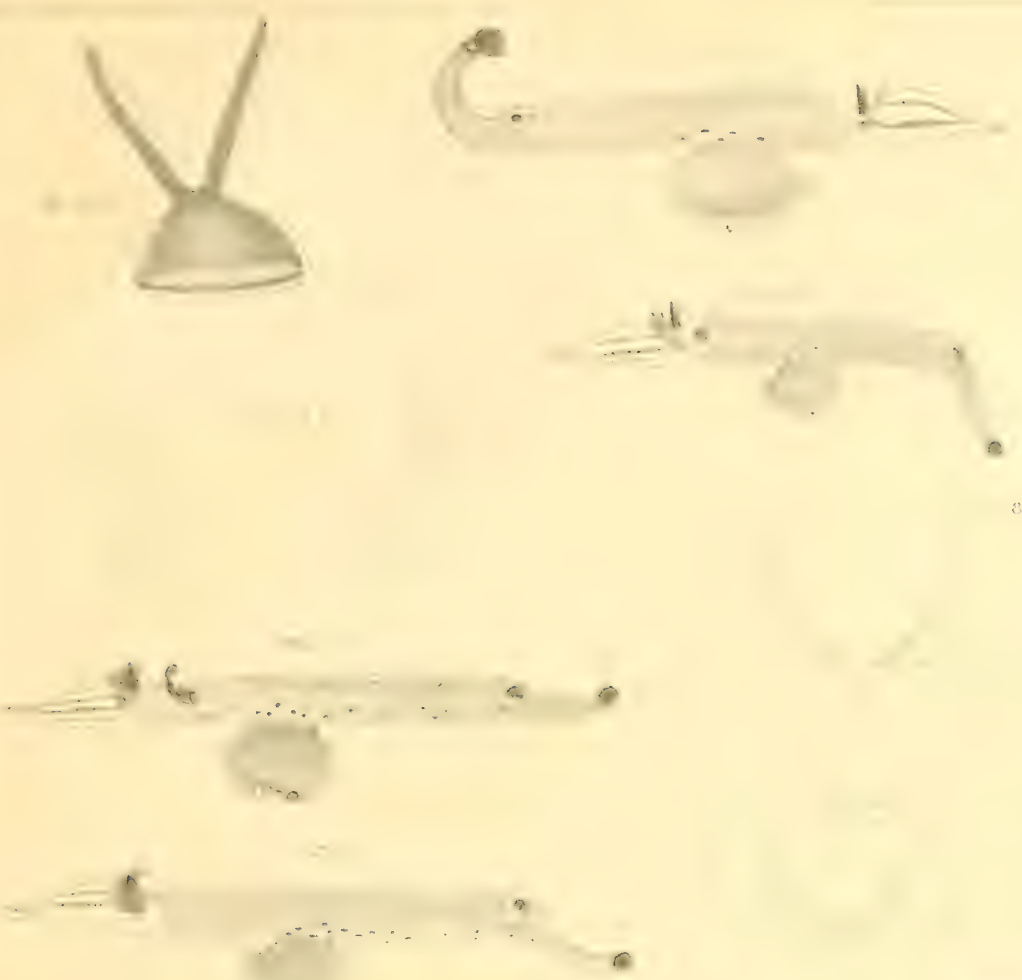

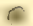

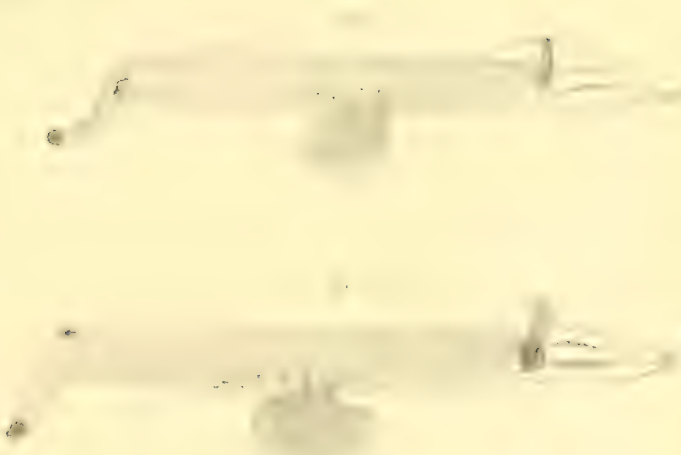

41 a. $290 x$

91. 2200 i 




\section{TAFEL XIV.}

Fig. 95-IIo. Firoloida kowulewskyi Vayssière.

Fin. 95. Kopf und Rüssel des Männchens, von der Dorsalseite. $12 \times . b m$, Buccalmasse; $r s$, Rückenlinie; t. Tentakel.

IFig. 96. Rüssel eines Männchens, von unten gesehen. Io X. bm, Buccalmasse; qm, Quermusculatur; $b s$, Bauchlinie.

Fir. 97. Ein Teil des Rumpfes und die Basis der Flosse. $56 \times . m$, Rumpfmusculatur; $a$, erster, $b$, zweiter Fortsatz der Flossenmusculatur, flm.

Firs. 98. Hinterende des Rumpfes und Nucleus eines Männchens. 20 \% an, Anus; $k$, Kiemen; n, Nucleus; $p$, Penis; $s$, Schwanz; sf, Schwanzfaden; $f$, keulenförmiger Anhang des männlichen Geschlechtsapparates von Firoloida; $o$, Osphradium; $n$, Niere, no, Nierenöffnung; $a$, Atrium; $v$, Ventrikel des Herzens.

Fis. 99-ior. Derselbe Körperteil verschiedener Weibchen, wo der Schwanz, je nachdem das Tier in Alcohol oder Formol aufbewahrt war, eine etwas verschiedene Gestalt hat. Fig. 99 u. Ior nach Formol-Exemplaren, das Tier von Fig. 100-rooa zeigt die Seitenlappen des Schwanzes, infolge Schrumpfung durch Alcohol kleiner als den Mittellappen. Fig. 99, 100, $20 \times$. Fig. 101, $10 \times$. Erklärung der Buchstaben wie in Fig. 98. Ausserdem: sl, 'Seitenlappen des Schwanzes, svg, zweites Visceralganglion; evg, erstes Visceralganglion, von dem ein Nerv zum Osphradium zieht; ei, Eier.

Fig. I02. Osphradium, von unten gesehen. $100 \times . n$, Nerv, der vom ersten Visceralganglion kommend, am concaven Hinterrande des Organes mit einer ganglionären Anschwellung gn, endet; ar, Vorderrand; $m$, Muskeln, welche das Organ zu einer Änderung der Gestalt befähigen.

Firg. I03. Penis und langer Fortsatz der wahrscheinlich als Haftapparat bei der Begattung dient; von rechts. $3 S \times . p$, Penis; $s f$, Samenfurche; $h$, Haftapparat.

Firs. 104-106. Weibchen; das erste Exemplar (Fig. 104) hat am Ende des Rumpfes zwei deutliche Torsionen (der Nucleus dieses Tieres ist in Fig. IOI abgebildet); vom zweiten Tiere (Fig. I05) ist der vordere Teil der Eischnur abgebildet worden; in Fig. I06 fehlt diese gänzlich, ist wohl zufällig abgerissen. $3 \times$.

Fïg. I07-ro8. Männchen; beachtenswert ist namentlich das verschiedene Aussehen des Schwanzfadens. Fig. $107,3 \times$; Fig. 108, $5 \times$.

Fis.s. I09. Schwanzfaden des Männchens, an einzelnen Stellen knotig verdickt. 120 .

Fig. IIO. Mittelplatte und Zwischen- und Seitenplatten der Radula. I5e Querreihe. 290 x. m, Mittelplatte; $\approx$, Zwischenplatte; $s$, Seitenplatte. 
Silurat Expeclitic: I.I. J. J. Tescis, Heteropoda.
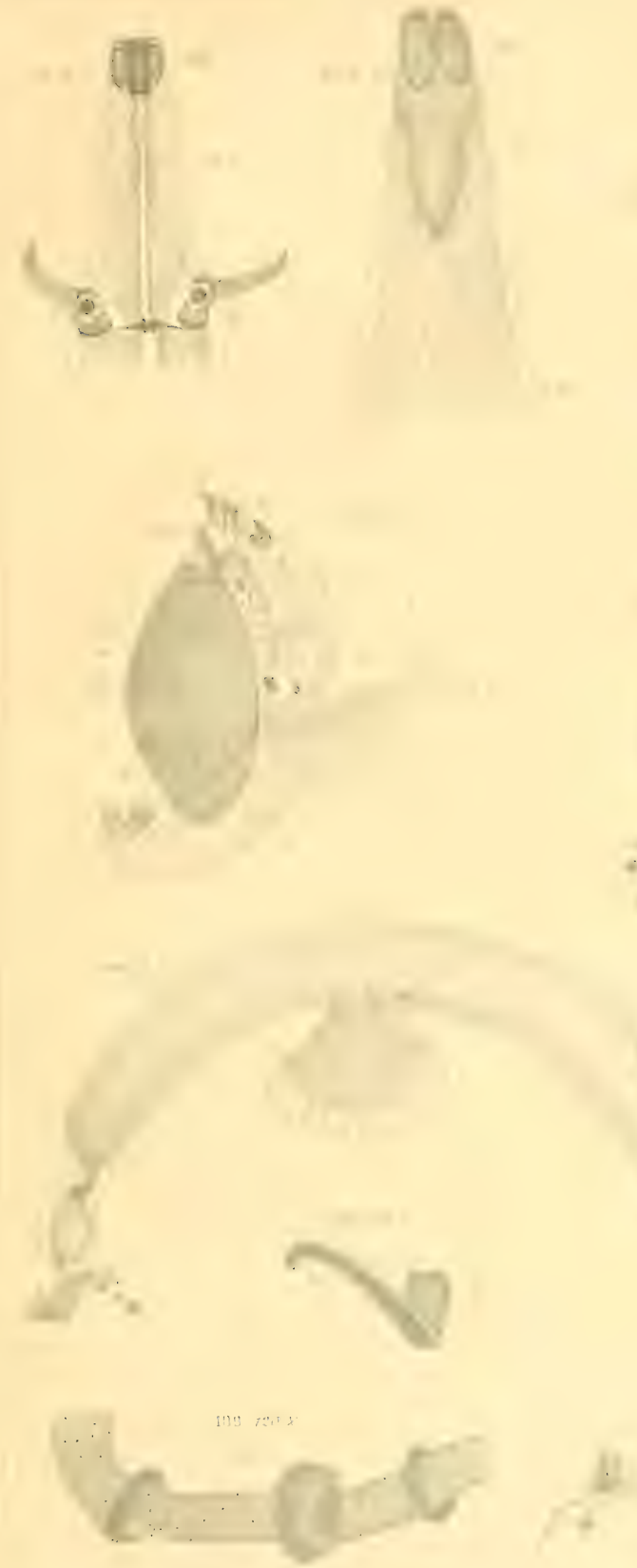
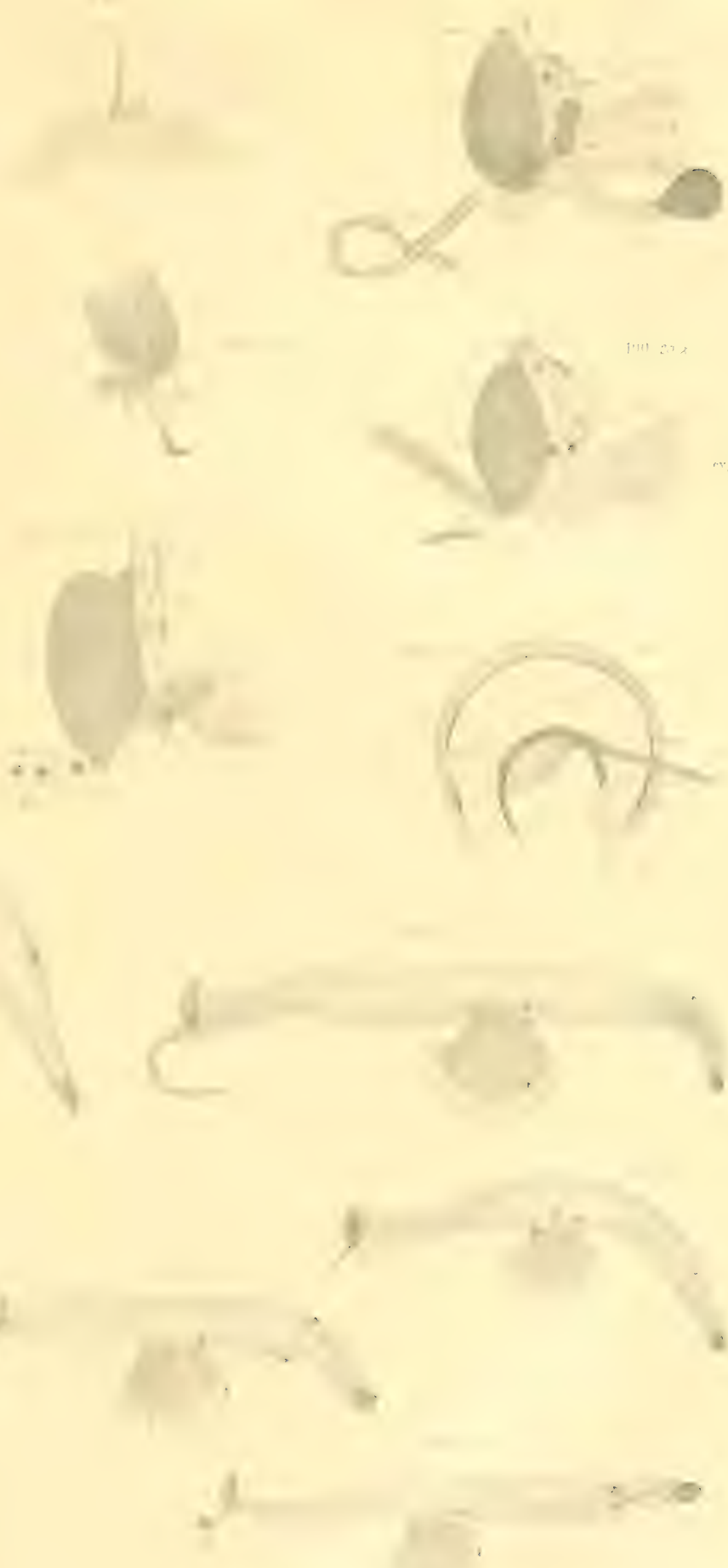

P. W M. Trap, 



\section{CONDITIONS GÉNÉRALES DE VENTE.}

$r^{2}$. L'ouvrage du „Siboga" se composera d'une série de monographies.

$2^{\circ}$. Ces monographies paraîtront au fur et à mesure qu'elles seront prêtes.

$3^{\circ}$. Le prix de chaque monographie sera différent, mais nous avons adopté comme base générale du prix de vente: pour une feuille d'impression sans fig. flor. 0.15; pour une feuille avec fig. flor. 0.20 à 0.25 ; pour une planche noire flor. 0.25 ; pour une planche coloriée flor. 0.40 ; pour une photogravure flor. 0.60 .

$4^{\circ}$. Il y aura deux modes de souscription:

a. La souscription à l'ouvrage complet.

b. La souscription à des monographies séparées en nombre restreint.

Dans ce dernier cas, le prix des monographies sera majoré de $25 \%$.

$5^{\circ}$. L'ouvrage sera réuni en volumes avec titres et index. Les souscripteurs à l'ouvrage complet recevront ces titres et index, au fur et à mesure que chaque volume sera complet. 
c Livr. (Monogr. XLIV) C. Ph. Sluiter. Die Holothurien der Siboga-Expecition. Mit 1o Tafeln. $f$. $6 .-$. $f 7.50$

Livr. (Monogr. LX) E. S. Barton. The genus Halimeda. With 4 plates.

$\pi 1.80,2.40$

3" Livx. (Mlonogr. I) Max Weber. Intruduction et description de l'expédition. Avec Liste des Stations et 2 cartes

4" Livr. (ALnogr. II) G. F. Tydeman. Description of the ship and appliances used for scientific exploration. With 3 plates and illustrations.

5 Livr. (Monogr. XLVII) H. F. Nierstrasz. The Solenogastres of the Siboga-Exp. IVith 6 plates.

J. Livr. (Monogr. XIII) J. Versluys. Die Gorgoniden der Siboga-Expedition.

I. Die Chrysogorgiidae. Mit 170 Figuren im Text.

$7^{e}$ I.ivr. (Monogr. XVIa) A. Alcock. Report on the Deep-Sea Madreporaria of the SibogaExpedition. With 5 plates. . . . . . . . . . . . . . . . . . . .

Se Livr. (Monogr. XXV) C. Ph. Sluiter. 1)ic Sipunculiden und Echiuriden der Siboga-Exp. Mit 4 Tafeln und 3 Figuren, im Text.

9. Livr. (Monogr. VI a) G. C. J.'Vosmaer and J. H. Vernhout. The Porifera of the SibogaExpedition.

I. The genus Placospongia. With 5 plates.

Ioc Livr. (IIonogr. XI) Otto Maas. Die Scyphomedusen der Siboga-Expedition. Mit 2 Tafeln.

Ife Livr. (Monogr. XII) Fanny Moser. Die Ctenophoren der Siboga-Expedition. Mit 4 Tafeln.

I2e Livr. (Monogr. XXXIV) P. Mayer. Die Caprellidae der Siboga-Expedition. Mit to Tafeln.

$13^{e}$ Livr. (Monogr. III) G. F. Tydeman. Hydrographic results of the Siboga-Expedition. With 24 charts and plans and 3 charts of depths

I.4" Livr. (Monogr. XliII) J. C. H. de Meijere. Die Echinoidea der Siboga-Exp. Mit 23 Tafeln.

$15^{\circ}$ Livr. (Monogr. XLVa) René Koehler. Ophiures de l'Expédition du Siboga.

Ie Partie. Ophiures de Mer profonde. Avec 36 Planches.

IOC I.ivr. (Monogr. LII) J. J. Tesch. The Thecosomata and Gymuosomata of the SibogaExpedition. With 6 plates.

$17^{\mathrm{c}}$ Livr. (Monogr. LVIa) C. Ph. Sluiter. Die Tunicaten der Siboga-Expedition.

I. Abteilung. Die socialen und holosomen Ascidien. Mit 15 Tafeln .

ISe Livr. (Monogr. LXI) A. Weber-van Bosse and M. Foslie. The Corallinaceae of the SibogaExpedition. With 16 plates and 34 textfigures . . . . . . . . . . .

$1 g^{e}$ Livir. (Monogr. VIII) Sydney J. Hickson and Helen M. England. The Stylasterina of the Siboga Expedition. With 3 plates.

20 Livr. (Monogr. XLVIII) H. F. Nierstrasz. Die Chitonen der Siboga-Exp. Mit 8 Tafeln.

$21^{\mathrm{e}}$ Livr. (Monogr. XLVb) René Koehler. Ophiures de l'Expédition du Siboga.

$2^{e}$ Partie. Ophiures littorales. Avec is Planches.

, 6.75 ᄁ9.-

, 2. - $\pi 2.50$

त 3.90 त 4.90

3.-, 3.75

$4.60,5.75$

" 3.- , 3.75

" $2.40,3 .-$

" 7.50 " 9.50

, $2.80,3.50$

, $7.80,9.75$

79.- $\rightarrow 11.25$

"15.- 18.75

$\eta 16.50 \quad n 20.50$

$\approx 3.75 \leadsto 4.70$

" $6.75,9 .-$

$\pi 12.50, I 5.50$

, $1.50 \geqslant 1.90$

, 5.-, 6.25

$10.25, \mathrm{I} 2.75$

220 Livr. (Alonogr. XXVIbis) Sidney F. Harmer. The Pterobranchia of the Sibogra-Expedition, with an account of other species. With i4 plates and 2 text-figures.

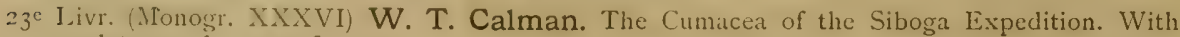
2 plates and 4 text-figures . . . . . . . .

$24^{e}$ Livr. (Monogr. LVIa) C. Ph. Sluiter. Die Tunicaten der Siboga-Expédition.

Supplement zu der I. Abteilung. Die socialen und holosomen Ascidien. Mit I Tafel.

$25^{\circ}$ Livr. (Monogr. L) Rud. Bergh. Die Opisthobranchiata der Siboga-Exped. Mit 20 Tafeln.

204 Livr. (Monogr. X) Otto Maas. Die Craspedoten Medusen der Siboga-Exp. Mit 44 Tafeln.

$27^{c}$ Livr. (Monogr. XIII a) J. Versluys. Die Gorgoniden der Siboga-Expedition.

II. Die Primnoidae. Mit 10 Tafeln, 178 Figuren im Text und einer Karte.

$, 6.75,9 .-$

I.SO $\# 2.40$

$7-.75 \geqslant 1 .-$

nI $11.25,14.10$

, $9.25 \sim 12.50$

$n 12.50,16.75$

25e I.ivr. (Monegr. XXI) G. Herbert Fowler. The Chactognatha of the Siboga Expedition. IVith 3 plates and 6 charts

210" Livr. (Monogr. LI) J. J. Tesch. Die Heteropoden der Siboga-Expedition. Mit I4 Tafeln.

๓ $4.20 \gg 5.25$

$6.75,9 .-$ 









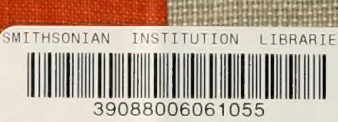

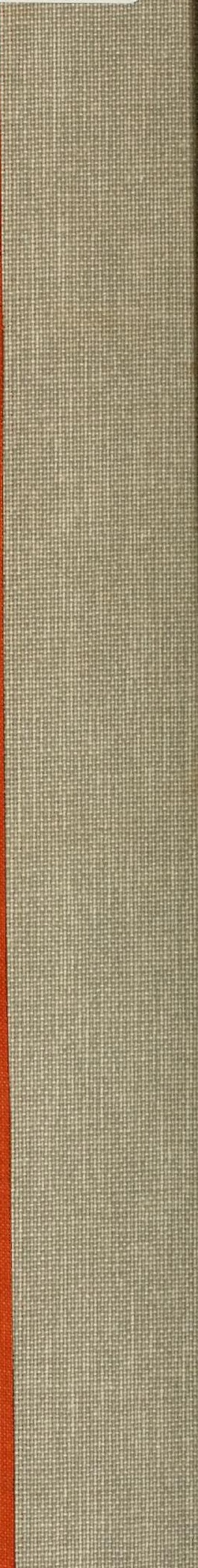

